\title{
Controls on Spatial and Temporal \\ Variation in Snow Accumulation on Glaciers in the Southern Alps, \\ New Zealand.
}

A thesis submitted in fulfilment of the requirements

for the degree of

Doctor of Philosophy

by

Heather Purdie

Victoria University of Wellington

2011 



\begin{abstract}
Mountain glaciers are already responding to climatic warming, and are expected to make a substantial contribution to sea-level rise in the coming decades. The aim of this investigation in the New Zealand Southern Alps was to improve our understanding of snow accumulation variability on mid-latitude maritime glaciers, in order to allow for better estimation of future glacier mass balance. The specific aim was to investigate snow accumulation processes at a range of spatial and temporal scales, focussing on synoptic-scale atmospheric circulation influences, moisture sources for snow accumulation and local-scale dependencies of snow accumulation in relation to topography. A range of methods were utilised including direct measurement, snow and ice core analysis, statistical analysis and modelling.
\end{abstract}

Snow accumulation in the Southern Alps was found to be derived predominantly from the Tasman Sea, and deposited during low pressure troughs and fronts. Although precipitation increased with elevation, wind processes redistributed this mass. On a monthly timescale this redistribution caused an unexpected result, namely that wind deflation of snow on Franz Josef Glacier countered the effects of greater accumulation, and total accumulation was similar at both Franz Josef and Tasman Glaciers over this period. These processes make it challenging to simulate snow accumulation patterns by simply extrapolating snowfall over an orographic barrier from lowland climate station data. On an inter-annual basis, temperature, especially during the ablation season, had most influence on net accumulation, and warm summers served to homogenise winter variability. Consequently, atmospheric circulation patterns that affect summer temperature, for example the El Niño Southern Oscillation (ENSO) and the Southern Annular Mode (SAM) also influence inter-annual variability in net accumulation.

Together, these results highlight the dependence of maritime glaciers in the New Zealand Southern Alps on the prevailing westerly circulation. Although some uncertainty surrounds how global warming will affect atmospheric circulation and synoptic weather patterns, the results of this research indicate that New Zealand glaciers can be expected to lose significant mass in the coming decades if the current positive trend in the SAM continues, and if La Niña events (positive ENSO) become more frequent. 


\section{Acknowledgements}

This thesis has benefited from the support and guidance of many people.

Andrew Mackintosh, Wendy Lawson and Brian Anderson made up the supervisory team. With all of us based in different parts of the country this was no easy task. I am grateful for the support and flexibility that you all maintained through-out this project, and feel that I benefited from the diverse range of skills and talents that you all have. Thanks for your time and patience.

In addition to the core supervisory team I would like to acknowledge the support and advice that I received from a number of other scientists: Nancy Bertler, Ian Owens, Tim Kerr, Kate Sinclair, Joel Baker, Uwe Morgenstern, Trevor Chinn, Paul Mayewski, Andrew Willsman, Jordy Hendrikx, Mike Green, Simon Allen, Rob McKay and Shelley MacDonnell. Tim requires additional thanks as not only did he provide scientific and moral support, but along with his partner Clare, gave me a home away from home when working at University of Canterbury. Thanks to fellow post-grad students who have fielded questions, engaged in discussion and kept up morale: Rachael Rhodes, Mette Riger-Kusk, Alice Dougherty, Julia Bull, Lawrence Kees and Stephen Stuart. Thanks also to the many people who have assisted with academic, administrative and technical support: Nick Key, Justin Harrison, John Thyne, Tamsin Falconer, Michelle Dow, Anna Petrie, Nokuthaba Sibanda, Ross Marsden, Julian Thomson, Andrew Rae and Marney Brosnan.

Measuring snow accumulation on glaciers in the New Zealand Southern Alps requires long hours with heavy packs, often in adverse conditions. A number of fantastic and hard-working people have earned their place in "Team Glaciators" namely: Jason Watson, Ewan Paterson, Vernon Reid, Graham Wilcox, Julian Thomson, Bob Williams, Grant Pearson, Kimberley Wallace, John Hooker and Craig Clark. Jason and Ewan require special thanks, as in addition to participating in a large number of regular trips, also endured the intensive winter snow survey, which involved living in a high mountain hut and measuring snow accumulation often in storm conditions - I am indebted. 
I am grateful for the variety of funding and support that has made this research possible: Victoria University PhD scholarship, Victoria University PhD submission scholarship, Comer Science and Education Foundation, FRST ANZICE programme, Victoria University Science Faculty and School of Geography, Environment and Earth Science Grants, Antarctic Research Centre, University of Canterbury Department of Geography, Royal Society of New Zealand Travel Grant, GNS Science Ice Core Research Facility, New Zealand Mountain Safety Council, National Institute of Water and Atmospheric Science, New Zealand Alpine Club, Department of Conservation, Mount Cook SkiPlanes and Helicopters, Fox Glacier Heli-services and the Helicopter Line.

On a more personal level, fellow 'doctors' Jen Purdie and Grant McKenzie require acknowledgement for inspiring me to begin, and making me believe that I would finish. Thanks to Mum, Dad, Fiona, Julie and to Elayne and Vernon who have taken an interest and supported me through the good and bad times. Finally to Jason, who in addition to working many days in the field, endured hours of glacier-talk, glacier-frustrations, and time away from home; thank-you for your endless love and support. 


\section{Table of Contents}

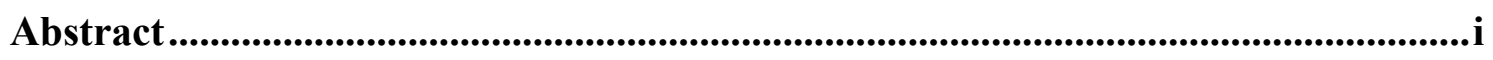

Acknowledgements.....................................................................................................................iii

Table of Contents ....................................................................................................................

1. Introduction ...........................................................................................................

1.1 Snow accumulation and glacier mass balance ................................................

1.2 Atmospheric circulation and snow accumulation ...........................................

1.3 Glacier mass balance and climate change ........................................................

1.4 Research objectives ...............................................................................

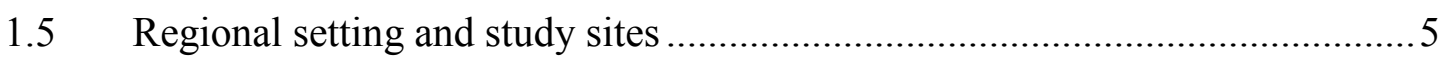

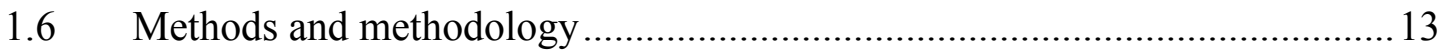

1.6.1 Snow accumulation measurement ..........................................................13

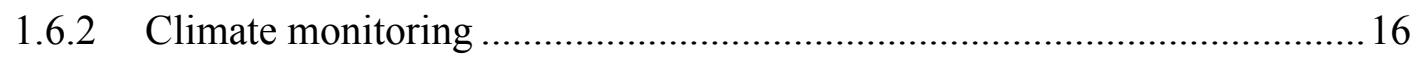

1.6.3 Modelling snow accumulation and ablation ............................................... 17

1.7 Thesis format and structure ..................................................................... 19

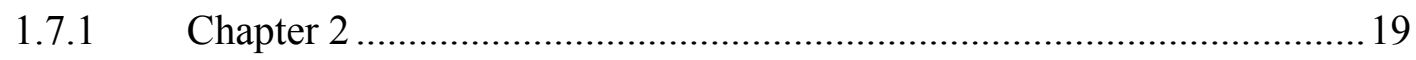

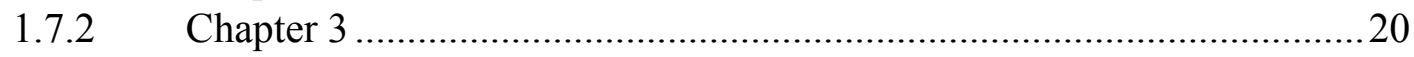

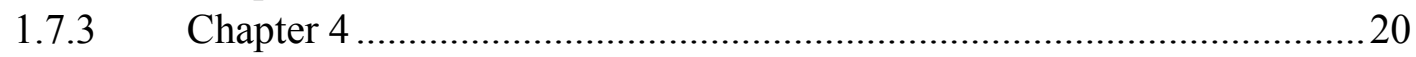

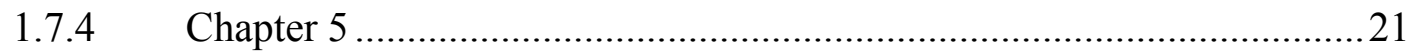

2. Controls on spatial variability in snow accumulation on glaciers in the Southern Alps, New Zealand, as revealed by crevasse stratigraphy.........................22

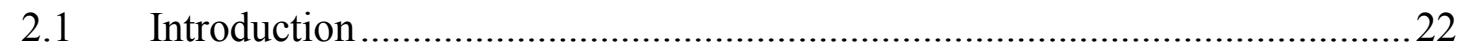

$2.2 \quad$ Study Area

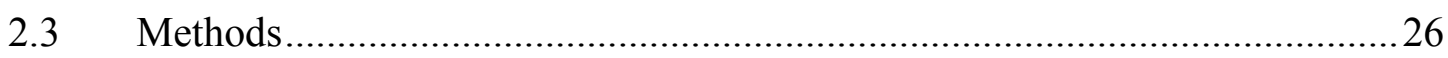

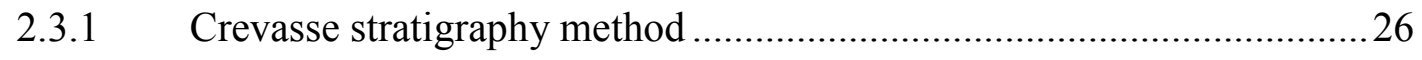

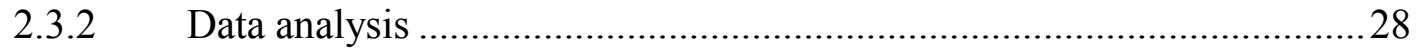

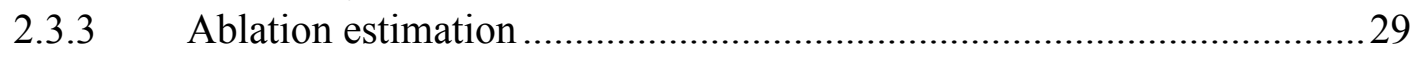

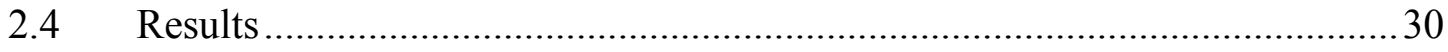

2.4.1 Spatial variability in net accumulation.....................................................30

2.4.2 Potential controls on net accumulation distribution..................................33

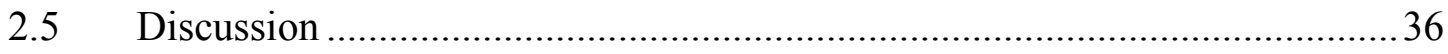

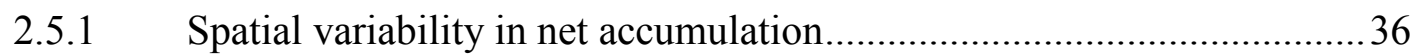

2.5.2 Control on spatial variability in net accumulation ....................................37

2.5.3 Inter-annual variability in controls on spatial variability..........................39

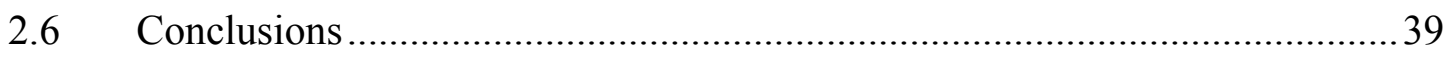

3. Synoptic influences on snow accumulation on glaciers east and west of a topographic divide: Southern Alps, New Zealand........................................................41

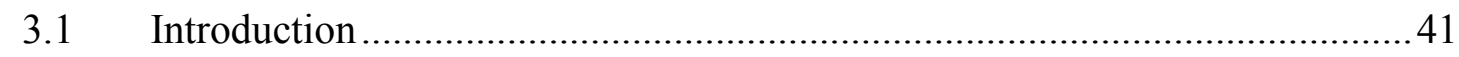

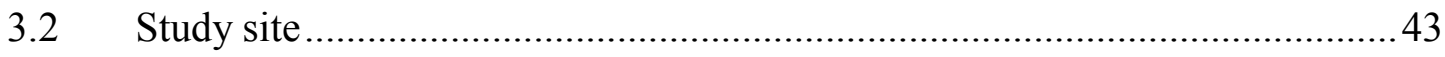

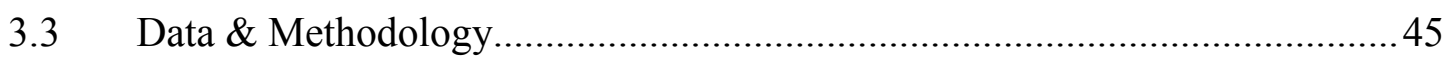




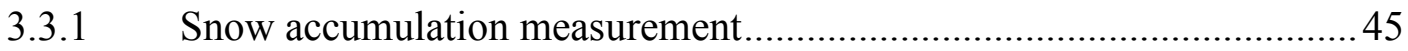

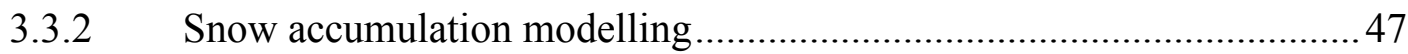

3.3.3 Synoptic classification and local climate ............................................ 48

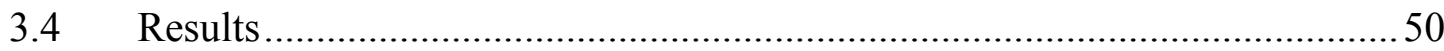

3.4.1 Synoptic variability in snow accumulation ...........................................50

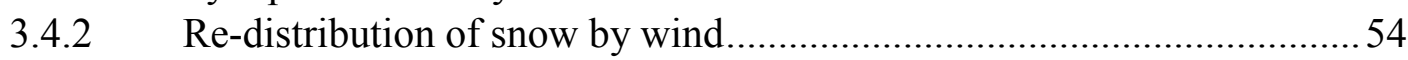

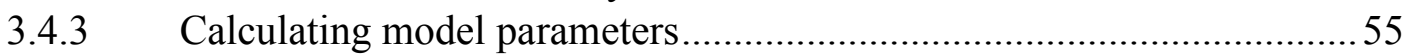

3.4.4 Comparison of measured and modelled snow .....................................57

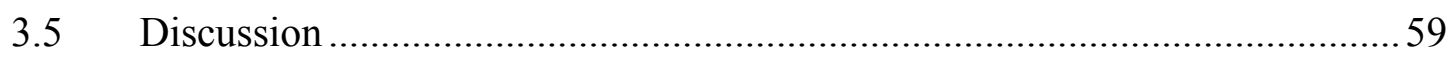

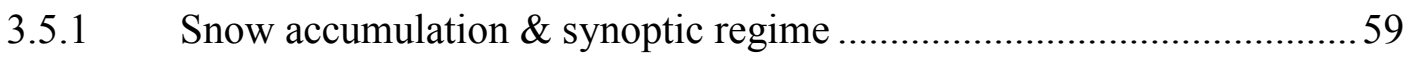

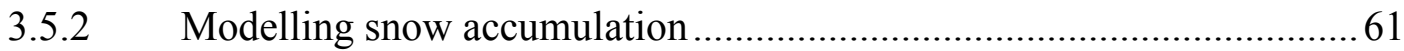

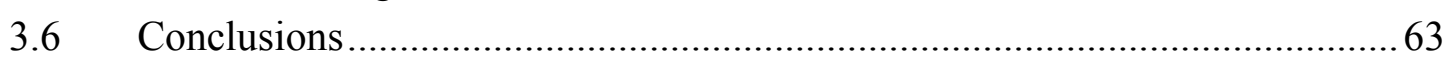

4. Isotopic and elemental changes in winter snow accumulation on glaciers in the Southern Alps of New Zealand..........................................................................64

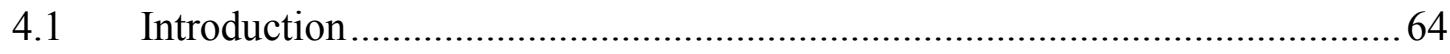

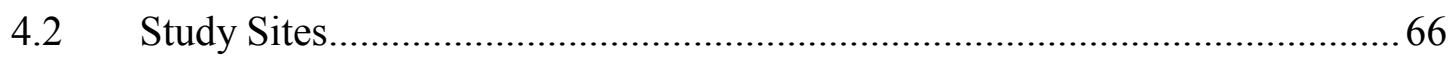

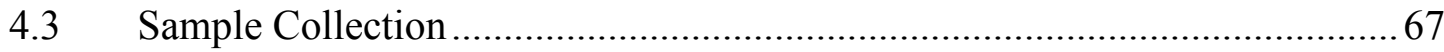

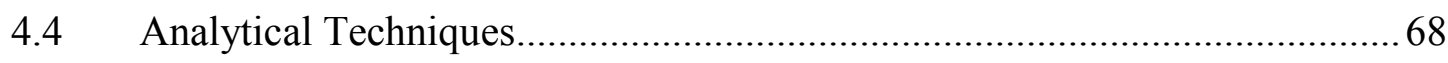

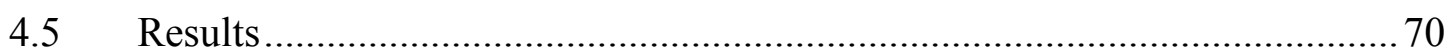

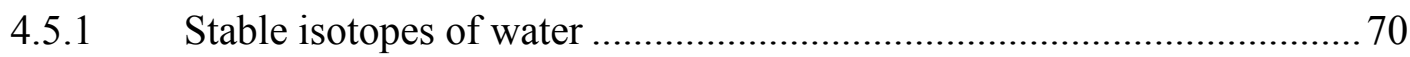

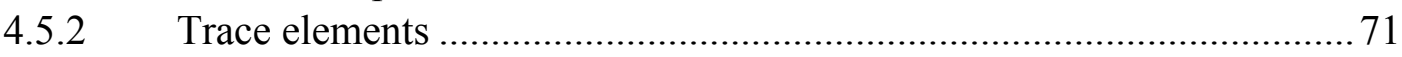

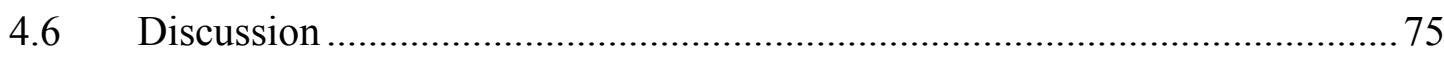

4.6.1 Temporal and spatial variability in stable water isotopes and trace

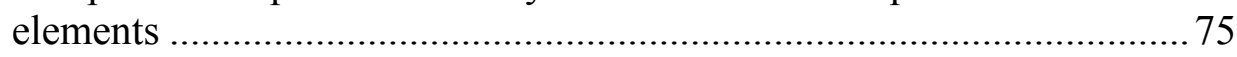

4.6.2 Determining moisture provenance and within storm variability ............78

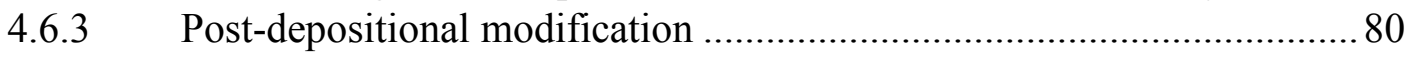

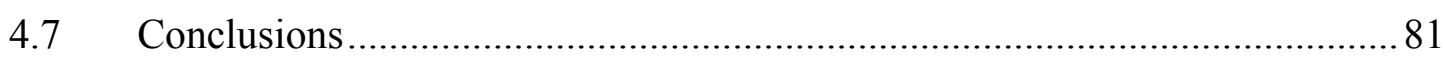

5. Inter-annual variability in net accumulation on Tasman Glacier and its relationship with climate. ............................................................................................................83

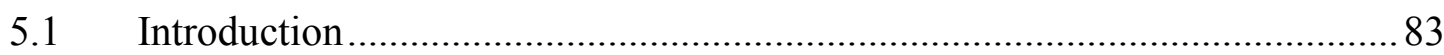

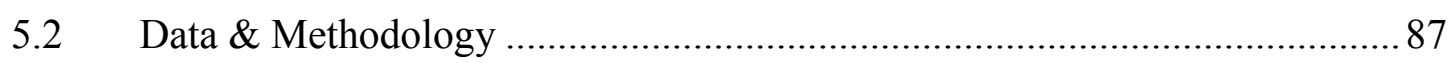

5.2.1 Measurement of net accumulation on Tasman Glacier.......................... 87

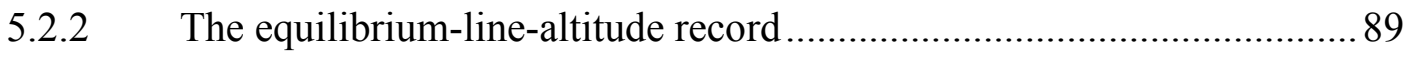

5.2.3 Analysis of the Tasman Glacier ice core ................................................ 90

5.2.4 Climate-accumulation relationships................................................. 90

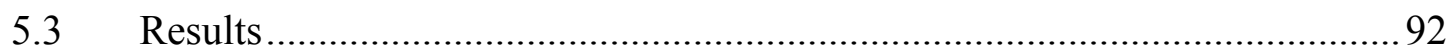

5.3.1 Net accumulation derived from Tasman Glacier ice core......................99

5.3.2 Inter-annual variability in net accumulation .................................... 94

5.3.3 Correlation of climate parameters with net accumulation data............... 94

5.3.4 Correlations between climate variables .............................................. 97

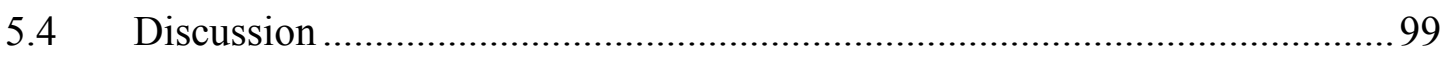

5.4.1 Relationships between temperature, precipitation and net accumulation

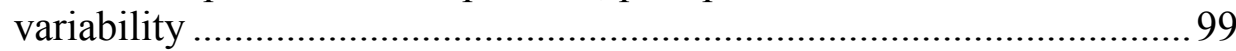

5.4.2 Influence of atmospheric circulation on net accumulation variability.. 100 
5.4.3 Recent and future trends in New Zealand climate ............................... 101

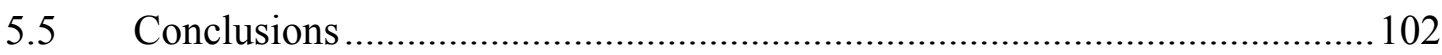

6. Synthesis and Conclusions....................................................................103

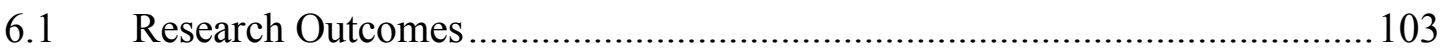

6.1.1 Spatial controls on snow accumulation on mid-latitude maritime glaciers 103

6.1.2 Temporal controls on snow accumulation on mid-latitude maritime

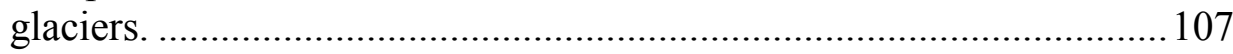

6.1.3 Implications of climate change on snow accumulation and glacier mass

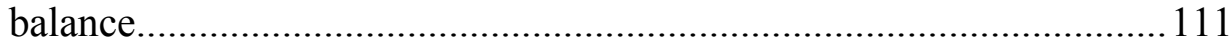

6.2 Future snow accumulation research ........................................................ 113

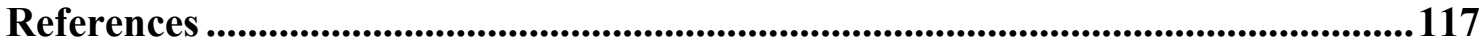

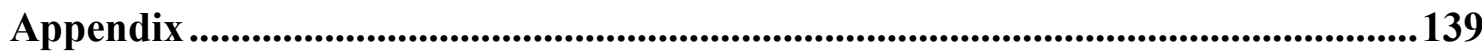

Appendix 1: End-of-winter snow accumulation measurement on Tasman Glacier.. 139

Appendix 2: Mass balance measurements from Tasman Glacier 2007-2009........... 141

Appendix 3: Spatial representivity of crevasse surveys ......................................... 144 



\section{Introduction}

\subsection{Snow accumulation and glacier mass balance}

This thesis has derived from a study of snow accumulation processes on maritime glaciers in the Southern Alps of New Zealand. Snow accumulation is an important component of glacier mass balance, which is the difference between snow and ice accumulation and ablation. The mass balance of a glacier is of fundamental importance to glacier behaviour and sustainability and can be defined by:

$$
b_{n}=b_{c}-b_{a}
$$

where $b_{n}$ is the net mass balance, $b_{c}$ accumulation and $b_{a}$ ablation. Glaciers gain mass from snowfall, freeze on, and avalanche inputs, while loosing mass though melting, sublimation, wind erosion and iceberg calving (Paterson, 1994). The balance between gains and losses is the mass balance of the glacier, usually measured over a glaciological year (April to March in the Southern Hemisphere). Changes in glacier mass balance result in dynamical change to ice flow, which over time are expressed at the terminal face of the glacier and throughout its length. A period of positive mass balance will result in glacial advance, whilst cumulating negative balance will result in glacial retreat (Paterson, 1994).

On glaciers the processes of accumulation and ablation vary spatially and temporarily. Currently more is known about glacial ablation than the physical processes affecting accumulation. Snow and ice ablation is controlled by the surface energy balance, principally involving radiative and turbulent heat fluxes. Relationships between climate and ablation are relatively well understood, and glacier ablation can be accurately estimated using energy-balance models (Hock, 2005). While some uncertainties remain, changes in the surface energy balance brought about for example by albedo changes, have already been incorporated into models (Oerlemans and Klok, 2004; Oerlemans et al., 2009), as has internal accumulation due to melt-refreeze processes (Greuell and Konzelmann, 1994; Reijmer and Hock, 2008). In addition, positive-degree-day models, which only require temperature as input, can estimate ablation reasonably well (Braithwaite, 1981; Braithwaite et al., 2002), especially when combined with a solar radiation component (Pellicciotti et al., 2005). 
On valley glaciers, accumulation estimates for mass balance models are usually based on simple relationships between elevation and precipitation (Oerlemans, 2001). However, this elevation-mass balance relationship is seen to weaken in the accumulation area, as the control exerted by temperature (the variable most strongly correlated with elevation), lessens and other processes come into play, often resulting in large spatial variability in snow accumulation (Hodgkins et al., 2005; Anderson et al., 2006; Machguth et al., 2006). A number of snow accumulation models attempting to address such spatial variability have been developed (Liston and Sturm, 1998; Lehning et al., 1999). However, in mid-latitude regions, and particularly in New Zealand and Patagonia, where glaciers with high precipitation totals are found, meteorological input data to drive these models are sparse and there are few direct measurements with which to validate model output. Increasing our knowledge about the processes that control spatial and temporal variability in accumulation on mid-latitude maritime glaciers will enable more accurate simulation of glacier mass balance in future applications.

\subsection{Atmospheric circulation and snow accumulation}

On a regional scale, spatial and temporal variability in snow accumulation and ablation on glaciers is influenced by synoptic-scale weather patterns. Relatively subdued seasonality in maritime climates means that snow accumulation and ablation can occur year-round. There is a good understanding of how ablation processes are affected by synoptic-scale weather patterns, with high ablation rates associated with anticyclonic conditions, and with frontal systems comprised of warm maritime air masses (Marcus et al., 1985; Owens et al., 1992; Neale and Fitzharris, 1997; Takeuchi et al., 1999; Cutler and Fitzharris, 2005). However, few studies have considered synoptic controls on snow accumulation processes, and much research to date has focused on seasonal snow accumulation in continental climates, where largest snowfalls are found to be associated with troughing synoptic regimes (Grundstein, 2003; Romolo et al., 2006). It is likely that synoptic weather patterns will change with impending climate change (Mullan et al., 2001). An improved understanding of snow accumulation processes under different synoptic regimes on mid-latitude maritime glaciers will help determine the impact a change in synoptic frequency will have on glacier mass balance in this environment. 
Synoptic-scale weather patterns influencing snow accumulation are embedded within large-scale atmospheric circulation variability. Understanding the contribution that different moisture source regions make to snow accumulation helps us to assess the importance of atmospheric circulation to snow accumulation and glacier mass balance. Information about atmospheric circulation and moisture provenance is contained in snow and ice chemistry, in particular, stable water isotope and trace element data (Legrand and Mayewski, 1997; Araguas-Araguas et al., 2000; Jouzel et al., 2007). Such research is more advanced in polar and continental climates where below freezing temperatures ensure signal preservation. Melt-water percolation and re-freezing, common on mid-latitude maritime glaciers, complicates isotopic and elemental interpretation (Arnason, 1969; Raben and Theakstone, 1994; Koerner, 1997; Shiraiwa et $a l ., 2002)$. Despite this issue, snow and ice geochemistry has been used to obtain information about temperature and accumulation patterns on maritime glaciers in Norway (He et al., 2002), and Patagonia (Shiraiwa et al., 2002) respectively. Further geochemical analyses of snow accumulation may allow us to quantify moisture provenance and learn more about the role of atmospheric circulation in snow accumulation patterns on mid-latitude maritime glaciers.

\subsection{Glacier mass balance and climate change}

The latest projections from the Intergovernmental Panel on Climate Change (IPCC) indicate that by the end of the $21^{\text {st }}$ century global average surface temperature may increase by $1.8-4.0^{\circ} \mathrm{C}$ as a consequence of increased atmospheric $\mathrm{CO}_{2}$ (Solomon et al., 2007). These projected temperature increases will result in accelerated melting of glaciers and ice sheets which, when combined with thermal expansion of the oceans, will result in sea level rise of approximately $18-59 \mathrm{~cm}$ by 2100 (Solomon et al., 2007). However, new research indicates that these estimates may be conservative and that sea level increases could be as high as 1-2 m (Rahmstorf, 2007; Pfeffer et al., 2008; Rohling et al., 2009), with small mountain glaciers contributing around $0.12 \mathrm{~m}$ of that estimated sea level rise (Radic and Hock, 2011). In the short term, the largest input to this projected sea level rise (excluding thermal expansion) will be from glaciers and small ice caps (Solomon et al., 2007), with rapid input from maritime glaciers, which will lose mass more quickly due to higher climate sensitivity (Oerlemans, 2001; Anderson et al., 2010), and in the case of tidewater glaciers, by iceberg calving (Muskett et al., 2008). 
Mid-latitude maritime glaciers like those in the Southern Alps of New Zealand, have large annual precipitation and ablation rates and are extremely sensitive, in that small changes in climate can result in a large change in glacier mass balance (Oerlemans, 2001; Anderson et al., 2010), although we still know relatively little about them.

The impact that global warming will have on large scale atmospheric circulation is unclear, with the possibility that different atmospheric circulation responses could enhance or subdue warming trends (Fyfe et al., 1999; Fedorov and Philander, 2000; Nyenzi and Lefale, 2006; Power and Smith, 2007). Time-series analysis of mass balance-climate data helps us to understand the mass balance response to atmospheric circulation variability in the past, thereby improving knowledge about how glaciers will react to climate change. A number of extended mass balance-climate records exist for polar (e.g. Mayewski and White, 2002; Kaspari et al., 2004; Jouzel et al., 2007) and continental (e.g. Miller and Pelto, 1999; McCabe et al., 2000; Kaspari et al., 2008) regions, but few such records exist for mid-latitude maritime regions (Andreassen et al., 2005; WGMS, 2008), despite glaciers in these regions being expected to have the most rapid response to climate warming. Establishing longer records of accumulation-climate relationships on mid-latitude maritime glaciers is required if we are to fully understand the response of these glaciers to climate change.

\section{$1.4 \quad$ Research objectives}

The overall aim of this research is to investigate the controls on spatial and temporal variability in snow accumulation on glaciers in mid-latitude maritime environments. This will help us to consider how accumulation and mass balance might change with projected climatic warming. Specific objectives are to:

1. Investigate spatial variability in snow accumulation on mid-latitude maritime glaciers, and determine the most important factors controlling that variability.

2. Determine how snow accumulation on mid-latitude maritime glaciers is influenced by synoptic-scale climate variability. 
3. Determine the moisture source regions of winter snow accumulation using stable water isotope and trace element signatures, and evaluate how these chemical signatures vary in time and space on mid-latitude maritime glaciers.

4. Determine how inter-annual variability in net accumulation on midlatitude maritime glaciers is influenced by climate and atmospheric circulation patterns on annual and seasonal timescales.

\subsection{Regional setting and study sites}

New Zealand is located in the mid-latitudes of the Southern Hemisphere and surrounded by ocean. The New Zealand continent disrupts two major ocean currents (Figure 1.1) the warm Subtropical Gyre, an anticyclonic system driven by regional winds, and the cold Antarctic Circumpolar Current (Carter, 2001). Dominant mid-latitude westerly atmospheric circulation (Figure 1.2) forces the warm subtropical water against the South Island of New Zealand.

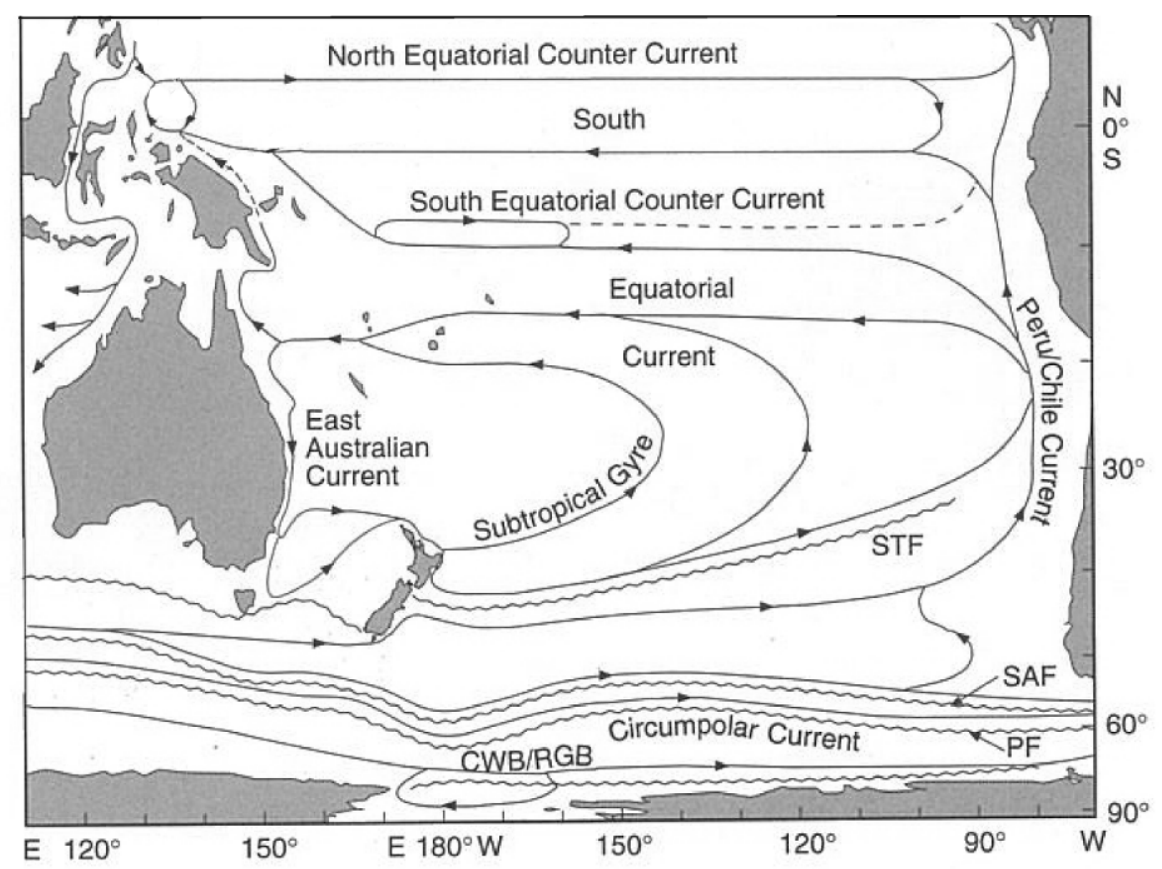

Figure 1.1: Main ocean currents in the Southern Hemisphere, including the Subtropical Gyre and the Circumpolar Current, which are intercepted by New Zealand. Other currents include the Subtropical Front (STF), Subantarctic Front (SAF), the Polar Front (PF) and the Continental Water Boundary/Ross Sea Gyre Boundary (CWB/RGB). Modified from Bury (2001), p221. 


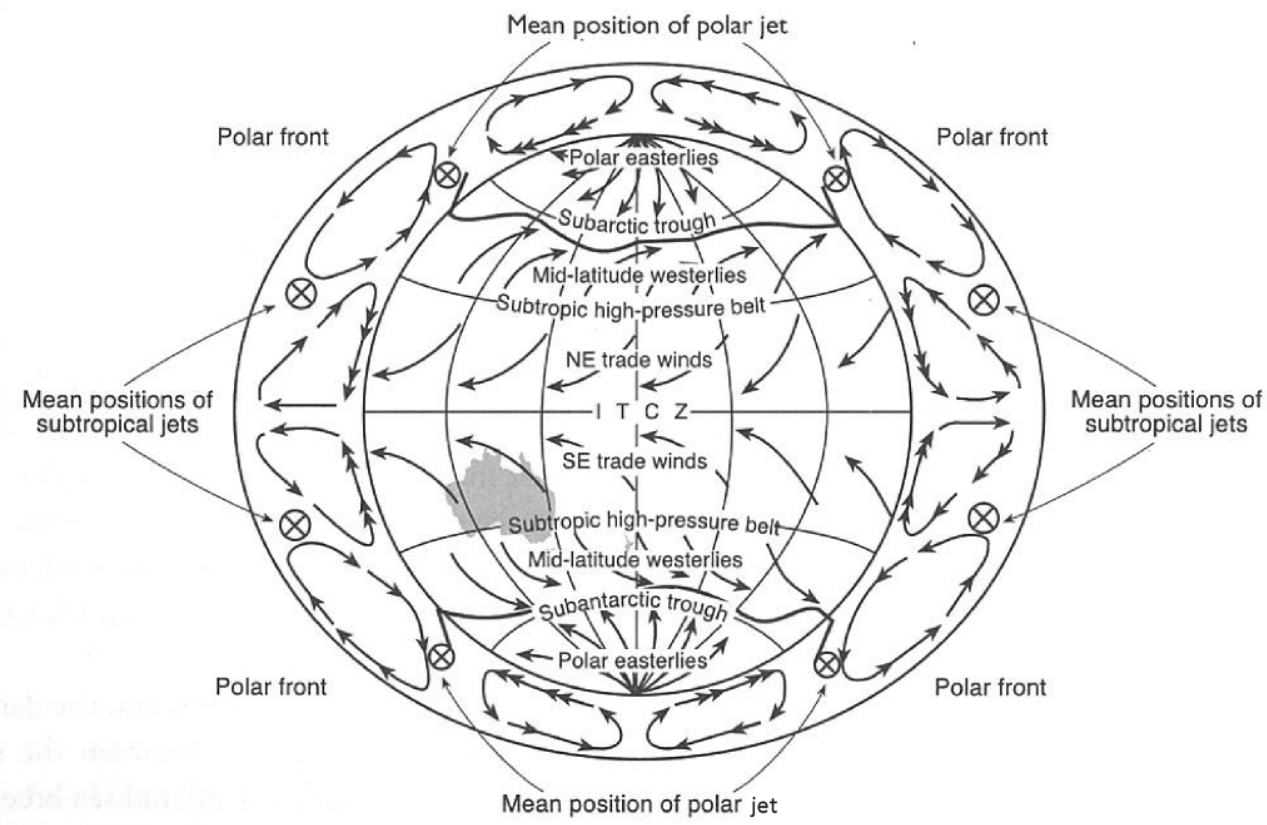

Figure 1.2: Global atmospheric circulation including the main systems that influence the New Zealand region, in particular the mid-latitude westerlies, subantarctic troughs and subtropical high pressure systems. Source: Sturman and Tapper (2006), p55.

In the South Island, the Southern Alps form a $700 \mathrm{~km}$ long, $2500 \mathrm{~m}$ high barrier to dominant westerly atmospheric circulation, intercepting air masses of both temperate and sub-tropical origin (Sturman and Tapper, 2006). Under prevailing westerly flow, moisture evaporated from the Tasman Sea is forced to rise up and over the Southern Alps, resulting in significant precipitation, especially on the western slopes of the mountain range.

Changes to the strength and persistence of westerly circulation are important to climate variability in the New Zealand region. Of particular interest is the El Niño Southern Oscillation (ENSO). ENSO is an ocean-atmosphere oscillation centred in the tropical Pacific affecting mean sea level pressure, wind, sea-surface-temperature and precipitation (Salinger et al., 2004). The strength and phase of the ENSO is indicated by several indices including the Southern Oscillation Index (SOI), which is the normalised difference in atmospheric pressure between Tahiti and Darwin. When pressure is high in Darwin relative to Tahiti, ENSO is in an El Niño phase (negative SOI), and when pressure is low in Darwin compared to Tahiti, the ENSO is in a La Niña phase (positive SOI). During El Niño phases, sea-surface temperatures increase in the eastern Pacific resulting in enhanced atmospheric convection that weakens the normal easterly trade 
winds (Figure 1.3). Conversely during a La Niña phase, sea-surface temperatures are warmer in the western Pacific, and uplift and condensation occurs over the Australian region, which enhances the trade winds (Brenstrum, 1998).

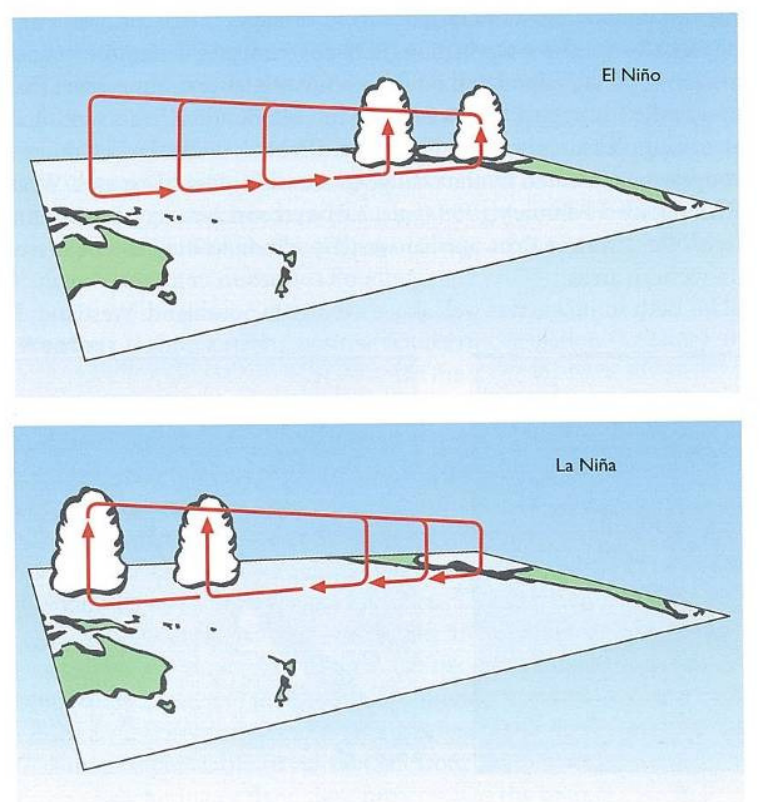

Figure 1.3: Schematic demonstrating the variations in atmospheric and oceanic circulation during El Niño (top) and La Niña (bottom) phases. Source: Brenstrum (1998), p103.

In the Southern Alps of New Zealand, El Niño phases are often associated with enhanced south-westerly atmospheric flow, which generally results in increased precipitation and decreased temperature especially during the spring and summer. During La Niña phases easterly atmospheric flow anomalies often prevail, which are associated with warm temperatures and reduced precipitation in the Southern Alps region (Mullan, 1995). Consequently, previous studies have demonstrated relationships between phase changes in ENSO and glacier fluctuations in New Zealand, with negative SOI associated with positive glacier mass balance and terminus advance, and positive SOI associated with negative mass balance and terminus retreat (Hooker and Fitzharris, 1999; Chinn et al., 2005b; Fitzharris et al., 2007).

Another mode of variability influencing climate in New Zealand is the Southern Annular Mode (SAM). The SAM is a ring of pressure variability between $60^{\circ} \mathrm{S}$ and $45^{\circ} \mathrm{S}$ brought about by changes to the position and strength of the mid-latitude jet (Renwick and Thompson, 2006; Marshall, 2007). In its positive phase, pressures are below average over Antarctica and higher than average in mid-latitudes (Figure 1.4), 
with the reverse pressure trend occurring during a negative phase. These pressure anomalies drive changes in windiness and storm activity, and are most prominent in the New Zealand climate during the summer months. In New Zealand, studies have demonstrated that when the SAM is positive there is an easterly flow anomaly, resulting in increased temperature and reduced precipitation especially over the South Island. In the negative phase, westerlies are enhanced, bringing increased precipitation and reduced temperatures (Kidston et al., 2009). Unlike ENSO, the influence that the SAM has on glacier fluctuations in New Zealand has yet to be examined.

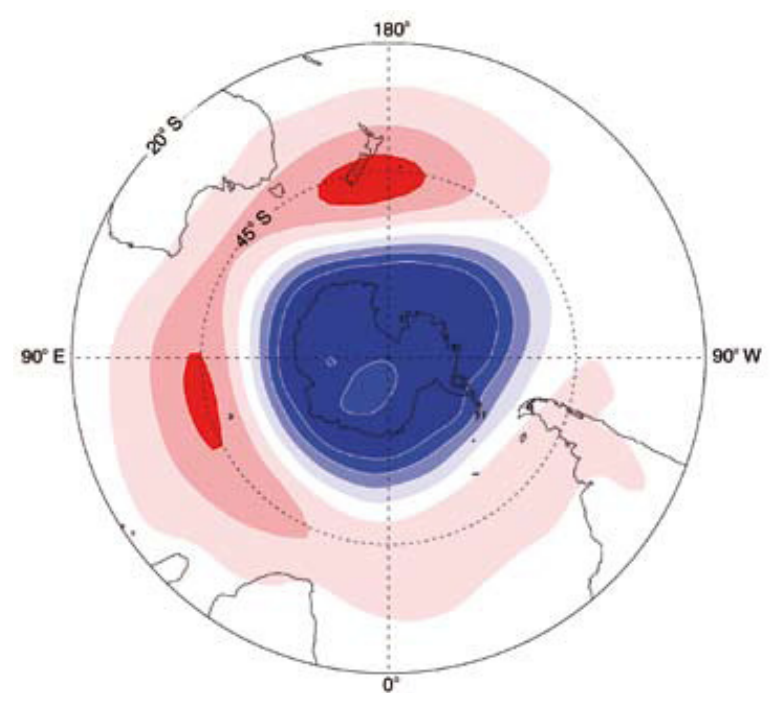

Figure 1.4: The Southern Annular Mode in its positive phase, showing below average pressure over Antarctica and above average pressure in the New Zealand region, especially over the South Island. Source: Renwick and Thompson (2006).

Prevailing westerly circulation means that a steep precipitation gradient exists in the vicinity of the Main Divide of the Southern Alps (Figure 1.5). Recent research has demonstrated that although a precipitation maximum has been recorded west of the Southern Alps (Griffiths and McSaveney, 1983; Henderson and Thompson, 1999), a secondary or subsidiary precipitation maximum may occur immediately east of the range (Kerr, 2009). However, due to a lack of precipitation measurement above $2000 \mathrm{~m}$ a.s.1., (Figure 1.5), much uncertainty still surrounds precipitation estimates in high glacier catchments. Two adjacent glaciers have been chosen for this study in order to enable snow accumulation to be sampled along this west-east precipitation gradient; the Franz Josef Glacier, located to the west of the Main Divide and the Tasman Glacier to the east (Figure 1.6). The position of these glaciers, astride an orographic barrier in a mid-latitude location with prevailing westerly flow, means that the following 
investigations into snow accumulation and climate variability will be of value to other regions with similar topographic and climatological influences. For example, glaciers located in southern Patagonia, Norway and western North America.

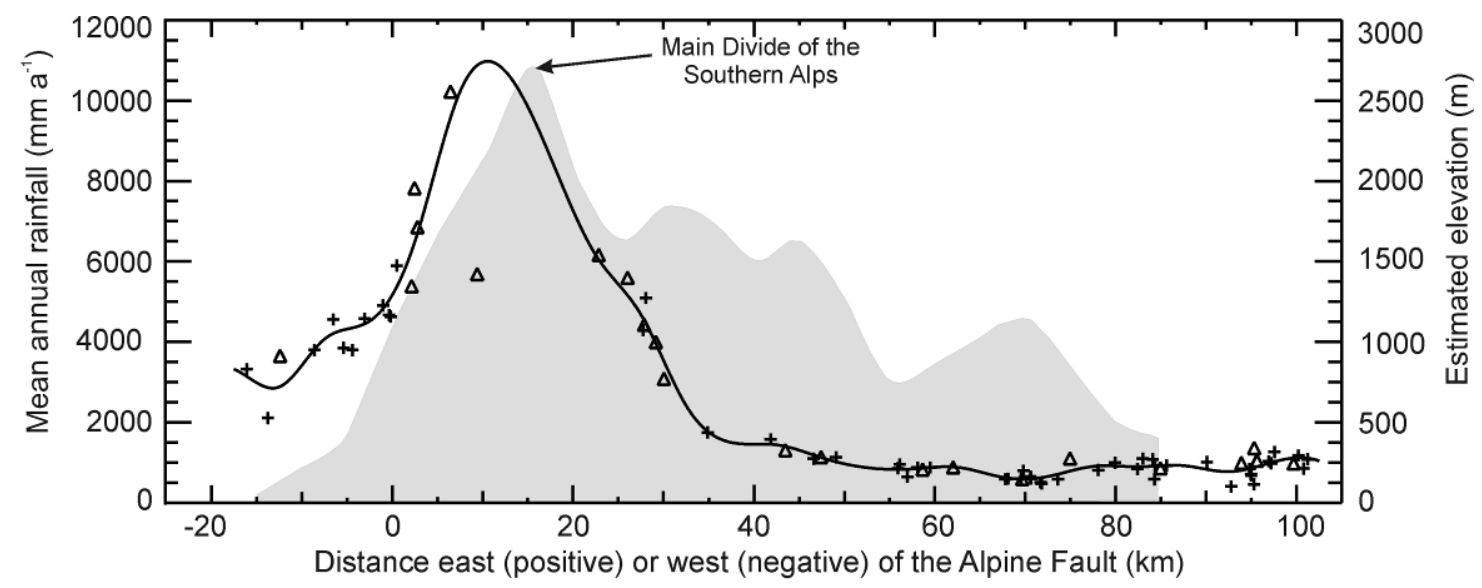

Figure 1.5: Estimated precipitation transect (fitted spline) in the region of the Franz Josef Glacier based on data from 1971-2000 (pers. comm., S. Stuart, 2010). + are data from the National Institute of Water and Atmospheric Science (NIWA) National Climate Database and $\Delta$ are data from stations in the NIWA Water Resources Archive. Estimated topography (shaded region) was added by Purdie based on data from Henderson \& Thompson (1999). Note the distinct lack of data in the immediate vicinity of the Main Divide (i.e. above $2000 \mathrm{~m}$ a.s.1.).

The Franz Josef Glacier is situated in a predominately windward basin and has a large mass balance gradient recording high annual accumulation ( $\sim 6 \mathrm{~m}$ w.e. $)$ and ablation ( $20 \mathrm{~m}$ w.e.) (Anderson et al., 2006). This large mass turn-over along with a steep slope means that the Franz Josef Glacier is highly dynamic, and responds quickly to climate perturbations (Oerlemans, 1997; Anderson et al., 2006). The time taken for a glacier to mostly adjust to perturbations in mass (around two-thirds of the volume) is commonly referred to as the response time (Johannesson et al., 1989). The response time of the Franz Josef Glacier has been estimated at around 20 years, which is very short in comparison to glaciers in the European Alps, where response times are often in excess of 70 years (Hoelzle et al., 2007). A glaciers response time should not be confused with its much shorter reaction time, which is the time taken for a glacier terminus to start responding to a mass balance perturbation, which in the case of the Franz Josef Glacier is typically around 7 years (Hessell, 1983; Hoelzle et al., 2007). 


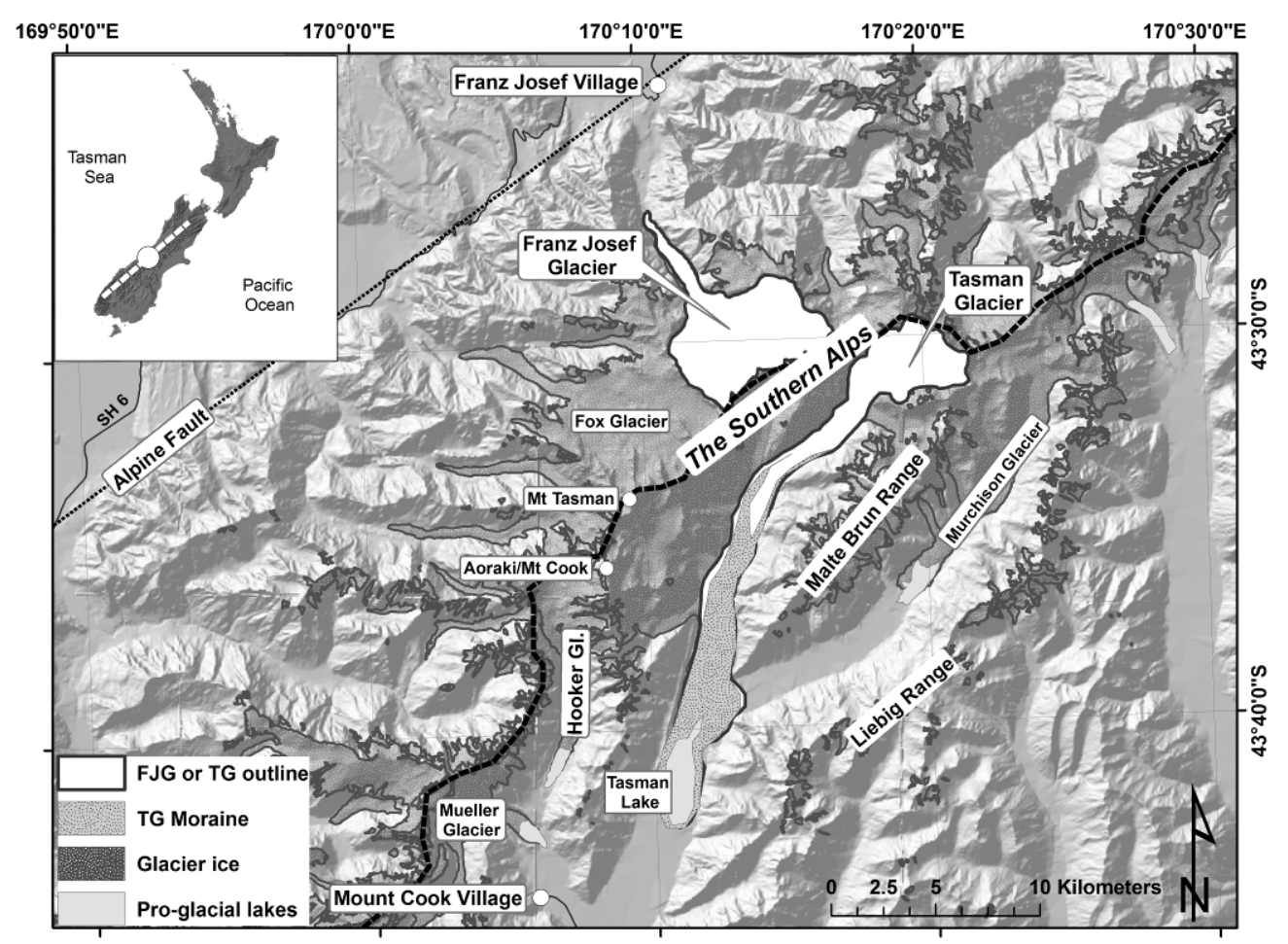

Figure 1.6: Location map of the Southern Alps and surrounding major glaciers, including the Franz Josef (FJG) and Tasman (TG) Glaciers and the Alpine Fault. Insert shows the location of the study sites in relation to the Southern Alps (dashed line) and the South Island of New Zealand.

Consequently, the Franz Josef Glacier has advanced/retreated in response to climate variability since monitoring began. Although the general trend of the glacier from the 1800 s to present has been one of retreat, a number of advance phases have been recorded (Figure 1.7), with the most recent advance starting in late 2004 and culminating in mid-2008. Presently, the glacier is slowly retreating (pers.comm., Anderson, 2010). 


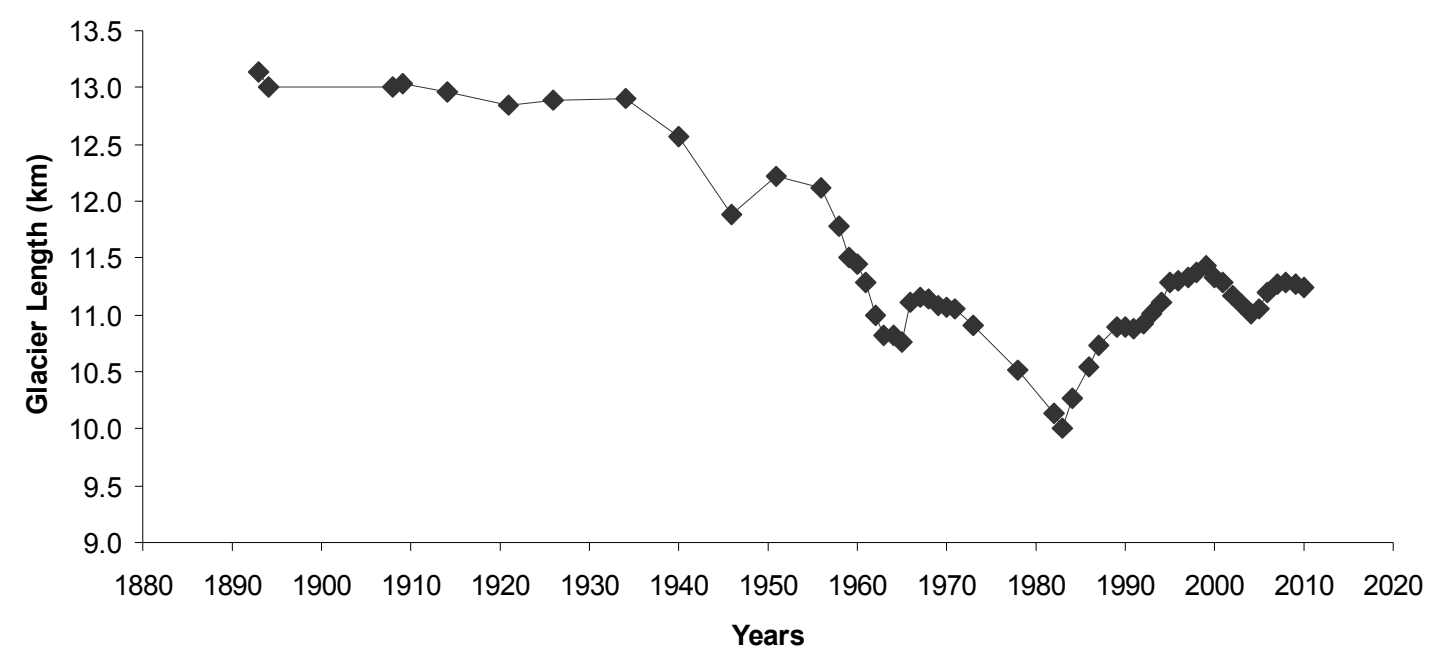

Figure 1.7: Recorded variations in length of the Franz Josef Glacier from the late 1800s to present. Despite an overall trend of retreat there have been a number of notable advance phases, for example during the 1960s and 1990s.

With its dynamic nature and easy access the Franz Josef Glacier is one of the most studied glaciers in the Southern Hemisphere, with initial surveys dating back to the late 1800s (Douglas, 1894; Harper, 1894). Early research focused on terminus location and ice velocity (Bell, 1910; Speight, 1935; Suggate, 1952; Gunn, 1964; McSaveney and Gage, 1968; Sara, 1968), and progressed to the investigation of the exceptional ablation rates and associated energy transfers (Marcus et al., 1985; Ishikawa et al., 1992; Owens et al., 1992; Kelliher et al., 1996). Less research has focused on snow accumulation (Ruddell, 1995; Anderson et al., 2006), and attempts to measure snow depth using ground penetrating radar (GPR) produced mixed results (Nobes and Owens, 1995), possibly due to the high water content in the snowpack. With sparse snow accumulation data, mass balance modelling studies have utilised data from low elevation weather stations and precipitation estimates (Woo and Fitzharris, 1992; Oerlemans, 1997). More recent modelling attempts have been improved by field validation (Anderson et al., 2006; 2008). Snow accumulation data from Franz Josef Glacier have been primarily used for the testing of numerical models, with the climate signal embedded within these accumulation data yet to be fully explored.

The Tasman Glacier, situated in the lee-side of the Main Divide of the Southern Alps, also receives high annual snow accumulation ( $\sim 6 \mathrm{~m}$ w.e.) (Appendix 1$)$, but a thick and extensive debris cover along the lower glacier trunk (Figure 1.6) results in much lower 
ablation rates $\left(\sim 2\right.$ m w.e. $\left.\mathrm{a}^{-1}\right)$ at the terminus (Kirkbride, 1995; Purdie and Fitzharris, 1999). Maximum ablation rates (13 $\mathrm{m}$ w.e. $\mathrm{a}^{-1}$ ) occur on clean ice above the debris transition (Appendix 2). Initial glaciological surveys date to the mid 1800s (Haast, 1864; Brodrick, 1889; 1891; 1894), and mass balance measurements were carried out on Tasman Glacier in the 1960s and 1970s (Goldthwait and McKellar, 1962; Anderton, 1975; Chinn, 1994), with net accumulation measured again in the late 1980s (Ruddell, 1995). In conjunction with direct mass balance measurement, the end-of-summer snowline (EOSS) has been estimated from aircraft intermittently on Tasman Glacier since 1955 (pers. comm., Chinn, 2007), and annually since 1977 (Willsman et al., 2009). In 2004, a $54 \mathrm{~m}$ ice core was recovered from the accumulation area of Tasman Glacier (Morgenstern et al., 2004), the analysis of which forms part of this research. Previous research has examined relationships between the position of the EOSS and atmospheric circulation (e.g. Fitzharris et al., 1997; Clare et al., 2002; Chinn et al., 2005b). However as yet, the direct accumulation measurements, although intermittent, have not been combined to further examine accumulation-climate relationships.

In contrast to the dynamic Franz Josef Glacier, the Tasman Glacier has been gradually thinning and retreating during the $20^{\text {th }}$ and early $21^{\text {st }}$ centuries. There are currently a number of thermokarst ponds on the lower glacier surface (Hochstein et al., 1995; Röhl, 2008) and a rapidly enlarging terminal lake (Figure 1.8), where mass loss is primarily by calving retreat (Kirkbride and Warren, 1999; Purdie and Fitzharris, 1999; Röhl, 2006; Quincey and Glasser, 2009). 


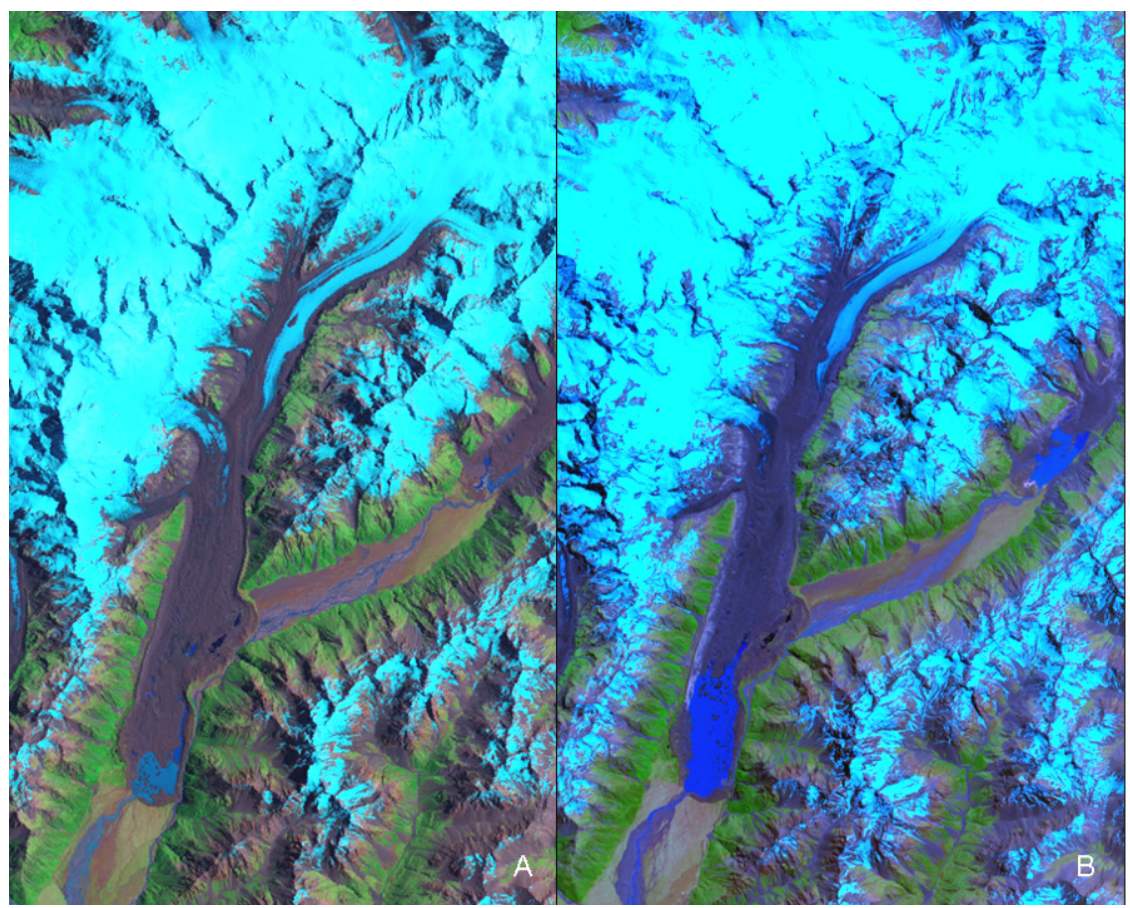

Figure 1.8: Rapid change at the Tasman Glacier terminus recorded by ASTER satellite images in 1990 (A) and 2007 (B). Small disconnected lakes were recorded on the glacier surface in 1983 (Hochstein et al., 1995), which by 1990 had coalesced to form Tasman Lake. Since 2006 lake expansion has become increasingly rapid (Dykes and Brook, 2010).

Source: http://earthobservatory.nasa.gov/

\subsection{Methods and methodology}

The research objectives outlined in section 1.4 are addressed using a combination of field-based measurement, geochemical processing, data analysis and modelling. Details of the methods used are included in each thesis chapter. However, the following sections provide some additional information including method rationale and some methodological discussion.

\subsubsection{Snow accumulation measurement}

Snow accumulation was measured in the accumulation areas of Franz Josef and Tasman Glaciers over a variety of temporal and spatial scales, ranging from daily point measurements to high density annual measurement. The measurement of gross winter snow accumulation proved extremely difficult due to large quantities received (Appendix 1). Originally, it was planned to use Ground Penetrating Radar (GPR) to measure total winter snowfall, but when no GPR was available, the focus switched to field measurement of net accumulation. In particular, net accumulation was measured 
on both glaciers at the end-of-summer in 2007, 2008 and 2009 by the crevasse stratigraphy method.

The crevasse stratigraphy method (also see section 2.3.1) is an ideal way to measure net accumulation on glaciers with large annual snowfall. In such environments other methods like digging snow pits, installing and maintaining stakes or probing are inefficient. The crevasse stratigraphy method is based on the measurement of annual ablation surfaces formed by summer melting and sedimentation, which can be clearly viewed as horizontal horizons down crevasse walls (Figure 1.9). The method works by having four people working roped together in pairs. One pair of researchers has a long tape measure that is lowered into the crevasse, while the other pair, positioned on the opposite side of the crevasse, instructs the alignment of the tape measure with the annual layer. Once the tape measure is accurately positioned the first rope-team can read-off and record the annual layer depth. The position of each measurement is recorded by hand-held GPS. Multiple measurements can be taken from a single crevasse, and crevasses can be surveyed over a variety of terrain. Surveys are only conducted in crevasses that have vertical walls and clear layering (Pelto, 1988).

Although the crevasse stratigraphy method has been utilised by a number of researchers (Pelto, 1988; Ruddell, 1995; Pelto, 1996; Anderson et al., 2006) it is not without criticism. Meier et al., (1997) questioned the validity of this method when utilised by Pelto (1996) for measuring accumulation on a number of glaciers in the North Cascades. Some concern was expressed over potential ambiguity of dust layers, in that all layers visible may not be annual. It was also noted that snow/ice density would not be accurate from crevasse walls due to metamorphic processes. Indeed care is needed when 'reading' crevasse layers as in New Zealand layers of Australian dust can be deposited during exceptionally strong westerly windstorms when conditions are very dry in Australia. From experience, the author notes that these layers are distinctly orange in colour, not the brown/black of the annual layer, so should not cause confusion to an experienced field party. However, experience and familiarity with local climate conditions is important in achieving proficiency with the method. No density measurements were collected from crevasse walls during these surveys, as previous research has found that snow density in the accumulation area of New Zealand glaciers is usually around $600 \mathrm{~kg} \mathrm{~m}^{-3}$ by the end of summer (Chinn, 1994; Ruddell, 1995) . 
Instead, the elevation/density conversion developed by Ruddell (1995) and based on a number of previous density measurements, was adopted for estimating density of the measured annual layers (see section 2.3.1).

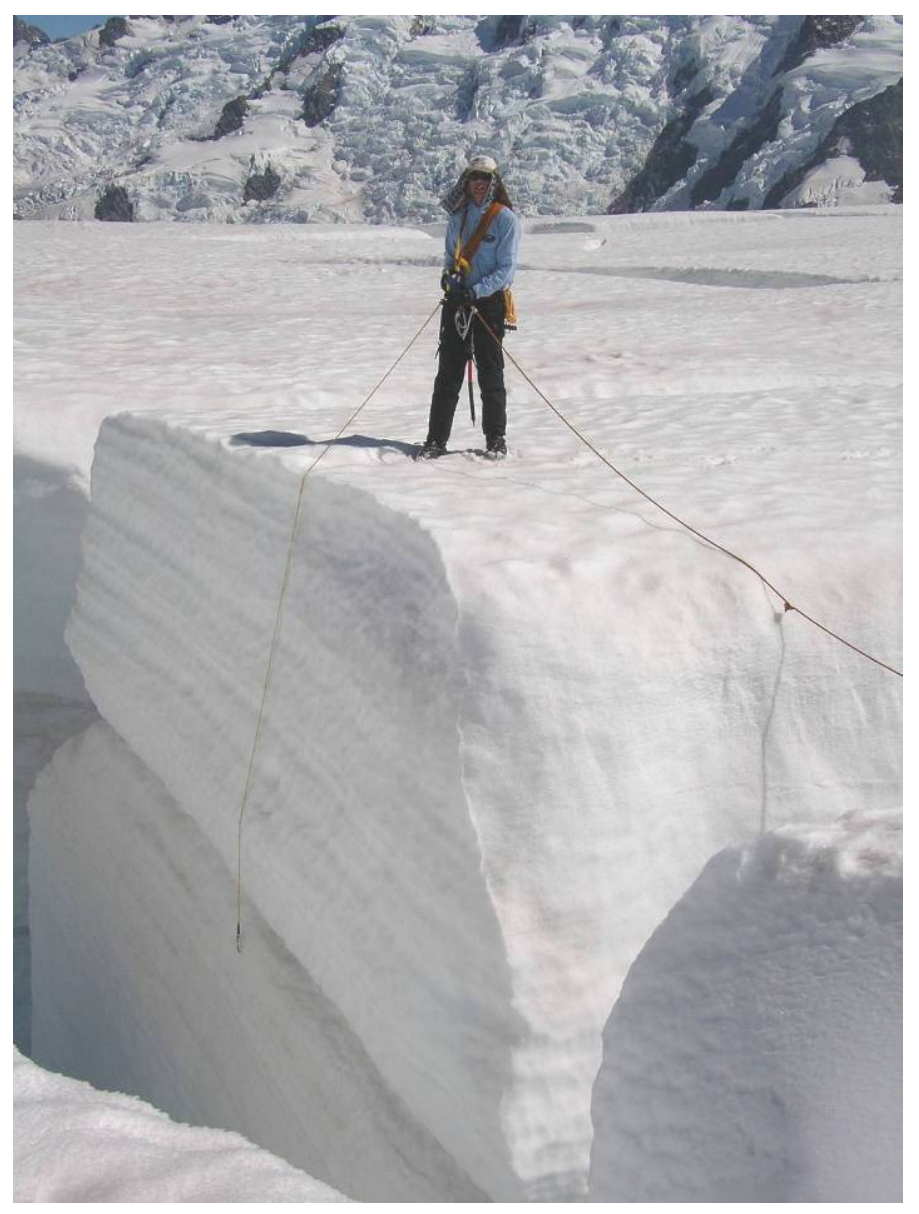

Figure 1.9: Measuring annual layers down a crevasse in the Tasman Glacier accumulation area. The annual layer can be clearly seen just above the bottom of the tape measure. Photo by Purdie.

Consideration of the importance of sampling density in mass balance studies has suggested that sampling may be scale invariant, and that larger glaciers do not necessarily require more sampling points compared to smaller glaciers which can be topographically more heterogeneous (Fountain and Vecchia, 1999; Pelto, 2000). On Lemon Creek Glacier, Pelto (2000) found improvement in the mass balance estimate by increasing sampling density from 1 to 4 points per $\mathrm{km}^{2}$, but no improvement beyond that. Errors at 1 point per $\mathrm{km}^{2}$ were estimated at $\pm 0.15 \mathrm{~m} \mathrm{a}^{-1}$ and at 2 points per $\mathrm{km}^{2}$ only $\pm 0.10 \mathrm{~m} \mathrm{a}^{-1}$. In 2008 sampling density from applying the crevasse stratigraphy method in the accumulation area of Tasman Glacier $\left(\sim 16 \mathrm{~km}^{2}\right)$ was 2.75 points $\mathrm{km}^{2}$, and on Franz Josef Glacier $\left(\sim 25 \mathrm{~km}^{2}\right) 2.64$ points $\mathrm{km}^{2}$. On these high accumulation glaciers, such measurement density would not be possible from stakes or pits. In addition, Pelto 
(2000) compared errors (repeatability) between probing and crevasse stratigraphy, reporting $\pm 0.03 \mathrm{~m}$ and $\pm 0.02 \mathrm{~m}$ respectively.

Aside from net accumulation measurement, daily measurement of winter snow accumulation was conducted at a high elevation site on both Tasman and Franz Josef Glaciers over a three week period (also see section 3.3.1). For this high temporal study snow accumulation was measured using snowboards. This simple approach to accumulation measurement was chosen due to the extreme nature of the conditions. There are no moving parts to freeze, they can be set up and measured quickly, and if securely anchored, should withstand extreme winds. Snowboards are a standard method for measuring snow accumulation, especially in the ski industry (New Zealand Mountain Safety Council, 2008), and have been used to determine percentage undercatch from other precipitation gauges (Barry, 1992). Snowboards clearly partition new from old snow, ensuring that density measurement is only made from the most recent snowfall. This enables ease of conversion of snow depth to snow water equivalent. However, snowboards cannot be used to discriminate between freshly fallen snow and snow that is re-deposited, and there is nothing to prevent deposited snow being subsequently removed from the board during strong winds. Despite these limitations, snowboards are a highly robust way to measure winter snowfall at high elevation, and provide true representation of surface accumulation at a point.

\subsubsection{Climate monitoring}

In order to quantify on-glacier climate three automatic weather stations (AWS) were installed. On Tasman Glacier an AWS was installed on the white ice mid-glacier (1100 m a.s.1.) from March 2007 to March 2009. This weather station measured temperature, humidity, wind speed, wind direction and incoming and outgoing solar radiation. In addition, during the winter months a sonic ranger was installed to measure changes in snow surface height. However, this data was found to be of variable quality, with particularly poor data quality during windy conditions. During the period of the winter snow accumulation survey, two additional AWS were installed at $2300 \mathrm{~m}$ a.s.1. in the accumulation areas of Tasman and Franz Josef Glaciers. These AWS measured temperature, humidity, wind speed and wind direction (also see section 3.3.3). Data from the temporary AWS could be compared to permanent AWS installed and run by 
the National Institute of Water and Atmospheric Science (NIWA) at Mount Cook (765 $\mathrm{m}$ a.s.1.) and Franz Josef ( $80 \mathrm{~m}$ a.s.1.) villages respectively.

\subsubsection{Modelling snow accumulation and ablation}

Measuring daily snow accumulation on two glaciers during winter provided a unique opportunity to compare measured data to a simple accumulation model (Chapter 3). To do this, the mass balance model of Anderson et al., (2006) was used. This model is representative of models commonly utilised for estimating snow accumulation whether on a glacier or in a seasonal snow environment (Barringer, 1989; Fitzharris and Garr, 1995; Ruddell, 1995; Oerlemans, 1997; 2001). In the model, snow accumulation occurs on days when precipitation $(p)$ is $>0$ and temperature $(T)$ is lower than a critical threshold $\left(T_{\text {crit }}\right)$. Anderson et al., (2006) applied $T_{\text {crit }}$ of $1^{\circ} \mathrm{C}$, which was determined from best-fit modelling in previous accumulation studies in New Zealand (Moore and Owens, 1984; Barringer, 1989). Modelled hourly accumulation (c) at elevation $(z)$ is determined from hourly averaged temperature $\left(T_{a v h r}\right)$ and total hourly precipitation $\left(P_{h r}\right)$ by:

$$
c(z)=T_{a v h r}(z)<T_{c r i t}, \quad \sum P_{h r} * f_{c}
$$

where $f_{c}$ is the precipitation factor, which is a multiplier applied to precipitation recorded at a low elevation weather station in order to account for observed increases in precipitation at higher elevations, due to orographic processes. For Franz Josef Glacier $f_{c}$ was empirically derived by Anderson et al., (2006), based on previous precipitation measurement and modelling. It was found that a polynomial equation best-fitted the data, and enabled precipitation to be estimated at any elevation. This gave an $f_{c}$ of 1.41 for the measurement site at Franz Josef Glacier (2310 m a.s.1.) when forcing the model with precipitation recorded at Franz Josef village AWS (80 $\mathrm{m}$ a.s.1.). The Tasman Glacier $f_{c}$ was derived from interpolation of precipitation gradient maps constructed by Henderson and Thompson (1999). An $f_{c}$ of 1.46 was estimated from the maps to account for precipitation increases from the AWS at Mount Cook village (765 $\mathrm{m}$ a.s.1.) and the measurement site at the top of the Tasman Glacier (2340 m a.s.1.).

In order to estimate $T_{\text {avehr }}$ from low-elevation AWS data, various temperature lapse rates were considered based on previous studies (Barringer, 1989; Anderson et al., 2006). This resulted in an initial a temperature lapse rate of $-5^{\circ} \mathrm{C} \mathrm{km}^{-1}$ being applied. Both the 
temperature lapse rates and the precipitation factors were later modified based on data collected during this study (see section 3.4.3).

Although more complex snow accumulation and evolution models exist, for example SnowModel (Liston and Elder, 2006) and Snowpack (Lehning et al., 1999), these require input data currently unavailable for glacier sites in the New Zealand Southern Alps. For example, SnowModel requires temporally varying fields for precipitation, wind speed and wind direction. The model also needs temperature and humidity data ideally from meteorological stations within or near the simulation area (Liston and Elder, 2006). Snowpack is designed to utilise measured snow depth, which is then evolved using meteorological data to determine snow surface heat flux (Lehning et al., 1999). While such models are obviously more advanced, they are not practicable in data poor environments. Consequently a simple, accumulation model that requires fewer inputs is used in this study.

In addition to estimating snow accumulation as outlined above, snow ablation was estimated only in order to characterise the mass balance years that net accumulation had been measured (see section 2.3.3). Again, the lack of on-site meteorological measurements prevented the application of an energy-balance model, but a degree-day model, which only requires temperature as an input could be applied. A degree-day model uses a simple temperature index to estimate snowmelt $(m)$ where:

$$
m=f_{a}\left(T_{\text {avehr }}-T_{b}\right), m=0 \text { for } T_{\text {avehr }}<0^{\circ} \mathrm{C}
$$

where $m$ is snowmelt (mm w.e.), $f_{a}$ is a degree-day factor $\left(\mathrm{mm}^{\circ} \mathrm{C} \mathrm{d}^{-1}\right), T_{b}$ is the base temperature $\left(0^{\circ} \mathrm{C}\right.$ for snow), and $\left(T_{a v e h r}-T_{b}\right)$ is the accumulated degree-days $\left({ }^{\circ} \mathrm{C} \mathrm{d}^{-1}\right)$ for $T_{\text {avehr }}>0{ }^{\circ} \mathrm{C}$.

For Franz Josef Glacier, a degree-day factor for snow of $4.5 \mathrm{~mm}^{\circ} \mathrm{C} \mathrm{d}^{-1}$ was determined by Anderson et al., (2006) by simultaneous measurement of temperature and ablation in the Franz Josef accumulation area. At Tasman Glacier an average degree-day factor of $3.4 \mathrm{~mm}^{\circ} \mathrm{C} \mathrm{d}^{-1}$ was determined by Cutler and Fitzharris (2005) over a 34 day period in summer in the Tasman Glacier accumulation area. These previously calculated $f_{a}$ are utilised for ablation estimation in this study. 
Finally, to estimate the proportion of melting $(M)$ that could be attributable to differences in net radiation received at snowfields in the Franz Josef Glacier accumulation area (see section 2.4.2), the energy balance for a melting snow surface was used (Neale \& Fitzharris, 1997):

$$
M=Q m /\left(\rho L_{f}\right)
$$

where $Q m$ is energy used for snowmelt, $\rho$ is density of water $\left(1000 \mathrm{~kg} \mathrm{~m}^{-3}\right)$, and $L_{f}$ is the latent heat of fusion $\left(0.335 \mathrm{MJ} \mathrm{kg}^{-1}\right)$

\subsection{Thesis format and structure}

At the core of this thesis are four scientific papers, each designed to address one of the primary research objectives outlined in section 1.4. At submission of this thesis, three papers have been published in international journals, while the fourth paper is currently under peer review. These papers are presented here as Chapters 2-5. The papers are maintained word for word as accepted for publication, but references are synthesised at the end of the thesis to enhance thesis flow and readability. As a consequence, some repetition does occur, in particular surrounding description of the study sites. Full paper citations and clarification of input from co-authors are outlined below. Chapter 6 provides a synthesis of the main research findings, revisiting the original research objectives, summarising how objectives have been met, and explaining the contribution that results of this research have made to scientific literature. Chapter 6 also provides suggestions for future snow accumulation research.

\subsubsection{Chapter 2}

Purdie H., Anderson B., Lawson W. and Mackintosh A. 2011. Spatial variability in snow accumulation on glaciers in the Southern Alps, New Zealand: as revealed by crevasse stratigraphy. Hydrological Processes, 25: 54-63.

This chapter addresses research objective one, by examining the possible controls on spatial variability in net accumulation at maritime glaciers located east and west of the Main Divide of the Southern Alps. Net accumulation data, determined using crevasse stratigraphy, are compared to controlling variables, for example: elevation, insolation 
and wind exposure, to identify which processes exert most influence on the spatial variability identified.

Co-authors: Brian Anderson provided the net accumulation data for Franz Josef Glacier and assisted with feedback and revisions. Wendy Lawson and Andrew Mackintosh provided feedback and assisted with revisions.

\subsubsection{Chapter 3}

Purdie H., Mackintosh A., Lawson W. and Anderson B. 2011. Synoptic influences on snow accumulation on glaciers east and west of a topographic divide: Southern Alps, New Zealand. Arctic, Antarctic and Alpine Research, 43: 82-94.

This chapter focuses on synoptic-scale variability in winter snow accumulation (research objective two) by means of a simultaneous daily snow accumulation survey conducted in the accumulation areas of Franz Josef and Tasman Glaciers. It identifies which synoptic flow types are associated with the majority of snow accumulation, and how this snow accumulation varies across the Southern Alps. In addition, measured daily snow accumulation is compared to a simple snow accumulation model to see if such models can capture synoptic scale variability and to identify model parameters most in need of refinement.

Co-authors: Andrew Mackintosh, Wendy Lawson and Brian Anderson all provided feedback and assisted with revisions.

\subsubsection{Chapter 4}

Purdie H., Bertler N., Mackintosh A., Baker J. and Rhodes R. 2010. Isotopic and ionic changes in winter snow accumulation on glaciers in the Southern Alps, New Zealand. Journal of Climate, 23: 4737-4749.

This chapter addresses research objective three by examining whether climate and moisture source information is contained in fresh winter snow, from the analysis of stable water isotope and trace element geochemistry. This analysis enables the most important moisture source regions and the influence that atmospheric circulation has on 
snow accumulation to be determined. Results from Franz Josef and Tasman Glaciers are compared to see how geochemical signals change as air masses cross the Southern Alps.

Co-authors: Nancy Bertler assisted with interpretation, feedback and revisions. Andrew Mackintosh provided feedback and assisted with revisions. Joel Baker assisted with interpretation, feedback, revision, and laboratory procedures. Rachael Rhodes provided additional SLRS data (Table 4.2) and assisted with laboratory procedures.

\subsubsection{Chapter 5}

Purdie H., Mackintosh A., Lawson W., Anderson B., Morgenstern U., Chinn T., and Mayewski P. submitted. Inter-annual variability in net accumulation on Tasman Glacier, New Zealand, and its relationship with climate. Global and Planetary Change.

This chapter examines how net accumulation varies with climate and atmospheric circulation on an inter-annual timescale (research objective four). To do this, a composite record of net accumulation is developed for the Tasman Glacier, including data from an ice core. This net accumulation record is then compared to local and regional climate on seasonal and annual timescales, to determine the effect that climate and atmospheric circulation have on inter-annual variability in net accumulation.

Co-authors: Andrew Mackintosh, Wendy Lawson and Brian Anderson all provided feedback and assisted with revision. Uwe Morgenstern and Paul Mayewski were involved in the extraction and analysis of the Tasman Glacier ice core, assisted with core interpretation and provided feedback. Trevor Chinn supplied some net accumulation data, the EOSS data, provided feedback and assisted with revisions. 


\section{Controls on spatial variability in snow accumulation on glaciers in the Southern Alps, New Zealand, as revealed by crevasse stratigraphy.}

Net accumulation measurements from two glaciers located on opposite sides of the New Zealand Southern Alps were used to explore processes controlling spatial variability in net accumulation. The degree of variability, as measured by the spatial variogram, differed in each of the three successive years, but lowest variance occurred on both glaciers in March 2008, after a hot, dry summer. Strong relationships between net accumulation and elevation within the accumulation area were only found on Franz Josef Glacier, despite this being the primary control used in glacier mass balance modelling. Interaction between wind and topography was found to be important to the distribution of net accumulation on both glaciers. The crevasse stratigraphy method is an ideal way to gain good spatial coverage of net accumulation, and particularly suited to glaciers with high annual precipitation.

\subsection{Introduction}

Snow accumulation and its spatial variability is the greatest uncertainty in both the measurement and modelling of glacier mass balance (Jansson and Pettersson, 2007). The degree of spatial variability affects how accurately mass balance can be measured, and how well any one mass balance measurement point represents the glacier as a whole (Fountain and Vecchia, 1999). Spatial variability in snow accumulation influences the amount of water equivalent contained in a glacier catchment, which is important for irrigation, hydro-electricity generation, recreation and tourism. Improved understanding about the spatial variability of snow accumulation will help clarify the processes controlling accumulation variability, and thereby assist in glacier mass balance modelling and water resource management.

On valley glaciers, mass balance is strongly controlled by elevation (Paterson, 1994; Fountain and Vecchia, 1999) and mass balance models rely on this relationship when calculating accumulation and ablation, sometimes from remote climate data (Fitzharris and Garr, 1995; Oerlemans, 2001; Anderson et al., 2006). However, this relationship is 
seen to weaken in the accumulation area, as the control exerted by temperature (the variable most strongly correlated with elevation), lessens and other processes come into play (Hodgkins et al., 2005; Machguth et al., 2006). Significant spatial variability in accumulation has been found between adjacent glaciers (Machguth et al., 2006), suggesting that glacier-scale processes may be more important than regional-scale processes at controlling snow accumulation distribution.

In mountainous regions orographic processes result in precipitation enhancement as moist air parcels are forced up and over a topographic barrier, cooling and condensing with the associated reduction in temperature (Barry, 1992). Increased height of a topographic barrier generally leads to increased precipitation, whereas the width of the barrier effects the location of the precipitation maximum (Colle, 2004; Barstad et al., 2007). The height of the freezing level, and air-mass properties lee of a barrier, also influence precipitation distribution, particularly on lee slopes (Zangl, 2005; 2008). In New Zealand a rapid rise in topography beginning at the Alpine Fault, and culminating at the Main Divide of the Southern Alps, leads to a large precipitation gradient and a precipitation maximum of $\sim 10 \mathrm{~m} \mathrm{a}^{-1}$ (Griffiths and McSaveney, 1983; Henderson and Thompson, 1999). Previously it has been believed that this maximum occurs west of the Main Divide (Henderson and Thompson, 1999), but recent research suggests that there may also be a secondary or subsidiary maximum immediately east of the Main Divide (Kerr, 2009).

At local-scale, preferential deposition and re-distribution of snow by wind are important controls on spatial variability in snow accumulation, both resulting in increased snow accumulation on lee slopes (Liston and Sturm, 1998; Lehning et al., 2008; Mott et al., 2008; Dadic et al., 2010). The susceptibility of snow on individual glaciers to wind transport will depend on many variables, for example, wind speed and direction in relation to the amount of snow available for transport (Kind, 1981). Terrain characteristics, like slope and aspect, interact with wind, creating areas of high and low snow accumulation (Anderton et al., 2004; Jansson and Pettersson, 2007). Slope angle also determines the importance of gravitational processes, with reduced snow accumulation on steep slopes, and increased accumulation on low angle slopes (Verge and Willams, 1981). 
In the accumulation area of glaciers, net solar radiation is an important source of energy for melting, particularly during the ablation season. Surface melting enhances snow metamorphism, reducing the susceptibility of the snow surface to wind transport processes (Verge and Willams, 1981). In maritime climates, turbulent heat and radiative fluxes each provide around half of the energy available for melt (Willis et al., 2002). On Franz Josef Glacier, short-term measurements indicate that the influence of radiative fluxes might be somewhat higher (Kelliher et al., 1996).

Inter-annual variability in net accumulation, driven by synoptic scale weather systems, means that the processes exerting most control on the spatial distribution of accumulation can vary year to year (Elder et al., 1991; Hodgkins et al., 2005). Combining this inter-annual variability with the large unexplained variability within, and between, glacier accumulation areas it is clear that the processes involved in determining the spatial distribution in net accumulation are complex and varied. This study aims to improve understanding about controls on the spatial variability of net accumulation on glaciers. Specifically this study will:

1. Determine the degree of spatial variability in net accumulation within, and between, accumulation areas of two glaciers located on opposite sides of an orographic barrier.

2. Identify which variables exert most control on the variability identified e.g. elevation, orography or wind redistribution.

3. Determine if, on an inter-annual time-scale, altered prominence occurs between the different variables controlling the spatial distribution of net accumulation.

\subsection{Study Area}

The New Zealand Southern Alps contain over 3100 glaciers (Chinn, 1999). The range forms a $700 \mathrm{~km}$ long, $\sim 2500 \mathrm{~m}$ high barrier to the dominant westerly atmospheric circulation. To capture spatial variability on either side of the Main Divide, two glaciers are used in this study. The Franz Josef Glacier (FJG) is located on the western flank of the Southern Alps $\left(43^{\circ} 30^{\prime} \mathrm{S}, 170^{\circ} 14^{\prime} \mathrm{E}\right.$ ), covering an area of $\sim 35 \mathrm{~km}^{2}$ (Figure 2.1). The accumulation area of FJG is large $\left(\sim 25 \mathrm{~km}^{2}\right)$ in relation to the total glacier area, and is comprised of three distinct snowfields; Davis, Chamberlain, and Geikie (Figure 2.1). Overall, the accumulation area has a low gradient, north-west aspect, and ice descends 
steeply from the accumulation area into a narrow valley, with the glacier terminating at $\sim 300$ m a.s.1.

The Tasman Glacier (TG), is $\sim 95 \mathrm{~km}^{2}$, and situated immediately on the eastern side of the range $\left(43^{\circ} 30^{\prime} \mathrm{S}, 170^{\circ} 20^{\prime} \mathrm{E}\right)$. TG is a compound valley glacier, with a number of tributary glaciers feeding into the main glacier trunk below the long-term equilibrium line (Willsman et al., 2009). This study focuses on the accumulation area at the top of the glacier which is relatively small at $\sim 16 \mathrm{~km}^{2}$. The glacier has a broad, gently sloping tongue, which descends southwards, with the glacier terminating at $700 \mathrm{~m}$ a.s.l. at a rapidly-growing pro-glacial lake (Figure 2.1). The ablation area of TG is especially large, in part because the lower $10 \mathrm{~km}$ of TG has a thick covering of debris, which significantly reduces melt rates on this part of the glacier (Purdie and Fitzharris, 1999).

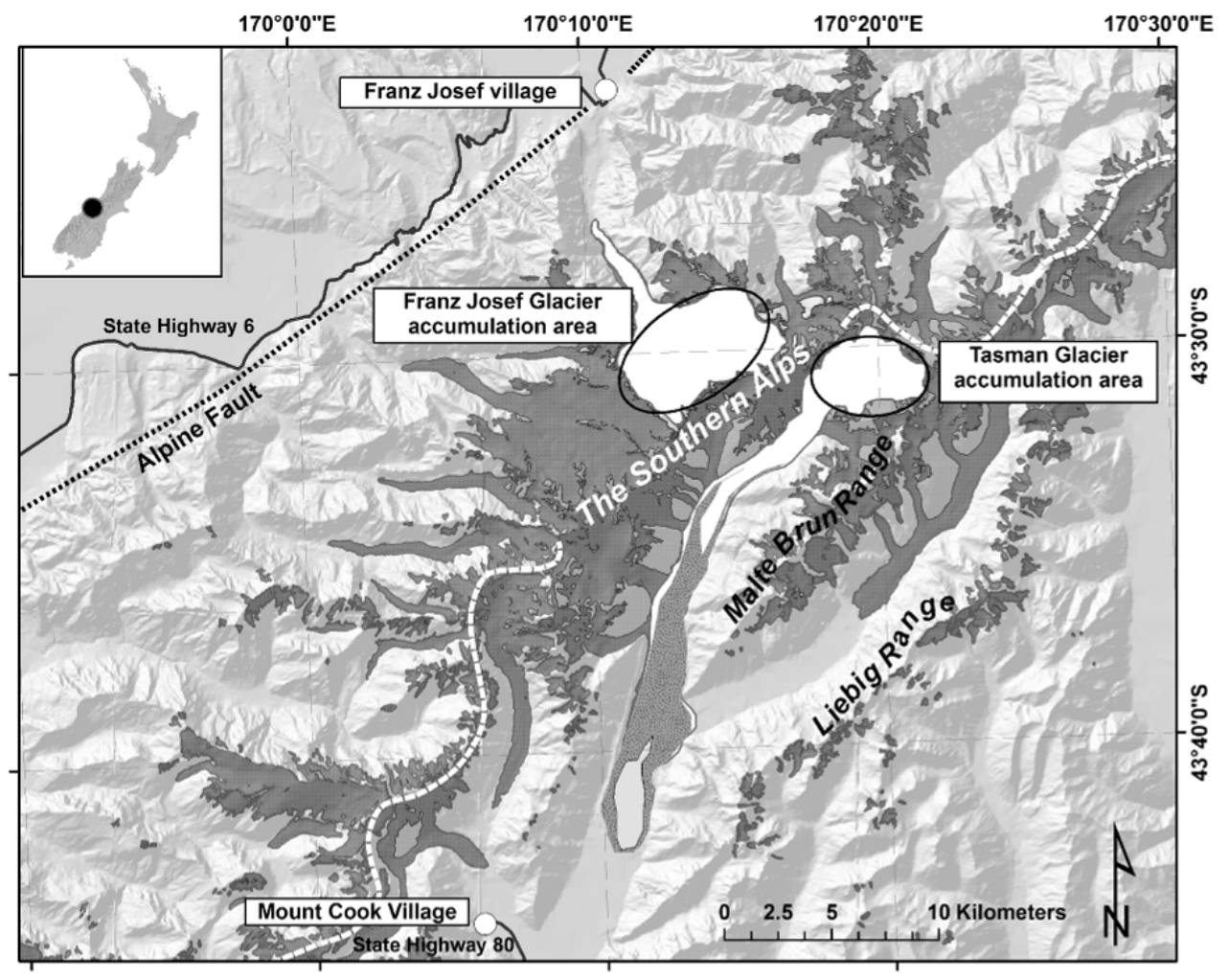

Figure 2.1: Location map of the Franz Josef and Tasman Glaciers, highlighting the accumulation areas of both glaciers.

There are no long-term high elevation climate data available for either TG or FJG, but low elevation automatic weather stations (AWS) are located at Mount Cook (765 m a.s.1.) and Franz Josef ( $80 \mathrm{~m}$ a.s.1.) villages (Figure 2.1). Mean annual temperature at 
Mount Cook and Franz Josef village is $9^{\circ} \mathrm{C}$ and $11^{\circ} \mathrm{C}$ respectively. Annual average precipitation is $4.3 \mathrm{~m}$ at Mount Cook village and $5.5 \mathrm{~m}$ at Franz Josef village, with rainfall spread throughout the year and a peak during spring (Figure 2.2). For the mass balance years ending March 2007-2009, precipitation was below the long-term average, but temperature was close to average. 2008 was the driest and warmest year, particularly during the ablation season (Figure 2.2).
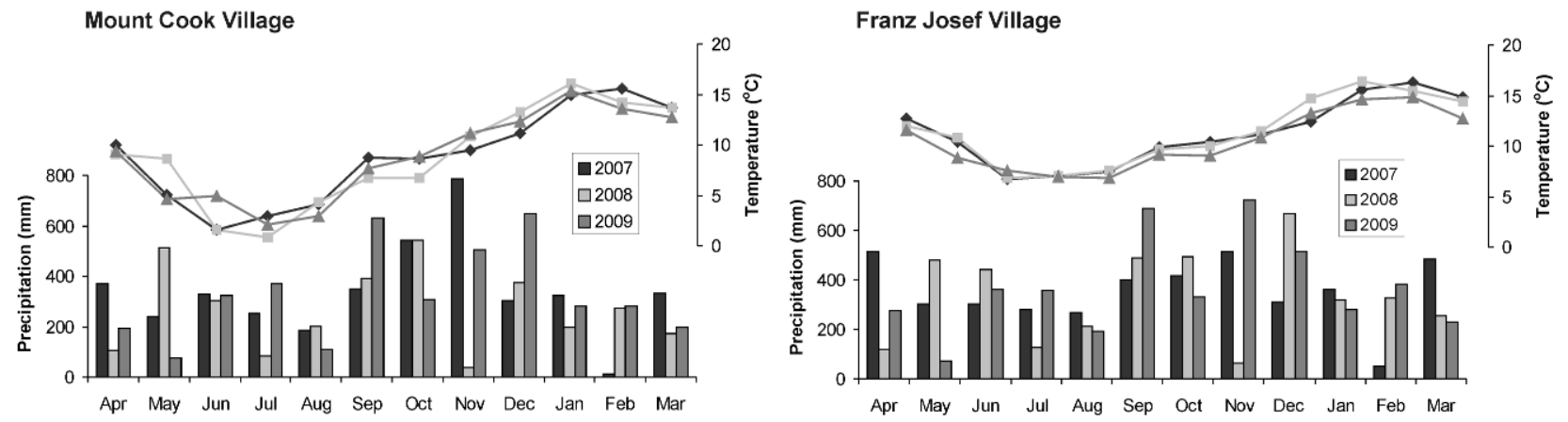

Figure 2.2: Monthly temperature and precipitation data for Mount Cook and Franz Josef villages for the mass balance years ending 2007-2009 (source NIWA climate database, http://cliflo.niwa.co.nz/).

\subsection{Methods}

\subsubsection{Crevasse stratigraphy method}

To determine the degree of spatial variability in net accumulation, crevasse stratigraphy was conducted in the accumulation area ( 2000-2400 m a.s.1.) of both glaciers in March 2007-2009. Each year the same circuit is walked around the accumulation areas by two rope teams surveying as may crevasses as possible. Access, weather, and snow conditions influence the number of crevasses that can be surveyed each year. A lowaccumulation year (e.g. 2008) tends to have more exposed crevasses by the end of summer whereas an early snowfall (e.g. 2009) can cover crevasse walls on some aspects, reducing the number of crevasses available for accurate measurement.

The crevasse stratigraphy method is well suited for high accumulation glaciers, and has been utilised by researchers for over 30 years (Pelto, 1988; Ruddell, 1995; Pelto, 1996; Anderson et al., 2006). Crevasse stratigraphy utilises ablation surfaces formed by summer melt and sedimentation, which are preserved by winter snowfall. These horizons are observed down crevasse walls and can be easily measured (Post and 
LaChapelle, 2000). The method is fast, so large areas can be surveyed, and multiple measurements can often be taken from each crevasse, due to the clarity of the annual layer sequence. At FJG only top annual layers were measured, but at TG, measurements for both 2007 and 2008 include some data from second annual layers. The estimated error in measuring annual layer depth by this method is $\pm 0.05 \mathrm{~m}$.

The high precipitation in the Southern Alps results in large annual accumulation, often in excess of $10 \mathrm{~m}$ snow depth. This factor renders traditional measurement techniques such as stakes and snow-pits unsatisfactory. In addition, the maritime climate means that it is common for a number of ice layers to be present in the snow pack, thereby making probing potentially inaccurate unless combined with another method to verify depth. Certainly, by only sampling crevassed areas some bias will occur (Appendix A3), but similar bias applies to other techniques, for example, digging snow-pits requires a safe, crevasse free spot. Snow-pits are usually dug at a 'representative' location, somewhere relatively flat, providing a single point measurement for many hours work. Crevasses occur over a variety of terrain enabling researchers to choose flat 'representative' areas, or include crevasses in depressions, on slopes, and on convex or concave surfaces, thereby providing a detailed spatial assessment of accumulation.

In order to determine net annual accumulation, depth measurements from crevasse stratigraphy need to be converted into metres water equivalent ( $\mathrm{m}$ w.e.). This requires knowledge of snowpack density, a parameter difficult to determine with the crevasse stratigraphy method (Meier et al., 1997). However, in New Zealand, it has been found that snow density in the accumulation area at the end of the ablation season is reasonably consistent at $\sim 600 \mathrm{~kg} \mathrm{~m}^{-3}$ (Chinn, 1994; Ruddell, 1995). On temperate maritime glaciers melt/refreeze processes dominate snow metamorphism and densification, resulting in a strong elevation-depth-density relationship (Paterson, 1994). Ruddell (1995) analysed density measurements from a variety of temperate glaciers finding that, in these environments, layer density $(\rho)$ could be determined as a function of the age of the layer (depth) and the elevation $(E)$ of the crevasse, where density of the first annual layer is defined by;

$$
\rho_{\text {snow }}=44.75 E^{-0.557}
$$


and the second annual layer by;

$$
\rho_{\text {firn }}=5.234 E^{-0.255}
$$

\subsubsection{Data analysis}

To determine the degree of spatial variability in net accumulation within the accumulation area of each glacier, each year, descriptive statistics and spatial variograms were used. A spatial variogram plots the distance between each measurement pair against the semi-variance $(\gamma)$ of each measurement pair,

$$
\gamma=0.5 \frac{\sum(x-\bar{x})^{2}}{(n-1)}
$$

where $x$ is net accumulation at each measurement point, $\bar{x}$ mean net accumulation of the sample, and $n$ the total number of measurements. This allows testing of the hypothesis that points closer together will be more similar than those further apart, and thereby gauge the degree of spatial variability. To explore within-glacier difference, an analysis of variance (ANOVA) of net accumulation (and control variables) was conducted between the three FJG snowfields.

A number of variables were investigated to see which exert control on the spatial distribution of net accumulation namely; elevation, distance from Alpine Fault, distance from Main Divide, slope, aspect, potential wind exposure and insolation. As already outlined, elevation is thought to be a primary control on snow accumulation and melt, due to its effect on temperature. The influence of orography, in particular, precipitation distribution, is represented by distance from the Alpine Fault, where initial, rapid, increases in topography occur, and distance from the Main Divide, the topographic maxima.

The effect of wind re-distribution/preferential deposition is assessed by the development of a wind exposure index, derived by calculating the average elevation of $90^{\circ}$ wedges (100 m radius) for four main compass directions (NW, SW, SE and SE) similar to the methods of Anderton et al., (2004) and Winstral et al., (2002). This identified whether windward terrain was higher (positive index) or lower (negative index) than each 
measurement point, providing information on the degree of sheltering or exposure each point had to wind from those sectors.

Potential terrain controls, slope and aspect, were derived from a $25 \mathrm{~m}$ digital elevation model in ArcMap GIS, and values were extracted for each measurement point. The amount of insolation received at each measurement point was calculated from the ArcMap solar radiation function. Incoming solar radiation per square metre $\left(\mathrm{MJ} \mathrm{m}^{-2}\right)$ over the ablation season (1 November - 31 March) was calculated for each measurement point each year.

Once all variables had been extracted for each net accumulation measurement, Spearman's Rank correlation was conducted between net accumulation and the variables. Due to its non-linear nature, aspect data was transformed into north-south and east-west scalars as per Copland (1998). The north-south scalar is the cosine of the aspect, resulting in $0^{\circ} \rightarrow 1$ and $180^{\circ} \rightarrow-1$. The east-west scalar is the sine of the aspect, where $90^{\circ} \rightarrow 1$ and $270^{\circ} \rightarrow-1$. Inter-relationships exist between some of the variables. For example, there is a linear relationship between net solar radiation and aspect scalars, as aspect is an important component of net radiation calculations. Due to co-linearity between some parameters, an un-rotated Principle Component Analysis (PCA) was conducted (Copland, 1998), which was followed by multiple-regression of net accumulation data with the new uncorrelated PC factors. Only PCs with an eigen value $>1$ were carried forward for regression analysis, as only these PCs are regarded as statistically significant.

\subsubsection{Ablation estimation}

Annual net accumulation is the combined result of winter accumulation and summer ablation. In order to estimate the magnitude of summer ablation (1 Nov-31 Mar) a positive degree-day model was applied. Utilising parameters from Anderson et al. (2006) and Cutler and Fitzharris (2005), hourly temperature data from Franz Josef and Mount Cook village AWS were used to estimate ablation season melting each year for both glaciers. Summer snowfall was estimated using a standard accumulation model (see Anderson et al., 2006; Purdie et al., 2011b). Combined, these data allow the summer balance to be calculated. 


\subsection{Results}

\subsubsection{Spatial variability in net accumulation}

Of the three years, 2007 recorded highest net accumulation and 2008 lowest (Table 2.1). Mean net accumulation was similar between the glaciers each year, but accumulation maxima were consistently higher at FJG, and consequently FJG recorded larger annual range. Least range in measurement occurred on both glaciers in 2008, which was a year of lower average net accumulation, and high ablation season melting (Table 2.1).

Table 2.1: Summary statistics for measured net accumulation data, and estimated summer balance (all in m w.e.), for Franz Josef and Tasman Glaciers for the mass balance years ending March 2007, 2008 and 2009.

\begin{tabular}{|l|c|c|c|c|c|c|}
\hline Parameter & FJG 2007 & FJG 2008 & FJG 2009 & TG 2007 & TG 2008 & TG 2009 \\
\hline Count & 14 & 66 & 30 & 26 & 44 & 11 \\
Mean & 4.32 & 2.45 & 3.17 & 3.97 & 2.43 & 3.95 \\
Median & 4.22 & 2.48 & 2.94 & 3.88 & 2.39 & 3.96 \\
Std. Dev. & 0.93 & 0.86 & 1.15 & 1.05 & 0.56 & 0.91 \\
Minimum & 3.28 & 0.86 & 1.08 & 1.80 & 1.55 & 2.66 \\
Maximum & 7.26 & 4.63 & 5.44 & 5.73 & 3.77 & 5.59 \\
\hline Est. summer & -1.09 & -1.90 & -0.32 & -1.36 & -2.35 & -1.08 \\
balance & & & & & & \\
\hline
\end{tabular}

The degree of spatial variability in net accumulation changed every year, at each site (Figure 2.3). The bi-modal trend in semi-variance seen at FJG in 2007 is due to a single outlier. Excluding that, data in 2007 and 2008 have no strong spatial trend, indicated by the similar semi-variance over all distances. However, in 2009 FJG does show a trend of increasing variability over increasing distance. Data from TG do not exhibit a strong spatial trend in 2008 or 2009 , but in 2007 , net accumulation appears more variable over smaller spatial scales $(<1.5 \mathrm{~km})$. The lowest average semi-variance recorded for each glacier occurred in 2008 .

Comparison of net accumulation between the three FJG snowfields showed that the variance in net accumulation between snowfields was significantly greater than the variance within each snowfield. The Davis Snowfield recorded the highest net accumulation, while the Geikie Snowfield recorded the lowest (Table 2.2 and Figure 2.4). 

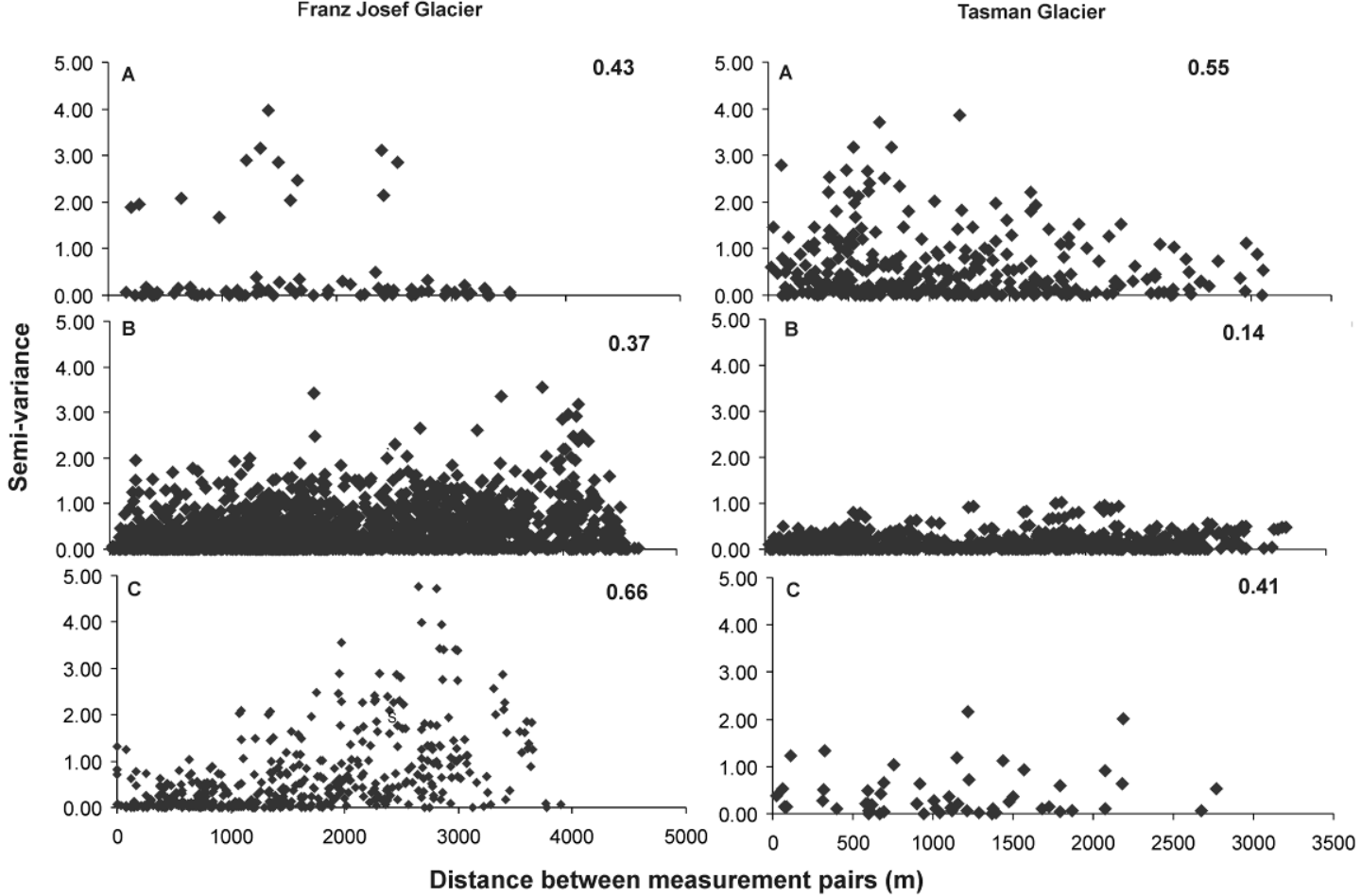

Figure 2.3: Variation in net snow accumulation over increasing distance within the accumulation areas of Franz Josef and Tasman Glaciers for A. 2007, B. 2008 and C. 2009. The average semi-variance for all data pairs is shown in the top right corner of each graph. Note the larger $x$-axis for FJG.

Table 2.2: Analysis of variance (single factor ANOVA) in net accumulation between the three snowfields that comprise the Franz Josef Glacier accumulation area. Results for the three most significant control variables are also shown (also see Figure 2.4).

\begin{tabular}{|l|c|c|c|c|}
\hline & $\begin{array}{c}\text { Net } \\
\text { Accumulation } \\
(\mathrm{m} \text { w.e. })\end{array}$ & $\begin{array}{c}\text { Elevation } \\
(\mathrm{m})\end{array}$ & $\begin{array}{c}\text { Solar Radiation } \\
\left(\mathrm{MJ} \mathrm{m}^{-2}\right)\end{array}$ & $\begin{array}{c}\text { Distance from } \\
\text { Main Divide } \\
(\mathrm{km})\end{array}$ \\
\hline Davis variance & 0.68 & 146 & 1148 & 0.22 \\
Chamberlain variance & 0.48 & 462 & 1959 & 0.07 \\
Geikie variance & 0.20 & 1265 & 4453 & 0.08 \\
Variance between snowfields & 25.1 & 970607 & 524763 & 27.7 \\
Variance within snowfields & 0.45 & 50852 & 206176 & 10.5 \\
$p$-value & $\mathbf{. 0 0 0}$ & $\mathbf{. 0 0 0}$ & $\mathbf{. 0 0 0}$ & $\mathbf{. 0 0 0}$ \\
F & 55.3 & 782 & 104 & 108 \\
\hline
\end{tabular}



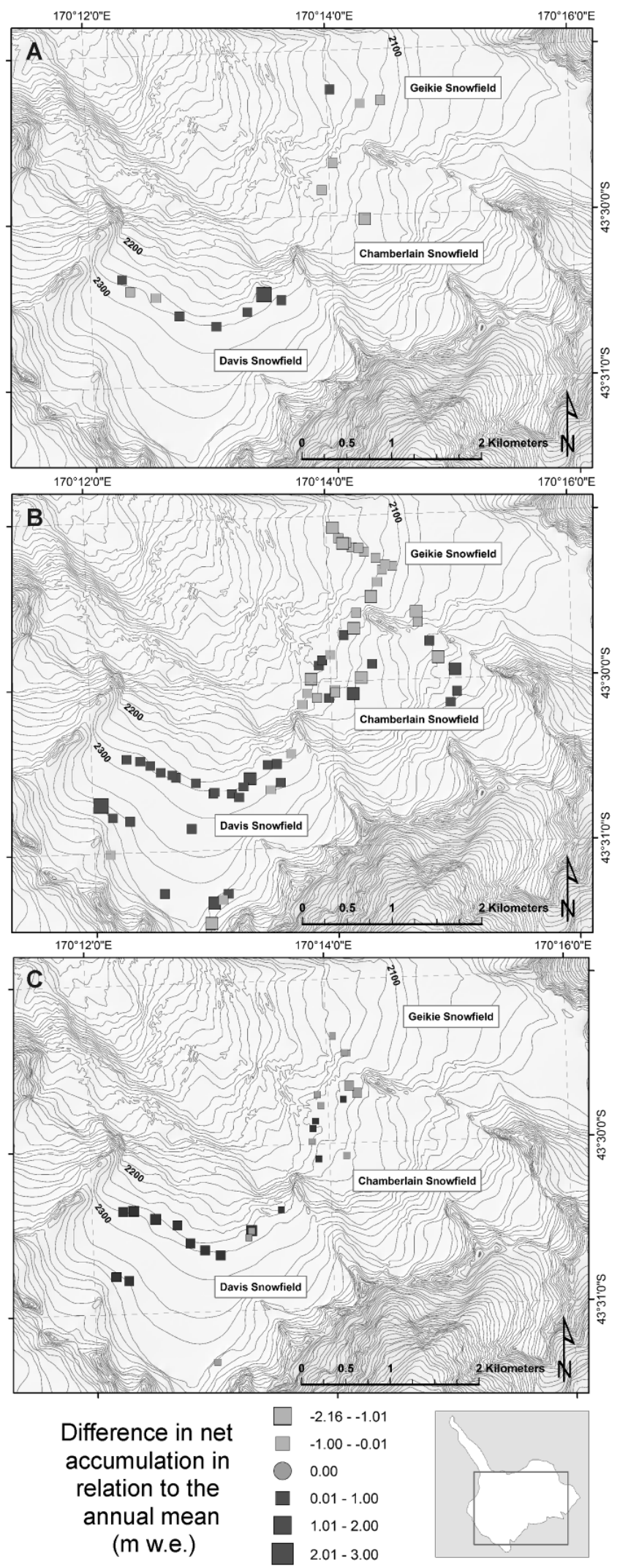

Figure 2.4: Variation in net accumulation in relation to the annual mean for A. 2007, B. 2008 and C. 2009, of the three main snowfields that comprise the accumulation area of the Franz Josef Glacier. The area of the glacier covered by the maps is shown bottom right. 


\subsubsection{Potential controls on net accumulation distribution}

Non-parametric correlation of the potential control variables with net accumulation data tested to see which variables (if any) could account for observed spatial variability (Table 2.3). Relationships with elevation were weak at TG, but statistically significant at FJG in 2008 and 2009. Due to the importance placed on the elevation-accumulation relationship in snow accumulation modelling, closer inspection of the elevationaccumulation relationship is made (Figure 2.5). On both glaciers, the accumulation area covers a small elevation range, compared to the elevation range over the entire glacier. However, it is in the accumulation area where the relationship between elevation and accumulation is found to weaken, demonstrated by the significantly lower regression coefficients. There are no mass balance data for 2008 on FJG between 500-1800 m a.s.1. as this section of the glacier is characterised by ice falls and crevassing. Previous measurements at $\sim 900$ m a.s.1. (Anderson et al., 2006) indicate a strong relationship between elevation and mass balance on the lower glacier trunk.

Table 2.3: Results of Spearman's Rank correlation between net snow accumulation and variables that potentially influence net accumulation distribution. Results that are statistically significant at 0.01 are in bold, and those significant at 0.05 are italicised.

\begin{tabular}{|c|c|c|c|c|c|c|}
\hline Variables & $\begin{array}{c}\text { FJG 2007 } \\
(n=14)\end{array}$ & $\begin{array}{c}\text { FJG } 2008 \\
(n=66)\end{array}$ & $\begin{array}{c}\text { FJG 2009 } \\
(n=30)\end{array}$ & $\begin{array}{c}\text { TG } 2007 \\
(n=26)\end{array}$ & $\begin{array}{c}\text { TG } 2008 \\
(n=44)\end{array}$ & $\begin{array}{c}\text { TG } 2009 \\
(n=11)\end{array}$ \\
\hline Elevation $^{1}$ & .376 & .520 & .642 & .088 & -.210 & -.473 \\
\hline Alpine Fault ${ }^{2}$ & .262 & .296 & -.078 & .061 & -.387 & -.609 \\
\hline Main Divide $^{2}$ & -.447 & -.378 & -.166 & -.259 & -.152 & .018 \\
\hline $\mathrm{N}-\mathrm{S}$ aspect ${ }^{3}$ & .576 & .367 & .399 & -.293 & -.396 & -.309 \\
\hline E-W aspect ${ }^{3}$ & .428 & .474 & .778 & .128 & .223 & .575 \\
\hline Slope $e^{4}$ & .359 & -.191 & -.138 & .015 & .235 & .709 \\
\hline Insolation $^{5}$ & .636 & .501 & .481 & -.034 & -.200 & -.364 \\
\hline Wind Exposure $^{6}: \mathrm{NW}$ & -.649 & -.507 & -.669 & .307 & .265 & .445 \\
\hline SW & -.317 & .191 & .442 & .142 & .411 & -.009 \\
\hline SE & .515 & .462 & .724 & .104 & -.233 & .018 \\
\hline $\mathrm{NE}$ & .318 & -.324 & -.616 & -.019 & -.071 & .282 \\
\hline
\end{tabular}

Temperature depends largely on elevation and influences surface melting through sensible heat fluxes.

Decreasing temperature with increasing elevation also influences the position of the snow/rain temperature threshold.

${ }^{2}$ The rate at which an air mass cools and condenses as it rises up and over an orographic barrier influences precipitation onset and intensity. In this case net accumulation is related to the distance from the Alpine Fault or alternatively the Main Divide.

${ }^{3}$ Aspect affects melting by influencing the duration and intensity of sun exposure. Aspect also influences the orientation of the snow surface to varying wind directions.

${ }^{4}$ Slope angle influences gravitational processes (i.e. avalanche). Slope angle also influences wind redistribution processes through its effect on wind dynamics. 
${ }^{5}$ Insolation is a direct source of energy for melting.

${ }^{6}$ The exposure or sheltering of the snow surface to different wind directions influences the susceptibility of the snow surface to wind redistribution.

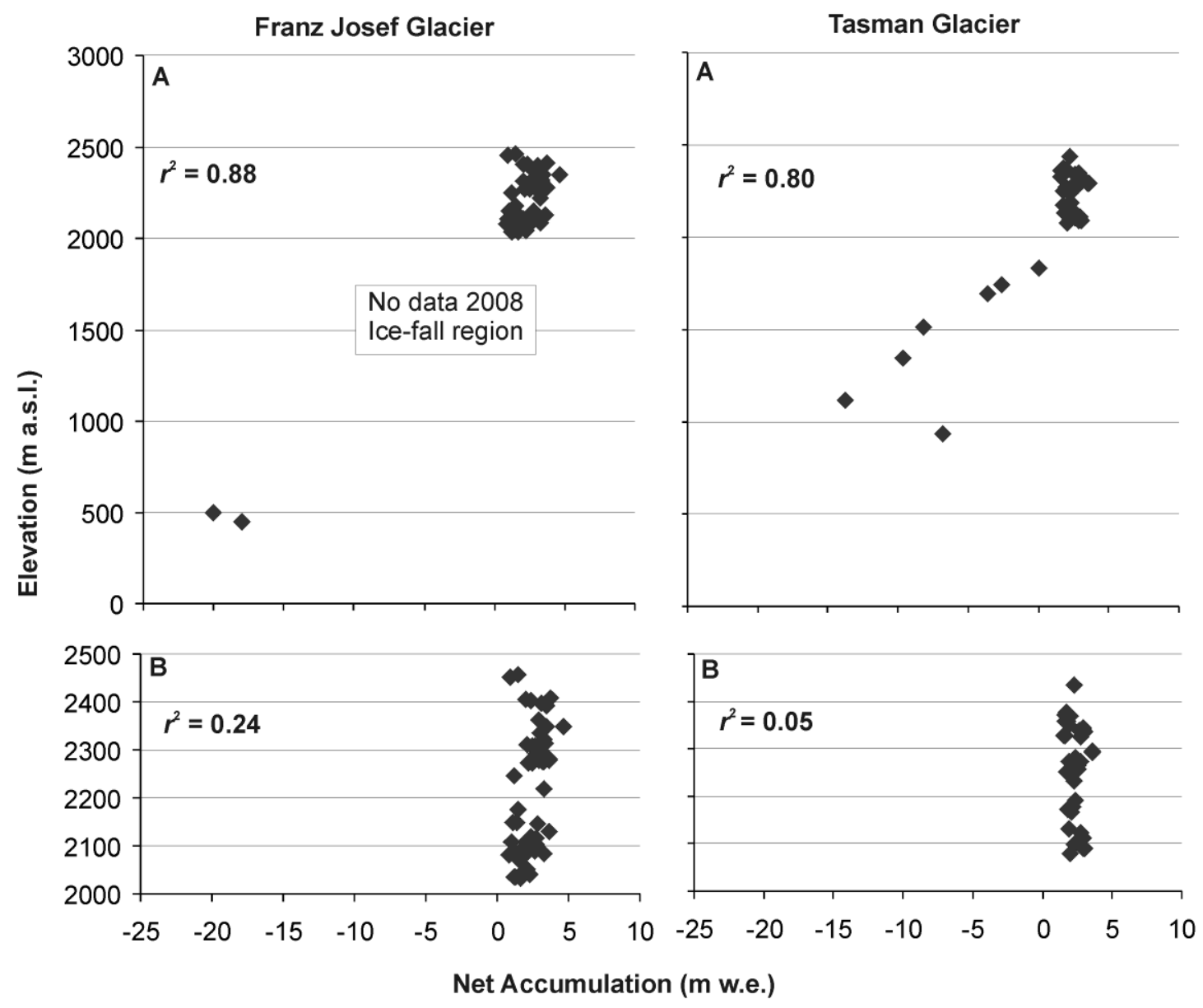

Figure 2.5: Relationship between elevation and mass balance for the 2008 mass balance year.

A. Mass balance data from both the accumulation and ablation area (measured by stakes this study). B. Accumulation area only. An outlier at TG below $1000 \mathrm{~m}$ a.s.1. is due to insulating effects of surface moraine. The $r^{2}$ of the regression between elevation and net accumulation is shown.

Aside from elevation, other variables that demonstrated statistical significance with net accumulation include the wind exposure indices, aspect, distance from the Alpine Fault, distance from the Main Divide and insolation. On FJG correlation coefficients show that higher net accumulation is associated with measurement points that were exposed to NW (and NE) winds, yet sheltered from SE winds. Results for aspect showed that higher (lower) accumulation was associated with points on northerly and easterly (southerly and westerly) aspects. Interestingly, measurement points with higher ablation 
by the small data-set. Multiple-regression of PC factors did not produce statistically significant results for TG in any year.

As well as a statistically significant difference in net accumulation between the three FJG snowfields, there was also a significant difference in some of the control variables between the snowfields, with the exception of SW and NE wind exposure indices and slope. In particular largest differences were found in elevation, distance from Main Divide and ablation season insolation (Table 2.3). The Geikie Snowfield (which had lowest net accumulation) has the lowest elevation, is the greatest distance from the Main Divide, has lowest insolation, and is most exposed to SE winds (sheltered from NW). Conversely Davis Snowfield (which recorded the highest net accumulation) has the highest elevation, is closest to the Main Divide, has highest insolation and is most exposed to the NW winds (sheltered from SE).

The fact that the Davis Snowfield recorded highest net accumulation and highest insolation is surprising and warrants further investigation. Using a positive degree-day approach, we would expect summer ablation at the Geikie Snowfield to be $\sim 0.6 \mathrm{~m}$ w.e. more than at Davis Snowfield, based on an elevation difference of $250 \mathrm{~m}$ a.s.1. Ablation from net radiation is implicitly included in a degree-day model, but we can estimate the proportion of melting attributable to net radiation using the energy balance for a melting snow surface (Neale and Fitzharris, 1997). The net radiation difference between measurement points in the Davis and Geikie Snowfields was $178 \mathrm{MJ} \mathrm{m}^{-2}$ (assuming albedo at 0.65 ), which can only account for a $\sim 0.2 \mathrm{~m}$ w.e difference in ablation. Therefore the elevation-temperature difference outweighs the net radiation effect, resulting in the Davis Snowfield experiencing lower ablation (and higher net accumulation) compared to the Geikie Snowfield.

\subsection{Discussion}

\subsubsection{Spatial variability in net accumulation}

Large spatial variability in net annual accumulation was recorded on FJG and TG, with least variability occurring in 2008, a low net accumulation year characterised by La Niña conditions, and a hot dry summer (Salinger et al., 2008). Mass balance modelling has demonstrated that even a small change in temperature (e.g. $0.5^{\circ} \mathrm{C}$ ) can have a 
significant effect on glacier mass balance (Oerlemans, 1997; Anderson et al., 2006). Therefore on inter-annual time-scales, it is possible that years with higher summer ablation rates (i.e. 2008) result in reduced spatial variability in net accumulation. This also indicates that the processes controlling the spatial distribution of winter accumulation and summer melt can be spatially disparate.

\subsubsection{Control on spatial variability in net accumulation}

Elevation is often considered a primary control on accumulation/mass balance, and therefore utilised for snow accumulation modelling (Fitzharris and Garr, 1995; Oerlemans, 2001). However, the glacier wide accumulation-elevation relationship was found to weaken in the accumulation area of both glaciers, a characteristic found on a number of other glaciers around the world (Popovnin et al., 1999; Braithwaite and Zhang, 2000; Machguth et al., 2006; Bidlake et al., 2007). This study found that the smaller accumulation area (TG) had a weaker relationship with elevation than the larger accumulation area (FJG). Likewise, other studies have found that smaller glaciers have less relationship with elevation than larger glaciers (Machguth et al., 2006). Smaller accumulation areas (glaciers) tend to have proportionally more heterogeneous topography (Fountain and Vecchia, 1999), and are therefore likely to be more strongly influenced by other processes.

Due to inter-relationships between elevation, temperature, and orography, this study included variables aimed to help clarify the importance of orographic precipitation distribution, an issue not clearly addressed in other studies (Elder et al., 1998; Anderton et al., 2004; Grabiec et al., 2006). By comparing glaciers both windward and lee of the Southern Alps the importance of orographic precipitation distribution to spatial variability in net accumulation could be assessed. Strongest orographic control was found at TG (2008 and 2009) with higher net accumulation at measurement points closer to the Alpine Fault, indicating a degree of spill-over to the lee of the mountain range (Zangl, 2005; 2008). In 2008 net accumulation at FJG did show relationship with orography, but this was noticeably weaker than the correlation with elevation. In 2009 PC3 had maximum loadings on the orographic variables, but only accounted for $16 \%$ of the variance in net accumulation, whereas PC1 with maximum loadings on elevation and aspect, accounted for $43 \%$ of the variance. Therefore orography appears to exert 
stronger influence on spatial variability in net accumulation on the eastern (lee) side of the Southern Alps.

Precipitation distribution estimates for the Main Divide of the Southern Alps vary, although most agree that that the precipitation maximum occurs $\sim 10 \mathrm{~km} \mathrm{NW}$ of the crest of the range (Griffiths and McSaveney, 1983; Henderson and Thompson, 1999; Anderson et al., 2006). However, the distribution of precipitation immediately east and west of the range is less certain. Net accumulation data from this study shows that precipitation does increase nearer the Main Divide, but whether this is due to a secondary smaller peak over the crest of the range (Griffiths and McSaveney, 1983) or possibly two subsidiary peaks east and west of the range (Sinclair et al., 1997; Zangl, 2005; Kerr, 2009) is still unclear. Resolving this issue is difficult as measuring accumulation at elevations above $\sim 2500 \mathrm{~m}$ a.s.1. is complicated by steep terrain prone to avalanche and wind transport.

Net solar radiation has been identified as an important factor for snow melt (Kelliher et al., 1996; Neale and Fitzharris, 1997), although in maritime climates turbulent heat fluxes are generally equally important (Willis et al., 2002). This study found that at FJG the snowfield with highest insolation (Davis) also recorded highest net accumulation. A similar paradox was found at Colle Gnifetti on Monte Rosa in the Swiss Alps, where south facing slopes recorded highest net accumulation and highest solar radiation (Alean et al., 1983). Alean et al. (1983) concluded that higher radiative energy formed more numerous melt layers, which in turn protected the snow surface from wind erosion. Indeed melt layers do protect the snow surface from wind redistribution, but they are no more prevalent at Davis Snowfield than in other parts of the FJG accumulation area. Ablation differences due to elevation/temperature relationships were found to out-weigh ablation differences due to variations in insolation. Therefore higher net accumulation found in Davis Snowfield is attributed in part to lower overall summer ablation.

A number of studies have previously demonstrated the importance of preferential deposition and wind-redistribution of snow to spatial variability in snow accumulation (Liston and Sturm, 1998; Lehning et al., 2008; Mott et al., 2008; Dadic et al., 2010). Therefore we expected some relationship between the distribution of net accumulation 
and the wind exposure indices. At TG, measurement points lee to the SW recorded highest net accumulation, while west of the range, at FJG, points lee to the SE had highest net accumulation. Substantial wind redistribution has been recorded at FJG especially during strong SE winds (Purdie et al., 2011b). Snow loading on lee slopes during such events may also contribute to higher net accumulation in the Davis Snowfield. The importance of wind and topographic interaction to the spatial distribution of snow has also been recorded on glaciers in Norway (Jansson and Pettersson, 2007) and Spitsbergen (Grabiec et al., 2006), as well as in non-glaciated environments (Lapen and Martz, 1996; Anderton et al., 2004).

\subsubsection{Inter-annual variability in controls on spatial variability}

This study found that the variables exerting most control over the spatial distribution in net accumulation altered in prominence from year to year. Inter-annual variability in the strength of the accumulation-elevation relationship was recorded in Svalbard, where a year of higher snow accumulation had a stronger relationship, leading Hodgkins et al. (2005) to suggest that snow redistribution processes may exert less influence in high accumulation years. The strongest elevation-accumulation relationship found during this study was at FJG in 2009, but higher net accumulation occurred in 2007. Synoptic control on the timing and magnitude of snow accumulation events will result in altering prominence of many of the variables investigated, for example wind redistribution processes, orographic processes and insolation. Such inter-annual variability in net accumulation distribution means that accurate estimation of glacier mass balance and the associated water resource is complex.

\subsection{Conclusions}

Processes controlling spatial variability in net accumulation on glaciers in the Southern Alps vary within and between glaciers as well as between successive years. Interaction between wind and topography, and orographic controls on precipitation, explain some of the variability in net accumulation on Tasman Glacier. On Franz Josef Glacier, wind and topographic interaction had influence, but elevation (temperature) relationships were also important. Smallest spatial variability in accumulation coincided with the year of lowest average net accumulation, possibly due to the modulating effect of summer melt. Altering prominence of variables controlling net accumulation distribution 
between glaciers in any one year highlights the difficulty in applying a generic snow accumulation model. Further research into intra-annual variability in the prominence of control processes, combined with synoptic climatology, would assist in clarifying what weight should be given to different control variables at different times of the mass balance year. 


\section{Synoptic influences on snow accumulation on glaciers east and west of a topographic divide: Southern Alps, New Zealand.}

Understanding relationships between snow accumulation and synoptic climatology is important for assessing the way in which future climate variability will impact on glacier mass balance. However, few studies have as yet examined these relationships. Variability in snow accumulation on mid-latitude glaciers is strongly influenced by atmospheric circulation, orography and redistribution of snow by wind. Very little is known about these processes in the New Zealand Southern Alps, where it is assumed that west-facing glaciers receive higher snow totals. However, few measurements are available to test this hypothesis. These processes were investigated over a 21-day period in winter 2008 on glaciers located west (Franz Josef Glacier) and east (Tasman Glacier) of the Main Divide of the Southern Alps. We directly measured snow accumulation and considered how it was affected by synoptic weather regime and location with respect to the Main Divide. Both glaciers received $\sim 75 \%$ of their snowfall during troughing regimes, which are characterised by strong westerly-quadrant winds bringing humid air masses from the Tasman Sea over the Southern Alps. The Franz Josef glacier site received $\sim 30 \%$ more snow than the Tasman Glacier site, but wind deflation meant that by the end of the study period, net snow accumulation was similar at both sites. Blocking synoptic regimes resulted in a reversal of prevailing westerly flow, generating strong down-slope winds at Franz Josef Glacier and snow loss.

\subsection{Introduction}

Understanding how synoptic weather systems influence snow accumulation is of increasing interest to the glaciological community (Romolo et al., 2006; Jansson et al., 2007), especially since climate warming will likely result in changes to atmospheric circulation patterns (Mullan et al., 2001; IPCC, 2007). Because atmospheric circulation exerts a primary control on processes influencing accumulation on glaciers - snowfall, wind redistribution of snow, avalanching and ablation - synoptic control is likely to be strong. It is already clear that synoptic variability affects snow accumulation on annual and decadal timescales in continental climates (Grundstein, 2003; Romolo et al., 2006), 
and that glacial ablation is strongly affected by synoptic conditions (Hay and Fitzharris, 1988; Neale and Fitzharris, 1997; Cutler and Fitzharris, 2005). However, little is known about the impact of synoptic conditions on glacial accumulation.

Relationships have been found between large scale atmospheric circulation and glacier mass balance. For example, advance and retreat of Scandinavian glaciers have been linked to phase changes of the North Atlantic Oscillation (McCabe et al., 2000; Nesje et al., 2000; Nordli et al., 2005). In western North America the El Niño Southern Oscillation (ENSO) and the Pacific Decadal Oscillation (PDO) have been correlated to both glacier fluctuations (Walters and Meier, 1989; Hodge et al., 1998), and to North American snowpack variability (McCabe et al., 2000; Jin et al., 2006). Similarly in New Zealand, ENSO has been related to the advance and retreat of glaciers in the Southern Alps (Fitzharris et al., 1997; Chinn et al., 2005b). Embedded within these glacier-atmospheric circulation relationships are changes to frequencies in synoptic weather systems. Improved understanding of how synoptic weather systems manifest in snow accumulation on glaciers will assist in prediction of glacier behaviour with climate change.

The distribution of snowfall in New Zealand is affected by the presence of the Southern Alps. Henderson and Thompson (1999) found that orographic processes result in higher precipitation on the western side of the Main Divide, with maximums $\left(\sim 10 \mathrm{~m} \mathrm{a}^{-1}\right)$ recorded at elevations of 600 - 1700 m a.s.l. Recent work by Kerr (2009) suggests that there may also be a secondary or subsidiary precipitation maximum on the eastern side. However, both these studies suffer from a lack of direct measurement at elevations greater than $2000 \mathrm{~m}$ a.s.1.

Accurate measurement of snow accumulation in high alpine catchments is problematic (Barry, 1992). Automatic weather stations, precipitation gauges and stakes are prone to burial by large snowfall in mountain regions. As a result a number of studies utilise accumulation/mass balance proxies rather than direct measurement (Fitzharris et al., 1997; Grundstein, 2003; Romolo et al., 2006). Success in snow measurement has been gained by utilising ground penetrating radar (e.g. Machguth et al., 2006; Dunse et al., 2009), but this technique has yet to gain full success in New Zealand (Nobes and Owens, 1995). Therefore, limited data means that we are currently unable to assess how 
snow accumulation patterns vary across the Southern Alps, and therefore cannot assess how such patterns may change in the future.

Models are increasingly useful for understanding how glacier mass balance varies in response to climate (De Woul and Hock, 2005; Hock et al., 2009). Energy balance or degree day models are relatively good at simulating ablation (Hock, 2005), but they rarely consider snow accumulation processes in much detail. Orographic processes are usually included by calculating accumulation as a function of elevation (Oerlemans, 2001; Anderson et al., 2006). Large-scale orographic gradients, potential effects of preferential deposition, wind re-distribution or avalanching are not often included, although it is acknowledged that this approach is simplistic (Hodgkins et al., 2005; Machguth et al., 2006). Models that do account for snow transport by wind (Lehning et al., 2008; Mott et al., 2008) and gravitational processes (Dadic, 2008) exist, but are computationally expensive and are not used widely in accumulation studies.

In this paper, we use an empirical approach to investigate the impact of synoptic-scale climate systems on snow accumulation at two glacier sites during winter in the New Zealand Southern Alps. The specific objectives of this study are to:

1. Quantify temporal patterns of total and net snow accumulation, at daily and synoptic timescales, by simultaneous direct measurement.

2. Compare temporal patterns of measured snowfall across the precipitation gradient, that is, west and east of the Main Divide.

3. Interpret results in relation to the passage of different synoptic weather systems.

4. Evaluate whether a simple, standard accumulation model can capture synoptic scale variability in snow accumulation.

\subsection{Study site}

The New Zealand Southern Alps form a $700 \mathrm{~km}$ long, $\sim 2500 \mathrm{~m}$ high barrier to dominantly westerly atmospheric circulation, intercepting air masses of both temperate and sub-tropical origin. Rapid passage of weather systems over the New Zealand landmass means that a variety of synoptic situations can occur over a short time period (Sturman and Tapper, 2006). Franz Josef Glacier is located on the western flank of the Southern Alps ( $43^{\circ} 30^{\prime} \mathrm{S}, 170^{\circ} 14^{\prime} \mathrm{E}$ ), covering an area of $\sim 35 \mathrm{~km}^{2}$ while the Tasman 
Glacier at $\sim 95 \mathrm{~km}^{2}$, is situated immediately on the eastern side of the range $\left(43^{\circ} 30^{\prime} \mathrm{S}\right.$, $\left.170^{\circ} 20^{\prime} \mathrm{E}\right)$ (Figure 3.1).

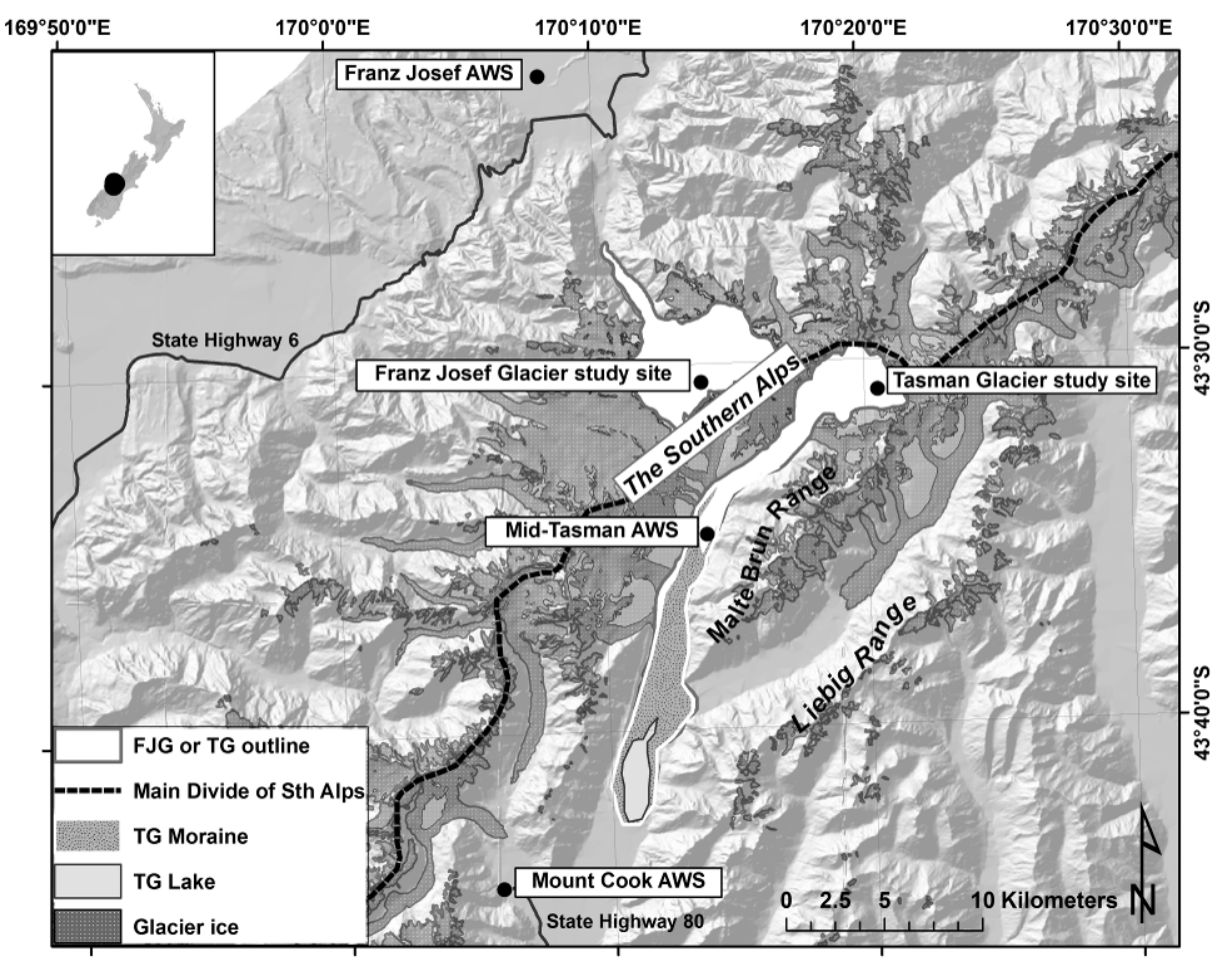

Figure 3.1: Location map of the Tasman (TG) and Franz Josef (FJG) Glacier study sites in relation to the Main Divide of the Southern Alps, and location of other automatic weather stations (AWS) utilised in the study.

The accumulation area of the Franz Josef Glacier is approximately $7 \mathrm{~km}$ in width, $3 \mathrm{~km}$ in length, has a low surface slope angle, and covers an area of $\sim 25 \mathrm{~km}^{2}$, approximately $70 \%$ of the total glacier area. It has a north-west aspect, and is $25 \mathrm{~km}$ from the coastline. It is therefore directly exposed to prevailing westerly air flow from the Tasman Sea. The Southern Alps flank the south-east border of the glacier, and ice descends steeply from the accumulation area into a narrow valley, terminating at $\sim 300 \mathrm{~m}$ a.s.1. The Tasman Glacier accumulation area is smaller at approximately $3.5 \mathrm{~km}$ wide, $5 \mathrm{~km}$ in length and covering an area of $\sim 16 \mathrm{~km}^{2}$ (excluding tributaries flowing into the glacier below the equilibrium line). The accumulation area comprises only approximately $20 \%$ of the total glacier area. The Main Divide of the Southern Alps borders the west and north of the Tasman Glacier accumulation area, with the Malte Brun Range flanking the east and south. This glacier has a broad, gently sloping tongue, which descends southwards, terminating at $700 \mathrm{~m}$ a.s.l. into a rapidly growing lake. The lower $10 \mathrm{~km}$ of the glacier 
tongue is debris covered, thereby reducing melt rates on this lower part of the glacier (Purdie and Fitzharris, 1999).

\subsection{Data \& Methodology}

\subsubsection{Snow accumulation measurement}

Study sites were established and field measurements undertaken during the austral winter of 2008. The Franz Josef Glacier study site (FJG) was established on 14 July, and measurements conducted over 24 days until 7 August. The Tasman Glacier study site (TG) was established on 17 July, and measurements conducted over 21 days, which were concurrent with the FJG site (Figure 3.1). Both study sites were set up at approximately $2300 \mathrm{~m}$ a.s.1., on relatively flat snow surfaces in the centre of the accumulation areas. Sites were chosen to be at least $100 \mathrm{~m}$ away from topography (ridges/depressions), which could potentially influence snow deposition patterns.

The FJG site was located in the Davis snowfield (Figure 3.2). There are no spatially comprehensive winter snow accumulation measurements for FJG. Previous net accumulation measurement shows that an area in close proximity to the winter site has recorded near average net accumulation (Purdie et al., 2011a). The TG site was located close to a previous long term mass balance measurement point (Chinn, 1994). Like at FJG, there have been no previous measurements of winter snow accumulation at high spatial resolution. However, a net accumulation survey in 2008 (Purdie et al., 2011a) recorded a point nearby with lower than average net accumulation (Figure 3.2).

At each study site four snowboards $(0.4 \mathrm{~m} \times 0.4 \mathrm{~m})$ with central poles $(2 \mathrm{~m})$ were installed at $1 \mathrm{~m}$ intervals in a linear array aligned perpendicular to prevailing westerly flow (Figure 3.3). Snowboards are a standard method for snow accumulation measurement (New Zealand Mountain Safety Council, 2008), and have been used to determine percentage under-catch for other precipitation gauges (Barry, 1992). However, a degree of under-catch is still likely, particularly during light snowfall accompanied by strong winds. 

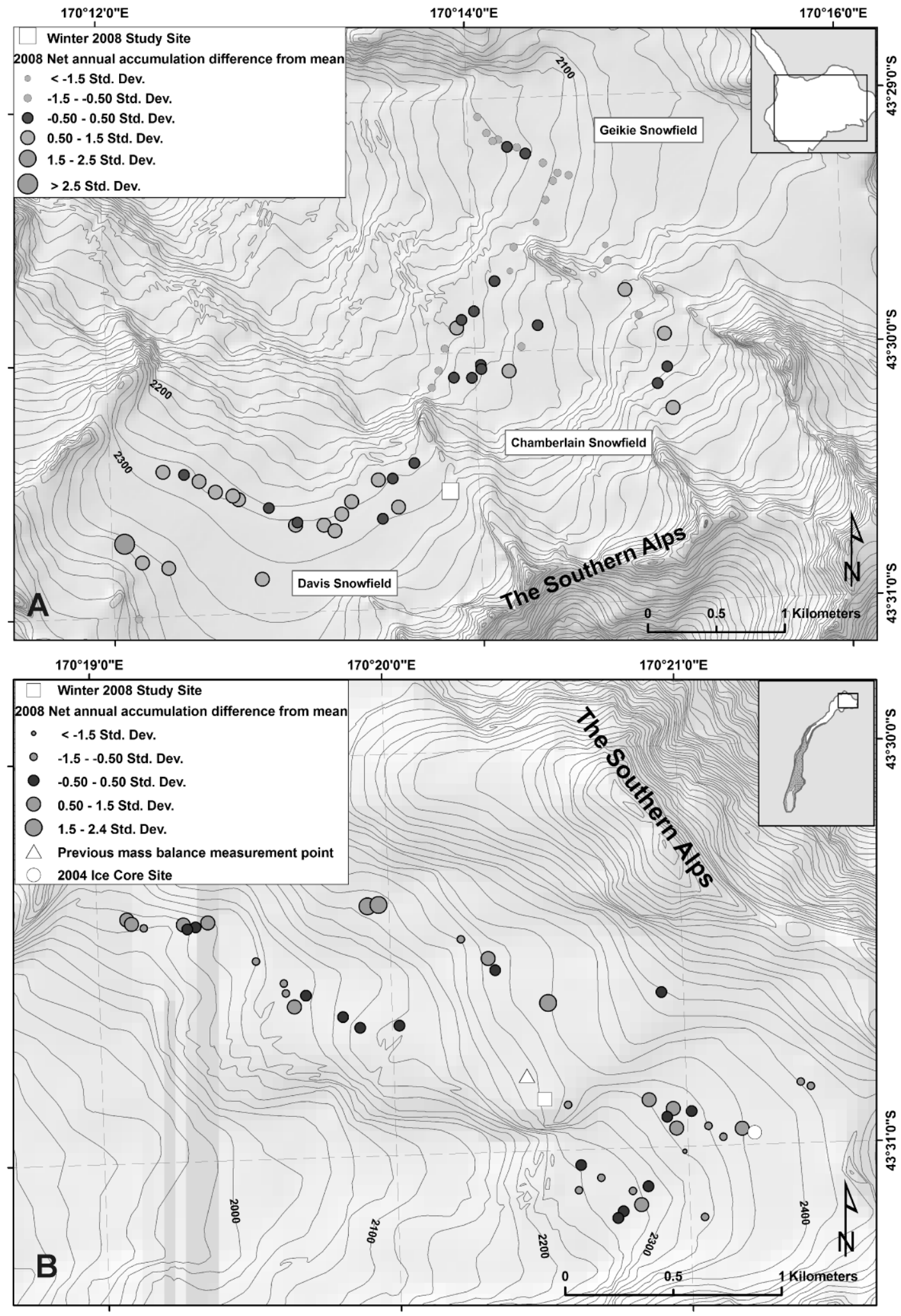

Figure 3.2: The Franz Josef (A) and Tasman (B) Glacier accumulation areas, showing the location of the winter study sites in relation to previous net accumulation measurement. 


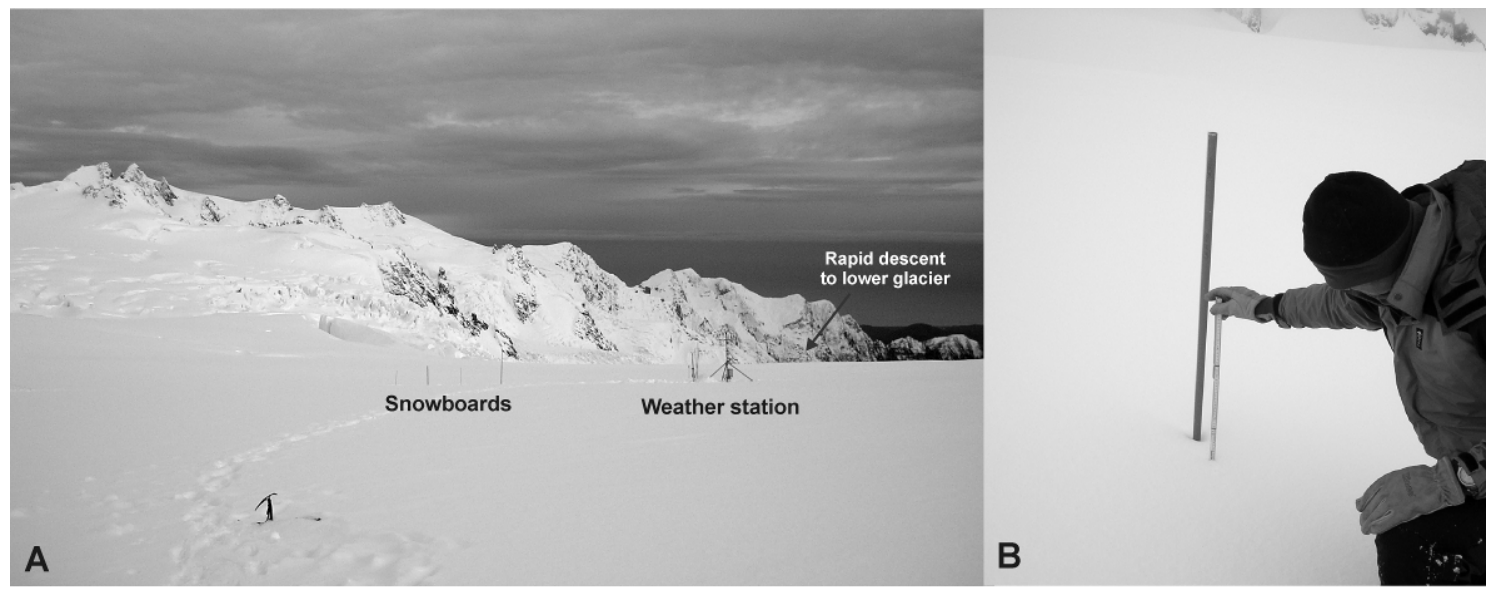

Figure 3.3: A: Site layout at Franz Josef Glacier showing the four snowboards and automatic weather station. Photo taken looking to the southwest. B: Snow depth measurement. The solid wooden ruler is easily inserted through the snow down to the wooden board. The central poles ensure relocation of boards after each snowfall. Photos by Purdie.

Each of the four snowboards in the array was used to measure accumulation at different timescales. For the purposes of this paper, results are presented from two of these boards: the 'total-board', at which net snow accumulation was measured on a daily basis, and which allowed measurement of snow loss as well as gain; and the ' 24 hour board' at which daily snowfall was measured at $0900 \mathrm{hrs}$. Each time the 24 hour board was measured it was subsequently cleared of snow and repositioned on the snow surface. For each measurement, four separate depth measurements were made in each quarter of the boards and averaged (Figure 3.3). Snow surface density was measured daily at the 24 hour board. Density was measured by weighing a $250 \mathrm{ml}$ sample (taken with a Snowmetrics RIP 2 cutter) of fresh surface snow on a digital scale. Comparison of measurement between adjacent boards found snow depths to be within $\pm 10 \mathrm{~mm}$.

Relative measurement errors are estimated as depth $( \pm 5 \%)$, mass $( \pm 0.5 \%)$ and volume $( \pm 2.5 \%)$, equating to a total relative measurement error of $\pm 8 \%$.

\subsubsection{Snow accumulation modelling}

Standard accumulation models, that predict snow accumulation using an elevation/temperature based approach, have been found to provide effective estimates of snow accumulation on glaciers on seasonal and annual timescales (Oerlemans, 2001; Braithwaite et al., 2002; Anderson et al., 2006). Here we evaluate the usefulness of such models at a synoptic scale, by applying the model from Anderson et al. (2006). In this 
model, snow accumulation occurs on the glacier when precipitation occurs at a nearby low elevation weather station and air temperature on the glacier is estimated to be below a snow/rain temperature threshold. A threshold of $1^{\circ} \mathrm{C}$ was determined by best-fit modelling in New Zealand accumulation models (Moore and Owens, 1984; Barringer, 1989). Air temperature at the glacier site is calculated by applying a locally-measured temperature lapse rate $\left(-5^{\circ} \mathrm{C} \mathrm{km}^{-1}\right)$ to temperature measured at the low elevation weather station (Anderson et al., 2006). A precipitation factor is applied to the low elevation precipitation total, to account for orographic processes. For FJG, a precipitation factor (1.41) was empirically derived (Anderson et al., 2006) and for TG a precipitation factor of (1.46) was derived on the basis of interpolation of precipitation gradient maps (Henderson and Thompson, 1999).

Modelling was conducted using two configurations. The first model run (M1) utilises the model parameters outlined above, and is forced with hourly temperature and precipitation data from an automatic weather station (AWS) at Franz Josef (80 m a.s.1.) or Mount Cook (765 m a.s.1.) village for the FJG or TG site respectively. These AWS are owned and operated by the National Institute of Water and Atmospheric Science (NIWA). The second model run (M2) uses modified model parameters, including temperature lapse rates, based on AWS data measured at the low elevation weather stations run by NIWA and AWS installed at glacier study sites (see following section for AWS details). For M2, precipitation input data for each site are modified to better reflect regional variations in precipitation. This is done by combining precipitation from weather stations, using distance weighting. A new measured precipitation factor is also applied to the distance-weighted precipitation. This derives a daily precipitation total for each site that is a reflection of precipitation recorded on both sides of the Southern Alps. For both model runs, hourly modelled precipitation is summed daily to enable comparison with daily (0900 hrs) measured snow accumulation.

\subsubsection{Synoptic classification and local climate}

To assess the influence of synoptic type on snow accumulation, each day during the study was categorised as one of three synoptic regimes (troughing, zonal or blocking; Figure 3.4). Daily synoptic weather types were supplied by NIWA and classified according to the scheme of Kidson (2000). Kidson utilised 40-year NCEP/NCAR data to identify 12 different weather types for New Zealand, which were further categorised 
into zonal, troughing or blocking regimes. Troughing regimes are characterised by frequent troughs and frontal systems crossing New Zealand, zonal regimes typically have high pressure systems north of New Zealand with zonal flow to the south, and blocking regimes are characterised by high pressure systems being more prominent in the south, stalling or slowing the passage of approaching weather systems (Kidson, 2000). Since their development, Kidson indices have been applied to studies of air pollution (Appelhans, 2009; Baldi et al., 2009), climate change (Lorrey et al., 2007; Mullan, 2009), drought patterns (Salinger, 2009) and marine biodiversity (Dunn et al., 2009).

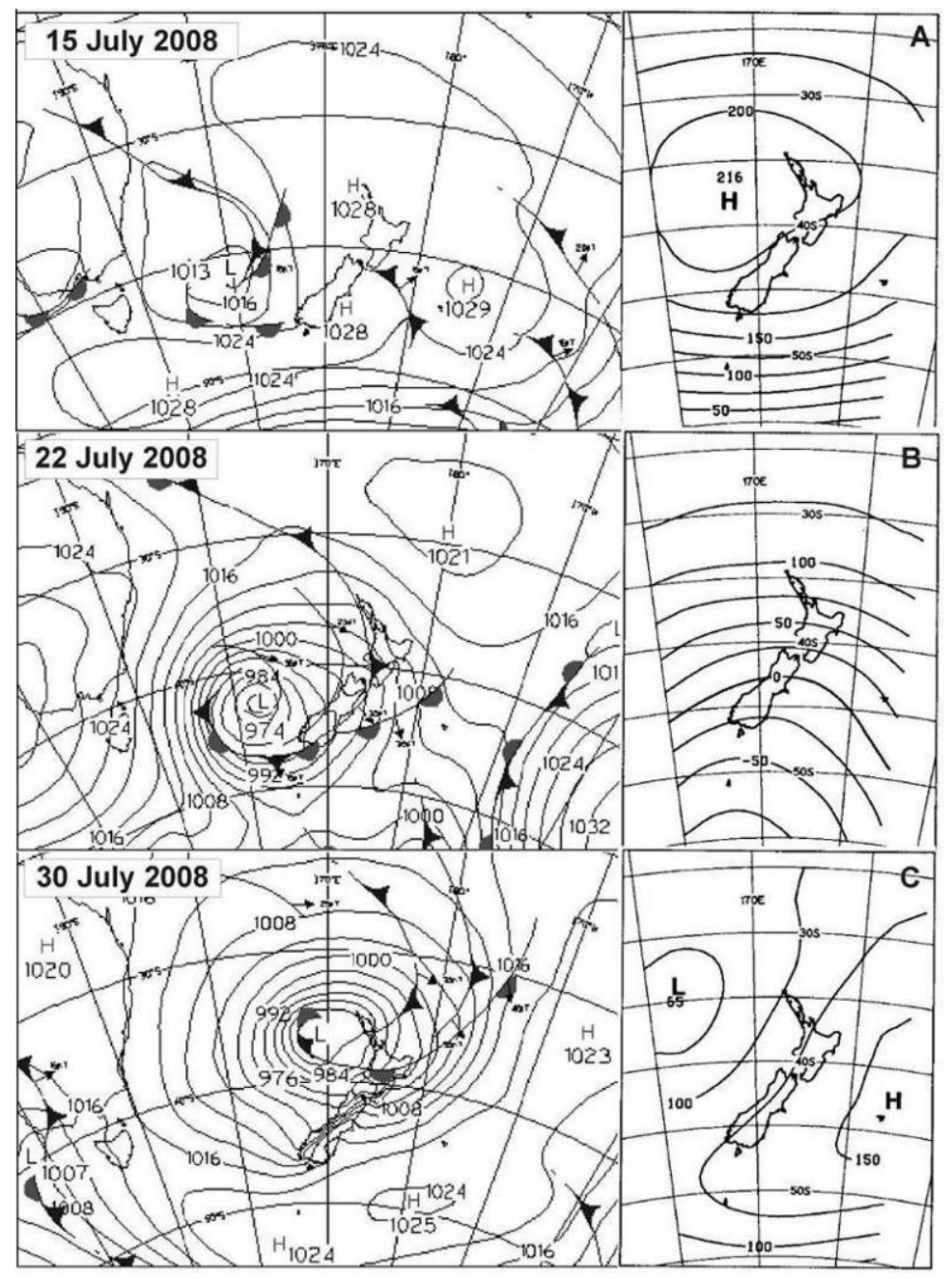

Figure 3.4: Examples of A. zonal flow (15 July), B. troughing (22 July) and C. blocking (30 July) regimes at 00UTC during the study period. Synoptic analysis charts provided by New Zealand Metservice, and Kidson diagrams from Kidson (2000).

Meteorological variables were measured and compared between the glacier study sites. Temporary AWS were set up at each site, $\sim 4 \mathrm{~m}$ from the snowboard array, recording 
hourly temperature, humidity, wind speed and direction (Figure 3.3). Each site had a catch precipitation gauge ( $150 \mathrm{ml}$ capacity) in case of liquid precipitation. Riming of AWS sensors occurred during storms, and both stations periodically required excavation and repositioning on the snow surface. Manual recordings (temperature, humidity, wind speed, barometric pressure) were made daily at $0900 \mathrm{hrs}$ at the sites with a Kestrel 4000 pocket weather tracker. Upper level wind directions were determined by tracking cloud movement with a compass and used to confirm synoptic scale flow. The degree of wind transport was categorised using the blowing snow scale from the New Zealand Mountain Safety Council (2008), which records snow transport as nil, light, moderate or intense. In addition, data from an AWS situated on the mid-Tasman Glacier (1110 m a.s.1.), and data from the two low elevation AWS run by NIWA were used to consider local-scale climate variability. Data from the latter two were used to calculate the modified temperature and precipitation lapse rates for M2, and force both model runs.

\subsection{Results}

\subsubsection{Synoptic variability in snow accumulation}

Direct observations and the absence of any liquid catch in the rainguages at the study sites indicated that all precipitation received during the study period at both sites was solid. Snowfall events occurred on 15 of 24 days at FJG, and 14 of 21 days on the TG (Table 3.1 and Figure 3.5). During the period of concurrent measurement, FJG received more snow on $56 \%$ of the days when snow occurred, and under all synoptic regimes.

Table 3.1: Snow accumulation measured at the $24-\mathrm{hr}$ snowboard in relation to synoptic frequency, including the long-term synoptic average.

\begin{tabular}{|c|c|c|c|c|c|c|}
\hline \multicolumn{2}{|c|}{ Synoptic Regime } & \multicolumn{2}{c|}{$\begin{array}{c}\text { Franz Josef Glacier } \\
\text { Snow Accumulation }\end{array}$} & \multicolumn{2}{c|}{$\begin{array}{c}\text { Tasman Glacier } \\
\text { Snow Accumulation }\end{array}$} \\
\hline Regime & $\begin{array}{c}\text { \% } \\
\text { this } \\
\text { study }\end{array}$ & $\begin{array}{c}\text { \% } \\
\text { 1957-2008 }\end{array}$ & $\begin{array}{c}\text { Measured } \\
\text { (mm w.e.) }\end{array}$ & $\begin{array}{c}\text { \% } \\
\text { total }\end{array}$ & $\begin{array}{c}\text { Measured } \\
\text { (mm w.e.) }\end{array}$ & $\begin{array}{c}\% \\
\text { total }\end{array}$ \\
\hline $\begin{array}{c}\text { Troughing } \\
\text { Zonal† } \dagger\end{array}$ & 54 & 38 & 202 & 77 & 136 & 76 \\
Blocking & 20 & 28 & 10 & 9 & 0 & 0 \\
\hline \multicolumn{2}{|c|}{ Total Snow All Regimes } \\
(mm w.e.)
\end{tabular}

$\uparrow$ Simultaneous measurement was conducted during troughing and blocking regimes, but only two days of zonal flow were recorded at TG in comparison to five at FJG. 


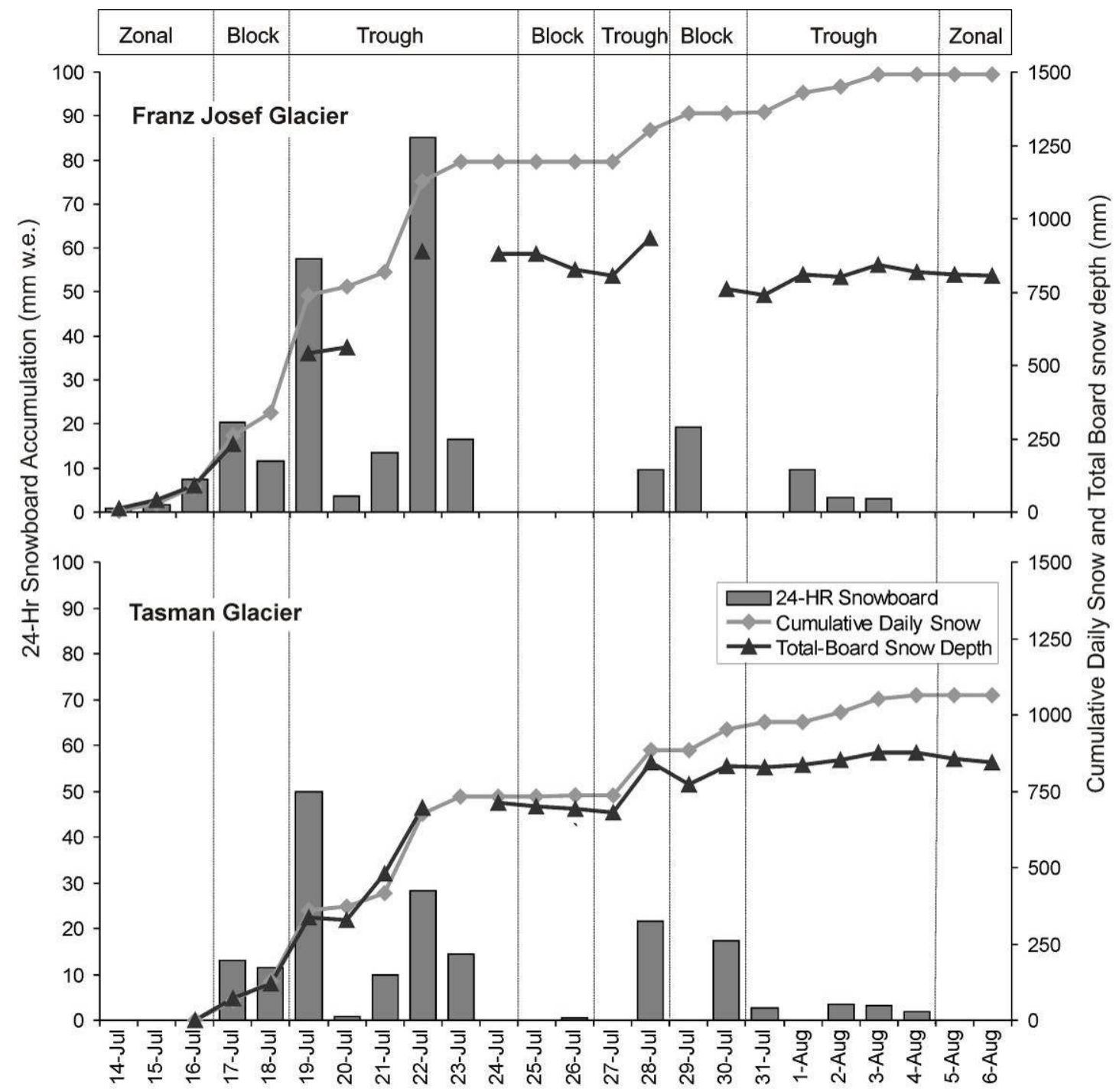

Figure 3.5: Daily measured snow fall recorded at 24-hour snowboard, cumulative daily snow, and snow depth at the total board (gains and losses) on Franz Josef and Tasman Glaciers. The study period is divided into synoptic regimes as per Kidson (2000). Snow was measured at 0900 hrs and assigned to the previous day as per standard meteorological convention.

In order to determine the extent to which the 24-day study period was representative of mid-winter conditions in other years, daily Kidson synoptic types from 14 July - 8 August for the previous 50 years (1958-2007) were compared to those occurring during this study. The long-term (1958-2007) average frequency of twice daily (00UTC, 12UTC) Kidson synoptic weather types shows that during this time of year troughing is most frequent and zonal conditions occur the least (Table 3.1). During the study period, troughing was more frequent than mean conditions, but still within one standard deviation of the long-term mean. 23 of the previous 50 years also experienced higher frequencies of troughing (e.g. 1962, 1965, 1985 and 1986). In terms of the wider 
synoptic picture, of the 50 years of record, 21 years experienced similar regime frequency to 2008; the remaining 29 deviated from the mean by more than 1 standard deviation (e.g. 1970, 1974 and 2003). The regime frequency in the study period is therefore inferred to be reasonably representative of synoptic conditions of this midwinter period.

A comparison of daily meteorological variables during the different synoptic regimes shows that zonal conditions were generally warmer and less windy during the study (Figure 3.6). Troughing was associated with westerly-quadrant winds, cooler temperatures, high humidity and low pressure at both sites, with wind speeds higher at FJG. Blocking resulted in a reversal of normal wind direction (easterly-quadrant winds dominated) and cold, humid conditions were recorded on TG. Low humidity, cold temperatures and strong down-slope winds were recorded at FJG during these periods.

Of the $263 \pm 21 \mathrm{~mm}$ w.e. of daily snow accumulation recorded at FJG during the study, $77 \%$ occurred during troughing, $19 \%$ with blocking, and less than $10 \%$ during zonal conditions (Table 3.1). Likewise at TG the majority of snowfall (76\%) occurred during troughing regimes, with blocking conditions contributing the remainder. The later start date at TG meant that only two days of zonal flow were measured, and no snow accumulation was recorded on those days. Troughing conditions were in place over $50 \%$ of the time, and was the most persistent synoptic regime, sometimes lasting for five or more days.

By the end of the concurrent study period the western, FJG site had received $74 \pm 6 \mathrm{~mm}$ w.e. $(29 \%)$ more gross daily snowfall than the TG site, east of the Main Divide.

However, on six occasions there was $<2 \mathrm{~mm}$ w.e. difference in daily snow accumulation at both sites, which was below estimated measurement accuracy. On three occasions, when snow was recorded at both sites, the eastern glacier site recorded more snow accumulation (Figure 3.5), in particular, on 28 July, when wind direction recorded at the site was from the north-east, and $12 \mathrm{~mm}$ w.e. more snow was recorded at TG in comparison to FJG. Excavation of a snow pit at the total boards indicated that at the end of the study, net accumulation was $231 \pm 18 \mathrm{~mm}$ w.e. at FJG (indicating a loss of $22 \pm 2$ mmw.e.), and $217 \pm 17 \mathrm{~mm}$ w.e. at TG. The net total at TG was $38 \pm 3 \mathrm{~mm}$ w.e. more than the daily cumulative measurement ( $179 \pm 14 \mathrm{~mm}$ w.e.). This difference between 
cumulative and net accumulation at TG could be influenced by a lack of density data recorded below $300 \mathrm{~mm}$ in the TG pit, due to weather and time constraints, or an indication that the total board at TG received more snow than the 24-hr board, which was not detected by depth measurements due to compaction. So overall, difference in net accumulation between the two sites was very small at only $14 \pm 1 \mathrm{~mm}$ w.e. (6\%).

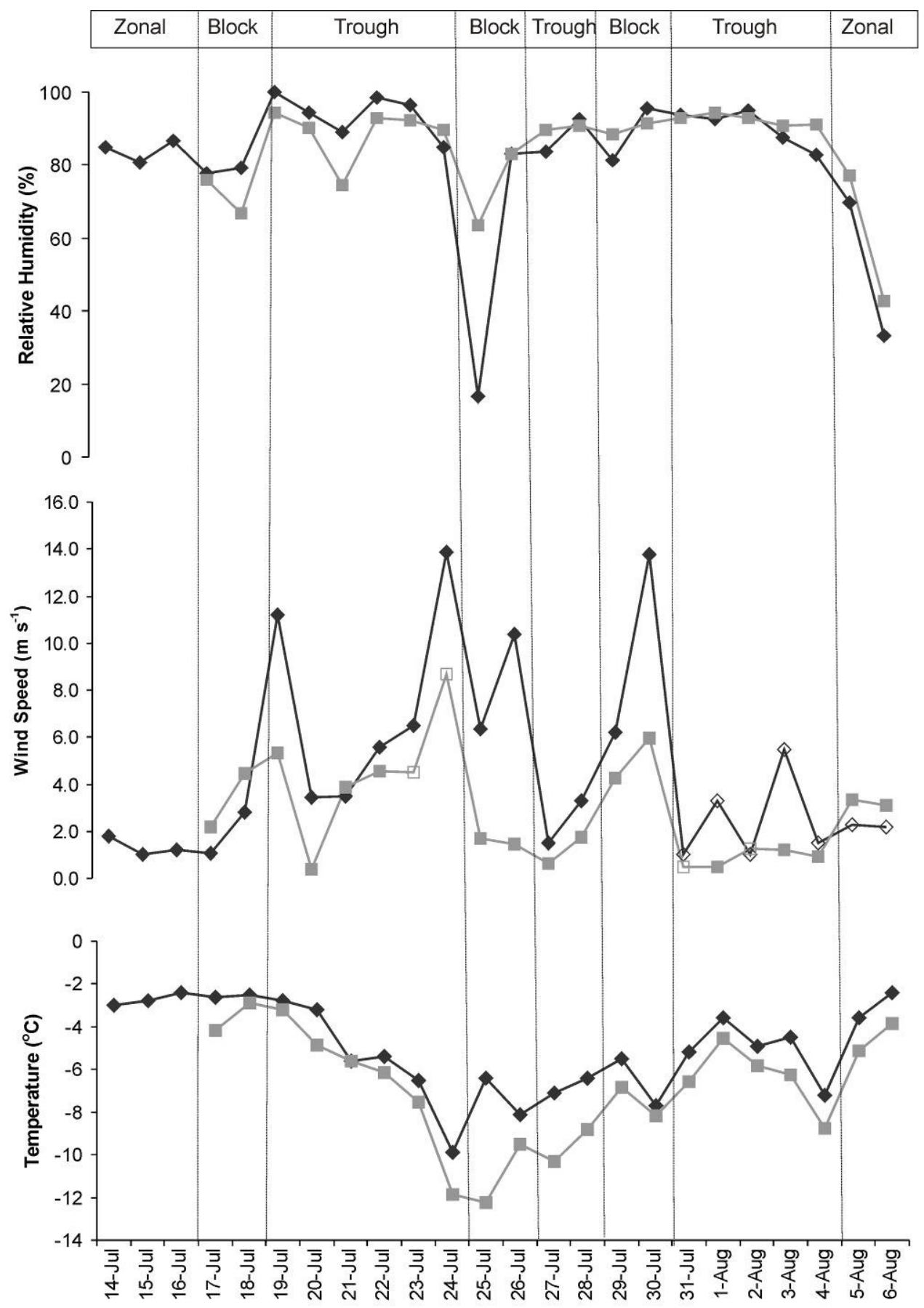

Figure 3.6: Average daily meteorological variables measured at the FJG (dark grey) and TG (light grey) study sites under different synoptic regimes. 


\subsubsection{Re-distribution of snow by wind}

During the study period, snow transport by wind was a regular occurrence, with 9 out of 24 days categorised as having 'moderate' or 'intense' snow transport. During intense transport it was difficult to determine how much snow was actually precipitating and how much was remobilised. Quantifying loss of snow is complex as changes to snow surface height can be a combination of wind deflation and compaction. In calm conditions a reduction in snow surface height is expected due to snow compaction and settling (Dewalle and Rango, 2008), and during fine, calm weather, the snow surface height at the total board was measured to decrease by 10-20 mm per day. Density measurements of fresh (or surface) snow were taken on a daily basis, but a full density profile was only completed at the end of the study to determine overall net accumulation. Reductions in snow surface height, in terms of water equivalent, are therefore estimated by first subtracting potential surface reduction due to compaction, and increasing the estimated error $( \pm 2 \mathrm{~mm}$ w.e. $)$ to account for the uncertainty in compaction rates.

Intense snow transport occurred during a SE storm on 30 July (Figures 3.4 and 3.6). At FJG wind speeds up to $30 \mathrm{~m} \mathrm{~s}^{-1}$ were recorded before the wind speed sensor failed. By $0900 \mathrm{hrs}$ on 31 July there had been a reduction in snow surface height (recorded at the total board) at FJG of $195 \mathrm{~mm}$ (Figure 3.5), equating to $16 \pm 3 \mathrm{~mm}$ w.e. On the eastern (windward) side of the Southern Alps at TG, the reduction in snow surface height, during the same storm, was only $56 \mathrm{~mm}(8 \pm 2 \mathrm{~mm}$ w.e.) (Figure 3.5$)$.

Although occasionally blowing from the SE, wind directions recorded at the TG site during the storm tended to come from N-NE-E directions, and at times, a $\mathrm{W}$ direction, with gust speeds also reaching $30 \mathrm{~m} \mathrm{~s}^{-1}$. Lower down the glacier, the mid-Tasman AWS recorded winds from the S-SE with a maximum average hourly wind speed of $11 \mathrm{~m} \mathrm{~s}^{-1}$. This indicates a degree of localised wind turbulence at the TG site. So although snow was observed blowing down and away from the accumulation area at FJG during this storm, it is likely that turbulence resulted in re-deposition of transported snow at the TG site. 
Under troughing or zonal regimes snow surface changes were small $(\leq 3 \mathrm{~mm}$ w.e. per day), and not beyond that which can be accounted for by compaction alone. However, during blocking regimes total snow surface reduction at FJG was $30 \pm 4 \mathrm{~mm}$ w.e., and despite an additional $16 \pm 1 \mathrm{~mm}$ w.e. of snow falling, there was an overall reduction in snow depth of $14 \pm 3 \mathrm{~mm}$ w.e. during this synoptic type. At TG, although $16 \pm 3 \mathrm{~mm}$ w.e. of snow surface reduction was recorded, there were still gains of $32 \pm 3 \mathrm{~mm}$ w.e., giving a positive total during the same synoptic conditions.

Sublimation can also result in snow loss, depending on temperature, humidity and wind speed (Liston and Sturm, 1998; Wever et al., 2009). However, sublimation was not thought to be an important process during this study, as periods of snow surface height reduction corresponded with high humidity $(>90 \%)$ and observed, extensive wind transport. Increases in snow density from wind packing (Sato et al., 2008) could account for some of the loss in snow surface height, but not of the magnitude of reductions recorded.

\subsubsection{Calculating model parameters}

Local climate data measured at the sites enabled the assessment and modification of standard model (M1) parameters, including temperature lapse rates, snow/rain thresholds and precipitation factors (Table 3.2).

Table 3.2: Model parameters utilised by the initial (M1) and modified (M2) model run based on data measured during the study period.

\begin{tabular}{|c|c|c|}
\hline Model Parameter & M1 & M2 \\
\hline $\begin{array}{l}\text { Temperature lapse rate } \\
\qquad \begin{array}{l}\text { Franz Josef AWS - FJG Site } \\
\text { Mt Cook AWS - TG Site }\end{array}\end{array}$ & $\begin{array}{l}-5.0^{\circ} \mathrm{C} \mathrm{km}^{-1} \\
-5.0^{\circ} \mathrm{C} \mathrm{km}^{-1}\end{array}$ & $\begin{array}{l}-5.5^{\circ} \mathrm{C} \mathrm{km}^{-1} \\
-5.7^{\circ} \mathrm{C} \mathrm{km}^{-1}\end{array}$ \\
\hline Snow/rain threshold & $1^{\circ} \mathrm{C}$ & $2.5^{\circ} \mathrm{C}$ \\
\hline $\begin{array}{r}\text { Precipitation factors (weightings in parenthesis) } \\
\text { Franz Josef AWS - FJG } \\
\text { Mt Cook AWS - TG } \\
\text { Mt Cook AWS - FJG } \\
\text { Franz Josef AWS - TG }\end{array}$ & $\begin{array}{l}1.41 \\
1.46 \\
\mathrm{n} / \mathrm{a} \\
\mathrm{n} / \mathrm{a}\end{array}$ & $\begin{array}{ll}1.51 & (0.64) \\
1.36 & (0.26) \\
1.92 & (0.36) \\
1.07 & (0.74)\end{array}$ \\
\hline
\end{tabular}

During the study, measured temperature lapse rates between low elevation AWS and glacier study sites were highly variable on an hourly scale, ranging from 0.1 to $-10^{\circ} \mathrm{C}$ $\mathrm{km}^{-1}$, but had an average over the whole study period of $-5.5^{\circ} \mathrm{C} \mathrm{km}^{-1}$ and $-5.7^{\circ} \mathrm{C} \mathrm{km}^{-1}$ at FJG and TG respectively. These values are similar to previously measured lapse rates in 
these catchments by Anderson et al., (2006) and Ruddell (1995) of $-5.0^{\circ} \mathrm{C} \mathrm{km}^{-1}$ and $-5.4^{\circ} \mathrm{C} \mathrm{km}^{-1}$ respectively. At FJG lowest average rates $\left(-4.3^{\circ} \mathrm{C} \mathrm{km}^{-1}\right)$ occurred during zonal flow, with near-average lapse rates during troughing and blocking. At TG blocking produced the lowest average lapse rates $\left(-4.7^{\circ} \mathrm{C} \mathrm{km}^{-1}\right)$, troughing near average rates, and zonal the highest $\left(-6.8^{\circ} \mathrm{km}^{-1}\right)$, although only two zonal days were measured at TG. Longer-term temperature monitoring on Tasman Glacier has found that throughout the course of a year, temperature lapse rates between Mount Cook AWS and midTasman AWS vary seasonally, with lowest rates $\left(<-4{ }^{\circ} \mathrm{C} \mathrm{km}^{-1}\right)$ occurring in winter and highest $\left(>-9^{\circ} \mathrm{C} \mathrm{km}^{-1}\right)$ in summer.

Although temperatures at TG remained below zero throughout, positive temperatures were recorded on occasion at FJG, including $4^{\circ} \mathrm{C}$ during snowfall on 20 July. Snowfall during this event was light, lasting for $\sim 1-2$ hours, and only resulting in $35 \mathrm{~mm}$ w.e. snow accumulation. Even so, this demonstrates that applying a $1^{\circ} \mathrm{C}$ snow/rain temperature threshold will result in under-estimation of snow accumulation. Kienzle (2008) conducted sensitivity analysis of snow/rain temperature thresholds, in Alberta, Canada, finding a mean threshold of $2.6^{\circ} \mathrm{C}$. Likewise, measurement at mid-Tasman AWS in winter 2007 recorded snow accumulation events when air temperature was $\sim 2-3^{\circ} \mathrm{C}$. Therefore a higher snow/rain threshold of $2.5^{\circ} \mathrm{C}$ is used in $\mathrm{M} 2$.

Measured average precipitation factors between the glacier study sites and lowland AWS over the course of the study period were 1.51 and 1.36 for FJG and TG respectively. However, on a per storm basis, factors could be highly variable, often ranging from 0.7 to 3.9 and in some cases being $>30$ or $<1$ (i.e. the lowland weather station received more precipitation than the glacier). These average precipitation factors measured during the study were applied to the M2 model run (Table 3.2). Franz Josef AWS is actually closer to the TG site than Mount Cook AWS, so with the change to distance weighting precipitation from both low elevation AWS in M2, more weight is given to precipitation recorded at the western AWS when calculating snowfall for TG. It is important to note that these modified model parameters are based on measurement made during this study. Measurement during other seasons (e.g. spring, autumn) may result in variations in snow/rain temperature thresholds and precipitation factors.

Despite this, comparing results from M1 and M2 provides opportunity to identify which 
model parameters are most sensitive over short temporal scales, and whether tuning a simple model to site parameters actually provides noticeable improvement.

\subsubsection{Comparison of measured and modelled snow}

Comparison between measured snow accumulation at FJG with a standard accumulation model (Anderson et al., 2006) found that by the end of the simulation, both M1 and M2 had underestimated total snow accumulation by $27 \mathrm{~mm}$ w.e. and 15 mm w.e. respectively (Figure 3.7), although the difference in M2 is below the estimated measurement error of $\pm 21 \mathrm{~mm}$ w.e. Simple linear regression between modelled and measured snow accumulation gave a correlation coefficient of $r^{2}=0.59$ for M1 and 0.70 for M2. On a daily basis results are variable. Both model runs underestimate accumulation during the first period of zonal flow. Orographic precipitation is not considered explicitly by the model, and although a precipitation factor is applied that accounts for some difference between low elevation AWS and the glacier accumulation area, the factor is held constant under all synoptic regimes. On occasions $<1 \mathrm{~mm}$ precipitation was recorded at the low elevation Franz Josef AWS yet $>50 \mathrm{~mm}$ snowfall was recorded at the top of the glacier, suggesting the precipitation factor needs to be synoptically adjusted. M2 produced improved results for the first period of blocking (least windy), but there is still large difference between modelled and measured precipitation with the blocking event at the end of July, although this was an exceptionally windy storm. During troughing both simulations overestimate $\left(19^{\text {th }}\right)$ and underestimate $\left(22^{\text {nd }}\right)$ snow accumulation. On the 23 July, large improvement is seen with M2, as a frontal system moved east across the Southern Alps, ceasing to rain at Franz Josef township, while rain continued at Mount Cook village. Overall the largest differences between measured and modelled (either run) precipitation occurred during troughing, when differences exceed $50 \mathrm{~mm}$ w.e. for M1 and $30 \mathrm{~mm}$ w.e. for M2. Best model performance (least difference) in either run was during zonal flow.

Simulation at the TG site also showed variable quality on an event based scale (Figure 3.7), but noticeable improvement was gained on some days by the additional precipitation data from Franz Josef AWS used in M2, with $r^{2}=0.31$ and 0.79 for M1 and M2 respectively. The cumulative difference between modelled and measured precipitation with either run was very small (3 $\mathrm{mm}$ w.e.), with M1 slightly overestimating and M2 underestimating cumulative snow accumulation. Consequently 
the difference in both simulations falls well below the estimated accuracy of the manual measurement ( $\pm 14 \mathrm{~mm}$ w.e.). On 28 July, large difference exists between modelled (either run) and measured precipitation at TG. This snowfall was accompanied by very light winds $\left(<2.5 \mathrm{~m} \mathrm{~s}^{-1}\right)$ from NE-NW directions, meaning that wind redistribution can not account for the difference. Temperature, both modelled and measured, was below zero so neither the temperature lapse rate or the snow/rain threshold can account for the difference. In other words, the local nature of precipitation means that it is difficult to simulate all events using lowland weather station data and a precipitation factor, even using values that are specifically tuned for the glacier in question.

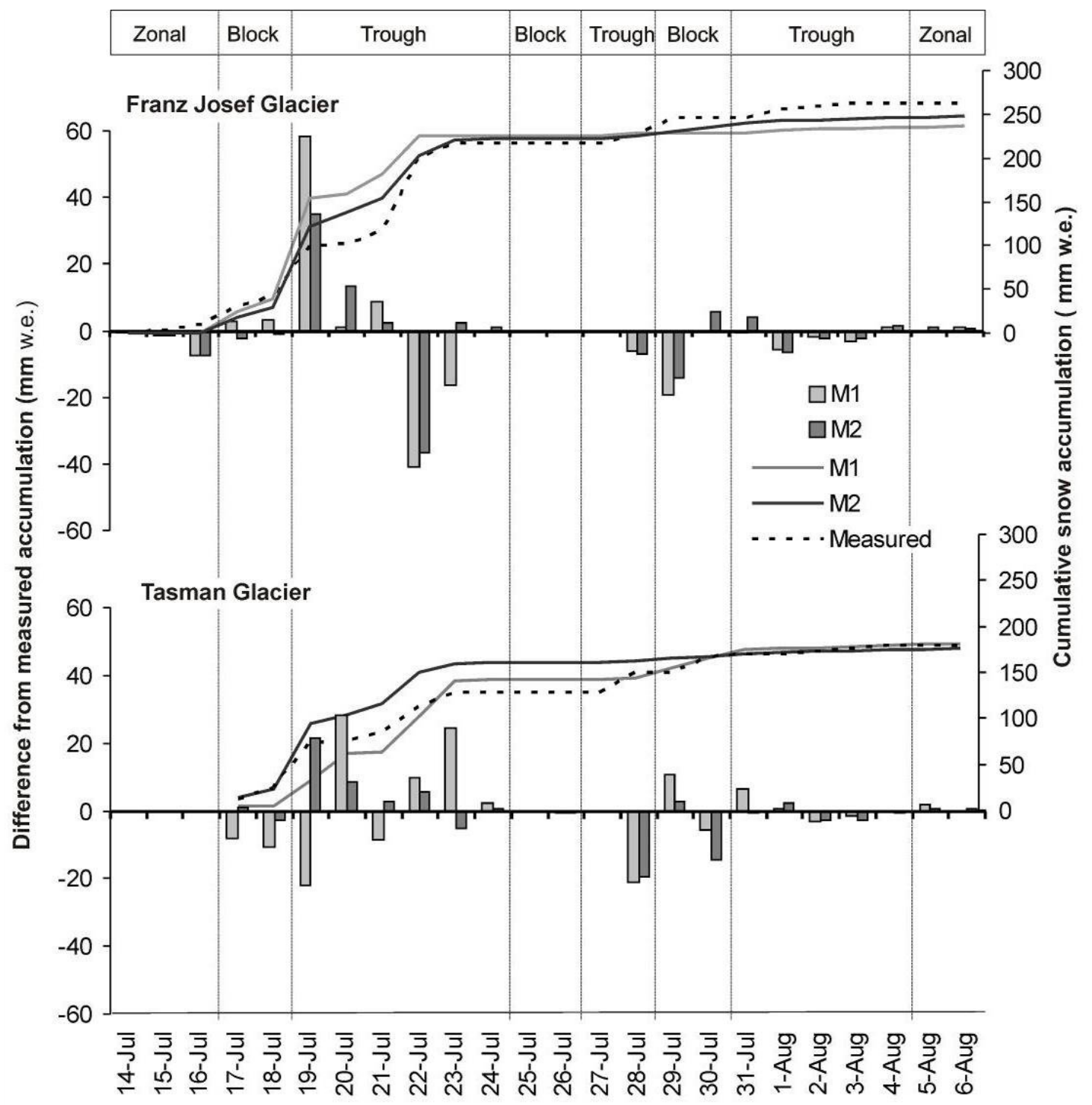

Figure 3.7: Difference between modelled and measured snow accumulation (bars) and cumulative modelled and measured snow accumulation (lines) at the study sites with a simple accumulation model. 


\subsection{Discussion}

\subsubsection{Snow accumulation \& synoptic regime}

This study aimed to simultaneously quantify snow accumulation on glaciers east and west of the Southern Alps in order to gain better understanding of relationships between synoptic weather systems and snow accumulation processes. As expected, the western and predominantly windward site on the Franz Josef Glacier recorded more snow accumulation than the eastern, predominantly lee, site on Tasman Glacier. But by the end of the study, there was little difference in net accumulation between the two sites, attributed at least in part to wind deflation.

During the study period, some of the largest snowfalls occurred with north-westerly conditions during troughing regimes, and both sites received $>75 \%$ of their total measured snowfall during troughing events. The largest difference in snow accumulation east and west of the Southern Alps occurred under blocking conditions, which resulted in snow loss from FJG during strong south-east winds. On a regional scale, blocking is not necessarily associated with strong winds (Kidson, 1994), but in this case, the stalling of low pressure systems east of the South Island resulted in large pressure gradients, generating very strong down-slope winds west of the Southern Alps. Zonal circulation occurred least during the study period, and also resulted in the least snow accumulation.

New Zealand's maritime climate means that snow accumulation can occur year around, but seasonal shifts in freezing levels results in the majority of snow accumulation occurring during winter and spring. As this study was conducted during winter, a question remains about relationships between synoptic weather systems and spring snowfall patterns. Synoptic frequencies in the New Zealand winter are similar to those occurring in spring, with larger differences to frequencies in the autumn and summer seasons (Kidson, 2000). Although it would have been desirable to undertake this experiment over a whole year, results from this winter survey, in terms of proportions of snow accumulation received under different synoptic regimes, still provides some insight into the potential impact that a change to synoptic frequency during the accumulation season could have to snow accumulation on glaciers. 
Variation in synoptic frequency is driven by changes in atmospheric circulation patterns (Sturman and Tapper, 2006). In New Zealand, ENSO/Interdecadal Pacific Oscillation (IPO) phases have been linked to anomalous south-westerly (El Niño, negative ENSO, positive IPO) and north-easterly (La Niña, positive ENSO, negative IPO) circulation anomalies (Salinger et al., 2001). La Niña (El Niño) conditions in the Pacific are associated with a reduced (increased) frequency of troughing regimes and higher (lower) frequency of blocking circulation in New Zealand (Kidson, 2000). On longer timescales, increased troughing frequency was identified as an important factor associated with cooling and increased precipitation in New Zealand during the Little Ice Age (Lorrey et al., 2008). The recent negative phase shift in the IPO (Folland, 2008) indicates that the Southern Alps are likely to become warmer and receive less precipitation in future years than they did between 1977-2001 (Salinger et al., 2004).

Associations between synoptic frequencies, atmospheric circulation, and snow accumulation demonstrated in this and other studies are important on longer timescales. During the last few decades, glacier advances in Patagonia have been linked to increased westerly circulation and reduced blocking events, associated with positive IPO (negative ENSO) phases, whereas an anti-phase relationship exists between New Zealand and tropical Andean glaciers (Fitzharris et al., 2007). Similar relationships are evident worldwide. For example, increased troughing synoptic regimes have been associated with higher rates of snow accumulation in the Peace River Basin, Canada (Romolo et al., 2006), and on the Great Northern Plains, USA (Grundstein, 2003). Similarly, positive phases of the NAO have resulted in increased winter accumulation, on western Norwegian glaciers (Nesje et al., 2000; Nordli et al., 2005), and an inverse mass balance response is seen between Wolverine Glacier, Alaska, and South Cascade Glacier, Washington, USA in association with phase changes of the Pacific Decadal Oscillation (PDO) (Josberger et al., 2007). In conclusion, one must consider the role of regional (synoptic-scale) climate variability and its affect on mass balance when considering the future response of temperate glaciers, as the direction of change may enhance or buffer the anticipated negative mass balance of glaciers. 


\subsubsection{Modelling snow accumulation}

While there are a number of complex snow accumulation models available (Liston and Elder, 2006; Lehning et al., 2008) which would likely improve snow accumulation estimation on glaciers, neither the meteorological input data (i.e. multi-level wind speeds from alpine catchments) to drive these models, nor the detailed accumulation measurements to calibrate and validate these models exist, except for a few specialised studies (Liston and Sturm, 1998; Mott et al., 2008; Dadic et al., 2010). Many of the world's regions suffer from paucity of data - for example South America (Popovnin et al., 1999), China (Sakai et al., 2009) and the Himalaya (WGMS, 2008). Therefore our data provided an opportunity to evaluate the ability of a simple snow accumulation model to capture synoptic scale variability.

Troughing synoptic regimes accounted for $\geq 75 \%$ of measured snow accumulation during the winter study period. However, largest difference between modelled and measured precipitation also occurred during troughing regimes, which were most frequent (Figure 3.7). Total snow accumulation during blocking regimes was underestimated, with largest difference coinciding with snow accumulation during high winds. Simulation of snow accumulation under zonal flow was most successful, although it is important to note that this synoptic regime occurred least frequently, and overall contributed least to total snow accumulation.

Model performance was better at the eastern (TG) site, where after 21 days there was only a small $(2 \%)$ difference between measured and modelled snow accumulation. It is likely that wind redistribution of snow was a factor in performance at the western FJG site, with biggest discrepancies between modelled and measured snow accumulation often associated with strongest wind speeds. Wind redistribution not only potentially removed snow from the site (e.g. $19^{\text {th }}$ July), but also enhanced deposition (e.g. $22^{\text {nd }}$ July).

The importance of redistribution and preferential deposition of snow by wind has been quantified on complex glaciated terrain in the European Alps (Liston and Sturm, 1998; Lehning et al., 2008; Mott et al., 2008; Dadic et al., 2010). Interaction between wind dynamics and topography tend to result in increased snow deposition on lee slopes and reduced deposition on exposed slopes (Liston and Sturm, 1998). Strong down-slope 
(SE) winds under blocking conditions resulted in significant loss of snow from the FJG site, but during the same period the TG site recorded both wind deflation and deposition, with complex topography resulting in turbulence, generating winds contrary to the general synoptic flow.

Aside from wind transport, event scale variability in precipitation factors between low elevation weather stations and high elevation sites means that accurate snow accumulation estimation cannot be achieved by using a single precipitation factor. Applying a range of precipitation factors based on synoptic regime, may provide improvement. Likewise, increasing precipitation input data to include a larger number of surrounding weather stations (especially at high elevation) would better capture regional precipitation patterns.

During this study, cold winter temperatures at the low elevation AWS meant that the model was not very sensitive to choice of lapse rate, or snow/rain temperature thresholds. In the New Zealand Southern Alps, snow accumulation can occur year around, with some of the largest snowfalls in spring, when warm moist air masses cross the Tasman Sea and intercept the mountain range. On Tasman Glacier, temperature lapse rates between low elevation AWS and glacier AWS have been found to vary seasonally, with largest rates during summer and smallest in winter. Kienzle (2008) recorded seasonal variations in snow/rain temperature thresholds in Alberta, Canada, with mean monthly maximums $\left(\sim 5^{\circ} \mathrm{C}\right)$ occurring in winter, and minimums $\left(0^{\circ} \mathrm{C}\right)$ in summer. How such thresholds vary in the Southern Alps is unclear, but during the study, snowfall occurred at the FJG site when temperature was $4^{\circ} \mathrm{C}$. So although these two model parameters did not account for inaccuracies during this winter simulation, such may not be the case if the study were repeated in spring.

In the absence of increased meteorological observation allowing application of higher order models, this study demonstrated that a simple snow accumulation model did provide reasonable approximation of cumulative snow accumulation, but still failed to capture event scale variability. Interestingly, there was only small cumulative improvement by tuning model parameters specifically to the sites (M2), thus highlighting the difficulty in utilising input data measured at low elevation weather stations to estimate snow accumulation at a single point on a glacier. Utilising more 
precipitation input data, and gaining a better understanding of precipitation relationships between low elevation meteorological sites and glacier catchments under varying synoptic flow is essential to improve snow accumulation simulation. The challenge is to find ways to refine models without large increases to input data and computational requirements.

Spatial variability in snow accumulation on glaciers is important to both accurate mass balance measurement and modelling (Fountain and Vecchia, 1999; Jansson and Pettersson, 2007). This study has demonstrated links between synoptic frequencies and snow accumulation but in order to be applied to the glacier as a whole, an assessment of how snow accumulation is spatially distributed on these glaciers is essential and is part of ongoing research (Purdie et al., 2011a).

\subsection{Conclusions}

Synoptic flow type was found to influence snow accumulation patterns during winter at two glacier study sites in the New Zealand Southern Alps, with troughing regimes accounting for over $75 \%$ of recorded snowfall. Although only $8 \mathrm{~km}$ apart, the predominantly windward, Franz Josef Glacier site received $\sim 30 \%$ more snow accumulation than the Tasman Glacier site, lee of the Southern Alps. However, wind deflation meant that after 21 days, net accumulation at both sites was similar. A simple accumulation model estimated snow accumulation to within $8 \%$ of measured values, but large discrepancies occurred from day to day. Improvement could be gained by using a more complex snow accumulation model, but as yet in New Zealand (and other parts of the world) insufficient data exist to force such models.

Only capturing a short time-period during winter, this research needs to be extended for longer time periods and to other regions. If such relationships between synoptic frequency and snow accumulation are shown to hold over longer time scales then expected future changes to atmospheric circulation patterns and synoptic frequency, in particular, a decrease in troughing, would lead to more negative mass balance on glaciers in New Zealand. Similar outcomes may also be likely on other maritime glaciers (e.g. Patagonia, Norway, Alaska), where the position of winter storm tracks are influenced by regional-scale climate variability. 


\section{Isotopic and elemental changes in winter snow accumulation on glaciers in the Southern Alps of New Zealand.}

The authors present stable water isotope and trace element data for fresh winter snow from two temperate maritime glaciers located on opposite sides of the New Zealand Southern Alps. $\delta^{18} \mathrm{O}$ and $\delta D$ were more depleted at the eastern Tasman Glacier site, due to prevailing westerly flow and preferential rain-out of heavy isotopes as air-masses crossed the Alps. The deuterium-excess provided some indication of moisture provenance, with the Tasman Sea contributing $\sim 70 \%$ of the moisture received at Franz Josef and Tasman glaciers. This source signal was also evident in trace elements, with a stronger marine signal (Na, Mg, Sr) associated with snow from the Tasman Sea and larger concentrations of terrestrial species $(\mathrm{Pb}, \mathrm{V}, \mathrm{Zr})$ in air masses from Southern and Pacific Oceans. Although post-depositional modification of signals was detected, our results indicate that there is exciting potential to learn more about climate trends and moisture source pathways and from geochemical signals contained in snow and ice in the New Zealand region.

\subsection{Introduction}

Geochemical records from ice cores provide a realm of information on past climate variability, including information about temperature (Dansgaard, 1964), moisture provenance (Araguas-Araguas et al., 2000), atmospheric aerosol loading (Bertler et al., 2005), atmospheric circulation variability (Legrand and Mayewski, 1997; Jansson et al., 2007), precipitation (Shiraiwa et al., 2002), sea surface temperature (Jouzel et al., 2005) and anthropogenic pollution (Gabrielle et al., 2008). As such these data give insight into understanding natural climate variability and provide an important baseline against which to assess climate change.

Most research to date has focused on polar ice cores (Jouzel et al., 1987; Legrand and Mayewski, 1997; Kreutz et al., 1999) as below freezing temperatures ensure the preservation of primary isotopic/ionic signatures. However, other environments have also been studied, including tropical glaciers (Thompson et al., 2000; Ginot et al., 2002) 
and glaciers at high altitude sites, for example the Siberian Altai (Aizen et al., 2005), the Yukon, Canada (Holdsworth and Krouse, 2002; Fisher et al., 2008) and the Himalaya (Kaspari et al., 2008). Even sites at lower elevation with melting, for example the Canadian Arctic, have been found to contain important climate information (Fisher et al., 1998; Goto-Azuma et al., 2002).

Temperate maritime glaciers have not received as much study, as summer ablation and consequent melt water percolation (often coupled with large annual snow accumulation), pose significant challenges (Arnason, 1981). Yet these sites have potential to contribute important information, in particular in the Southern Hemisphere, where meteorological records are relatively sparse and short (Jones and Moberg, 2003). Already exciting work has been carried out in Patagonia (Shiraiwa et al., 2002), Sweden (Jansson et al., 2007), Norway (Raben and Theakstone, 1994; He et al., 2002) and the Canadian Rockies (Sinclair and Marshall, 2009). Here we present a systematic evaluation of the potential of New Zealand glaciers for ice core reconstruction.

Orographic processes can modify both isotopic (Guan et al., 2009) and trace element (Gilfedder et al., 2007) signatures, due to preferential rain-out and air mass pathways (Dansgaard, 1964). Such effects can cause geochemical records of glaciers located on opposite sides of an orographic barrier to show different concentrations and patterns, even if the snow is derived from the same precipitation event. To evaluate this effect in New Zealand ice, we compare data from fresh snow, concurrently collected at two sites during snow precipitation events.

Post-depositional modification of stable water isotopes and trace elements may affect the climate integrity of ice core records, especially on temperate maritime glaciers at relatively low altitude (Raben and Theakstone, 1994; Yoshimura et al., 2000; Shiraiwa et al., 2002; Kameda et al., 2003). Previous studies on temperate glaciers have used snow pit sampling at the end of winter to determine if discrete snow storm event information is maintained (Raben and Theakstone, 1994; He et al., 2002). However, changes in snow density, redistribution, and compaction make it difficult to unambiguously identify and correlate snow depth to each precipitation event (Jansson et $a l ., 2007)$. Here we attempt to reduce this uncertainty by adopting methods that allow clearer identification of snow storm increments in a snowpit. 
Temperate maritime glaciers, like those in New Zealand, experience high annual accumulation ( $\sim 6 \mathrm{~m}$ w.e.) coupled with significant summer melt ( $\sim 1 \mathrm{~m}$ w.e.) within the accumulation area, posing significant challenges for ice core interpretation (Ruddell and Budd, 1990). However, in New Zealand, little analysis has been conducted into the preservation and integrity of isotopic and trace element records stored in glaciers.

We analysed fresh snow samples, simultaneously collected during snow precipitation, from two temperate glaciers located on opposite sides of New Zealand's Southern Alps, in order to determine the climate signal contained in fresh snow, and to evaluate how the geochemical signal is modified by the passage of an air mass across the Southern Alps orographic barrier. Furthermore, we sample the same precipitation events in the snow pit at the end of the sampling campaign.

The two data sets will allow us to:

1. Contrast isotopic and trace element signatures present in winter snow accumulation on two glaciers located on opposite sides of New Zealand's Southern Alps.

2. Establish their potential to provide information on moisture provenance and climate variability.

3. Quantify the level of signal preservation.

\subsection{Study Sites}

The New Zealand Southern Alps contain over 3100 glaciers (Chinn, 1996), and have an average altitude of $\sim 2500 \mathrm{~m}$ a.s.1. The mountain range lies perpendicular to the path of mid-latitude westerly winds, resulting in sites having prevailing westerly flow. For this reason, we select two sites from opposite sides of the orographic barrier: the Franz Josef Glacier (FJG) on the western flank of the Southern Alps (43 $\left.30^{\prime} \mathrm{S}, 170^{\circ} 14^{\prime} \mathrm{E}\right)$ and the Tasman Glacier (TG), immediately on the eastern side of the range $\left(43^{\circ} 30^{\prime} \mathrm{S}, 170^{\circ} 20^{\prime}\right.$ E) (Figure 4.1). These glaciers have been chosen as they are at similar latitude, and their accumulation areas extend from $\sim 1900$ to $2500 \mathrm{~m}$ a.s.l., enabling study sites to be set up at similar elevation ( $\sim 2300 \mathrm{~m}$ a.s.1.). Net annual accumulation on these glaciers is around 3-5 $\mathrm{m}$ w.e., derived from a combination of large winter snowfall and summer ablation ( 1-2 m w.e.) at high elevations (Anderson et al., 2006; Purdie et al., 2011a). 
There are no long-term weather data from these glaciated sites, but annual mean annual temperature at the top of FJG is estimated to be around $-4^{\circ} \mathrm{C}$ (Anderson et al., 2006).

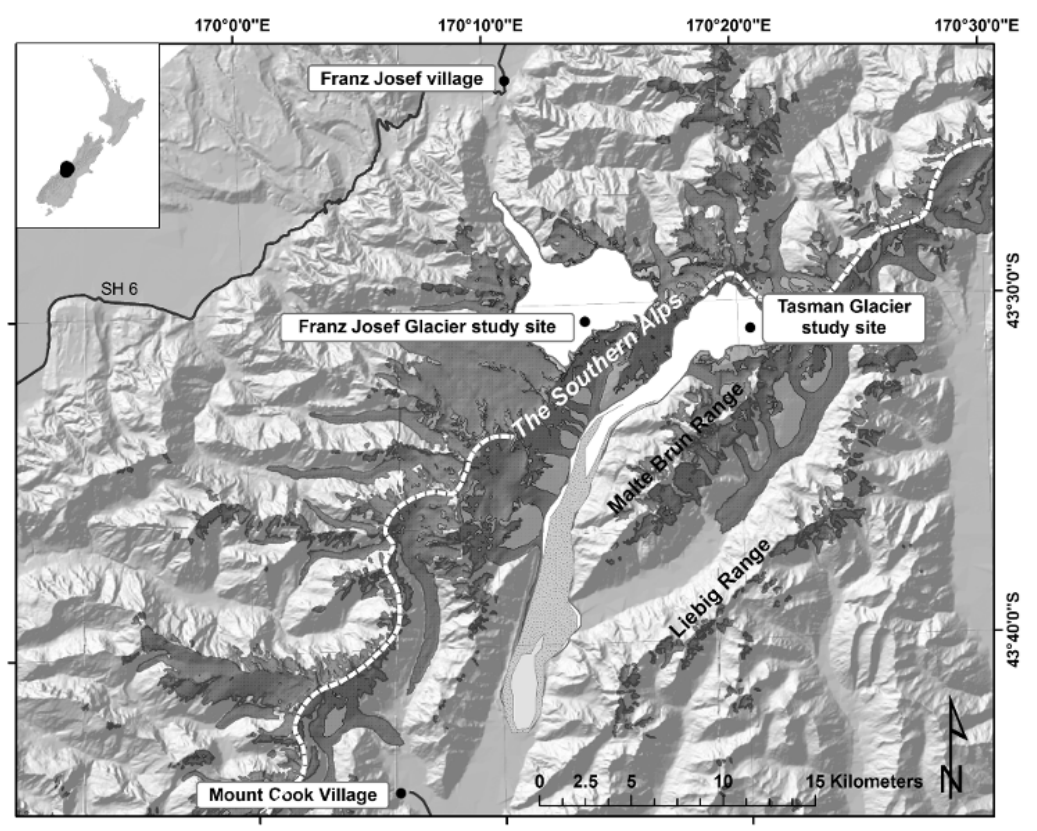

Figure 4.1: Map showing the location of the Southern Alps and the Tasman and Franz Josef Glacier study sites.

\subsection{Sample Collection}

During winter 2008 we simultaneously measured snow fall at a snowboard $(0.4 \mathrm{~m}$ x 0.4 $\mathrm{m}$, with $2 \mathrm{~m}$ central pole), in the accumulation area of TG and FJG from 14 July to 6 August. Surface snow samples were collected daily at $0900 \mathrm{hrs,} \mathrm{immediately} \mathrm{adjacent} \mathrm{to}$ the snowboards, with a clean plastic scoop and deposited directly into sterile $18 \mathrm{oz}$ Whirlpak bags. Bags were filled to minimise headspace, secured tightly, labelled and kept frozen. Additional snow samples were taken after storm cycles and at time intervals within storms when conditions permitted. Snow depth, density, morphology and temperature were measured daily. In addition during the same time period, automatic weather stations were installed at each site, $\sim 4 \mathrm{~m}$ from the snowboards, to record local temperature, humidity, wind speed and direction. This sampling strategy allows isotopic and trace element data to be linked directly to the synoptic weather systems from which they derived, and to meteorological data measured on site.

To clearly identify individual snow events being measured at the snowboard, coloured wool markers were placed between snow storm increments. This was done by tying a single thread of wool ( $\sim 1 \mathrm{~m}$ long) around the central pole and extending the ends of the 
wool across the snow surface beyond the snowboard boundary. At the end of the study at the FJG site (24 days), a snow pit was dug down to the initial snow surface (the snowboard) and snow samples were collected from between the wool markers. The integrity of the wool markers was checked by calculating compaction of fresh snow using depth and density measurements, and comparing that to the depth indicated by the markers, and the density of snow pit layers. Wind deflation, as measured at the site, was also taken into account (see Purdie et al., 2011b). The use of the coloured wool markers provided a time-stamp down the pit, and a robust way to identify the snow layers rather than relying solely on density conversion.

Samples were kept frozen during transportation and sub-sampling took place in the clean laboratory at the GNS Science Ice Core Research Facility. The samples were melted at room temperature and two aliquots were taken, one for stable isotope analysis $\left(\delta^{18} \mathrm{O}, \delta \mathrm{D}\right.$ and $d$-excess), and the other for inductively coupled plasma mass spectrometry (ICP-MS) analysis (major cation, trace metals and rare earth elements).

\subsection{Analytical Techniques}

Stable water isotope analysis $\left(\delta^{18} \mathrm{O}\right.$ and $\left.\delta \mathrm{D}\right)$ was conducted at the National Isotope Centre, GNS Science, Lower Hutt, NZ. Oxygen stable isotopes were analysed on a GVI AquaPrep attached to a GVI IsoPrime mass spectrometer by the classical equilibration method. $400 \mu \mathrm{L}$ of water are equilibrated with $3 \mathrm{~mL}$ of headspace flushed with $\mathrm{CO}_{2}$ for 24 hours at $25.5^{\circ} \mathrm{C}$. The $\mathrm{CO}_{2}$ is then extracted and analysed by dual inlet on the IsoPrime. All oxygen results are reported with respect to Vienna Standard Mean Ocean Water (VSMOW), normalized to internal standards INS11, INS9 and MM1 with reported values of $-0.3 \%$ o, $-17.3 \%$, and $-29.4 \%$ respectively. All internal standards are routinely measured against VSMOW for quality control and international comparability. The analytical precision of these measurements are $\pm 0.1 \%$.

Hydrogen stable isotopes were analysed on a GVI PyrOH attached to a GVI IsoPrime mass spectrometer by direct injection over hot chromium. $5 \mu \mathrm{L}$ of water was injected into a helium stream through a quartz reactor filled with chromium granules and quartz chips held at $1050^{\circ} \mathrm{C}$ where it was reduced to $\mathrm{H}_{2}$ gas. The $\mathrm{H}_{2}$ is then analysed by continuous flow mode on the IsoPrime. All hydrogen results are reported with respect to 
VSMOW, normalized to internal standards INS11, INS9 and MM1 with reported values of $-3.3 \%,-136.5 \%$, and $-231.5 \%$ respectively. The analytical precision of these measurements are $\pm 1.0 \%$.

ICP-MS analysis of trace elements was carried out at Victoria University of Wellington on an Agilent $7500 \mathrm{cs}$ for twenty trace elements. Samples were acidified prior to analysis to $1 \% \mathrm{HNO}_{3}$ using high purity SeaStar acid. Samples were transferred to the ICP-MS via an ASX-520 micro-volume auto-sampler and introduction kit with PFA Teflon nebuliser and quartz spray chamber. Blanks were run after every six samples to establish detection limits ( $3 \sigma$ of blanks). Calibration standards were also acidified to $1 \%$ $\mathrm{HNO}_{3}$ and prepared daily. The standards were run every twelve samples to correct for machine drift and calculate overall precision. Elemental concentrations were determined from ICP-MS count data using bracketing analyses of the calibration standards.

Reported elemental concentrations comprise the sum of soluble ions and acid digested particulates. Certified river water reference material (SLRS-4) was run to check data accuracy and ascertain reproducibility.

To identify moisture source regions, back-trajectory analysis was conducted using the HYSPLIT model available at http://ready.arl.noaa.gov/HYSPLIT.php (Draxler and Rolph, 2003). NCEP/NCAR reanalysis data $\left(2.5^{\circ}\right.$ grid size $)$ was selected to force the model, and time stamps were set to concur with snow storm events. To consider synoptic scale trends in isotopic and trace element data, each day during the study was categorised as one of three synoptic regimes following the classification of Kidson (2000) (Figure 4.2). Kidson utilised 40-year NCEP/NCAR data to identify 12 different weather types for New Zealand, which were further categorised into zonal, troughing or blocking regimes. Since their development, Kidson indices have been applied to studies of air pollution (Appelhans, 2009; Baldi et al., 2009), climate change (Lorrey et al., 2007; Mullan, 2009), drought patterns (Salinger, 2009) and marine biodiversity (Dunn et al., 2009). 


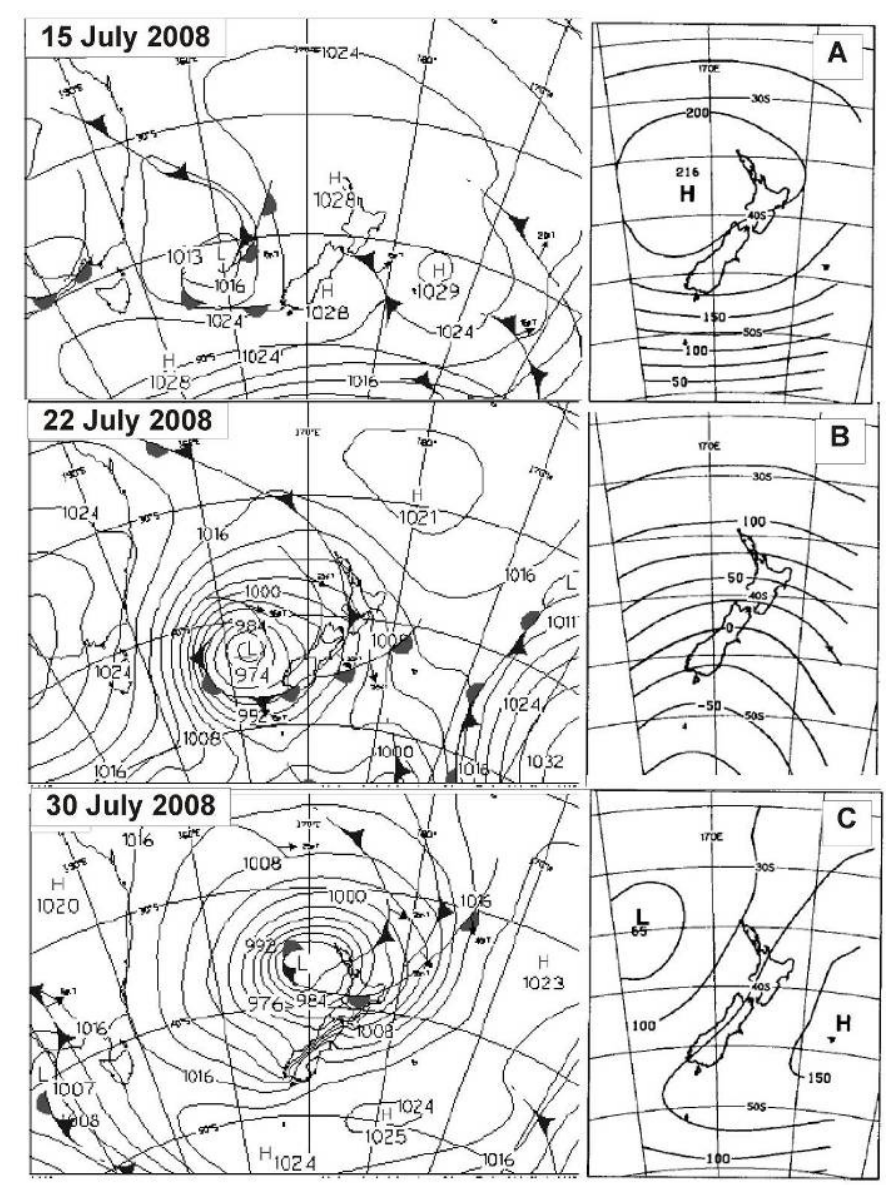

Figure 4.2: Examples of A. zonal flow (15 July), B. troughing (22 July) and C. blocking (30 July) regimes at 00UTC during the study period. Synoptic analysis charts provided by Metservice, and Kidson diagrams, showing composite patterns of $1000 \mathrm{hPa}$ height are from Kidson (2000).

\subsection{Results}

\subsubsection{Stable isotopes of water}

Stable isotope data are summarised in Table 4.1. On average $\delta^{18} \mathrm{O}$ and $\delta \mathrm{D}$ values of fresh snow were more negative at the TG site than at FJG by $1.15 \%$ and $9.24 \%$ o respectively. Overall, the data showed large variability, ranging from $\sim-9$ to $-24 \%$ for $\delta^{18} \mathrm{O}$ and from $\sim-57$ to $-180 \%$ o for $\delta \mathrm{D}$, resulting in a deuterium excess $(d)$ range of $\sim 5$ to 20. This large range suggests that local temperature alone is unlikely to be the dominant influence on the isotopic ratio. 
Table 4.1: Summary of $\delta^{18} \mathrm{O}, \delta \mathrm{D}$ and $d$ data for fresh surface snow samples from FJG and TG during winter 2008.

\begin{tabular}{|c|c|c|c|c|c|c|c|c|}
\hline \multirow{2}{*}{$\begin{array}{c}\text { Isotope } \\
\left(\%_{\mathrm{o}}\right)\end{array}$} & $\bar{x}$ & $\sigma$ & $\min$ & $\max$ & $\bar{x}$ & $\sigma$ & $\min$ & $\max$ \\
\cline { 2 - 9 } & -14.28 & 3.18 & -23.26 & -9.38 & -15.43 & 2.70 & -24.11 & -9.82 \\
$\delta^{18} \mathrm{O}$ & -102.04 & 28.11 & -177.30 & -57.80 & -111.28 & 23.06 & -183.30 & -58.60 \\
$\delta \mathrm{D}$ & 12.20 & 3.52 & 4.50 & 17.56 & 12.20 & 2.99 & 6.96 & 19.96 \\
$d$ & \multicolumn{4}{|c}{} & \multicolumn{3}{|c|}{ Franz Josef Glacier } \\
\hline
\end{tabular}

Comparison of pit and fresh snow from FJG, showed that in all cases both $\delta^{18} \mathrm{O}$ and $\delta \mathrm{D}$ values became less negative over time, with enrichment ranging from $0.26-2.0 \%$ for $\delta^{18} \mathrm{O}$ and $1.5-15.3 \%$ for $\delta \mathrm{D}$ (Figure 4.3). In addition, the $\delta^{18} \mathrm{O} / \delta \mathrm{D}$ slope relation had decreased in the older pit snow, with the amount of change in $d$ averaging $1.03 \%$.
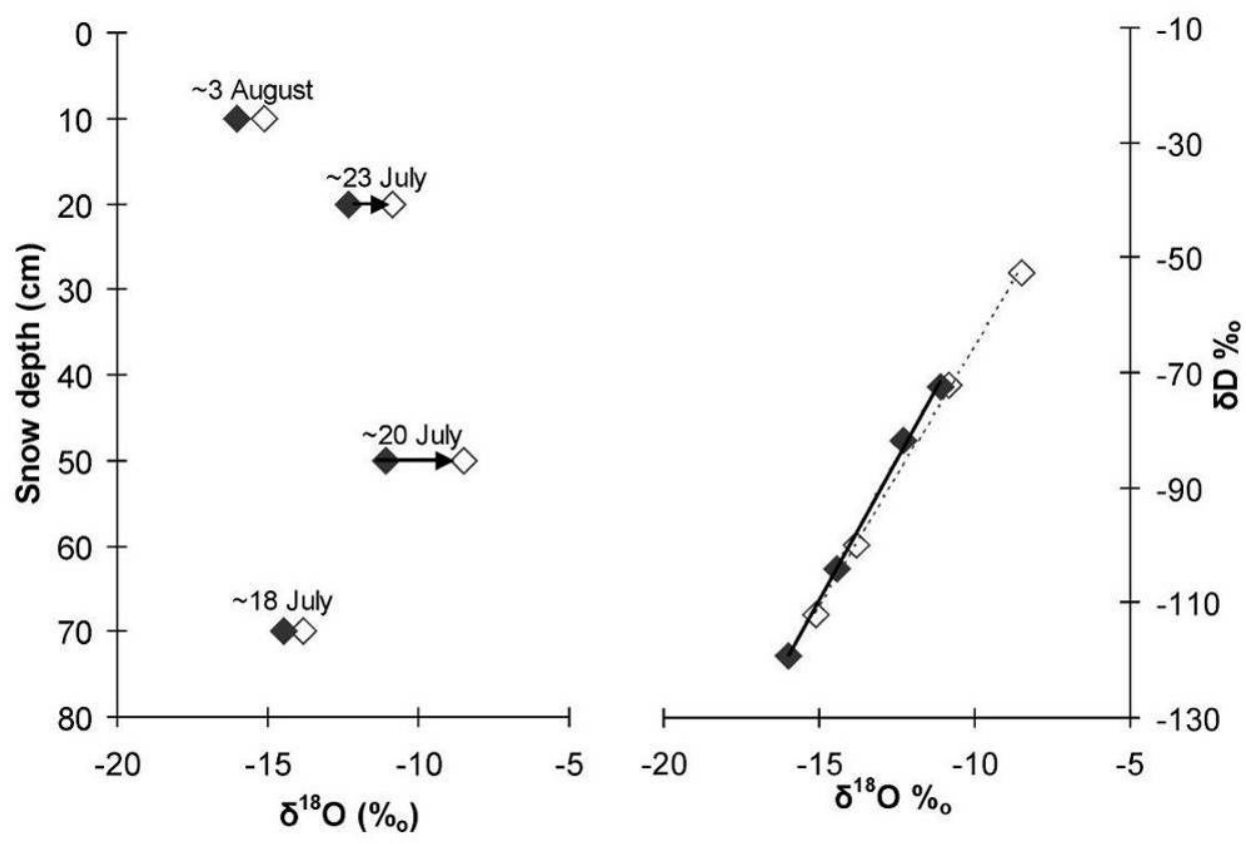

Figure 4.3: Changes in isotope concentrations between fresh (solid) and pit (hollow) snow over a $\sim 20$ day period at FJG during winter.

\subsubsection{Trace elements}

Trace element concentrations (ppb or ppt) in snow samples from both sites were found to be highly variable, with the standard deviation, for most elements, greater than the mean (Table 4.2). FJG recorded higher average concentrations for 11 of the 20 analysed elements, including marine species, for example $\mathrm{Na}, \mathrm{Mg}$, Ca and $\mathrm{Sr}$ (Millero, 2007). TG snow samples were higher in most terrestrial elements including $\mathrm{Pb}, \mathrm{Zr}$ and $\mathrm{V}$ (Gaillardet et al., 2007). 
Pearson's correlation analysis was conducted on trace element data to identify potential relationships. Three elements (Tl, Th and $\mathrm{U}$ ) were removed before analysis as the concentrations of a number of samples fell below detection limits. At FJG marine aerosols ( $\mathrm{Na}, \mathrm{Mg}$ and $\mathrm{Sr}$ ) are correlated above 95\% confidence interval, but not so at TG. In contrast, terrestrial elements are highly correlated at both sites: FJG shows high correlation between $\mathrm{Ce}$ and $\mathrm{La}$ as well as $\mathrm{Ca}$ and $\mathrm{Rb}$ and $\mathrm{TG}$ shows high correlations between $\mathrm{La}$ and $\mathrm{Ce}$, as well as $\mathrm{Pb}$ and $\mathrm{Rb}$ (Table 4.3).

Principle component analysis (PCA) of trace element concentrations (using varimax rotation) was also conducted. For FJG two PC's had eigenvalues $>1$; PC1 accounted for $67 \%$ of snow chemistry variance, with the top three loadings on $\mathrm{Ti}, \mathrm{Rb}$ and $\mathrm{Al}$, while PC2, representing $20 \%$ of the variance was dominated by $\mathrm{Mg}$, Na and V. At TG four PC's had eigen values $>1$; PC1 explained $40 \%$ of variance with top three loadings on terrestrial species Ce, As and Mn. PC2 explained 18\% of variance with loadings on marine elements, $\mathrm{Mg}, \mathrm{Na}$ and $\mathrm{Sr}$. PC3 explained $12 \%$ of variance $(\mathrm{Zr}, \mathrm{Y}$ and $\mathrm{Mg})$ and $\mathrm{PC} 4,7 \%$ of the variance ( $\mathrm{Ti}, \mathrm{V}$ and $\mathrm{Ba}$ ). 
Table 4.2: Trace element data including detection limits, average concentrations, standard deviations and accuracies. The concentrations of the first six elements are reported in parts per billion (ppb) and the remainder in parts per trillion (ppt).

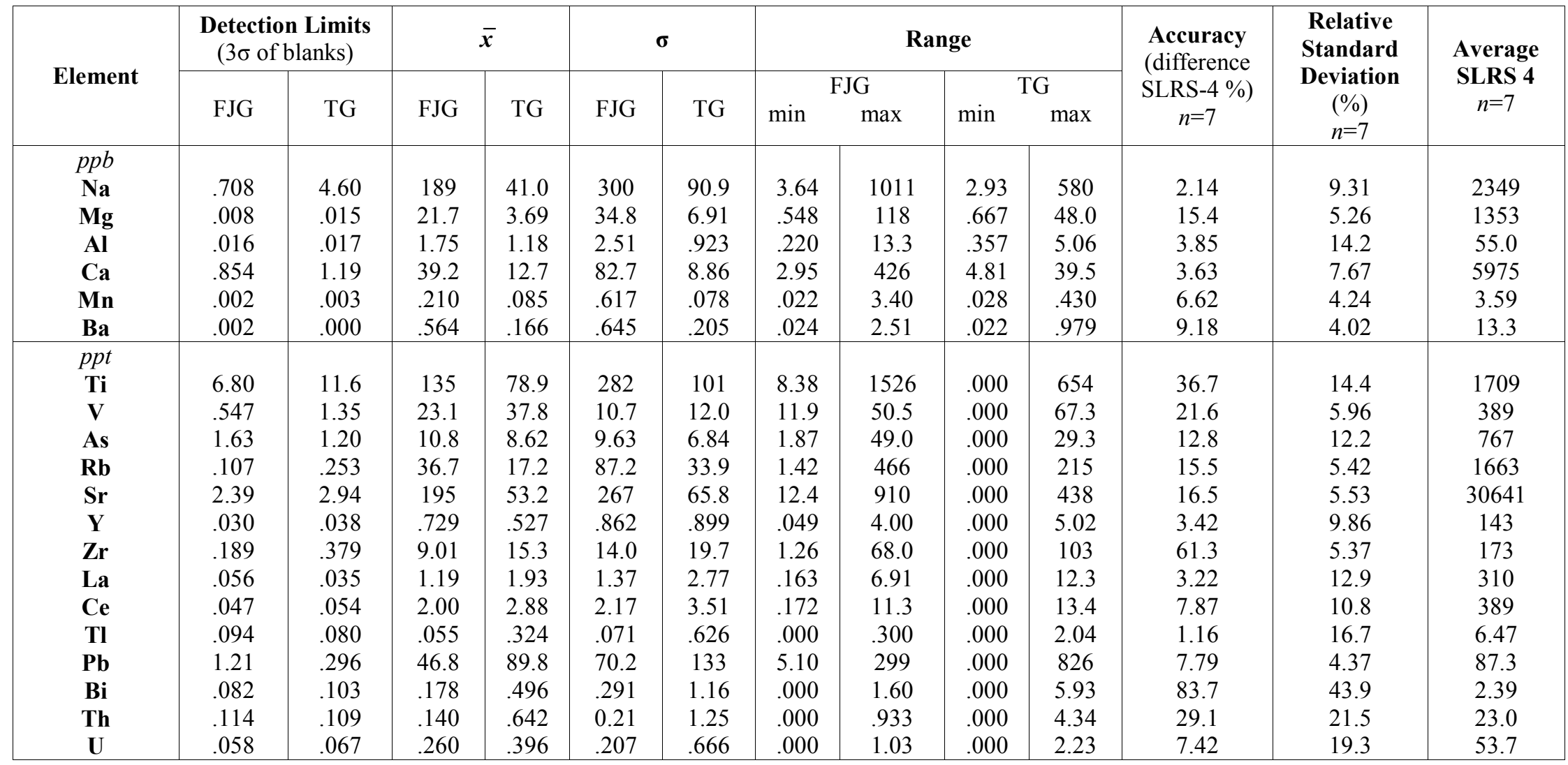


Table 4.3: Pearson's correlation coefficients of trace element chemistry for FJG ( $n=29)$ and TG $(n=45)$ snow samples.

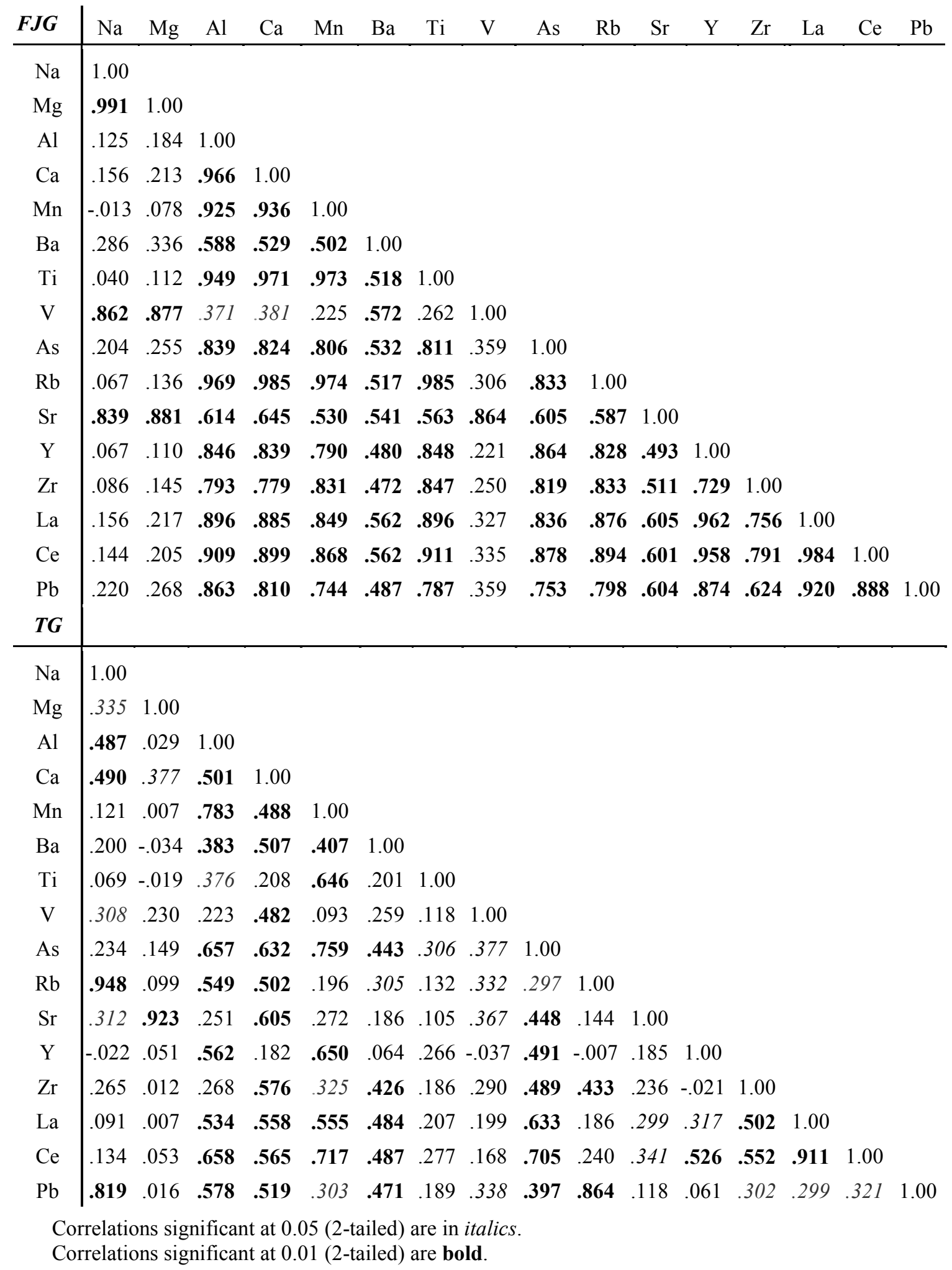




\subsection{Discussion}

\subsubsection{Temporal and spatial variability in stable water isotopes and trace}

elements

Comparison of $\delta^{18} \mathrm{O}$ and $\delta \mathrm{D}$ values between the sites showed in seven out of nine occasions when snow was recorded at both sites, TG samples were more negative than FJG samples (Figure 4.4). Isotopic depletion in precipitation occurs with increasing altitude, due to the preferential rain-out of heavier isotopes, as an air mass passes over an orographic barrier (Dansgaard, 1964; Guan et al., 2009). Precipitation also becomes more negative the further an air mass travels inland, with an increasing deficit in heavier isotopes due to preferential precipitation, often referred to as the continental effect (Dansgaard, 1964). Under prevailing westerly flow, an air parcel precipitating at TG has already passed over the Southern Alps, and the air parcel is likely to have precipitated at FJG. Consequently, moisture arriving under these conditions at TG should be isotopically lighter than at $\mathrm{FJG}$, and this was found $78 \%$ of the time. Lee-side increases in $\delta^{18} \mathrm{O}$, due to sub-cloud evaporation and moisture exchange (Guan et al., 2009), were not expected at TG due to the site's close proximity to the Southern Alps, and below freezing temperatures. However, on two occasions ( 23 \& 28 July) when snowfall was recorded at both sites, the isotopic trend was reversed. During these days, back trajectory analysis, $500 \mathrm{mb}$ geopotential height maps, and observed upper level wind direction, indicate that an easterly flow pattern dominated. During such conditions, an air parcel would reach the eastern (TG) site first, thereby reversing orographic effects and preferential rain out. Consequently snow precipitation during such an event is expected to show depleted values at FJG in comparison to TG.

While synoptic scale patterns are strongly modified by large daily variability, caused by local air flow changes, on average higher $\delta^{18} \mathrm{O}$ was recorded under zonal flow (Figure 4.4). Isotope values were highly variable during blocking and troughing regimes, although a rapid drop in $\delta^{18} \mathrm{O}$ was recorded during two troughing events on 20 July and 3 August (Figure 4.4). Precipitation under zonal flow tended to be lighter, with less aggressive air-mass lifting compared to troughing regimes. This may result in slower isotopic rain-out compared to faster-moving frontal systems. The sharp drop in $\delta^{18} \mathrm{O}$ recorded during troughing on two occasions coincided with south to south-west changes 
in airflow, typical as frontal systems crossed the Southern Alps (Sturman and Tapper, 2006).

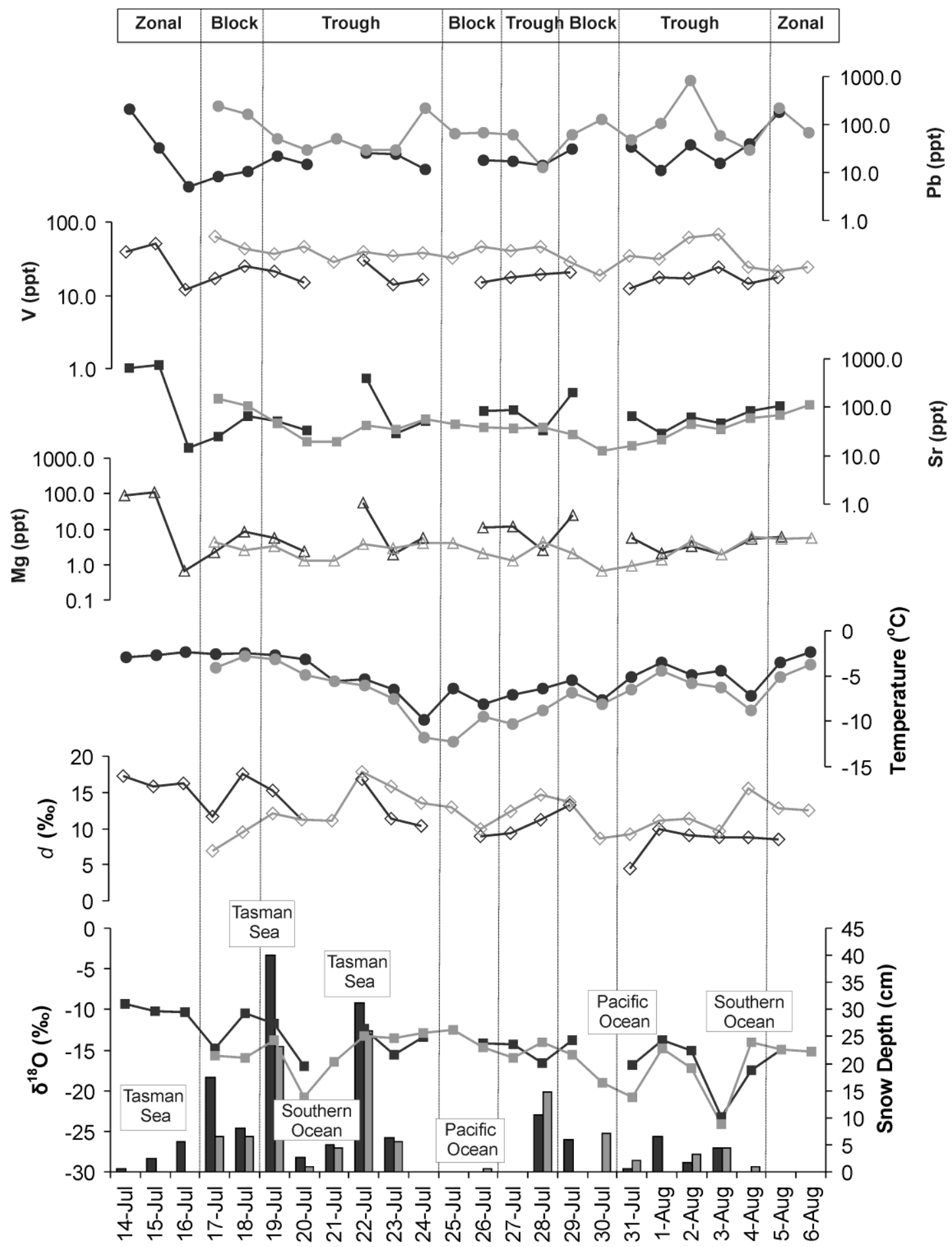

Figure 4.4: Daily variability in $\delta^{18} \mathrm{O}, d$, temperature, $\mathrm{Mg}, \mathrm{Sr}, \mathrm{V}$ and $\mathrm{Pb}$ at FJG (dark grey) and TG (light grey) during the study period under the different synoptic regimes of Kidson (2000). Moisture source regions for specific storm events are noted above snow accumulation data. 
No statistically significant correlation was found between $\delta^{18} \mathrm{O}$ and daily average temperature (or snow surface temperature) at either site, despite some days appearing to co-vary (Figure 4.4). Other climate parameters were tested against $\delta^{18} \mathrm{O}$, including humidity and wind direction, but likewise did not produce any statistically significant relationships. Instead, the data indicate that the isotopic signature on the scale of individual events might be dominated by air mass pathway and moisture source origin.

Despite the strong influences of air mass trajectory, $\delta^{18} \mathrm{O}$-temperature relationships have been found on maritime glaciers. Regression analysis between snowpack and storm temperature on glaciers in the Canadian Rocky Mountains resulted in an adjusted $r^{2}=$ 0.47 (Sinclair and Marshall, 2009), and in annual layers on Tasman Glacier, winter season snow was less enriched than snow from other seasons (Ruddell and Budd, 1990). We propose that the lack of relationship found in this study lies in the briefness of our observations. A longer study, encompassing at least a full seasonal cycle is more likely to detect a temperature/isotopic ratio relationship in New Zealand ice.

Variability in trace element concentration also occurred between sites, but due to the variable nature of data it was difficult to discern trends between different synoptic conditions (Figure 4.4).The western (FJG) glacier site recorded higher concentrations of marine elements (e.g. Na and $\mathrm{Sr}$ ) with highest concentrations coinciding with zonal flow and a strong NW storm on 22 July. Prevailing westerly flow explains why FJG tended to have a clearer marine signal, with the signal appearing to dampen as moisture travels across the Southern Alps. Increased travel distance and orographic lifting (Gilfedder et al., 2007) results in progressive removal of marine elements as the air mass crosses the Southern Alps.

The TG site generally recorded higher concentrations of terrestrial elements (e.g. $\mathrm{Pb}$, V), attributed to the larger landmass over which moisture has to travel to reach the site, and its proximity to industrialised cities. Vanadium, for example, is associated with industry and fossil fuels (Moskalyk and Alfantazi, 2003), but is also found in schist and greywacke, prominent rock types in the Southern Alps (Dow, 1998). High correlation between $\mathrm{Rb}$, Ce and La concentrations at FJG may indicate dust originating from greywacke rock, whereas reduced correlation observed between these elements at TG would suggest a combination of natural and anthropogenic sources. 
$\mathrm{Pb}$ was often highest east of the Southern Alps, indicating that the $\mathrm{Pb}$ source is the more industrialised eastern South Island, although $\mathrm{Pb}$ concentrations are high in greywacke rock in comparison to the average crustal abundance (Kennedy and Gadd, 2003). High $\mathrm{Pb}$ levels were also found in dust samples from ice on the Fox and Franz Josef Glaciers (Marx et al., 2005). After comparison to potential local and Australian sources, Marx et al. (2005) concluded that the $\mathrm{Pb}$ was not of New Zealand origin, instead derived from long-travelled Australian dust. In our study, high $\mathrm{Pb}$ concentrations on the eastern Tasman Glacier appear to coincide with airflow from the SE or S, indicating that during our observations some portion of the $\mathrm{Pb}$ is likely attributable to a New Zealand source. It is important to note that $\mathrm{Pb}$ is a component of aviation fuel, and during winter, the Tasman Glacier accumulation area is subject to regular helicopter landings as part of heli-sking operations. We find highest $\mathrm{Pb}$ concentrations at FJG in the first snow sample, collected soon after helicopter activity. Further research is needed to establish concentrations and dispersion of $\mathrm{Pb}$ in relation to local sourced (aircraft activity on these glaciers) and more distant sources from New Zealand and elsewhere.

\subsubsection{Determining moisture provenance and within storm variability}

Tracing moisture source regions and airmass trajectories improves our understanding of regional climate systems and helps to distinguish climate variability from climate trends (Jansson et al., 2007). The deuterium-excess parameter (d) originally defined by Dansgaard (1964) is used as an indicator of precipitation source region and/or changes at the source region (Araguas-Araguas et al., 2000; Schwikowski et al., 2005; Jouzel et $a l ., 2007)$. Values of $d$ vary seasonally, and generally high values indicate a warm/dry source region and low values a cold/humid source region (Schwikowski et al., 2005). Average $d$ during the study (12.2) was higher than the long-term average (10) recorded for July/August precipitation in Invercargill (IAEA, 2010), situated near the southern tip of the South Island.

Large deuterium excess values can be an indication of variability in kinetic fractionation during initial evaporation from the ocean and/or a more complex evaporation history, including re-evaporation of moisture from land surfaces and mixing along air-mass trajectories (Aizen et al., 2009). High $d$ values recorded from alpine sites have been attributed to effects of moisture recycling and sub-cloud evaporation (Froehlich et al., 
2008). Sub-cloud evaporation is small during winter, so the high $d$ values recorded at both sites during this study may be attributable to moisture recycling.

Back-trajectory analysis can assist in providing an estimation of moisture source regions (Kahl et al., 1997; Sinclair and Marshall, 2009), but absolute certainty is limited by spatial and temporal representivity of meteorological data (Kahl, 1993). Even so, compared to upper level wind direction and back-trajectory analysis (Figure 4.5), values of $d$ did appear to be sensitive to moisture provenance. High $d$ values $(\sim 17)$ were associated with snow likely derived from the warm Tasman Sea $(n=11)$, and lower values $(\sim 10)$ were found in snow which probably originated in the colder/humid Southern Ocean $(n=3)$. Moisture travelling over the landmass (most likely from a Pacific Ocean source) had intermediate $d$ values $(n=4)$. It is important to note that sample sizes for the latter two categories are small in comparison to samples from a Tasman Sea source. The predominant snow moisture source during the winter survey appeared to be the Tasman Sea, with $82 \%$ (FJG) and $68 \%$ (TG) of snowfall measured from this source.
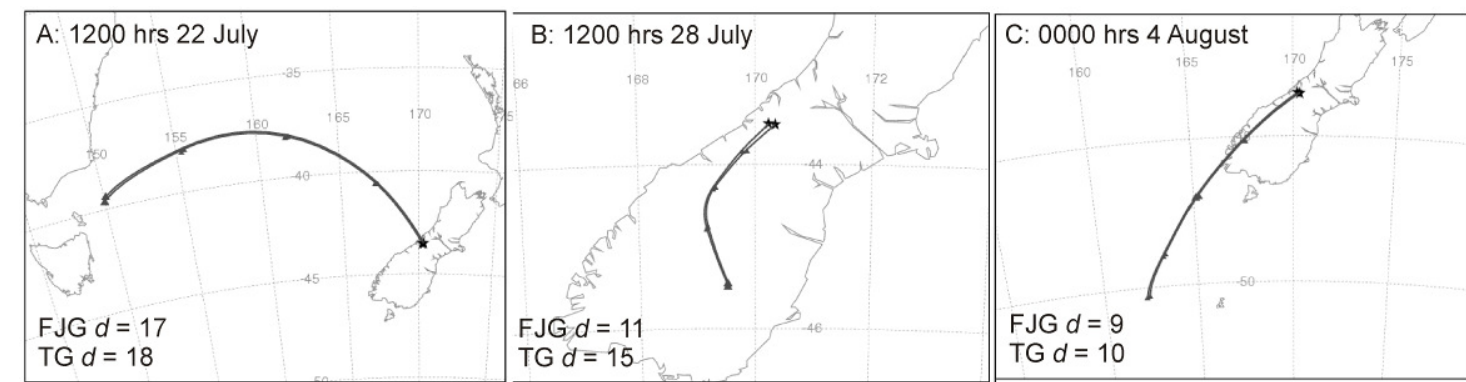

Figure 4.5: Back-trajectory airflow analysis (2300 $\mathrm{m}$ a.s.1.) showing different water vapour pathways during snow storm events; A. Tasman Sea, B. overland and C. Southern Ocean. The deuterium excess $(d)$ recorded in snow samples from both sites on this days is shown in the bottom left corner of each map.

In addition to deuterium excess, variations in trace element composition can also provide a 'finger-print' of moisture source region (Legrand and Mayewski, 1997; Gabrielle et al., 2008). Due to the intensive on-site sampling strategy adopted for this study, associations between snow samples and individual storm events were possible. 
Moisture source signal was recorded in trace element data from FJG and TG, with a stronger marine signal contained in Tasman Sea storms, and higher levels of pollutants in snow arriving from the Southern or Pacific Oceans (Figure 4.4). The source signal was clearer at FJG, which showed large difference in marine aerosols between the Tasman Sea and other moisture source areas. The smaller marine signal at TG meant there was less difference in those elements between successive storms, but higher concentrations of terrestrial components were seen in snow from a Southern Ocean source or during easterly flow. Therefore snow from the eastern side of the Southern Alps could be useful for tracking chances in atmospheric pollutants while snow from the western side appears to provide a clearer moisture source signal.

\subsubsection{Post-depositional modification}

At FJG enrichment of $\delta^{18} \mathrm{O}$ and $\delta \mathrm{D}$ was recorded in older pit snow in comparison to its initial fresh value (Figure 4.3). This enrichment appeared not to be related to depth (time) or density changes. The $10 \mathrm{~cm}$ snow depth temperature, (measured daily at 0900 hrs), remained below freezing throughout the study, although positive air temperatures (up to $6.9^{\circ} \mathrm{C}$ ) were recorded on 6 of the 24 days during mid-afternoon. Three snow pits were dug during the study, and all showed snow temperatures tending towards $0^{\circ} \mathrm{C}$ at 1.2 metres depth. Temperature in the sampled snow pit was $-0.8^{\circ} \mathrm{C}$ at $80 \mathrm{~cm}$ depth. Studies in the European Alps (Moser and Stichler, 1970) and in Sierra Nevada, California (Taylor et al., 2001), have found that even during winter metamorphic processes enrich the snowpack. Indeed, such changes can occur rapidly ( $\sim$ days) (Moser and Stichler, 1970), as snow crystals enlarge and water vapour migrates from convex to concave crystal surfaces (Whillans and Grootes, 1985; Dewalle and Rango, 2008). Isotopic enrichment can also be driven by evaporation/sublimation (Earman et $a l ., 2006)$, and even without surface heating, wind ventilation can drive snow sublimation if vapour gradients allow (Neumann and Waddington, 2004).

Percolation of melt water through the snowpack is known to modify both the isotopic and trace element signal, with isotopic fractionation occurring during melt/refreeze processes (Arnason, 1969; Hashimoto et al., 2002; Zhou et al., 2008) and elution and mobility of ions by melt water percolation (Goto-Azuma et al., 1993; Raben and Theakstone, 1994; Yoshimura et al., 2000; Shiraiwa et al., 2002; Kameda et al., 2003). It has been suggested that a trend in $\delta^{18} \mathrm{O}$ can be maintained on temperate glaciers for 
some months into the summer season when surface melt re-freezes in the snowpack, creating ice layers which prevent further melt water percolation (He et al., 2002). In fact preservation of climate information has been demonstrated in cores from the Penny Ice Cap, Baffin Island, Canada, where over $40 \%$ of annual accumulation can be subject to melt-refreeze processes (Fisher et al., 1998; Goto-Azuma et al., 2002).

Results of this study demonstrate high variability in isotope values between successive storms, mixing of old and new snow due to wind redistribution (Purdie et al., 2011b), plus enrichment from metamorphic processes, which when combined, mean that the isotopic signal left in the snowpack at the end of winter can be complex. Over the course of our observations, the shift in isotopic ratios was systematic towards heavier values, which is most likely attributable to a combination of snow metamorphism and wind sublimation. Our extremely high sampling resolution means that even slight offset between actual precipitation of an event and neighbouring material that might be mixed during wind scouring can have significant effects. Without sampling over at least one full seasonal cycle, we cannot determine the full effect this can have. However, it is likely that some variability will be smoothed when sampled at seasonal rather than hourly or daily resolution.

\subsection{Conclusions}

Differences in stable water isotopes, and trace elements, were recorded in winter snow accumulation on glaciers east and west of the Southern Alps over a 24 day period. The dominant westerly airflow and orographic processes result in snow being isotopically depleted when deposited on the eastern (Tasman) glacier, but this trend is reversed under easterly flow conditions, which are less common. Trace elements were likewise influenced by the dominant westerly flow, with snow on Franz Josef Glacier containing a stronger marine signal and less terrestrial pollutants in comparison to Tasman Glacier. Freshly deposited snow was found to contain information on moisture provenance, in both deuterium excess and trace element variability. We were able to identify three different moisture source groupings (Tasman Sea, Southern Ocean and Overland/Pacific Ocean). From this study, we conclude that a variety of interesting climate information is contained in snow accumulating on New Zealand glaciers, and that potential exists for these sites to contribute further to climate research studies. 
However post-depositional modification of signals occurred during the short 24 day period in winter. Such modifications are likely to be more pronounced during summer, including the possibility of substantial melt. While this study provides a high resolution, systematic, geochemical snap-shot, identifying some of the major influences on geochemical records from New Zealand glaciers, clearly more research is required, such as obtaining longer records from either side of the orographic barrier, containing at least one and preferable a number of seasonal cycles. 


\section{Inter-annual variability in net accumulation on Tasman Glacier and its relationship with climate.}

Mid-latitude maritime glaciers are already responding quickly and directly to climate warming. This response is expected to continue, and result in maritime glaciers making a large contribution to sea level rise over the coming decades. Maritime glaciers in the New Zealand Southern Alps provide an opportunity to learn more about climate-mass balance relationships in a high precipitation setting, and how these relationships might change in the future. Ice core and direct glaciological measurements are used to construct a 24-year record of net accumulation, the longest of its type in New Zealand. We demonstrate that variations in net accumulation on Tasman Glacier are more strongly influenced by temperature than by precipitation. Further, it is temperature during the ablation season that exerts most control. Atmospheric circulation patterns, in particular the state of the El Niño Southern Oscillation (ENSO) and Southern Annular Mode (SAM), were found to influence net accumulation. When the SAM and the ENSO are in their positive phase, they enhance easterly and northerly wind anomalies increasing temperature in the Southern Alps region and resulting in more negative glacier mass balance. Conversely, when in negative phase, westerly and southerly wind anomalies predominate, decreasing temperature in the Southern Alps region and resulting in more positive glacier mass balance. However, relationships between glacier mass balance and these atmospheric circulation modes are not straight forward, with some of the lowest net accumulation years associated with inverse polarity between the SAM and the ENSO.

\subsection{Introduction}

As climate changes, many long-term glacier mass balance monitoring programmes are reporting significant ice loss on alpine glaciers world wide (WGMS, 2008). Modelling studies indicate that glacier mass balance could be almost twice as sensitive to a temperature increase than a temperature decrease of the same magnitude (Kuhn, 2003). Anecdotal evidence indicates that multiple years of net accumulation can be removed in a single summer with above average temperatures. Such could be the impact of a single hot year, that improved understanding of climate-mass balance relationships is essential. 
This is especially relevant because many of the warmest years of the past century have occurred during the last few decades (IPCC, 2007).

Maritime glaciers are particularly sensitive to temperature changes (Oerlemans, 1992; 1997; Braithwaite and Zhang, 2000; Anderson et al., 2008; Anderson et al., 2010), but due to difficulty in measuring mass balance in these environments, where annual accumulation can exceed $\sim 6$ metres water equivalent ( $\mathrm{m}$ w.e.), there are few long-term records, and none from the mid-latitudes of the Southern Hemisphere. Longer records of mass balance from these regions would provide an opportunity to document and understand the processes controlling inter-annual variability in mass balance including the influence of changing atmospheric circulation.

Previous studies have identified relationships between the El Niño Southern Oscillation (ENSO) and glacier fluctuations in New Zealand and South America (Fitzharris et al., 1997; Clare et al., 2002; Chinn et al., 2005b; Fitzharris et al., 2007; Leiva et al., 2007). However, as yet, the potential influence of the Southern Annular Mode (SAM) on glacier mass balance has not been fully considered (Clare et al., 2002; Fitzharris et al., 2007), even though it is known to explain $~ 35 \%$ of Southern Hemisphere climate variability (Marshall, 2007). The SAM has been linked to changes in Australian precipitation (Meneghini et al., 2007; Karpechko et al., 2009), Antarctic temperature and precipitation (van den Broeke and van Lipzig, 2004; Tedesco and Monaghan, 2009), Antarctic sea ice extent (Lefebvre et al., 2004), and more recently to temperature and precipitation variability in New Zealand (Ummenhofer and England, 2007; Kidston et al., 2009). Therefore, it is expected that this annular mode could provide some forcing to inter-annual variability in mass balance on glaciers in the Southern Alps of New Zealand.

There has been discussion as to whether New Zealand glaciers are more sensitive to changes in precipitation (Hessell, 1983) or temperature (Salinger et al., 1983; Anderson and Mackintosh, 2006). Lack of long-term (>10yrs) mass balance measurement means that such research has relied on utilising records of glacier terminus position (Hooker and Fitzharris, 1999), mass balance proxies, for example, the equilibrium line altitude (Fitzharris et al., 1997; Clare et al., 2002), or model output (Woo and Fitzharris, 1992; Oerlemans, 1997; Anderson et al., 2006; Anderson and Mackintosh, 2006). 
An important component of glacier mass balance is annual net accumulation. In temperate climates, annual net accumulation is the resultant effect of winter snow accumulation and summer melting, and represents the amount of 'fuel' available for glacier nourishment. Research on some mid-latitude maritime glaciers previously identified that winter balance (i.e. precipitation) exerted most control on inter-annual variability in glacier mass balance, for example in Norway (Nesje et al., 2000) and western North America (Walters and Meier, 1989). However, other research is showing that warmer, drier summers are overriding this precipitation influence (Josberger et al., 2007; Winkler et al., 2009). In New Zealand, snow accumulation on glaciers can occur year around, but most snow accumulation occurs during the winter and spring seasons (April to October), with a slightly shorter (November-March) ablation season (Fitzharris et al., 1992). Relationships have been identified between atmospheric circulation and decadal-scale advance and retreat of New Zealand glaciers (Hooker and Fitzharris, 1999; Fitzharris et al., 2007), but seasonal controls on inter-annual variability in net accumulation have not been examined.

Ice cores provide records of net accumulation (Mayewski and White, 2002), with annual layers identifiable via stratigraphy, stable isotopes and trace element concentrations (Legrand and Mayewski, 1997; Aizen et al., 2009), as well as by biological markers, for example, pollen (Nakazawa et al., 2005) or algae (Yoshimura et al., 2000). Ice core interpretation in maritime climates is more challenging than in polar areas, due to the presence and movement of melt-water (Koerner, 1997). For example, elution of ions and homogenisation of stable isotopes has been recorded in cores from Norway (Raben and Theakstone, 1994), Switzerland (Eichler et al., 2001), Patagonia (Shiraiwa et al., 2002; Schwikowski et al., 2005), Nepal (Yoshimura et al., 2000) and the Russian Altai (Kameda et al., 2003). However, some potential markers are more likely to stay in situ than others. For example, fine dust particles may persist while soluble ions are removed (Raben and Theakstone, 1994; Kameda et al., 2003), and useful climate information was found to persist in an ice core retrieved from Baffin Island, Canada, a site with significant melting (Fisher et al., 1998; Goto-Azuma et al., 2002). The potential to derive net accumulation data from ice cores retrieved from New Zealand glaciers is yet to be fully explored, although information pertaining to moisture provenance is found in fresh winter snow (Purdie et al., 2010). 
The New Zealand Southern Alps contain over 3100 glaciers (Chinn, 1996). Tasman Glacier is the largest, covering an area of $\sim 95 \mathrm{~km}^{2}$ and containing $\sim 30 \%$ of New Zealand's ice volume (Chinn, 2001) (Figure 5.1). But like many glaciers globally, Tasman Glacier has been undergoing significant ice loss, and is now rapidly calving into a pro-glacial lake (Kirkbride and Warren, 1999; Röhl, 2006). Through a combination of melting, downwasting and calving, the Tasman Glacier is losing volume at around $\sim 0.1 \mathrm{~km}^{3}$ per year (Thomas, 2009; Chinn et al., submitted). However, some mass gain was recorded in the accumulation zone during the mid 1980s and 1990s (Chinn et al., submitted), and some fast responding glaciers, for example the Fox and Franz Josef Glaciers subsequently advanced (Chinn et al., 2005b; Purdie et al., 2008).
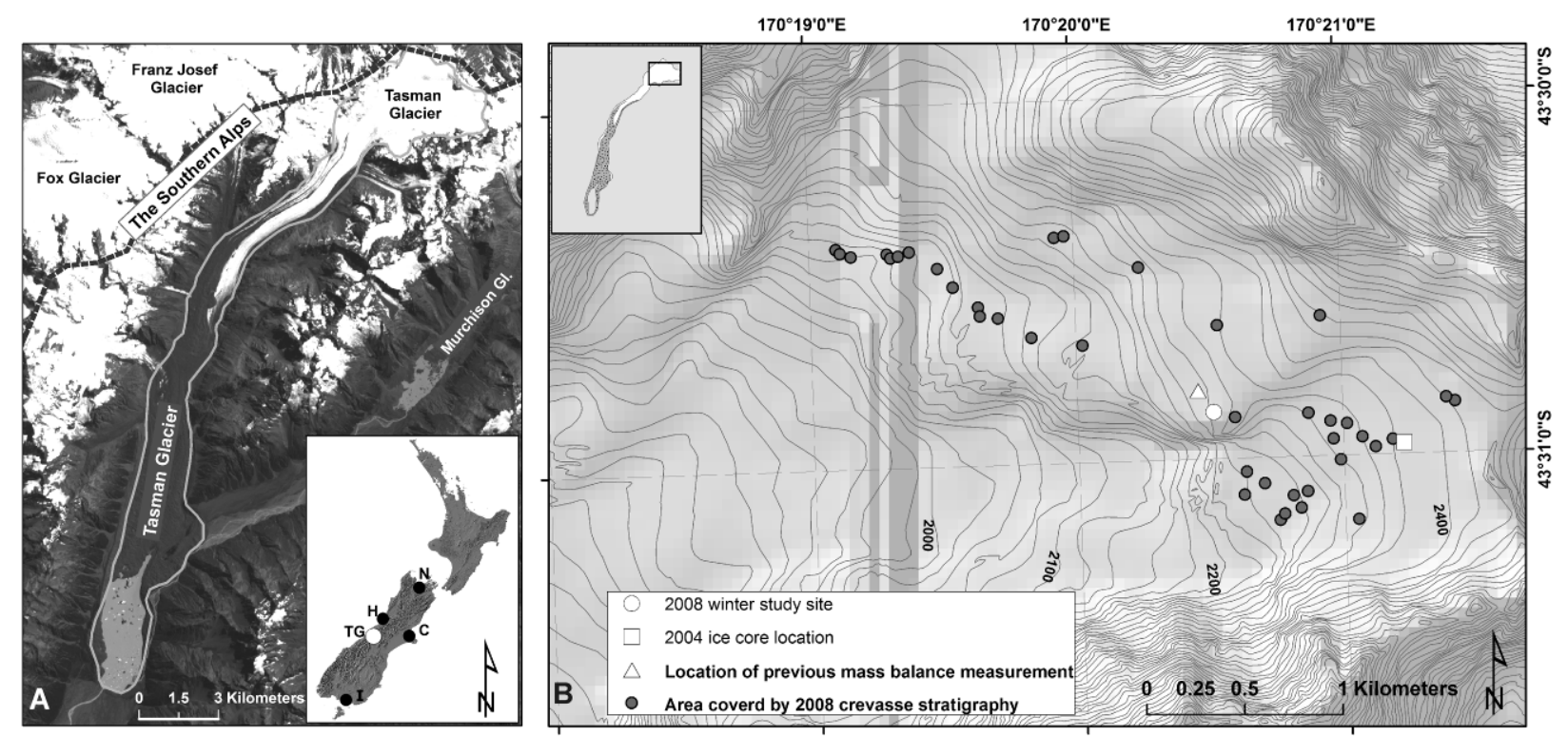

Figure 5.1: A. The location of the Tasman Glacier (TG) in relation to the Southern Alps and other large glaciers. The insert shows the location of the study site in relation to New Zealand, and the locations used to derive flow indices, $\mathrm{N}=$ Nelson, $\mathrm{C}=$ Christchurch, $\mathrm{I}=$ Invercargill and $\mathrm{H}=$ Hokitika. B. Tasman Glacier accumulation area, including a previous net accumulation survey, the location of previous mass balance measurements, and the ice core site.

In 2004 an ice core was taken from the accumulation area of the Tasman Glacier (Morgenstern et al., 2004). This was the first deep ice core taken from a New Zealand glacier for comprehensive analysis. This core helps fill a data gap in New Zealand mass balance records. By combining net accumulation data derived from the ice core, with previous direct measurements, more than 20 years of net accumulation data can be gained, the longest record for any New Zealand glacier (Anderton and Chinn, 1978; Chinn, 1994; Anderson et al., 2010). 
We use this composite record to:

1. Analyse inter-annual variability in net accumulation on Tasman Glacier in relation to variations in climate and atmospheric circulation.

2. Evaluate whether annual or seasonal climate conditions exert more control on net accumulation variability.

\subsection{Data \& Methodology}

\subsubsection{Measurement of net accumulation on Tasman Glacier}

Net snow accumulation has been measured intermittently on Tasman Glacier since 1957 (Goldthwait and McKellar, 1962; Anderton, 1975; Chinn, 1994; Ruddell, 1995; Purdie et al., 2011a). Analysis of an ice core retrieved from the Tasman glacier in 2004 has added an additional 2 years net accumulation to the record (see results). By combining these data, Tasman Glacier has 24 years of net accumulation measurement (Table 5.1 and Figure 5.2). Although these data are discontinuous, they provide the longest record of measured accumulation for any New Zealand glacier.

Table 5.1: Net accumulation measurements on Tasman Glacier.

\begin{tabular}{|c|c|c|c|c|}
\hline Year & $\begin{array}{c}\text { Net } \\
\text { Accumulation } \\
\text { (m w.e.) }\end{array}$ & Study & Notes & $\begin{array}{c}\underset{\text { ELA }}{\text { A }} \\
(\mathbf{m} \text { a.s.l. })\end{array}$ \\
\hline $\begin{array}{l}1959 \\
1960\end{array}$ & $\begin{array}{l}3.10 \\
5.53\end{array}$ & $\begin{array}{c}\text { (Goldthwait and McKellar, } \\
\text { 1962) }\end{array}$ & Stakes and pits & $\begin{array}{c}1830 \\
-\end{array}$ \\
\hline $\begin{array}{l}1964 \\
1965 \\
1966 \\
1967 \\
1968 \\
1969 \\
1970 \\
1971 \\
1972 \\
1973 \\
1974 \\
1975\end{array}$ & $\begin{array}{l}5.16 \\
6.01 \\
5.12 \\
2.40 \\
5.54 \\
4.58 \\
1.25 \\
1.96 \\
3.63 \\
4.45 \\
2.78 \\
1.83\end{array}$ & $\begin{array}{c}\text { (Chinn, 1968; Chinn, 1969; } \\
\text { 1994) } \\
\text { (Chinn et al., 2005) } \\
\text { (Anderton, 1975) }\end{array}$ & Stakes, pits \& coring & $\begin{array}{c}1750 \\
- \\
1700 \\
1970 \\
1630 \\
1690 \\
2200 \\
1930 \\
1850 \\
1900 \\
1945 \\
2050\end{array}$ \\
\hline $\begin{array}{l}1987 \\
1988 \\
1989 \\
1990 \\
1991\end{array}$ & $\begin{array}{l}4.68 \\
3.12 \\
3.76 \\
1.34 \\
3.80\end{array}$ & (Ruddell, 1995) & Crevasse stratigraphy & $\begin{array}{l}1761 \\
1840 \\
1760 \\
2100 \\
1755\end{array}$ \\
\hline $\begin{array}{l}2004 \\
2005\end{array}$ & $\begin{array}{l}5.87 \\
4.60\end{array}$ & $\begin{array}{c}\text { pers. comm., Morgenstern \& } \\
\text { Mayewski (2009). } \\
\text { \& analysis this study }\end{array}$ & $\begin{array}{c}\text { Tasman Glacier Ice } \\
\text { Core }\end{array}$ & $\begin{array}{l}1750 \\
1750\end{array}$ \\
\hline $\begin{array}{l}2007 \\
2008 \\
2009\end{array}$ & $\begin{array}{l}3.97 \\
2.43 \\
3.95\end{array}$ & $\begin{array}{c}\text { this study } \\
\text { also see } \\
\text { Purdie } \text { et } \text { al.,(2011a) }\end{array}$ & Crevasse stratigraphy & $\begin{array}{l}1796 \\
2025 \\
1969\end{array}$ \\
\hline
\end{tabular}




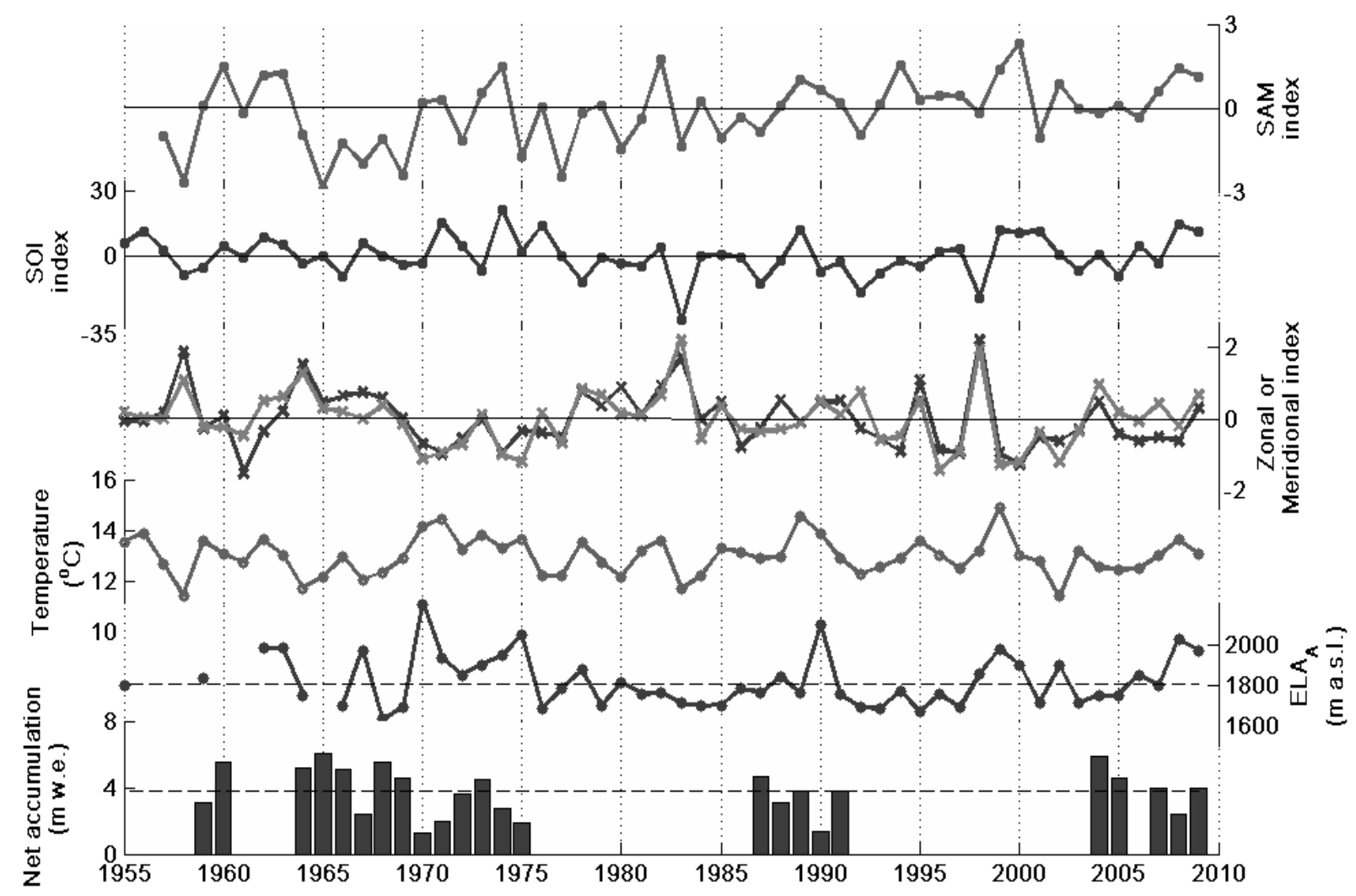

Figure 5.2: Inter-annual variability in net accumulation and the ELA $A_{A}$ on Tasman Glacier in relation to ablation season temperature, zonal (dark grey) and meridional (light grey) flow anomalies, and the SOI and the SAM. Average net accumulation and the ELA $\mathrm{A}_{0}$ are represented as dashed lines.

One possible limitation of the accumulation data presented in this study is that they have been collected at different sites (Figure 5.1), using different methods. An assessment of the crevasse stratigraphy method found little difference $(\sim 0.15 \mathrm{~m}$ w.e. $)$ in deriving an annual estimate of accumulation from multiple crevasse measurements, whether by interpolation, clustering, or using the population median or mean; the mean is reported here. Sites for digging snow pits or coring are usually chosen to be relatively low gradient, and are thereby less affected by topographic influences on snow accumulation or ablation. Net accumulation has been measured in crevasses on Tasman Glacier in close proximity to other previous measurement sites. In 1987, a crevasse measured close to the 1960-70s measurement site (Figure 5.1) recorded net accumulation that was $0.04 \mathrm{~m}$ w.e. less than the mean derived from all crevasse measurements that year. In 2008 a crevasse measured in a similar location to the ice core site (Figure 5.1), recorded net accumulation that was $0.32 \mathrm{~m}$ w.e. higher than annual mean for that year. Although a limited comparison, it does indicate that a 
possible error of $\pm \sim 0.36 \mathrm{~m}$ w.e. might result when comparing net accumulation measurements at different measurements sites taken by different methodologies. Although not ideal, combining data from different sites and different methodologies is still considered worthwhile because no other data of this type exists

\subsubsection{The equilibrium-line-altitude record}

A glacier's transient annual end-of-summer-snowline (EOSS) indicates the elevation where annual mass balance is zero, and is referred to as the annual equilibrium line altitude $\left(E^{2} A_{A}\right)\left(\right.$ Meier and Post, 1962). The ELA $A_{A}$ is a useful mass balance proxy, and has been used to estimate changes in glacier mass balance in areas where direct measurement is lacking (Braithwaite, 1984; Chinn et al., 2005a). The EOSS has been intermittently recorded for Tasman Glacier since 1955, with a near-complete record from 1977 onwards (Figure 5.2), due to its inclusion in an annual aerial glacier survey conducted by the National Institute of Water and Atmospheric Science (NIWA) (Chinn, 1995; Willsman et al., 2009). The derived steady state ELA (ELA $)$ for Tasman Glacier for the EOSS study period is $1806 \mathrm{~m}$ a.s.1.; years with higher (lower) $\mathrm{ELA}_{\mathrm{A}}$ are representative of negative (positive) glacier mass balance (Willsman et al., 2009). The regional significance of the Tasman Glacier annual ELA $\mathrm{A}_{\mathrm{A}}$ record can be assessed by comparing it to the mean annual Southern Alps ELA, a composite of 50 index glaciers. The correlation $\left(r^{2}\right)$ for the period 1977-2009 is 0.83, indicating that the Tasman Glacier $E A_{A}$ can be considered representative of wider glacier mass balance conditions in the New Zealand Southern Alps (Willsman et al., 2009). The Tasman Glacier ELA A $_{\mathrm{A}}$ record spans 50 years, and over this time there has been gradual downwasting (thinning) of the glacier tongue. Average downwasting in the region of observed annual ELA variation (1500-2200 m a.s.l) from 1965-2008 is $13 \mathrm{~m}$. This amount of downwasting is smaller than the estimated accuracy in deriving the $\mathrm{ELA}_{\mathrm{A}}$ from oblique aerial photographs $( \pm 20$ $\mathrm{m})$ therefore no correction is applied to the $\mathrm{ELA}_{\mathrm{A}}$ dataset to account for this. However, this issue may need to be addressed in future applications. In this study the Tasman Glacier ELA $\mathrm{A}_{\mathrm{A}}$ record is used in addition to the intermittent net accumulation data to help assess glacier-climate relationships. 


\subsubsection{Analysis of the Tasman Glacier ice core}

A $54 \mathrm{~m}$ ice core was obtained from the accumulation area of Tasman Glacier in October 2004 (Morgenstern et al., 2004). Although ice thickness at the site was estimated at $\sim 130 \mathrm{~m}$ (Thomson, 2005), complications during the drilling process prevented sampling below $54 \mathrm{~m}$ depth. The core was extracted in $\sim 1 \mathrm{~m}$ sections, with each section immediately sealed in plastic, labelled, and kept frozen at the site. The frozen core was transported to, and stored at, GNS Science Ice Core Research Facility, Lower Hutt, New Zealand, and in $2008 \mathrm{sub}$-sampled at $10 \mathrm{~cm}$ resolution using a continuous melter (Osterberg et al., 2006) in sterile conditions. Samples derived from the most inner section of the core were analysed for major ions $\left(\mathrm{Na}^{+}, \mathrm{K}^{+}, \mathrm{Mg}^{2+}, \mathrm{Ca}^{2+}, \mathrm{MS}^{-\mathrm{Cl}^{-}}, \mathrm{NO}_{3}\right.$,

$\left.\mathrm{SO}_{4}{ }^{2-}\right), 26$ trace elements, and stable water isotope, $\delta \mathrm{D}$ at the Climate Change Institute, University of Maine.

By the end of summer in the New Zealand Southern Alps, the snow surface of glaciers becomes visually discoloured, due to concentration of dust particles from summer surface melting and fewer snowfalls. This 'dirty' horizon is utilised in the crevasse stratigraphy method for determining annual layers (Pelto, 1988; Post and LaChapelle, 2000) and is also represented down an ice core as a spike in trace element concentration (Legrand and Mayewski, 1997).

\subsubsection{Climate-accumulation relationships}

To investigate the processes contributing to net accumulation variability, a number of climate data were analysed. The influence of local air temperature and precipitation was assessed using monthly data from the nearby Mount Cook village weather station (765 m a.s.1.) (NIWA, 2009). The Tasman Sea has been identified as a major contributor to snow accumulation on Tasman Glacier due to prevailing westerly flow (Purdie et al., 2010). Therefore a monthly composite of Sea Surface Temperature (SST) was compiled by averaging the SST from 33 grid points (NCEP/NCAR reanalysis) in an area ranging from $33-44^{\circ} \mathrm{S}$ to $156-170^{\circ} \mathrm{E}$, which comprises an area of the Tasman Sea adjacent to the western coast of New Zealand (NOAA, 2009).

To consider the influence of regional air-flow anomalies over the Southern Alps a zonal and meridional index was developed following the methods of Trenberth (1976) and 
Salinger and Mullan (1999). Monthly mean sea level pressure (MSLP) data for Hokitika, Christchurch, Nelson and Invercargill were obtained from the NIWA climate database (NIWA, 2009). The zonal index was created by using the normalised monthly MSLP difference between Nelson and Invercargill (Figure 5.1), with positive (negative) values an indication of enhanced westerly (easterly) flow. A meridional index is based on the normalised monthly MSLP difference between Hokitika and Christchurch (Figure 5.1), where positive (negative) values are an indication of enhanced southerly (northerly) flow. McKendry et al. (1986) demonstrated that pressure differences between Hokitika and Christchurch are influenced by topographic effects on the wind field, caused by the presence of the Southern Alps. This is one reason why flow indices were specifically developed for this study - so that they were reflective of the Southern Alps region. Incidentally, the standard Trenberth M1, which is the pressure difference between Hobart and the Chatham Islands, was also correlated against the net accumulation data. Correlation results with the M1 were less statically significant than that achieved with the specifically developed indices, which highlights the importance of local wind anomalies in mountainous regions. Only results from the locally developed meridional and zonal flow indices are reported.

To investigate the influence of larger scale atmospheric circulation on net accumulation an index for the SAM was used (Marshall, 2003; 2009). This index is the difference in the normalised mean zonal pressure at 40 and $65^{\circ} \mathrm{S}$, derived from 12 Southern Hemisphere weather stations, and characterises north-south shifts in the mid-latitude jet and fluctuations in jet strength (Marshall, 2007).

The ENSO is represented by the Southern Oscillation Index (SOI) (Australian Bureau of Meteorology, 2009) as the normalised anomaly of MSLP difference between Tahiti and Darwin. Although Trenberth and Shea (1987) identified lags in MSLP anomalies between Darwin and New Zealand, Mullan (1995) used simultaneous data for southern oscillation-climate relationships noting there was a strong zero-lag relationship between the SOI and zonal and meridional pressure gradients. As a check, SOI data was lagged by 1, 2 and 3 months, but lagged data produced weaker correlations with net accumulation data, so only results for simultaneous SOI data are reported in this paper. 
For each of the seven climate parameters above, monthly data was combined into an annual average (1 April - 31 March), an ablation season average (1 November - 31 March) and an accumulation season average (1 April - 31 October) following Fitzharris et al., (1997). Precipitation data was summed as opposed to averaged over the same time periods. Following this, statistical analysis was conducted, using the Spearman's Rank test, between all climate parameters and the Tasman Glacier net accumulation data and the $\mathrm{ELA}_{\mathrm{A}}$ record. In addition, net accumulation data was regressed against the ELA $_{\mathrm{A}}$ record to assess the strength of this relationship.

\subsection{Results}

\subsubsection{Net accumulation derived from Tasman Glacier ice core}

A number of peaks in trace element concentration can be identified throughout the length of the core. The first two peaks occur at around 10 and $18 \mathrm{~m}$ depth, with another six significantly smaller peaks identified between 20 and $40 \mathrm{~m}$ depth. Below $40 \mathrm{~m}$ there is a large increase in trace element concentrations, in particular at $43 \mathrm{~m}$ depth. This concentration spike occurs at a density transition to $900 \mathrm{~kg} \mathrm{~m}^{-3}$ and where dirt bands are visible. It is possible that this spike is related to melt-water ponding and/or the presence of a former drainage conduit. It could also represent a previous discontinuous ice surface.

In the upper $20 \mathrm{~m}$ of the ice core enrichment of $\delta \mathrm{D}$ concurs with increased trace element concentrations, supporting interpretation that the first two peaks in trace element concentrations are representative of a former summer snow surface (Figure 5.3). Numerous ice layers are present along the length of the core, and below $20 \mathrm{~m}$, rapid homogenisation of $\delta \mathrm{D}$ and large increases in the $\mathrm{Cl}^{-} / \mathrm{Na}^{+}$ratio (well above standard sea water), suggest that the integrity of the core has been reduced by melt-water percolation and refreezing (Shiraiwa et al., 2002; Schwikowski et al., 2006). For this reason, only the upper $20 \mathrm{~m}$ of the core is used in this study. However future analysis, including tritium dating (Morgenstern et al., 2004) may still derive important climate information, as other research has found that even sites with significant melting can retain a climate signal (Fisher et al., 1998; Goto-Azuma et al., 2002). 
Within the upper $20 \mathrm{~m}$ of the core, 19 out of 26 trace elements analysed had peaks in concentration at around 10 and $18 \mathrm{~m}$ depth, for example $\mathrm{Al}, \mathrm{Ba}, \mathrm{Ce}, \mathrm{Cs}, \mathrm{Co}, \mathrm{La}, \mathrm{Mn}, \mathrm{Pb}$, $\mathrm{Pr}, \mathrm{U}$ and $\mathrm{V}$. Concentrations in major ions were more variable although $\mathrm{MS}$ and $\mathrm{SO}_{4}{ }^{2-}$ recorded peaks at 10 and $18 \mathrm{~m}$ depth. An interesting double peak occurs at $10 \mathrm{~m}$ with concentration spikes at both 9.2 and $10.5 \mathrm{~m}$ depth. This peak most likely represents the 2003/04 summer surface. Climate data from Mount Cook village shows an initial warming (melt) period in early spring, followed by high summer precipitation in January/February, with a return to drier conditions in March. Such a climate pattern could create a double peak in the ice core record with the initial melt surface re-buried by the summer snowfalls, then re-established in late summer. These early (October) and late (March) season melt surfaces have also been observed by the author (Purdie) on regular field trips to the glacier. Therefore the shallower peak at $9.2 \mathrm{~m}$ depth could represent the end-of-summer (March) snow surface. This double peak and the peak at $18.1 \mathrm{~m}$ depth are used to characterise two years of net accumulation data for Tasman Glacier.

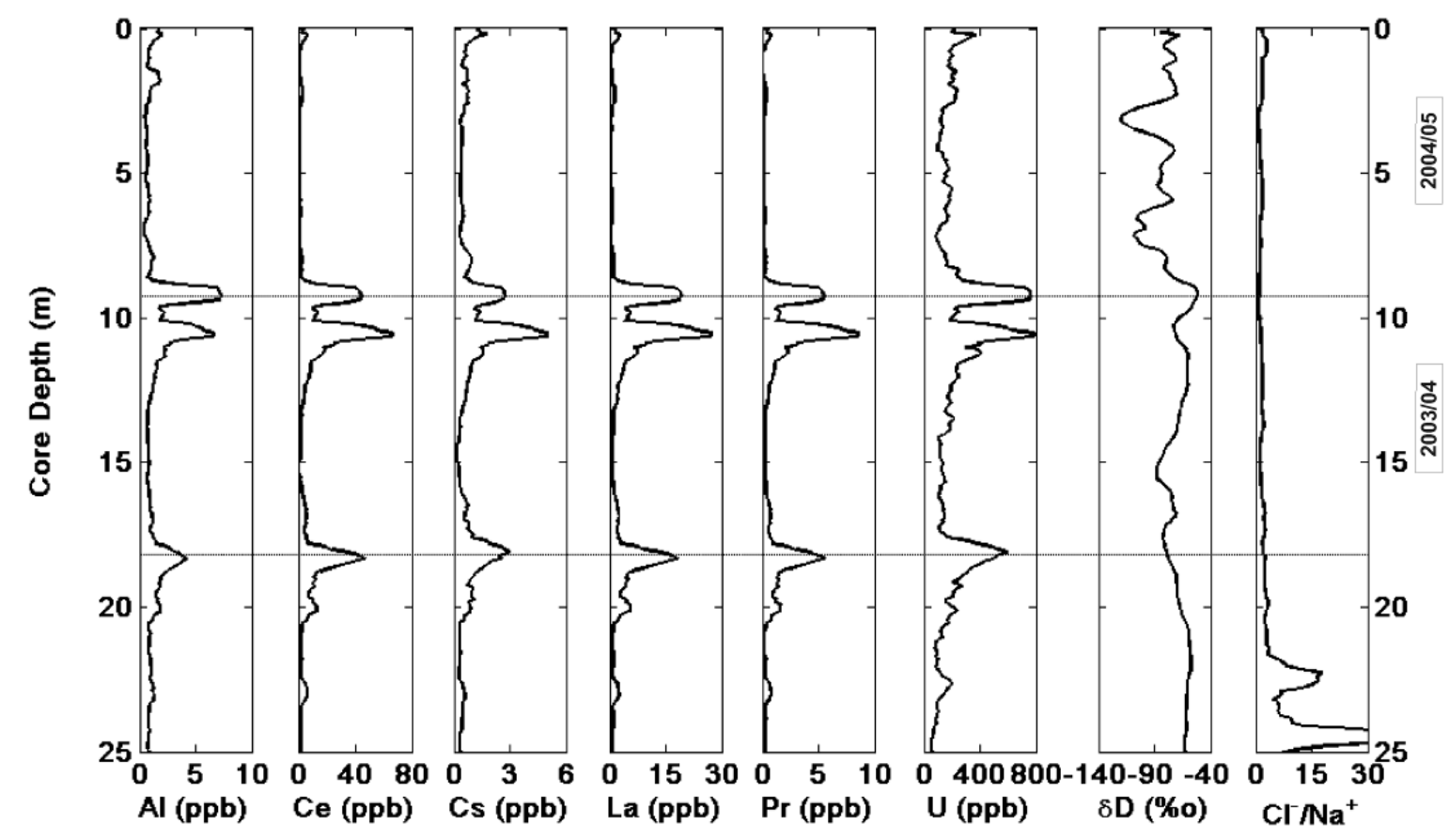

Figure 5.3: Summer peaks in trace element chemistry and $\delta \mathrm{D}$ in the top $25 \mathrm{~m}$ of the Tasman Glacier ice core used to determine two additional years of net accumulation.

The average density of the core between $0-9 \mathrm{~m}$ is $520 \mathrm{~kg} \mathrm{~m}^{-3}$, and between $9-18 \mathrm{~m}$ is $660 \mathrm{~kg} \mathrm{~m}^{-3}$. These average densities are used to convert core depth to meters water 
equivalent ( $\mathrm{m}$ w.e.). The coring drill was set up below the snow surface in a snow-pit therefore an additional $0.83 \mathrm{~m}$ w.e. was added to the top (first) core section. Since the core was retrieved prior to the end of the mass balance year, accumulation and ablation need to be calculated from the period after the core was taken $\left(25^{\text {th }}\right.$ October $)$ through till the end of March. This was done by utilising temperature and precipitation data from local weather stations and a standard mass balance model (see Anderson et al., 2006 and Purdie et al., 2011b). Together, this analysis results in estimated net accumulation for 2004 and 2005 of 5.90 and $4.60 \mathrm{~m}$ w.e. respectively (Table 5.1).

\subsubsection{Inter-annual variability in net accumulation}

Average net accumulation of all data is $3.79 \mathrm{~m} \mathrm{w}$.e. $(n=24)$ with a standard deviation of $1.43 \mathrm{~m}$ w.e., indicating large inter-annual variability. There is little difference between the mean and median ( $3.88 \mathrm{mw}$ w.e.). Lack of continuous measurement means it is hard to assess decadal trends, particularly in net accumulation data. However, the longer ELA $A$

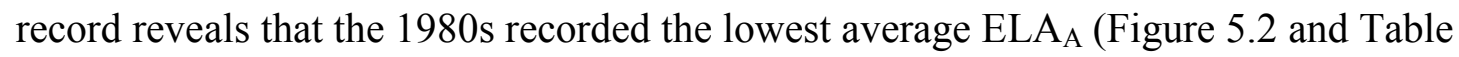
5.1). Regressing net accumulation data against the $E_{L A}$ record resulted in a strong correlation, with an adjusted $r^{2}=0.75(n=22)$. This suggests that the ELA $A_{\mathrm{A}}$ provides a reasonable proxy of net accumulation and vice versa (Figure 5.4).

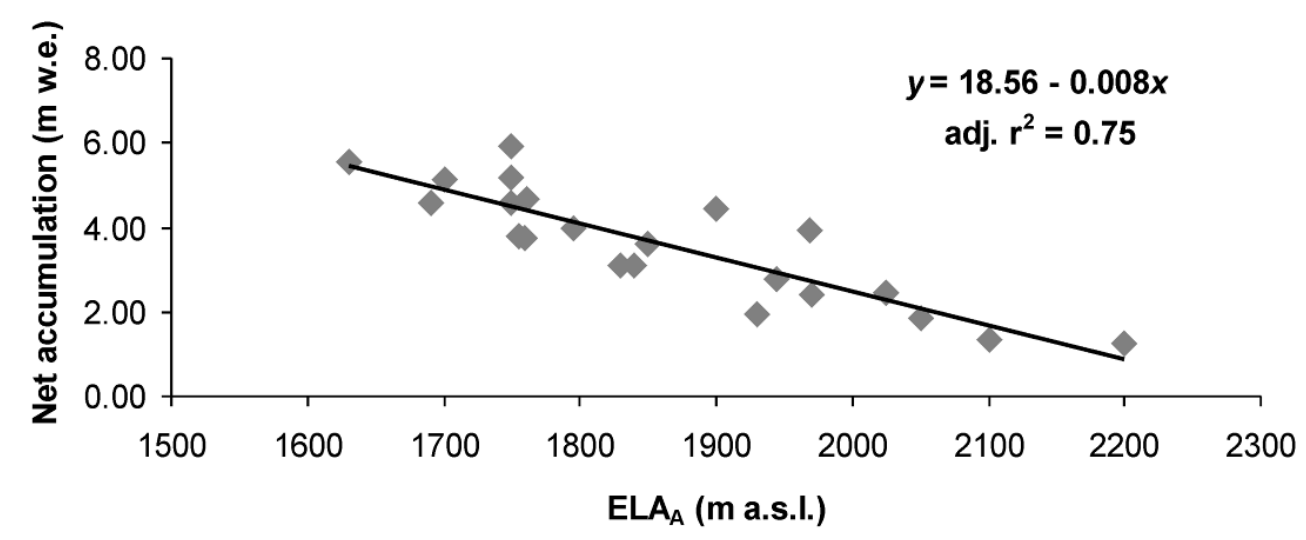

Figure 5.4: Relationship between net accumulation measurements and the annual equilibrium line altitude $\left(\mathrm{ELA}_{\mathrm{A}}\right)$.

\subsubsection{Correlation of climate parameters with net accumulation data}

Statistically significant correlations $(p=0.01)$ were found between net accumulation (and ELA $_{\mathrm{A}}$ ) and annual and ablation season temperature and SST (Table 5.2 and Figure 5.2). 
Significant correlations were also found between the longer ELA $\mathrm{A}_{\mathrm{A}}$ record and annual and accumulation season precipitation totals. The ELA $\mathrm{A}_{\mathrm{A}}$ record also showed relationships ( $p=0.05$ ) with annual and ablation season SAM and SOI. Net accumulation data correlated with the atmospheric flow indices, whereas ELA $\mathrm{A}_{\mathrm{A}}$ variations did not. Strong relationships $(p=0.01)$ between meridional flow and net accumulation were found on an annual and ablation season basis, with higher net accumulation associated with enhanced southerly flow. Relationships with the zonal index $(p=0.05)$ indicate that enhanced westerlies during the ablation season were associated with higher net accumulation.

Table 5.2: Spearman's Rank correlation between net accumulation (mw.e.) and climate variables. Results in bold are significant at the 0.01 level and those in italics at 0.05 .

\begin{tabular}{|c|c|c|c|c|}
\hline \multirow{2}{*}{$\begin{array}{c}\text { Climate Parameter } \\
\text { \& season }\end{array}$} & \multicolumn{2}{|c|}{$\begin{array}{c}\text { Net accumulation } \\
(n=24)\end{array}$} & \multicolumn{2}{|c|}{$\begin{array}{l}\mathbf{E L A}_{\mathbf{A}} \\
(n=49)\end{array}$} \\
\hline & $\begin{array}{l}\text { Correlation } \\
\text { co-efficient }\end{array}$ & $p$-value & $\begin{array}{l}\text { Correlation } \\
\text { co-efficient }\end{array}$ & $p$-value \\
\hline \multicolumn{5}{|l|}{ Temperature } \\
\hline - annual & -.525 & .008 & .405 & .004 \\
\hline -ablation & -.661 & .000 & .510 & .000 \\
\hline -accumulation & -.166 & .438 & .191 & .188 \\
\hline \multicolumn{5}{|l|}{ Precipitation } \\
\hline - annual & .192 & .368 & -.406 & .004 \\
\hline -ablation & .067 & .756 & -.102 & .486 \\
\hline -accumulation & .117 & .585 & -.419 & .003 \\
\hline \multicolumn{5}{|l|}{ Sea Surface Temperature } \\
\hline -annual & -.573 & .003 & .556 & .000 \\
\hline -ablation & -.704 & .000 & .579 & .000 \\
\hline -accumulation & -.260 & .220 & .301 & .035 \\
\hline \multicolumn{5}{|l|}{ Southern Annular Mode } \\
\hline -annual & -.144 & .501 & .327 & .023 \\
\hline -ablation & -.270 & .203 & .344 & .017 \\
\hline -accumulation & -.025 & .907 & .163 & .269 \\
\hline \multicolumn{5}{|l|}{ Southern Oscillation Index } \\
\hline -annual & -.295 & .162 & .283 & .049 \\
\hline -ablation & -.292 & .166 & .317 & .026 \\
\hline -accumulation & -.169 & .431 & .197 & .175 \\
\hline \multicolumn{5}{|l|}{ Zonal } \\
\hline -annual & .277 & .191 & -.278 & .053 \\
\hline -ablation & .490 & .015 & -.238 & .100 \\
\hline -accumulation & .008 & .971 & -.162 & .266 \\
\hline \multicolumn{5}{|l|}{ Meridional } \\
\hline -annual & .522 & .009 & -.262 & .069 \\
\hline -ablation & .556 & .005 & -.214 & .140 \\
\hline -accumulation & .108 & .616 & -.156 & .286 \\
\hline
\end{tabular}

Inter-annually, years with lower net accumulation (e.g. 1974, 1999, 2000 and 2008) were associated with warm ablation season temperatures, enhanced northerly and 
easterly flows and positive phases of the SOI and the SAM (Figure 5.2). However, some of the lowest net accumulation years occur when the SOI and the SAM are out-ofphase, for example 1967 and 1990. In 1987 net accumulation was above average and this coincided with the SOI and the SAM being in negative phase. 1983 and 1998 were characterised by a strongly negative ablation season SOI. Although there are no net accumulation data for these years, in 1983 the ELA $A_{A}$ does show a depression of the EOSS in response to lower temperatures and more persistent westerly and southerly circulation anomalies; the SAM was also negative. In 1998, despite being a negative ENSO year, the SAM was neutral, and although westerly and southerly circulation anomalies occurred, cooling did not, and a near-average ELA $\mathrm{A}_{\mathrm{A}}$ was the result (Figure $5.2)$.

Due to potential non-linearity in relationships between net accumulation and the ELA $A$ with the SAM and the ENSO, a $t$-test was used to compare means during positive and negative phase years. Analysis was conducted on both ablation season and annual averages of the SAM and SOI, and ignored years of neutral conditions (i.e. $0 \pm 0.2$ for the SAM, and $0 \pm 2$ for SOI. Results in Table 5.3 show a statistically significant difference in average net accumulation and average ELA $\mathrm{A}_{\mathrm{A}}$ between positive and negative SAM years. For the SOI, the only significant relationship found was with the annual average SOI and the ELA $\mathrm{A}_{\mathrm{A}}$

Table 5.3: Results of a two-tailed $t$-test for the difference in means in net accumulation ( $\mathrm{m}$ w.e.) and the $\mathrm{ELA}_{\mathrm{A}}$ (m a.s.1.) between positive (+ve) and negative (-ve) phases of the SAM and SOI. In each instance, the mean for + ve and -ve years is shown along with the associated $p$-value and $t$-statistic.

\begin{tabular}{|c|cc|cc|}
\hline Parameter & \multicolumn{2}{|c|}{ Net Accumulation } & \multicolumn{2}{c|}{ ELA $_{\mathbf{A}}$} \\
\hline SAM - ablation season average & $3.20+\mathrm{ve}$ & $4.49-\mathrm{ve}$ & $1878+\mathrm{ve}$ & $1783-\mathrm{ve}$ \\
& $p=\mathbf{0 . 0 5}$ & $t=-2.10$ & $p=\mathbf{0 . 0 2}$ & $t=2.45$ \\
& & & & \\
SAM - annual average & $3.53+\mathrm{ve}$ & $3.92-\mathrm{ve}$ & $1877+\mathrm{ve}$ & $1779-\mathrm{ve}$ \\
& $p=0.61$ & $t=-0.53$ & $p=\mathbf{0 . 0 2}$ & $t=2.41$ \\
\hline SOI - ablation season average & $3.14+\mathrm{ve}$ & $3.82-\mathrm{ve}$ & $1863+\mathrm{ve}$ & $1799-\mathrm{ve}$ \\
& $p=0.25$ & $t=-1.19$ & $p=0.13$ & $t=1.54$ \\
& & & & \\
SOI - annual average & $3.07+\mathrm{ve}$ & $4.14-\mathrm{ve}$ & $1888+\mathrm{ve}$ & $1787-\mathrm{ve}$ \\
& $p=0.12$ & $t=-1.66$ & $p=\mathbf{0 . 0 2}$ & $t=2.45$ \\
\hline
\end{tabular}


Longer-term trends are more difficult to discern because we lack net accumulation data in many key years. However, it is clear that the 1960s were characterised by generally higher net accumulation and a persistently negative phase of the SAM. ELA $A_{A}$ data indicate that this trend of generally positive balance (occasionally interrupted by a high melt year) probably continued until recently. Since around 2006 we have seen some low net accumulation years resulting from northerly circulation anomalies driving higher ablation season temperatures. These years have coincided with a positive trend in both the SAM and the ENSO.

\subsubsection{Correlations between climate variables}

To further understand the relationship between climate and glaciers, we also investigated the relationships between the climate patterns themselves. Significant correlations were found between local Mount Cook temperature and SST both annually and over the ablation season (Table 5.4). Mount Cook temperature was also positively correlated with the SAM, especially in the ablation season. SST positively correlated with the SOI in all seasons, despite no direct correlation being found between the SOI and net accumulation.

A number of significant correlations were found between the zonal flow index and the other climate variables, especially during the ablation season. Enhanced westerly flow was associated with decreased SST, increased precipitation, and reduced temperatures. Westerly flow was also enhanced when the SAM and the SOI are in negative phase. Correlations between the meridional index and the other climate variables were less clear, but enhanced southerly flow was associated with decreased SST, and the negative phase of the SOI. A number of relationships between the various climatic variables were at their strongest during the ablation season. 
Table 5.4: Correlation matrix of relationships between all climate variables used for the analysis of net accumulation and ELA $A_{A}$ trends.

\begin{tabular}{|c|c|c|c|c|c|c|c|c|c|c|c|c|c|c|c|c|c|c|c|c|c|}
\hline & \multicolumn{3}{|c|}{ Temperature } & \multicolumn{3}{|c|}{ Precipitation } & \multicolumn{3}{|c|}{ SST } & \multicolumn{3}{|c|}{ SAM } & \multicolumn{3}{|c|}{ SOI } & \multicolumn{3}{|c|}{ Zonal } & \multicolumn{3}{|c|}{ Meridional } \\
\hline & Ann. & Abl. & Acc. & Ann. & Abl. & Acc. & Ann. & Abl. & Acc. & Ann. & Abl. & Acc. & Ann. & Abl. & Acc. & Ann. & Abl. & Acc. & Ann. & Abl. & Acc \\
\hline $\mathbf{T}$ & & & & & & & & & & & & & & & & & & & & & \\
\hline Ann. & 1.00 & & & & & & & & & & & & & & & & & & & & \\
\hline Abl. & .765 & 1.00 & & & & & & & & & & & & & & & & & & & \\
\hline $\begin{array}{c}\text { Acc. } \\
\mathbf{P}\end{array}$ & .852 & .375 & 1.00 & & & & & & & & & & & & & & & & & & \\
\hline Ann. & .044 & -.102 & .134 & 1.00 & & & & & & & & & & & & & & & & & \\
\hline Abl. & -.023 & -.092 & .005 & .531 & 1.00 & & & & & & & & & & & & & & & & \\
\hline $\begin{array}{l}\text { Acc. } \\
\text { SST }\end{array}$ & .174 & .050 & .243 & .641 & -.168 & 1.00 & & & & & & & & & & & & & & & \\
\hline Ann. & .467 & .409 & .427 & -.244 & -.224 & -.093 & 1.00 & & & & & & & & & & & & & & \\
\hline Abl. & .494 & .551 & .307 & -.265 & -.123 & -.121 & .739 & 1.00 & & & & & & & & & & & & & \\
\hline $\begin{array}{l}\text { Acc. } \\
\text { SAM }\end{array}$ & .152 & .012 & .290 & -.108 & -.174 & -.067 & .792 & .228 & 1.00 & & & & & & & & & & & & \\
\hline Ann. & .308 & .149 & .326 & .061 & .242 & -.058 & .180 & .238 & .094 & 1.00 & & & & & & & & & & & \\
\hline Abl. & .472 & .481 & .323 & .005 & -.010 & .135 & .207 & .289 & .007 & .698 & 1.00 & & & & & & & & & & \\
\hline $\begin{array}{l}\text { Acc. } \\
\text { SOI }\end{array}$ & .041 & -.223 & .209 & .059 & .388 & -.211 & .057 & .107 & .092 & .730 & .101 & 1.00 & & & & & & & & & \\
\hline Ann. & .252 & .252 & .288 & -.178 & -.304 & .093 & .493 & .439 & .325 & .058 & .236 & -.100 & 1.00 & & & & & & & & \\
\hline Abl. & .317 & .252 & .360 & -.126 & -.238 & .129 & .412 & .433 & .228 & .199 & .375 & -.005 & .880 & 1.00 & & & & & & & \\
\hline $\begin{array}{c}\text { Acc. } \\
\text { Zonal }\end{array}$ & .176 & .203 & .214 & -.158 & -.275 & .096 & .480 & .401 & .328 & -.040 & .109 & -.139 & .942 & .693 & 1.00 & & & & & & \\
\hline Ann. & .174 & .002 & .189 & .588 & .172 & .476 & -.185 & -.230 & -.137 & -.296 & -.203 & -.297 & -.183 & -.163 & -.152 & 1.00 & & & & & \\
\hline Abl. & -.246 & -.204 & -.208 & .386 & .451 & -.057 & -.323 & -.463 & -.114 & -.320 & -.383 & -.179 & -.360 & -.423 & -.270 & .543 & 1.00 & & & & \\
\hline Acc. & .410 & .203 & .380 & .330 & -.152 & .613 & -.043 & .029 & -.157 & -.142 & .054 & -.278 & .044 & .112 & .029 & .735 & .026 & 1.00 & & & \\
\hline Merid. & & & & & & & & & & & & & & & & & & & & & \\
\hline Ann. & .036 & -.058 & .050 & .331 & .088 & .221 & -.368 & -.483 & -.181 & -.155 & -.061 & -.235 & -.358 & -.300 & -.344 & .711 & .530 & .445 & 1.00 & & \\
\hline Abl. & -.181 & -.169 & -.127 & .199 & .224 & -.089 & -.283 & -.550 & .015 & -.110 & -.202 & -.070 & -.299 & -.364 & -.229 & .407 & .785 & -.101 & .683 & 1.00 & \\
\hline Acc. & .284 & .160 & .218 & .222 & -.077 & .369 & -.272 & -.136 & -.348 & -.015 & .180 & -.223 & -.209 & -.073 & -.247 & .561 & .026 & .719 & .740 & .107 & 1.00 \\
\hline
\end{tabular}

Note: Bold correlations are significant at 0.01 , and italics at 0.05 


\subsection{Discussion}

\subsubsection{Relationships between temperature, precipitation and net accumulation variability}

Changes in temperature and precipitation are embedded in large-scale atmospheric circulation variability. However, due to the direct and immediate influence that these two climate parameters have on glacier mass balance and our relatively poor processbased understanding of their influence in New Zealand, the impact of local temperature and precipitation will be discussed first.

Ablation season temperature was found to correlate most strongly with inter-annual variability in net accumulation on Tasman Glacier, with increases in both local and SST associated with lower net accumulation. These strong temperature relationships were also found in the $\mathrm{ELA}_{\mathrm{A}}$ record, with a higher ELA $\mathrm{A}_{\mathrm{A}}$ occurring in years with warmer ablation season temperatures. These results are consistent with climate sensitivity studies from mass balance models, which have found that maritime glaciers in the Southern Alps have high temperature sensitivity (Woo and Fitzharris, 1992; Oerlemans, 1997; Anderson et al., 2006; Anderson and Mackintosh, 2006).

Globally, warming during summer is having a large impact on mid-latitude maritime glaciers (Josberger et al., 2007; Winkler et al., 2009). Previously mass balance of Wolverine (Alaska) and South Cascade (Washington, USA) glaciers had strong correlation with winter balance due to fluctuations in the location of winter storm tracks, brought about in part by phase changes in the Pacific Decadal Oscillation (PDO), and changes in the strength of the Aleutian/Gulf of Alaska Low (Walters and Meier, 1989; Hodge et al., 1998; Moore et al., 2002). However recently, warm dry summers have begun to dominate net balance on these maritime glaciers (Josberger et al., 2007). The situation is similar in Norway where the dominance of winter precipitation on mass balance (Nesje et al., 2000) may be giving way to the influence of increased summer melting (Winkler et al., 2009).

No significant relationship was found between winter precipitation and net accumulation in the study, but a relationship was identified between the $\mathrm{ELA}_{\mathrm{A}}$ and 
winter precipitation; although it was less significant $(p=0.05)$ than ablation season relationships. These findings are consistent with the shorter (6-year) annual and seasonal mass balance record at Brewster Glacier, $90 \mathrm{~km}$ to the south, which indicates that the inter-annual variability in total annual mass balance is most strongly influenced by summer balance (Anderson et al., 2010).

\subsubsection{Influence of atmospheric circulation on net accumulation variability}

Variability in atmospheric circulation patterns have major influence on MSLP, anomalous air flow, and SST, all of which provide forcing to local temperature and precipitation patterns (Sturman and Tapper, 2006). When the SAM and ENSO are in positive (negative) phase there is often anomalous northerly and easterly (southerly and westerly) flow over the Southern Alps resulting warm (cool) temperatures and decreased (increased) precipitation (Mullan, 1995; Salinger et al., 2001; Kidston et al., 2009). Although precipitation can also be enhanced in this region during positive ENSO (La Niña) phases (Ummenhofer et al., 2009). In addition, climate relationships with the ENSO and the SAM are strongest during the austral spring (Mullan, 1995) and summer (Kidston et al., 2009) respectively. Therefore, the relationships found between Tasman Glacier mass balance and the ENSO and SAM are likely to be related to the effect that these circulation patterns can have on ablation season temperatures. In addition, when these modes are in negative phase they have potential to delay the onset of summer melting due to albedo increases associated with spring and summer precipitation (Oerlemans and Klok, 2004).

Considering what we already know about the ENSO and SAM, it was anticipated that a decrease (increase) in net balance would be associated with a positive (negative) phase of both indices. This was indeed the case in the majority of years, as 14 out of the 18 years when both indices were positive (negative), showed decreased (increased) balance. However, anomalies did occur (e.g.1960). This might perhaps be explained by the fact that ENSO related anomalies in New Zealand have been shown to occur only around two-thirds of the time (Mullan, 1995). In this study we found that low (high) net accumulation can also occur when only one of these modes is in positive (negative) phase, for example 1971 and 1975 (1965 and 1993). In addition, positive or negative balances can occur when both the ENSO and/or the SAM are neutral, for example 1970 and 2004 respectively. In these years the same regional northerly-easterly or southerly- 
westerly anomalous circulation occurs but without obvious large scale forcing. Consequently we found a stronger correlation between net accumulation and the regionally developed zonal and meridional flow indices. Interestingly some of the lowest net accumulation years (e.g. 1967 and 1990) coincide with the ENSO and the SAM being out-of-phase, and anomalous flow contrary to what is usually associated with low net accumulation. High ablation season temperatures in these years indicates that some other climate forcing is at work, demonstrating that there is more to learn about how these modes of regional climate variability influence glacial mass balance in mid-latitude regions.

\subsubsection{Recent and future trends in New Zealand climate}

The period 1977-2005 has been one of unprecedented El Niño dominance (Power and Smith, 2007), with exceptional events in 1983 and 1998. The fluctuations in the ENSO are known to be modulated by multi-decadal variability in the Interdecadal Pacific Oscillation (IPO), with increased (decreased) frequency of El Niño events associated with positive (negative) IPO phases (Salinger et al., 2001). A change point in the IPO has been identified around 1977, with the period 1944-77 one of generally negative phase and 1978-98 a positive phase. Since 1998 the IPO has been predominantly negative (Salinger et al., 2001; Folland, 2008). Indeed the average Tasman Glacier $\mathrm{ELA}_{\mathrm{A}}$ for the period 1955-1977 was higher (1860 m a.s.1.) than it was 1978-98 (1770 m a.s.1.), significant at $p=0.05$ (two-tailed $t$-test). However, net accumulation measurements in the late 1960s also show a short period of high net accumulation. This period of positive balance occurred in conjunction with a persistent negative phase of the SAM, supporting the idea that the SAM has a stronger influence on the New Zealand climate (Ummenhofer et al., 2009). In the last few years we have begun to see a more negative trend in mass balance in conjunction with increased northerly flow and a positive trend in both the SAM and the ENSO.

How projected climate warming will impact atmospheric circulation is still uncertain. It is possible that El Niño events may become more frequent (Fedorov and Philander, 2000; Nyenzi and Lefale, 2006; Power and Smith, 2007), which could potentially result in increased accumulation and positive mass balance on some New Zealand and Patagonian glaciers (Fitzharris et al., 2007). Conversely, the continuing positive trend of the SAM (Fyfe et al., 1999) might ultimately result in large warming of the Tasman Sea 
(Cai et al., 2005), a warming which could result in reduced net accumulation.

Preliminary modelling of future glacier length changes in New Zealand supports the contention that even modest rates of warming, including precipitation increase, will overpower any effects of regional climate variability, and that glacier retreat is to be expected (Anderson et al., 2008).

\subsection{Conclusions}

Reconstructing net accumulation data from direct measurements and an ice core has enabled a comprehensive interpretation of mass balance-climate relationships to be made. Specifically, a direct comparison between net accumulation and various climatic and atmospheric circulation variables has shown that temperature, especially during the ablation season, exerts strongest influence on inter-annual variability in net accumulation on Tasman Glacier. Our results have shown that although a clear relationship exists between glacier mass balance and the ENSO and SAM at times, in some years the response is not linear. Understanding these non-linear responses is crucial, especially since they can be associated with very negative mass balance. With the IPO currently in a negative phase, there is a likelihood of increased La Niña events, which coupled with increasing persistence of the positive SAM, means we can expect to see more negative mass balance in New Zealand in the immediate future. 


\section{Synthesis and Conclusions}

This final chapter provides a synthesis of the research findings by reflecting on the original research objectives, explaining how objectives have been met, outlining limitations encountered and highlighting the contribution this research has made to the scientific literature. It also identifies issues that have become apparent with hindsight, and identifies areas for ongoing research.

\subsection{Research Outcomes}

The overall aim of this research was to improve our knowledge of the controls on snow accumulation on mid-latitude maritime glaciers. This was achieved by investigating the spatial and temporal variability in snow accumulation over a variety of scales. Although written as four separate papers, Chapters 2-5 each address snow accumulation processes, ranging from the investigation of individual storm events to decadal-scale accumulation trends. The following sections demonstrate how each of the research objectives outlined in section 1.4 have been met, and explains how these findings add to our knowledge of snow accumulation.

\subsubsection{Spatial controls on snow accumulation on mid-latitude maritime glaciers}

One objective of this study was to determine the degree of spatial variability in net accumulation on glaciers located on opposite sides of an orographic barrier, and identify the factors exerting most control on that variability. To achieve this, net accumulation data obtained by the crevasse stratigraphy method was compared to a number of parameters that could potentially control the spatial distribution of snow accumulation. For example, elevation, aspect, solar radiation and wind exposure. It was found that each year on Franz Josef (FJG) and Tasman (TG) Glaciers the degree of spatial variability in net accumulation changed (Figure 2.3), and the least variability was recorded in 2008, a year characterised by high summer ablation. This result suggests that increased summer temperatures, which result in high summer ablation, could serve to homogenise variability in snow accumulation established during the accumulation season. 
Interestingly, the difference in average net accumulation between the two glacier sites each year was relatively small (Table 2.1). Based on previous precipitation estimates (Figure 1.5) it was assumed that the western glacier (FJG) would receive more snow accumulation than the eastern glacier (TG). Similarity in snow accumulation between the western and eastern glacier sites was also recorded during the winter snow accumulation survey (Chapter 3). Despite FJG receiving 30\% more snow accumulation than TG, by the end of the winter survey the western site had recorded only $6 \%$ more net snow accumulation than the eastern site. Some of the snow loss from the FJG site was attributed to wind deflation during strong south-easterly storms. Such an event-based snow loss could be concluded as being a specific anomaly of the winter study period. However, if both studies are considered, the data indicate that the difference in snow accumulation on glaciers immediately adjacent to the Main Divide of the Southern Alps is not as large as previously assumed. This outcome highlights how we still do not fully understand the precipitation gradient in the highest part of the Southern Alps.

Although elevation, through its influence on temperature, is commonly used to parameterise snow accumulation estimation, the relationship between mass balance and elevation weakened in the accumulation area (Figure 2.5), a factor also found on some continental glaciers (Machguth et al., 2006). However, limitations were imposed by the linear nature of the analysis. Reconsideration of the 2008 FJG data using a $4^{\text {th }}$ order polynomial relationship indicates that there maybe there a decrease in net accumulation above $2400 \mathrm{~m}$ a.s.1. (Figure 6.1). Even so, the strength of the polynomial relationship $\left(\mathrm{r}^{2}=0.30\right)$ is not substantially higher than that achieved with a linear fit (also see Figure 2.5). Anderson et al. (2006) used a polynomial relationship to estimate a decrease in precipitation in the FJG valley at elevations above $1000 \mathrm{~m}$ a.s.1. However, this study found that net snow accumulation did increase up to around $2300 \mathrm{~m}$ a.s.1., but with limited data points above $2400 \mathrm{~m}$ a.s.1. no conclusions could be drawn as to what was happening in the immediate vicinity of the Main Divide. Previous precipitation studies conducted in New Zealand lacked measurement from above $2000 \mathrm{~m}$ a.s.1. (Griffiths and McSaveney, 1983; Henderson and Thompson, 1999; Kerr, 2009), and although this study remedied this to some extent, it appears that a crucial transition may occur at $\sim 2400 \mathrm{~m}$ a.s.1. Measuring accumulation at these very high elevations becomes increasingly difficult due to steep terrain, the presence of bergschrunds, and obvious 
gravitational transport (i.e. avalanche). Future research, maybe using GPR technology, should concentrate on measuring accumulation across this higher elevation range to try and discriminate the increase/decrease in precipitation, from decreases in ablation due to colder temperatures, and increase/decrease in accumulation due to gravitational transport.

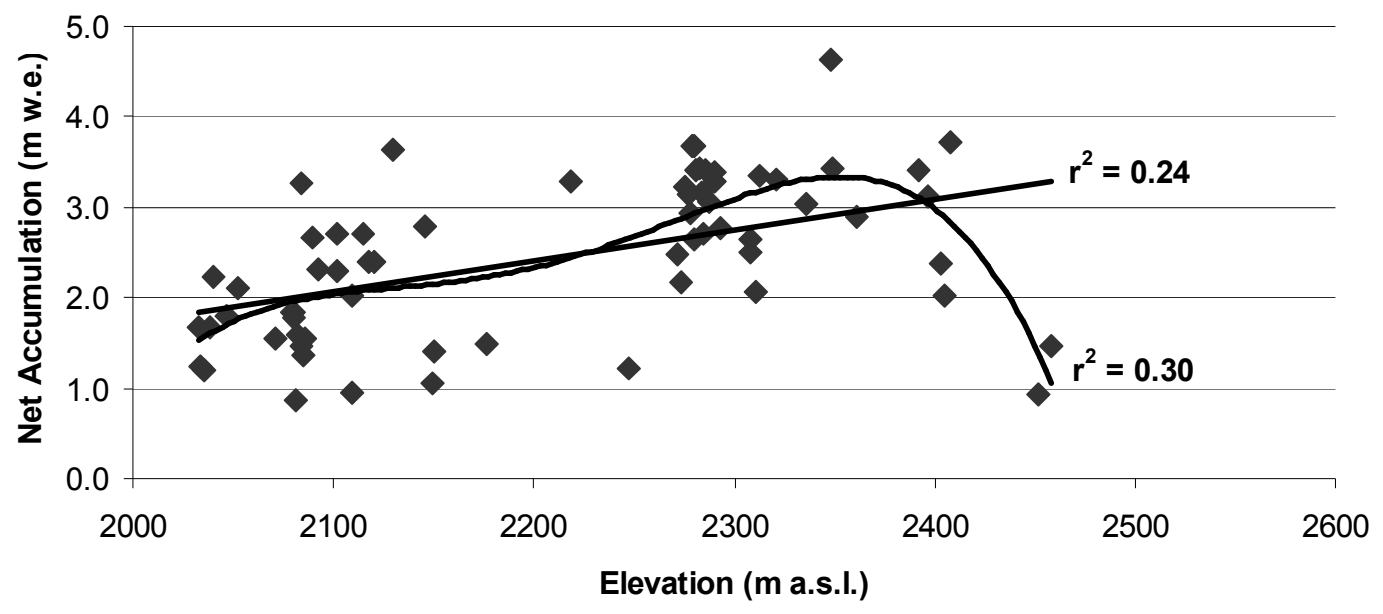

Figure 6.1: Reconsideration of the elevation-accumulation relationship on Franz Josef Glacier in 2008 using a $4^{\text {th }}$ order polynomial relationship.

In addition to elevation, wind redistribution processes were important on FJG and TG for determining net accumulation distribution (Table 2.3). These results were in agreement with observations made during the winter snow accumulation survey that recorded large snow transport during storms (section 3.4.2). It has been known for some time that wind redistribution of snow is important in cold, relatively dry climates, for example on polar (e.g. Grabiec et al., 2006) and continental glaciers (e.g. Lehning et al., 2008; Mott et al., 2008), and in seasonal snow distribution (e.g. Elder et al., 1991; Lapen and Martz, 1996). We now know that these processes are important on the full range of glaciers from extremely maritime to polar continental.

By utilising net accumulation data, results of this spatial analysis only reflect the distribution patterns established from the combined effects of winter accumulation, wind redistribution and summer melting. It would be ideal to repeat such spatial analysis at least twice during a mass balance year, i.e. at the end of winter and the end of summer. In doing this, we could learn more about interactions between different snow accumulation distribution processes. For example, to what degree does summer 
ablation modify the snow distribution pattern established at the end of winter? Do wind redistribution processes have more influence during winter when snow accumulation is frequent and unconsolidated, compared to during summer when protective melt/refreeze crusts form more rapidly? These are questions that require further investigation.

Although further refinement is desirable, results from this spatial analysis of snow accumulation can be used to improve the way that mass balance models parameterise snow accumulation on maritime glaciers. Specifically, results indicate that in addition to elevation/temperature relationships, wind redistribution processes should be included for a more realistic spatial simulation. Lack of wind measurement in the alpine regions of New Zealand is currently a limiting factor in the application of more advanced snow transport models (e.g. Liston and Elder, 2006; Lehning et al., 2008; Mott et al., 2008). Therefore the application of statistical relationships identified in this research may help to better estimate net accumulation distribution in the absence of more physical models.

Determining the moisture source regions of winter snow accumulation was another research objective. Learning where moisture is derived from helps us to understand the role of atmospheric circulation on snow accumulation. This objective was achieved through geochemical analysis whereby the deuterium excess parameter and variations in trace-element concentrations helped to identify three potential moisture source regions namely; Tasman Sea, Southern Ocean and Pacific Ocean (Figure 4.4 and 4.5). $70 \%$ of the winter snow accumulation was derived from a Tasman Sea source. The moisture source signal appeared clearer at FJG compared to TG. This finding was attributed to simpler air mass trajectories of moisture accumulation on FJG in comparison to TG, as TG is located lee of the Southern Alps, so a degree of moisture recycling could occur as an air mass crossed the range prior to snow deposition. However, sample size was a limiting factor in this analysis. The majority of the snow storms sampled were derived from a Tasman Sea source (see section 4.6.2), which is not surprising considering New Zealand's prevailing westerly flow. Further geochemical analysis of fresh snow over a longer time period would be desirable to help constrain the range of values that the deuterium excess and trace element concentrations could have in association with the different moisture source regions identified. 
Comparison of the geochemical signatures contained in winter snow accumulation at the eastern and western glacier sites found that water isotopes were more depleted at TG compared to FJG (Figure 4.4). This difference is attributed to prevailing westerly flow and rain-out of heavier isotopes as air masses crossed the Southern Alps, and is in keeping previously identified global patterns (Dansgaard, 1964). Spatial variability was also recorded in trace element geochemistry, with a stronger marine ( $\mathrm{Na}, \mathrm{Mg}, \mathrm{Sr})$ signal in snow accumulation on FJG and higher levels of terrestrial elements $(\mathrm{Pb}, \mathrm{V}, \mathrm{Zr})$ in snow on TG. These findings demonstrate how geographical location with respect to an orographic barrier can alter the geochemical signal contained in snow accumulation. In the case of moisture provenance, geographic location can affect signal clarity, a factor relevant to ice core interpretation. These results should be considered by future researchers to guide decisions about site selection, with western glacier sites likely retaining a clearer moisture source signal, while eastern sites could provide more information about how isotope and chemistry ratios change as an air mass crosses an orographic barrier and mixes with lee side moisture sources.

\subsubsection{Temporal controls on snow accumulation on mid-latitude maritime glaciers.}

As well as quantifying the processes that contributed to variability in snow accumulation distribution, this study also aimed to determine if the relative importance of different snow accumulation processes altered from year-to-year. Each year, different processes were found to be more or less prominent (Table 2.3). For example on FJG, a strong relationship existed between elevation and net accumulation in 2008 and 2009, but only in 2008 did the indicators of orographic precipitation distribution show any statistical significance. These results indicate that annual synoptic frequencies likely play a role on how strong the correlation is between spatial control parameters and snow accumulation patterns, a factor relevant to accurate mass balance estimation. For example, wind redistribution processes may predominate in a year with frequent troughing and frontal activity, whereas orographic processes may be more important in years with increased zonal flow.

The importance of synoptic frequencies to snow accumulation was confirmed during the winter snow survey (Chapter 3). Prior to this research, we did not know how synoptic- 
scale weather patterns affected snow accumulation in New Zealand, and although such relationships have been investigated in a continental setting (Grundstein, 2003; Romolo et al., 2006), it was unclear whether these findings would apply to a maritime setting. Results showed that troughing synoptic regimes accounted for $\geq 75 \%$ of snow accumulation on both FJG and TG, a similar finding to continental studies, while significantly lower snow accumulation was associated with zonal or blocking regimes (Figure 3.5 and Table 3.1). The analysis of how synoptic regimes affected snow accumulation patterns was conducted on a daily basis. It is acknowledged that this is not ideal, and that grouping data into individual storm events would have been preferable in terms of synoptic analysis. In the field there had been an attempt to collect data on a storm by storm basis, but at high elevation it quickly became apparent that it was extremely difficult to differentiate one storm from another, as frequently there was no clearance. This was complicated by the objective to make direct comparison between measurements east and west of the Main Divide, as each field party grappled with deciding when to call the break between storm events. Should there be opportunity to repeat this type of intensive survey, then some effort should go into trying to solve this problem. For example, get regular communications about the general synoptic weather situation, which might assist in determining individual storm events.

The results from the winter snow survey are in agreement with work done on avalanche occurrence in New Zealand where troughing synoptic regimes were associated with increased avalanche activity, and blocking synoptic regimes were positively correlated with reduced avalanche activity and reduced snow depth (Hendrikx, 2005). Combined, these results highlight how dependent annual snow accumulation is on troughing synoptic regimes, and demonstrates how any reduction in troughing frequency during the accumulation season would result in reduced snow accumulation, potentially leading to negative glacier mass balance. Troughing synoptic regimes are generally associated with westerly circulation and results from geochemical analysis (Chapter 4) confirmed that the Tasman Sea is the dominant moisture source. Therefore, although measured by different means and on different time scales, all results from this study highlight how atmospheric circulation patterns that maintain or enhance westerly flow are essential for snow accumulation input. 
Although low pressure troughs were found to be very important to winter snow accumulation, an evaluation of the ability of a simple accumulation model, based on an elevation/temperature approach, to capture synoptic-scale variability in snow accumulation revealed that that poorest model performance was associated with troughing synoptic regimes. Cumulative snow accumulation was estimated to within $8 \%$ of measured values (Figure 3.7), but large day-to-day discrepancy between measured and modelled snow accumulation occurred. Due to the short time duration of the model simulation it is hard to conclude whether the relatively small differences between modelled and measured snow accumulation were due to good model performance or indeed good luck. Usually such model comparisons are made over at least one entire mass balance season (e.g. Mott et al., 2008). This means that daily discrepancies will be smoothed, and there is no opportunity to identify which precipitation events were modelled well and which were not. By obtaining a high resolution dataset, as done during the winter survey, there was opportunity to examine how the individual model parameters performed. It was found that during this winter simulation, the model parameter with most uncertainty was the precipitation factor, as cold winter temperatures meant that snow/rain temperature thresholds and temperature lapse rates were not an issue. This highlights the difficulty in applying a simple multiplier to low elevation precipitation to account for complex orographic processes.

The fact that poorest model performance coincided with troughing synoptic regimes, found to be responsible for the majority of snow accumulation, demonstrates a need for further research into the way in which precipitation distribution varies with elevation, and how precipitation can be more realistically downscaled from climate models. It may be that precipitation factors can be synoptically adjusted in a way that improves precipitation estimation without large increases in input data. Ideally, the intensive winter snow survey should be repeated over a longer time period. In particular, during spring when increasing temperatures at low-elevation sites used to drive models may reveal inadequacies in other model parameters. For example, this study recorded large seasonal variability in temperature lapse rates (section 3.4.3), and research at midelevations ( $\sim 1500$ m a.s.1.) by Barringer (1989) found inadequate temperature lapse rates most limiting to accurate snow accumulation estimation. 
Although snow geochemistry was used to characterise spatial variability in snow accumulation, it was found that even during the New Zealand winter, post-depositional modification of these signals could occur (research objective 3). This was in contrast to a previous study on maritime glaciers in the Canadian Rocky Mountains, which determined that no post-depositional modification occurred during winter months (Sinclair and Marshall, 2008). However, it is acknowledged that winter temperatures in maritime regions of the Canadian Rockies are colder in comparison to the New Zealand Southern Alps. In particular, enrichment of stable water isotopes was recorded in older pit snow in comparison to initial fresh values (Figure 4.3). This enrichment was likely due to a combination of snow metamorphism, wind sublimation, and mixing of old and fresh snow by wind redistribution. Even so, average values of $\delta \mathrm{D}$ recorded in fresh winter snow on Tasman Glacier were found to be representative of winter minima recorded in the upper section of the Tasman Glacier ice core (Table 4.1 and Figure 5.3). These results are important to future research as they demonstrate that although eventscale information will be homogenised by the end of the accumulation season, a seasonal signal can still be preserved for at least one full melt season.

Finally, an objective of this research was to determine how inter-annual variability in net accumulation is influenced by climate, in particular atmospheric circulation on annual and seasonal time-scales. Local air and sea-surface temperature were found to be strongly correlated with inter-annual variability in net accumulation on Tasman Glacier, especially during the ablation season (Table 5.2). This finding is important considering current global temperature trends, and is in agreement with recent research from other mid-latitude maritime glaciers that indicate that these glaciers are more sensitive to changes in temperature than they are precipitation (Josberger et al., 2007; Anderson et al., 2010).

Relationships between net accumulation and regionally developed zonal and meridional flow indices were likewise strongest during the ablation season, with lower (higher) net accumulation associated with northerly and easterly (southerly and westerly) flow anomalies. Atmospheric circulation modes, which can potentially drive such flow anomalies, for example the ENSO and the SAM, were found to be associated with a decrease (increase) in net accumulation when both in positive (negative) phase (Figure 5.2). When the ENSO and the SAM were either out-of-phase or neutral, relationships 
with net accumulation were less clear, but some of the lowest net accumulation years were associated with reversed polarity in these circulation modes. Circulation anomalies associated with ENSO are known to occur only around two-thirds of the time (Mullan, 1995). These results support that finding, and suggest that an indirect relationship may at times also occur between atmospheric circulation and phases of the SAM. Even so, the lack of explanation for some of the very low net accumulation years highlights that there are other factors, yet undetermined, that can affect local temperature.

A number of previous studies have identified relationships between glacier mass balance and the ENSO (e.g. Hooker and Fitzharris, 1999; Clare et al., 2002; Chinn et al., 2005b; Fitzharris et al., 2007). However, this was the first attempt in New Zealand to identify links between glacier mass balance and the SAM. Indeed, only the last paper (Chapter 5) of this thesis addresses the potential influence of the SAM. Prior to 2009 there had only been limited research into potential relationships between the SAM and the New Zealand climate (e.g. Renwick and Thompson, 2006). However, during 2009 after the majority of the thesis papers had been written, new more detailed information became available (e.g. Kidston et al., 2009; Ummenhofer et al., 2009) stimulating its inclusion in the final piece of research.

Phase changes in the SAM can be relatively short, only persisting for a period of several weeks at a time (Renwick and Thompson, 2006). Such a fast rate of change means that trends the SAM can be compared to relatively short mass balance data sets, a factor common to New Zealand, which often creates limitations when trying to make associations with decadal modes of atmospheric variability like the ENSO. These initial results indicate that the SAM should be considered in future glacier mass balanceclimate studies. All results obtained during this research reflect the importance of westerly atmospheric circulation anomalies to snow accumulation on glaciers, of which the SAM has influence.

\subsubsection{Implications of climate change on snow accumulation and glacier mass balance}

The fact that global climate is warming due to anthropogenic climate change is unequivocal (IPCC, 2007). The results of this research provide some insight into how 
mid-latitude maritime glaciers could response to climate change. Increasing ablation season temperatures not only reduce overall net accumulation (Table 5.2) but appear to reduce spatial variability in net accumulation (Figure 2.2), with lowest spatial variability associated with a year characterised by a hot, dry summer (Table 2.3). In effect, temperature increases could lead to simplification of glacier mass balance estimation due to increasing dominance of ablation relationships, which are somewhat better understood. In addition, increased temperatures would lead to greater amounts of snow metamorphism, potentially reducing the susceptibility of snow to wind redistribution processes, which currently contributes to a significant proportion of the spatial variability identified in net snow accumulation.

Although this research demonstrated how geochemical signatures in snow accumulation can help to identify moisture source regions (section 4.6.2) and annual accumulation layers (section 5.3.1), such signals will likely be lost as temperature increases. Even in our present climate, winter temperature in the accumulation area of FJG was found to rise above $0^{\circ} \mathrm{C}$ on a number of occasions (section 3.4.3). Post-depositional changes in snow chemistry (Figure 4.3) will be more pronounced as temperatures rise and meltwater percolation increases.

Even though it is certain that temperature will continue to increase over the coming decades, some uncertainty still surrounds the impact global warming will have on atmospheric circulation. Although it appears likely that the SAM will maintain a positive trend (Fyfe et al., 1999; Cai et al., 2005), the response of the ENSO is less clear (Fedorov and Philander, 2000; Mullan et al., 2001; Nyenzi and Lefale, 2006; Power and Smith, 2007). These uncertainties are a function of the chaotic and unpredictable nature of the climate system (Rind, 1999; Solomon et al., 2007). Even so, the strong influence of summer temperature on net accumulation means that glaciers in mid-latitude regions like the New Zealand Southern Alps are likely to experience reduced accumulation and more negative mass balance in the coming decades, especially if northerly and easterly circulation anomalies occur and/or the Tasman Sea continues to warm. 


\subsection{Future snow accumulation research}

This research identified a number of important factors that influence snow accumulation on maritime glaciers in the New Zealand Southern Alps. A conceptual model (Figure 6.2) and summary table (Table 6.1) derived from the results of this research highlight the factors and relationships that are relatively well defined, as well as those areas that still require further investigation.

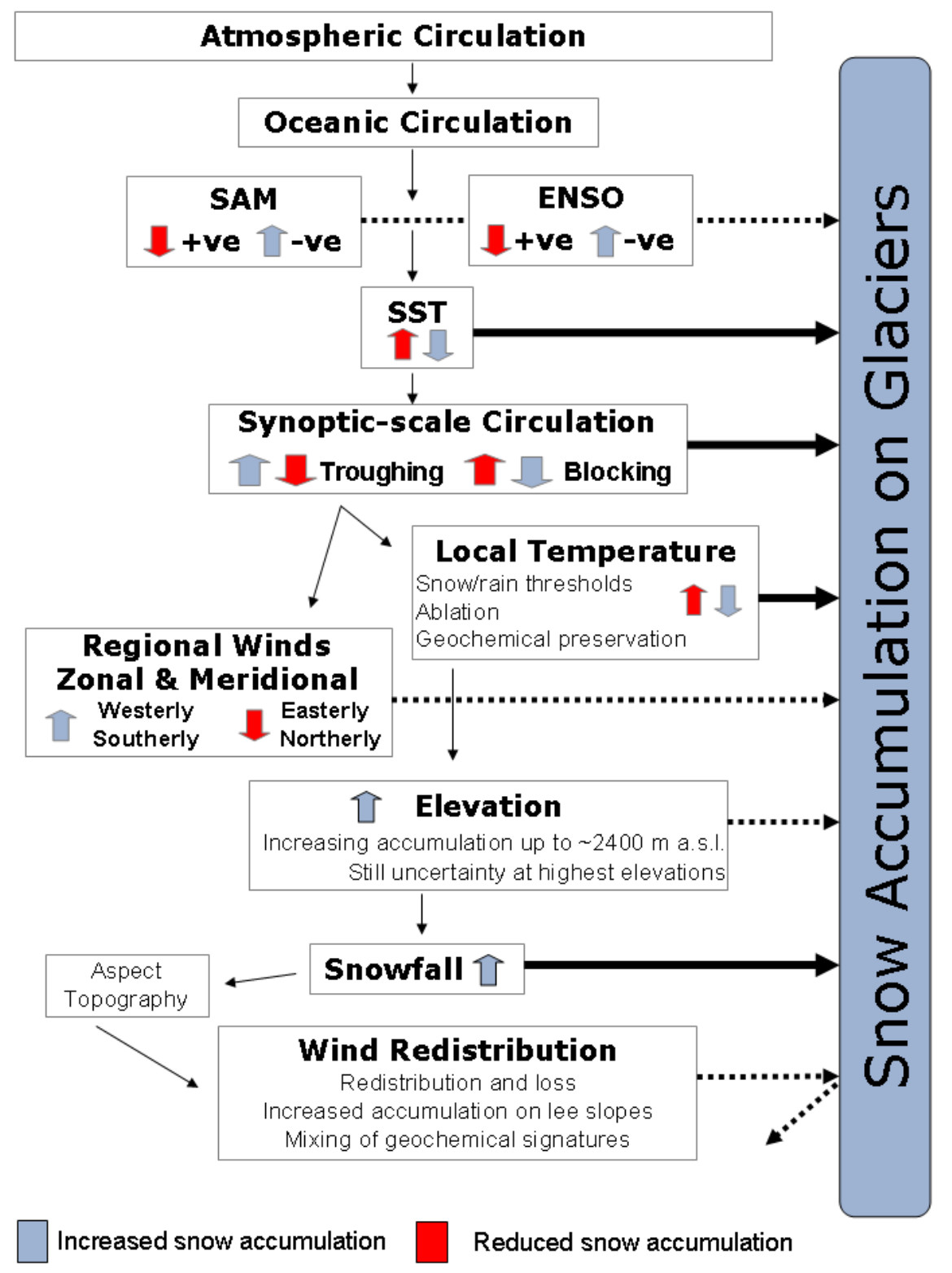

Figure 6.2: Conceptual model of the factors found to most influence snow accumulation on glaciers in the Southern Alps of New Zealand. Heavy dark arrows depict relationships that revealed strong correlations with accumulation, and these parameters should be included in future mass balance models. Dashed arrows indicate areas where relationships with snow accumulation were found, but further work is required in order to improve understanding. 
Table 6.1: Summary of parameters that were found to increase or decrease snow accumulation on glaciers in the Southern Alps of New Zealand. Parameters in italics are priorities for further research.

\begin{tabular}{|l|l|}
\hline \multicolumn{1}{|c|}{ Increased Snow Accumulation } & \multicolumn{1}{c|}{ Decreased Snow Accumulation } \\
\hline Negative SAM & Positive SAM \\
Negative SOI & Positive SOI \\
Increased westerly flow & Increased easterly flow \\
Increased southerly flow & Increased northerly flow \\
Increased Troughing (decreased Blocking) & Decreased Troughing (increased Blocking) \\
Decreased SST in Tasman Sea & Increased SST in Tasman Sea \\
Decreased Local Temperature & Increased Local Temperature \\
Increasing elevation up to $\sim 2400$ m a.s.l. & Areas above $\sim 2400$ m a.s.l. ? \\
& Wind deflation away from accumulation area \\
\hline
\end{tabular}

One key area requiring further work is the way that precipitation varies with increasing elevation, and with troughing synoptic regimes. Orographic processes were found to exert some control on net accumulation distribution (section 2.5.2), but our ability to accurately simulate precipitation enhancement between low elevation weather stations and glacier accumulation areas was limited (section 3.5.2). We still do not fully understand the precipitation gradient across the mountain range, especially at the very highest elevations (i.e. 2400 - $3500 \mathrm{~m}$ a.s.1.). Ideally to realise this goal, we need further snow accumulation measurement, in particular at elevations above $2300 \mathrm{~m}$ a.s.1., combined with the installation of high elevation weather stations. Some progress towards this ideal is currently underway, with NIWA developing a National Snow and Ice Monitoring Network (Hendrikx, 2009). This network includes the planned installation of weather stations above $2000 \mathrm{~m}$ a.s.l. that include snow measurement capabilities. Longer and more comprehensive meteorological data sets will assist in our understanding of the processes associated with snow accumulation more directly and may allow more complete physical models to be developed. In addition, identifying whether the potential decrease in accumulation at very high elevations is a result of decreased precipitation, wind deflation, gravitational transport, or some combination of these processes would enable improved snow accumulation parameterisation. High resolution GPR surveys may be able to distinguish between snow that has fallen as precipitation and that which has avalanched onto the glacier surface, going some way to clarifying the precipitation gradient. 
In all aspects of this research wind redistribution and deflation played a role at determining the quantity of snow deposited around glacier catchment as well as potentially affecting the quality of the geochemical signature preserved. Although acknowledged that there are a number of advanced snow redistribution models available (e.g. Liston and Elder, 2006; Lehning et al., 2008), it has already been highlighted that the required input data is not. Further refinement of statistical relationships between wind, topography, and snow accumulation distribution, will assist in snow accumulation estimation. Alternatively, defining and creating generalised wind fields for glacier catchments can improve glacier mass balance modelling (Dadic et al., 2010), although this still requires improved knowledge (i.e. measurement) of wind speed and direction in alpine catchments.

The potentially rapid post-depositional modification of stable isotope and trace element geochemistry means that the New Zealand Southern Alps are an ideal location to further our understanding of isotopic fractionation and trace element mobility, as these processes can be monitored over relatively short time periods. In addition, quantification of the impact that wind redistribution and sublimation have on geochemical signature preservation in the snowpack is essential, as this could potentially influence the accuracy of annual layer information. The fact that an annual signal was preserved for at least one full melt season indicates that geochemical analysis of shallow cores $(\sim 20 \mathrm{~m})$ can still be a valuable tool for determining net accumulation in strongly maritime climates. Such cores could provide a relatively fast way of retrieving accumulation information from a number of glaciers, especially those that are small, remote, and have limited crevassing.

The finding that the SAM has some influence on snow accumulation variability at an inter-annual scale is promising and should be explored further. Many previous studies have explored relationships between the ENSO and glacier mass balance, but this was the first study in New Zealand that has explored relationships between the SAM and glacier mass balance in any detail. Importantly, the inability at times of atmospheric circulation and regional flow anomalies to explain local climate phenomena and glacier response (section 5.4.2) means that more work is required at refining local glacierclimate relationships. If large-scale global atmospheric models are to be meaningfully downscaled (WCRP, 2009) then we need to make some attempt to explain the years 
when local wind and temperature anomalies do not match larger scale atmospheric patterns.

Finally, the strong relationship found between net accumulation and SST, especially in the ablation season, is interesting and offers potential for further investigation. It may be that already established Hadley Centre SST prediction models (Rayner et al., 2003) can provide important input for future glacier mass balance models. Indeed, an immediate follow up to this research would be analysing the strength of relationship between SST and net accumulation on a number of other glaciers in the Southern Alps. If, as at Tasman Glacier, relationships prove to be strong, then a SST predication model should be trialled for annual net accumulation estimation. 


\section{References}

Aizen V., Aizen E., Fujita K., Nikitin S., Kreutz K. J. and Takeuchi N. 2005. Stable-isotope time series and precipitation origin from firn-core and snow samples, Altai glaciers, Siberia. Journal of Glaciology, 51: 637-654.

Aizen V., Mayewski P., Aizen E., Joswiak D., Surazakov A., Kaspari S., Grigholm B., Krachler M., Handley M. and Finaev A. 2009. Stable-isotopes and trace element time series from Fedchenko glacier (Pamirs) snow/firn cores. Journal of Glaciology, 55: 275-291.

Alean J., Haeberli W. and Schadler B. 1983. Snow accumulation, firn temperature and solar radiation in the area of the Colle Gnefetti core drilling site (Monte Rosa, Swiss Alps): Distribution patterns and interrelationships. Zeitschrift Für Gletscherkunde und Glazialgeologie, 19: 131-147.

Anderson B., Lawson W., Owens I. and Goodsell B. 2006. Past and future mass balance of 'Ka Roimata o Hine Hukatere' Franz Josef Glacier, New Zealand. Journal of Glaciology, 52: 597-607.

Anderson B. and Mackintosh A. 2006. Temperature change is the major driver of late-glacial and Holocene glacier fluctuations in New Zealand. Geology, 34: 121-124.

Anderson B., Lawson W. and Owens I. 2008. Response of Franz Josef Glacier Ka Roimata o Hine Hukatere to climate change. Global and Planetary Change, 63: 2330.

Anderson B., Mackintosh A., Stumm D., George L., Kerr T., Winter-Billington A. and Fitzsimons S. 2010. Climate sensitivity of a high precipitation glacier in New Zealand. Journal of Glaciology, 56: 114-128.

Anderton P. 1975: Tasman Glacier 1971-1973, Ministry of Works and Development for the National Water and Soil Conservation Organisation, Wellington.

Anderton P. W. and Chinn T. 1978. Ivory Glacier, New Zealand, an I.H.D. representative basin study. Journal of Glaciology, 20: 67-84.

Anderton S. P., White S. M. and Alvera B. 2004. Evaluation of spatial variability in snow water equivalent for a high mountain catchment. Hydrological Processes, 18: 435-453.

Andreassen L., Elvehøy H. and Kjøllmoen B. 2005. Glacier mass-balance and length variation in Norway. Annals of Glaciology, 42: 317-325. 
Appelhans T. 2009. An air pollution climatology for Christchurch, New Zealand, The seventh International Conference on Urban Climate, 29 June- 3 July, Yokohama, Japan.

Araguas-Araguas L., Froehlich K. and Rozanski K. 2000. Deuterium and oxygen-18 isotope composition of precipitation and atmospheric moisture. Hydrological Processes, 14: 1341-1355.

Arnason B. 1969. The exchange of hydrogen isotopes between ice and water in temperate glaciers. Earth and Planetary Science Letters, 6: 423-430.

Arnason B. 1981. Chapter 7: Ice and Snow Hydrology, in Gat, J.R and Gonfiantini, R, Stable isotope hydrology: Deuterium and Oxygen -18 in the water cycle, International Atomic Energy Agency (IAEA), Vienna, 143-175.

Australian Bureau of Meteorology. 2009. The Southern Oscillation Index (SOI), http://www.bom.gov.au/climate/current/soihtm1.shtml. .

Baldi M., Salinger J., Dirks K. and McGregor G. 2009. Winter hospital admissions and weather types in the Auckland region, 9th International Conference on Southern Hemisphere Meteorology and Oceanography, Melbourne, Australia, 9-13 February.

Barringer J. 1989. A variable lapse rate snowline model for The Remarkables, Central Otago, New Zealand. Journal of Hydrology (NZ), 28: 32-46.

Barry R. 1992: Mountain Weather and Climate, Routledge, London.

Barstad I., Grabowski W. and Smolarkiewicz P. 2007. Characteristics of largescale orographic precipitation: Evaluation of linear model in idealized problems. Journal of Hydrology, 340: 78-90.

Bell J. M. 1910: A Geographical Report on the Franz Josef Glacier, New Zealand Geographical Survey, Wellington, New Zealand Geographical Survey, Wellington.

Bertler N., Mayewski P., Sneed S., Naish T., Morgenstern U. and Barrett P. 2005. Solar forcing recorded by aerosol concentrations in coastal Antarctica glacier ice, McMurdo Dry Valleys. Annals of Glaciology, 41: 52-56.

Bidlake W. R., Josberger E. G. and Savoca M. E. 2007: Water, ice and meteorological measurements at South Cascade Glacier, balance years 2004 and 2005, U.S Geological Survey Scientific Investigations Report 2007-5055, 69p,

Braithwaite R. 1984. Can the mass balance of a glacier be estimated from its equilibrium-line altitude? Journal of Glaciology, 30: 364-368. 
Braithwaite R., Zhang Y. and Raper S. 2002. Temperature sensitivity of the mass balance of mountain glaciers and ice caps as a climatological characteristic. Zeitschrift Fur Gletscherkunde Und Glazialgeologie, 38: 35-61.

Braithwaite R. J. 1981. On glacier energy balance, ablation and air temperature. Journal of Glaciology, 27: 381-391.

Braithwaite R. J. and Zhang Y. 2000. Sensitivity of mass balance of five Swiss glaciers to temperature changes assessed by tuning a degree-day model. Journal of Glaciology, 46: 7-14.

Brenstrum E. 1998: The New Zealand Weather Book, Craig Potton Publishing, Nelson.

Brodrick T. N. 1889. Report on the glaciers of Mount Cook. Appendix to the Journal of the House of Representatives of New Zealand, Vol 1, C-1A: 32-33.

Brodrick T. N. 1891. Report on the Tasman Glacier. Appendix to the Journal of the House of Representatives of New Zealand, Vol 1, C-1A: 39-43.

Brodrick T. N. 1894. Ice motion of the Canterbury glaciers. New Zealand Alpine Journal, 1: 307-316.

Bury S. 2001. Chapter 12: Oceans and their circulation, in Sturman, Andrew and Spronken-Smith, Rachel, The Physical Environment: A New Zealand Perspective, Oxford University Press, Oxford,

Cai W., Shi G., Cowan T., Bi D. and Ribbe J. 2005. The response of the Southern Annular Mode, the East Australian Current, and the southern mid-latitude ocean circulation to global warming. Geophysical Research Letters, 32: 1-4.

Carter L. 2001. Currents of change: the ocean flow in a changing world. NIWA Water \& Atmosphere, 9: 15-17.

Chinn T. J. 1968. Snow surveys on the Tasman Glacier. New Zealand Alpine Journal, 22: 411-416.

Chinn T. J. 1969: Tasman Glacier snow observations 1968-69 glacial year report, Ministry of Works, Timaru.

Chinn T. J. 1994: Snow and ice balance measurements from the Tasman Glacier, Waitaki Catchment, New Zealand, Institute of Geological and Nuclear Sciences Ltd, Lower Hutt.

Chinn T. J. 1995. Glacier fluctuations in the Southern Alps of New Zealand determined from snowline elevations. Arctic and Alpine Research, 27: 187-198. 
Chinn T. J. 1996. New Zealand glacier responses to climate change in the past century. New Zealand Journal of Geology and Geophysics, 39: 415-428.

Chinn T. J. 1999. New Zealand glacier response to climate change of the past 2 decades. Global and Planetary Change, 22: 155-168.

Chinn T. J. 2001. Distribution of the glacial water resources of New Zealand. Journal of Hydrology (NZ), 40: 139-187.

Chinn T. J., Heydenrych C. and Salinger M. J. 2005a. Use of the ELA as a practical method of monitoring glacier response to climate in New Zealand's Southern Alps. Journal of Glaciology, 51: 85-95.

Chinn T. J., Winkler S., Salinger M. J. and Haakense N. 2005b. Recent glacier advances in Norway and New Zealand: a comparison of their glaciological and meteorological causes. Geografiska Annaler, 87 A: 141-157.

Chinn T. J., Salinger J., Fitzharris B. and Willsman A. submitted. Annual ice volume changes 1976-2008 for the New Zealand Southern Alps. Arctic, Antarctic and Alpine Research,

Clare G. R., Fitzharris B. B., Chinn T. J. and Salinger M. J. 2002. Interannual variation in end-of-summer snowlines of the Southern Alps of New Zealand, and relationships with Southern Hemisphere atmospheric circulation and sea surface temperature patterns. International Journal of Climatology, 22: 107-120.

Colle B. 2004. Sensitivity of orographic precipitation to changing ambient conditions and terrain geometrics: An idealized modeling perspective. Journal of the Atmospheric Sciences, 61: 588-606.

Copland L. 1998. The use of terrain analysis in the evaluation of snow cover over an alpine glacier., in Lane, S.N, Richards, K.S. and Chandler, J.H., Landform Monitoring, Modelling and Analysis, John Wiley \& Sons, Chichester, 385-404.

Cutler E. and Fitzharris B. 2005. Observed surface snowmelt at high elevation in the Southern Alps of New Zealand. Annals of Glaciology, 40: 163-168.

Dadic R. 2008. Monitoring and Modeling Snow Accumulation Processes in Glacerized Alpine Basins, unpublished PhD thesis, ETH Zurich.

Dadic R., Mott R., Lehning M. and Burlando P. 2010. Wind influence on snow depth distribution and accumulation over glaciers. Journal of Geophysical Research, DOI:10.1029/2009JF001261:

Dansgaard W. 1964. Stable isotopes in precipitation. Tellus, 16: 436-468. 
De Woul M. and Hock R. 2005. Static mass-balance sensitivity of Arctic glaciers and ice caps using a degree-day approach. Annals of Glaciology, 42: 217-224.

Dewalle D. and Rango A. 2008: Principles of Snow Hydrology, Cambridge University Press, Cambridge.

Douglas C. E. 1894. On the Westland Alps. Appendix to the Journal of the House of Representatives of New Zealand, C-1, Appendix No 6, 71-75.

Dow M. 1998. Provenance and geochemical signatures of lake sediments, unpublished MSc thesis, University of Otago.

Draxler R. R. and Rolph G. D. 2003. 'HYSPLIT (HYbbrid Single-Particle Lagrangian Integrated Trajectory) Model access via NOAA ARL READY Website (http://www.arl.noaa.gov/HYSPLIT.php). NOAA Air Resources laboratory, Silver Spring, MD.'

Dunn M., Hurst R., Renwick J., Francis C., Devine J. and Mckenzie A. New Zealand Aquatic Environment and Biodiversity Report 31. 2009: Fish abundance and climate trends in New Zealand, New Zealand Aquatic Environment and Biodiversity Report 31, National Institute of Water and Atmospheric Science, Wellington, Wellington.

Dunse T., Schuler T., Hagen J., Eiken T., Brandt O. and Høgda K. 2009. Recent fluctuations in the extent of the firn area of Austfonna, Svalbard, inferred from GPR. Annals of Glaciology, 50: 155-162.

Dykes R. and Brook M. 2010. Terminus resession, proglacial lake expansion and 21st century calving retreat of Tasman Glacier, New Zealand. New Zealand Geographer, 66: 203-217.

Earman S., Campbell A., Phillips F. and Newman B. 2006. Isotopic exchange between snow and atmospheric water vapor: Estimation of the snowmelt component of groundwater recharge in the southwestern United States. Journal of Geophysical Research, 111:

Eichler A., Schwikowski M. and Gaggeler H. 2001. Meltwater-induced relocation of chemical species in alpine firn. Tellus, 53B: 192-203.

Elder K., Dozier J. and Michaelsen J. 1991. Snow accumulation and distribution in an alpine watershed. Water Resources Research, 27: 1541-1552.

Elder K., Rosenthal W. and Davis R. 1998. Estimating the spatial distribution of snow water equivalence in a montane watershed. Hydrological Processes, 12: 17931808. 
Fedorov A. and Philander S. 2000. Is El Niño changing? Science, 288: 19972002.

Fisher D., Koerner R., Bourgeois J., Zielinski G., Wake C., Hammer S., GotoAzuma K. and Hondoh T. 1998. Penny Ice Cap cores, Baffin Island, Canada and the Wisconsinan Foxe Dome connection: Two states of Hudson Bay ice cover. Science, 279: 692-695.

Fisher D., Osterberg E., Dyke A., Dahl-Jensen D., Demuth M., Zdanowicz C., Bourgeois J., Koerner R., Mayewski P., Wake C., Kreutz K., Steig E., Zheng J., Yalcin K., Goto-Azuma K., Luckman B. and Rupper S. 2008. The Mt Logan Holocene-late Wisconsinan isotope record: tropical Pacific-Yukon connections. The Holocene, 18: 667-677.

Fitzharris B. and Garr C. E. 1995. Simulation of past variability in seasonal snow in the Southern Alps, New Zealand. Annals of Glaciology, 21: 377-382.

Fitzharris B., Clare G. R. and Renwick J. 2007. Teleconnections between Andean and New Zealand glaciers. Global and Planetary Change, 59: 159-174.

Fitzharris B. B., Hay J. E. and Jones P. D. 1992. Behaviour of New Zealand glaciers and atmospheric circulation changes over the past 130 years. The Holocene, 2: 97-106.

Fitzharris B. B., Chinn T. J. and Lamont G. N. 1997. Glacier balance fluctuations and atmospheric circulation patterns over the Southern Alps, New Zealand. International Journal of Climatology, 17: 745-763.

Folland C. 2008. 'Interdecadal Pacific Oscillation time series', http://www.iges.org/c20c/IPO_v2.doc.

Fountain A. and Vecchia A. 1999. How many stakes are required to measure the mass balance of a glacier? Geografiska Annaler. Series A, Physical Geography, 81: 563-573.

Froehlich K., Kralik M., Papesch W., Rank D., Scheifinger H. and Stichler W. 2008. Deuterium excess in precipitation of Alpine regions - moisture recycling. Isotopes in Environmental and Health Studies, 44: 61-70.

Fyfe J. C., Boer G. J. and Flato G. M. 1999. The Arctic and Antarctic Oscillations and their projected changes under global warming. Geophysical Research Letters, 26: 1601-1604. 
Gabrielle P., Cozzi G., Torcini S., Cescon P. and Barbante C. 2008. Trace elements in winter snow of the Dolomites (Italy): A statistical study of natural and anthropogenic contributions. Chemoshpere, 72: 1504-1509.

Gaillardet J., Viers J. and Dupre B. 2007. Trace Elements in River Waters, in Holland, Heinrich and Turekian, Karl, Treatise on Geochemistry, Elsevier Ltd,

Gilfedder B. S., Petri M. and Biester H. 2007. Iodine and bromine speciation in snow and the effect of orographically induced precipitation. Atmospheric Chemistry and Physics, 7: 2661-2669.

Ginot P., Schwikowski M., Schotterer U., Stichler W., Gaggeler H., Francou B., Gallaire R. and Pouyaud B. 2002. Potential for climate variability reconstruction from Andean glaciochemical records. Annals of Glaciology, 35: 443-450.

Goldthwait R. and McKellar I. Wexler, H, Rubin, M.J and Caskey, J.E.Jr. 1962: New Zealand Glaciology, American Geophysical Union, Washington, D.C.

Goto-Azuma K., Nakawo M., Shimizu M., Azuma N., Nakayama M. and Yokoyama K. 1993. Temporal changes in chemical stratigraphy of snow cover. Annals of Glaciology, 18: 85-91.

Goto-Azuma K., Koerner R. and Fisher D. 2002. An ice-core record over the last two centuries from Penny Ice Cap, Baffin Island, Canada. Annals of Glaciology, 35: 29-35.

Grabiec M., Leszkiewicz J., Glowacki P. and Jania J. 2006. Distribution of snow accumulation on some glaciers of Spitsbergen. Polish Polar Research, 27: 309-326.

Greuell W. and Konzelmann T. 1994. Numerical modelling of the energy balance and the englacial temperature of the Greenland Ice Sheet. Calculations for the ETH-Camp location (West Greenland, $1155 \mathrm{~m}$ a.s.1.). Global and Planetary Change, 9: 91-114.

Griffiths G. and McSaveney M. J. 1983. Distribution of mean annual precipitation across some steepland regions of New Zealand. New Zealand Journal of Science, 26: 197-209.

Grundstein A. 2003. A synoptic-scale climate analysis of anomalous snow water equivalent over the Northern Great Plains of the USA. International Journal of Climatology, 23: 871-886.

Guan H., Simmons C. and Love A. 2009. Orographic controls on rain water isotope distribution in the Mount Lofty Ranges of South Australia. Journal of Hydrology, 374: 255-264. 
Gunn B. M. 1964. Flow rates and secondary structures of Fox and Franz Josef Glaciers, New Zealand. Journal of Glaciology, 5: 173-190.

Haast J. 1864. Notes on the Mountains and Glaciers of the Canterbury Province, New Zealand. Journal of the Royal Geographical Society of London, 34: 87-96.

Harper A. P. 1894. The Franz Josef Glacier. Appendix to the Journal of the House of Representatives of New Zealand, C-1, Appendix No 6, 75-79.

Hashimoto S., Shiqiao Z., Nakawo M., Sakai A., Ageta Y., Ishikawa N. and Narita H. 2002. Isotope studies of inner snow layers in a temperate region. Hydrological Processes, 16: 2209-2220.

Hay J. E. and Fitzharris B. B. 1988. The synoptic climatology of ablation on a New Zealand glacier. Journal of Climatology, 8: 201-215.

He Y., Theakstone W., Tandong Y., Guodong C., Dian Z. and Meixue Y. 2002. Winter-season climatic signals in the recently deposited snowpack on a Norwegian alpine glacier. Nordic Hydrology, 33: 111-122.

Henderson R. D. and Thompson S. M. 1999. Extreme rainfalls in the Southern Alps of New Zealand. Journal of Hydrology (NZ), 38: 309-330.

Hendrikx J. 2005. An examination of the snow and avalanche hazard on the Milford Road, Fiordland, New Zealand, unpublished PhD thesis, University of Canterbury.

Hendrikx J. 2009. NIWA's National Snow and Ice Monitoring Network. The Canterbury Mountaineer, 65: 58-59.

Hessell J. W. D. 1983. Climatic effects on the recession of the Franz Josef Glacier. New Zealand Journal of Science, 26: 315-320.

Hochstein M., Claridge D., Henrys S., Pyne A., Nobes D. and Leary S. 1995. Downwasting of the Tasman Glacier, South Island, New Zealand: changes in the terminus region between 1971 and 1993. New Zealand Journal of Geology and Geophysics, 38: 1-16.

Hock R. 2005. Glacier melt: a review of processes and their modelling. Progress in Physical Geography, 29: 362-391.

Hock R., De Woul M., Radic V. and Dyurgerov M. 2009. Mountain glaciers and ice caps around Antarctica make a large se-level rise contribution. Geophysical Research Letters, 36: DOI: 10.1029/2008GL037020. 
Hodge S., Trabant D., Krimmel R., Heinrichs T., March R. and Josberger E. 1998. Climate variation and changes in mass of three glaciers in Western North America. Journal of Climate, 11: 2161-2179.

Hodgkins R., Cooper R., Wadham J. and Tranter M. 2005. Interannual variability in the spatial distribution of winter accumulation at a high-Arctic glacier (Finsterwalderbreen, Svalbard), and its relationship with topography. Annals of Glaciology, 42: 243-248.

Hoelzle M., Chinn T., Stumm D., Paul F., Zemp M. and Haeberli W. 2007. The application of glacier inventory data for estimating past climate change effects on mountain glaciers: A comparison between the European Alps and the Southern Alps of New Zealand. Global and Planetary Change, 56: 69-82.

Holdsworth G. and Krouse H. R. 2002. Altitudinal variation of the stable isotopes of snow in regions of high relief. Journal of Glaciology, 48: 31-41.

Hooker B. L. and Fitzharris B. B. 1999. The correlation between climatic parameters and the retreat and advance of Franz Josef Glacier, New Zealand. Global and Planetary Change, 22: 39-48.

IAEA. 2010. GIS mapping for analysis, visualization and retrieval of hydrochemical and isotope data for local to global scales - Global Network of Isotopes in Precipitation, International Atomic Energy Agency (IAEA), Vienna. http://nds121.iaea.org/wiser/index.php, accesssed 2010.

IPCC 2007. Summary for Policymakers, in Climate Change 2007: The Physical Science Basis. Contribution of Working Group 1 to the Fourth Assessment Report of the Intergovernmental Panel on Climate Change, Cambridge,

Ishikawa N., Owens I. F. and Sturman A. P. 1992. Heat balance characteristics during fine periods on the lower parts of the Franz Josef Glacier, South Westland, New Zealand. International Journal of Climatology, 12: 397-410.

Jansson P., Linderholm H., Pettersson R., Karlin T. and Mörth C.-M. 2007. Assessing the possibility to couple the chemical signal in winter snow on Storglaciären, Sweden, to atmospheric climatology. Annals of Glaciology, 46: 335-341.

Jansson P. and Pettersson R. 2007. Spatial and temporal characteristics of a long mass balance record, Storglaciären, Sweden. Arctic, Antarctic and Alpine Research, 39: 432-437. 
Jin J., Miller N., L, Sorooshian S. and Gao X. 2006. Relationship between atmospheric circulation and snowpack in the western USA. Hydrological Processes, 20: 753-767.

Johannesson T., Raymond C. and Waddington E. 1989. Time-Scale for Adjustment of Glaciers to Changes in Mass Balance. Journal of Glaciology, 35: 355369.

Jones P. and Moberg A. 2003. Hemispheric and large-scale surface air temperature variations: An extensive revision and an update to 2001. Journal of Climate, 16: 206-223.

Josberger E., Bidlake W., March R. and Kennedy B. 2007. Glacier mass-balance fluctuations in the Pacific Northwest and Alaska, USA. Annals of Glaciology, 46: 291296.

Jouzel J., Lorius C., Petit J. R., Genthon C., Barkov N. I., Kotlyakov V. M. and Petrov V. M. 1987. Vostok ice core: a continuous isotope temperature record over the last climatic cycle (160,000 years). Nature, 329: 403-408.

Jouzel J., Masson-Delmotte V., Stievenard M., Landais A., Vimeux F., Johnsen S., Sveinbjornsdottir A. and White J. W. C. 2005. Rapid deuterium-excess changes in Greenland ice cores: a link between the ocean and atmosphere. C.R. Geoscience, 337: 957-969.

Jouzel J., Stievenard M., Johnsen S., Landais A., Masson-Delmotte V., Sveinbjornsdottir A., Vimeux F., von Grafenstein U. and White J. W. C. 2007. The GRIP deuterium-excess record. Quaternary Science Reviews, 26: 1-17.

Kahl J. 1993. A cautionary note on the use of air trajectories in interpreting atmospheric chemistry measurements. Atmospheric Environment, 27A: 3037-3038.

Kahl J., Martinez D., Kuhns H., Davidson C., Jaffrezo J.-L. and Harris J. 1997. Air mass trajectories to Summit, Greenland: A 44-year climatology and some episodic events. Journal of Geophysical Research, 102: (C12), 26861-26875.

Kameda T., Fujii Y., Nishio F., Savatyugin L., Arkhipov S., Ponomarev I. and Mikhailov N. 2003. Seasonality of isotopic and chemical species and biomass burning signals remaining in wet snow in the accumulation area of Sofiyskiy Glacier, Russian Altai Mountains. Polar Meteorology and Glaciology, 17: 15-24.

Karpechko A., Gillet N., Marshall G. and Screen J. 2009. Climate impacts of the Southern Annular Mode simulated by the CMIP3 models. Journal of Climate, 22: 37513768. 
Kaspari S., Mayewski P., Dixon D., Spikes V., Sneed S., Handley M. and Hamilton G. 2004. Climate variability in West Antarctica derived from annual accumulation-rate records from ITASE firn/ice cores. Annals of Glaciology, 39: 585594.

Kaspari S., Hooke R., Mayewski P., Kang S., Hou S. and Qin D. 2008. Snow accumulation rate on Qomolangma (Mount Everest), Himalaya: synchroneity with sites across the Tibetan Plateau on 50-100 year timescales. Journal of Glaciology, 54: 343352.

Kelliher F. M., Owens I. F., Sturman A. P., Byers J. N., Hunt J. E. and McSeveny T. M. 1996. Radiation and ablation on the névé of Franz Josef Glacier. Journal of Hydrology (NZ), 35: 131-150.

Kennedy P. and Gadd J. 2003: Preliminary Examination of Trace Elements in Tyres, Brake Pads and Road Bitumen in New Zealand, prepared for Ministry of Transport by Kingett Mitchell Ltd, New Zealand,

Kerr T. 2009. Precipitation distribution in the Lake Pukaki Catchment, New Zealand, unpublished $\mathrm{PhD}$ Thesis, University of Canterbury.

Kidson J. 1994. Relationship of New Zealand daily and monthly weather patterns to synoptic weather types. International Journal of Climatology, 14: 723-737.

Kidson J. 2000. An analysis of New Zealand synoptic types and their use in defining weather regimes. International Journal of Climatology, 20: 299-316.

Kidston J., Renwick J. and McGregor J. 2009. Hemispheric-scale seasonality of the Southern Annular Mode and impacts on the climate of New Zealand. Journal of Climate, 22: 4759-4770.

Kienzle S. 2008. A new temperature based method to separate rain and snow. Hydrological Processes, 22: 5067-5085.

Kind R. J. 1981. Chapter 8: Snow Drifting, in Gray, D.M and Male, D.H, Handbook of Snow: Principles, Processes, Management and Use, The Blackburn Press, Caldwell,

Kirkbride M. and Warren C. 1999. Tasman Glacier, New Zealand: $20^{\text {th }}$-century thinning and predicted retreat. Global and Planetary Change, 22: 11-28.

Kirkbride M. P. 1995. Relationships between temperature and ablation on the Tasman Glacier, Mount Cook National Park, New Zealand. New Zealand Journal of Geology and Geophysics, 38: 17-27. 
Koerner R. 1997. Some comments on climate reconstructions from ice cores drilled in areas of high melt. Journal of Glaciology, 43: 90-97.

Kreutz K. J., Mayewski P., Twickler M. S., Whitlow S. I., White J. W. C., Shuman C. A., Raymond C. F., Conway H. and McConnell J. R. 1999. Seasonal variations of glaciochemical, isotopic and stratigraphic properties in Siple Dome (Antarctica) surface snow. Annals of Glaciology, 29: 38-44.

Kuhn M. 2003. Redistribution of snow and glacier mass balance from a hydrometeorological model. Journal of Hydrology, 282: 95-103.

Lapen D. and Martz L. 1996. An investigation of the spatial association between snow depth and topography in a prairie agricultural landscape using digital terrain analysis. Journal of Hydrology, 184: 277-298.

Lefebvre W., Goosse H., Timmermann R. and Fichefet T. 2004. Influence of the Southern Annular Mode on the sea ice-ocean system. Journal of Geophysical Research, 109: doi: 10.1029/2004JC002403.

Legrand M. and Mayewski P. 1997. Glaciochemistry of polar ice cores: a review. Reviews of Geophysics, 35: 219-243.

Lehning M., Bartelt P., Brown B., Russi T., Stockli U. and Zimmerli M. 1999. SNOWPACK model calculations for avalanche warning based upon a new network of weather and snow stations. Cold regions Science and Technology, 30: 145-157.

Lehning M., Lowe H., Ryser M. and Raderschall N. 2008. Inhomogeneous precipitation distribution and snow transport in steep terrain. Water Resources Research, 44: 1-19.

Leiva J. C., Cabrera G. A. and Lenzano L. E. 2007. 20 years of mass balances on the Piloto Glacier, Las Cuevas river basin, Mendoza, Argentina. Global and Planetary Change, 59: 10-16.

Liston G. and Sturm M. 1998. A snow-transport model for complex terrain. Journal of Glaciology, 44: 498-516.

Liston G. and Elder K. 2006. A Distributed Snow-Evolution Modeling System (SnowModel). Journal of Hydrometeorology, 7: 1259.

Lorrey A., Fowler A. and Salinger J. 2007. Regional climate regime classification as a qualitative tool for interpreting multi-proxy palaeoclimate data spatial patterns: A New Zealand case study. Palaeogeography, Palaeoclimatology, Palaeoecology, 253: 407,433. 
Lorrey A., Williams P., Salinger J., Martin T., Palmer J., Fowler A., Zhao J.-x. and Neil H. 2008. Speleothem stable isotope records interpreted within a multi-proxy framework and implications for New Zealand palaeoclimate reconstruction. Quaternary International, 187: 52-75.

Machguth H., Eisen O., Paul F. and Hoelzle M. 2006. Strong spatial variability of snow accumulation observed with helicopter-borne GPR on two adjacent Alpine glaciers. Geophysical Research Letters, 33: 1-5.

Marcus M. G., Moore R. D. and Owens I. F. 1985. Short-term estimates of surface energy transfers and ablation on the lower Franz Josef Glacier, South Westland, New Zealand. New Zealand Journal of Geology and Geophysics, 28: 559-567.

Marshall G. 2003. Trends in the Southern Annular Mode from observations and reanalyses. Journal of Climate, 16: 4134-4145.

Marshall G. 2007. Half-century seasonal relationships between the Southern Annular Mode and Antarctic temperatures. International Journal of Climatology, 27: $373-383$.

Marshall G., 2009, 'The Southern Annular Mode, http://www.antarctica.ac.uk/met/gjma/sam.html'.

Marx S., Kamber B. and McGowan H. 2005. Provenance of long-travelled dust determined with ultra-trace-element composition: a pilot study with samples from New Zealand glaciers. Earth Surface Processes and Landforms, 30: 699-716.

Mayewski P. and White F. 2002: The Ice Chronicles, University Press of New England, Hanover.

McCabe G., Fountain A. and Dyurgerov M. 2000. Variability in winter mass balance of Northern Hemisphere glaciers and relations with atmospheric circulation. Arctic, Antarctic and Alpine Research, 32: 64-72.

McKendry I., Sturman A. and Owens I. 1986. A study of interacting multi-scale wind systems, Canterbury Plains, New Zealand. Meteorology and Atmospheric Physics, 35: $242-252$.

McSaveney M. J. and Gage M. 1968. Ice flow measurements on Franz Josef Glacier, New Zealand, in 1966. New Zealand Journal of Geology and Geophysics, 11: 564-592.

Meier M. F. and Post A. S. 1962. Recent variations in mass net budgets of glaciers in Western North America. IASH Publication, 58: 63-77. 
Meier M. F., Armstrong R. and Dyurgerov M. 1997. Comments on "Annual net balance of North Cascade glaciers 1984-1994" by Mauri S. Pelto. Journal of Glaciology, 43: 192-193.

Meneghini B., Simmonds I. and Smith I. 2007. Association between Australian rainfall and the Southern Annular Mode. International Journal of Climatology, 27: 109121.

Miller M. and Pelto M. 1999. Mass balance measurements on the Lemon Creek Glacier, Juneau Icefield, Alaska 1953-1998. Geografiska Annaler, Series 'A' Physical Geography, 81: 671-681.

Millero F. J. 2007. Physicochemical Controls on Seawater, in Volume 6: The Oceans and Marine Geochemistry, in Holland, Heinrich and Turekian, Karl, Treatise on Geochemistry, Elsevier Ltd,

Moore G., Holdsworth G. and Alverson K. 2002. Climate change in the North Pacific region over the past three centuries. Nature, 402: 401-403.

Moore R. D. and Owens I. F. 1984. Modelling alpine snow accumulation and ablation using daily climate observations. Journal of Hydrology (NZ), 23: 73-83.

Morgenstern U., Mayewski P., Bertler N. and Ditchburn B. 2004. Ice core research in the New Zealand Southern Alps. Geophysical Research Abstracts, 6:

Moser H. and Stichler W. 1970. Deuterium measurements on snow samples from the Alps., Isotope Hydrology, 1970, IAEA, Wien,

Moskalyk R. and Alfantazi A. 2003. Processing of vanadium: a review. Minerals Engineering, 16: 793-805.

Mott R., Faure F., Lehning M., Lowe H., Hynek B., Michlmayer G., Prokop A. and Schoner W. 2008. Simulation of seasonal snow-cover distribution for glacerized sites on Sonnblick, Austria, with the Alpine 3D model. Annals of Glaciology, 49: 155160.

Mullan B. 1995. On the linearity and stability of Southern Oscillation-climate relationships for New Zealand. International Journal of Climatology, 15: 1365-1386.

Mullan B., Wratt D. and Renwick J. 2001. Transient model scenarios of climate changes for New Zealand. Weather and Climate, 21: 3-34.

Mullan B. 2009. How might weather patterns change under climate warming, Climate and Oceans, New Zealand Marine Sciences and Meteorological Societies Joint Conference, Auckland, 2-4 September. 
Muskett R., Lingle C., Sauber J., Rabus B. and Tangborn W. 2008. Acceleration of surface lowering on the tidewater glaciers of Icy Bay, Alaska, U.S.A. from InSAR DEMs and ICESat altimetry. Earth and Planetary Science Letters, 265: 345-359.

Nakazawa F., Fujita K., Takeuchi N., Fujiki T., Uetake J., Aizen V. and Nakawo M. 2005. Dating of seasonal snow/firm accumulation layers using pollen analysis. Journal of Glaciology, 51: 483-490.

Neale S. M. and Fitzharris B. 1997. Energy balance and synoptic climatology of a melting snowpack in the Southern Alps, New Zealand. International Journal of Climatology, 17: 1595-1609.

Nesje A., Lie O. and Dahl S. O. 2000. Is the North Atlantic Oscillation reflected in Scandinavian glacier mass balance records? Journal of Quaternary Science, 15: 587 601.

Neumann T. and Waddington E. 2004. Effects of firn ventilation on isotopic exchange. Journal of Glaciology, 50: 183-194.

New Zealand Mountain Safety Council 2008: New Zealand Guidelines and Recording Standards for Weather, Snowpack and Avalanche Observations, New Zealand Mountain Safety Council, Wellington.

NIWA, 2009, 'NIWA Climate Database, http://cliflo.niwa.co.nz/'.

NOAA, 2009, 'NCEP/NCAR Reanalysis 1, Gridded Sea Surface Temperature, http://www.esrl.noaa.gov/psd.'

Nobes D. and Owens I. 1995. Preliminary results from the 1995 Ground Radar Profiling Programme of the Tasman Glacier and the névé of the Franz Josef Glacier, Geological Society of New Zealand Annual Conference 22-24 November, The University of Auckland.

Nordli O., Lie O., Nesje A. and Benestad A. 2005. Glacier mass balance in Southern Norway modelled by circulation indices and spring-summer temperatures $\mathrm{AD}$ 1781-2000. Geografiska Annaler, 87 A: 431-445.

Nyenzi B. and Lefale P. 2006. El Niño Southern Oscillation (ENSO) and global warming. Advances in Geosciences, 6: 95-101.

Oerlemans J. 1992. Climate sensitivity of glaciers in southern Norway: application of an energy-balance model to Nigardsbreen, Hellstugubreen and Alfotbreen. Journal of Glaciology, 38: 223-232.

Oerlemans J. 1997. Climate sensitivity of Franz Josef Glacier, New Zealand, as revealed by numerical modelling. Arctic and Alpine Research, 29: 233-239. 
Oerlemans J. 2001: Glaciers and Climate Change, A.A. Balkema Publishers, Lisse.

Oerlemans J. and Klok E. 2004. Effect of summer snowfall on glacier mass balance. Annals of Glaciology, 38: 97-100.

Oerlemans J., Giesen R. H. and van den Broeke M. 2009. Retreating alpine glaciers: increased melt rates due to accumulation of dust (Vadret da Morteratsch, Switzerland). Journal of Glaciology, 55: 729-736.

Osterberg E., Handley M., Sneed S., Mayewski P. and Kreutz K. 2006. Continuous ice core melter system with discrete sampling for major ion, trace element, and stable isotope analyses. Environmental Science and Technology, 40: 3355-3361.

Owens I. F., Sturman A. P. and Ishikawa N. 1992. High Rates of Ablation on the Lower Part of the Franz Josef Glacier, South Westland, Proceedings of the New Zealand Geographical Society, Hamilton.

Paterson W. S. B. 1994: The Physics of Glaciers, Butterworth-Heinemann, Oxford.

Pellicciotti F., Brock B., Strasser U., Burlando P., Funk M. and Corripio J. 2005. An enhanced temperature-index glacier melt model including a shortwave radiaiton balance: development and testing for Haut Glaicer d'Arolla, Switzerland. Journal of Glaciology, 51: 573-587.

Pelto M. 1988. The annual mass balance of North Cascade Glaciers, Washington, USA, measured and predicted using an activity index method. Journal of Glaciology, 34: 194-199.

Pelto M. 1996. Annual net balance of North Cascade glaciers, 1984-1994. Journal of Glaciology, 42: 3-9.

Pelto M. 2000. The impact of sampling density on mass balance determination. Hydrological Processes, 14: 3215-3225.

Pfeffer W. T., harper J. T. and O'Neel S. 2008. Kinematic constraints on glacier contributions to $21^{\text {st }}$-century sea-level rise. Science, 321: 1340-1343.

Popovnin V., Danilova T. and Petrakov D. 1999. A pioneer mass balance estimate for a Patagonian glacier: Glacier De los Tres, Argentina. Global and Planetary Change, 22: 255-267.

Post A. and LaChapelle E. 2000: Glacier Ice, University of Washington Press, Singapore. 
Power S. and Smith I. 2007. Weakening of the Walker circulation and apparent dominance of El Niño both reach record levels, but has ENSO really changed? Geophysical Research Letters, 34: doi:10.1029/2007GL030854.

Purdie H., Brook M., Fuller I. and Appleby J. 2008. Seasonal variability in velocity and ablation of Te Moeka o Tuawe/Fox Glacier, South Westland, New Zealand. New Zealand Geographer, 64: 5-19.

Purdie H., Mackintosh A., Bertler N., Baker J. and Rhodes R. 2010. Isotopic and elemental changes in winter snow accumulation on glaciers in the Southern Alps, New Zealand. Journal of Climate, 23: 4737-4749.

Purdie H., Anderson B., Lawson W. and Mackintosh A. 2011a. Spatial variability in snow accumulation on glaciers in the Southern Alps, New Zealand: as revealed by crevasse stratigraphy. Hydrological Processes, 25: 54-63.

Purdie H., Mackintosh A., Lawson W. and Anderson B. 2011b. Synoptic influences on snow accumulation on glaciers east and west of a topographic divide: Southern Alps, New Zealand. Arctic, Antarctic and Alpine Research, 43: 82-94.

Purdie J. and Fitzharris B. 1999. Processes and rates of ice loss at the terminus of the Tasman Glacier, New Zealand. Global and Planetary Change, 22: 79-91.

Quincey D. J. and Glasser N. F. 2009. Morphological and ice-dynamical changes on the Tasman Glacier, New Zealand, 1990-2007. Global and Planetary Change, 68: 185-197.

Raben P. and Theakstone W. 1994. Isotopic and ionic changes in a snow cover at different altitudes: observations at Austre Okindbreen in 1991. Annals of Glaciology, 19: 85-91.

Radic V. and Hock R. 2011. Regionally differentiated contribution of mountain glaciers and ice caps to future sea-level rise. Nature Geoscience, DOI: 10.1038/NGEO1052:

Rahmstorf S. 2007. A semi-empirical approach to projecting future sea level rise. Science, 315: 368-370.

Rayner N., Parker D., Horton E., Folland C., Alexander L., Rowell D., Kent E. and Kaplan A. 2003. Global analyses of sea surface temperature, sea ice, and night marine air temperature since the late nineteenth century. Journal of Geophysical Research, 108, DOI: 10.1029/2002JD002670: 
Reijmer C. and Hock R. 2008. Internal accumulation on Storglaciären, Sweden, in a multi-layer snow model coupled to a distributed energy and mass balance model. Journal of Glaciology, 54: 61-72.

Renwick J. and Thompson D. 2006. The Southern Annular Mode and New Zealand climate. Water and Atmosphere, 14: 24-25.

Rind D. 1999. Complexity and climate. Science, 284: 105-107.

Röhl K. 2006. Thermo-erosional notch development at fresh-water-calving Tasman Glacier, New Zealand. Journal of Glaciology, 52: 203-213.

Röhl K. 2008. Characteristics and evolution of supraglacial ponds on debriscovered Tasman Glacier, New Zealand. Journal of Glaciology, 54: 867-880.

Rohling E. J., Grant K., Bolshaw M., Roberts A. P., Siddall M., Hemleben C. and Kucera M. 2009. Antarctic temperature and global sea level closely coupled over the past five glacial cycles. Nature Geoscience, doi:10.1038/NGE0557: doi:10.1038/NGE0557.

Romolo L., Prowse T., Blair D., Bonsal B. and Martz L. 2006. The synoptic climate controls on hydrology in the upper reaches of the Peace River Basin. Part I: snow accumulation. Hydrological Processes, 20: 4097-4111.

Ruddell A. R. and Budd W. F. 1990: An investigation into the feasibility of using a New Zealand ice core for paleo-climate interpretations. A report to the Australian/New Zealand/ United Kingdom Tripartite Climate Change Committee, Department of Meteorology, University of Melbourne, Australia, Department of Meteorology, University of Melbourne, Australia, Melbourne.

Ruddell A. R. 1995. Recent glacier and climate change in the New Zealand Alps, unpublished PhD thesis, University of Melbourne.

Sakai A., Fujita K., Nakawo M. and Yao T. 2009. Simplification of heat balance calculation and its application to the glacier runoff from the July $1^{\text {st }}$ Glacier in northwest China since the 1930s. Hydrological Processes, 23: 585-596.

Salinger J., Gray W., Mullan B. and Wratt D. 2004. Atmospheric circulation and precipitation, in Harding, J., Mosley, P., Pearson, C. and Sorrell, B., Freshwaters of New Zealand, New Zealand Hydrological Society Inc., Christchurch, 2.1-2.18.

Salinger J., Lorrey D. and Hollis M. 2008: National Climate Centre, National Climate Summary: Summer 07/08, National Institute of Water and Atmospheric Research, Auckland. 
Salinger J., 2009, 'New Zealand Climate: Patterns of drought and future projections. Workshop on Drought and Extreme Temperatures: Preparedness and Management for Sustainable Agriculture, Rangelands, Forestry, and Fisheries, Beijing, China, 16-17 February 2009 http://www.wmo.int/pages/prog/wcp/agm/meetings/etdret09/wodret.html

Salinger M. J., Heine M. and Burrows C. J. 1983. Variations of the Stocking (Te Wae Wae) Glacier, Mount Cook, and climatic relationships. New Zealand Journal of Science, 26: 321-338.

Salinger M. J. and Mullan A. 1999. New Zealand climate: temperature and precipitation variations and their links with atmospheric circulation 1930-1994. International Journal of Climatology, 19: 1049-1071.

Salinger M. J., Renwick J. and Mullan A. 2001. Interdecadal Pacific Oscillation and South Pacific climate. International Journal of Climatology, 21: 1705-1721.

Sara W. A. 1968. Franz Josef and Fox Glaciers, 1951-1967. New Zealand Journal of Geology and Geophysics, 11: 768-780.

Sato T., Kosugi K., Mochizuki S. and Nemoto M. 2008. Wind speed dependence of fracture and accumulation of snowflakes on snow surface. Cold Regions Science and Technology, 51: 229-239.

Schwikowski M., Brutsch S., Palmer A., Jenk T., Gaggeler H. and Leuenberger M. 2005: Identification of precipitation source regions at Fiescherhorn Glacier using the deuterium excess Annual Report, Paul-Scherrer Insitiute, http://lch.web.psi.ch/files/anrep05/27.pdf,

Schwikowski M., Brutsch S., Casassa G. and Rivera A. 2006. A potential highelevation ice-core site at Hielo Patagonico Spur. Annals of Glaciology, 43: 8-13.

Shiraiwa T., Kohshima S., Uemura R., Yoshida N., Motoba S., Uetake J. and Godoi M. 2002. High net accumulation rates at Campo de Hielo Patagonico Sur, South America, revealed by analysis of a $45.97 \mathrm{~m}$ long ice core. Annals of Glaciology, 35: 8490.

Sinclair K. and Marshall S. 2008. Post-depositional modification of stable water isotopes in winter snowpacks in the Canadian Rocky Mountains. Annals of Glaciology, 49: 96-106.

Sinclair K. and Marshall S. 2009. Temperature and vapour-trajectory controls on the stable-isotope signal in Canadian Rocky Mountain snowpacks. Journal of Glaciology, 55: 485-498. 
Sinclair M., Wratt D., Henderson R. and Gray W. 1997. Factors affecting the distribution and spillover of precipitation in the Southern Alps of New Zealand - a case study. Journal of Applied Meteorology, 36: 428-442.

Solomon S., Qin D., Manning M., Chen Z., Marquis M., Averyt K., Tignor M. and Miller H. 2007. Climate change 2007: the physical science basis. Contribution of working group 1 to the Fourth Assessment Report of the Intergovernmental Panel on Climate Change, Cambridge University Press, Cambridge.

Speight R. 1935. Notes on the Franz Josef Glacier, February, 1934. Transactions of the New Zealand Institute, 64: 315-322.

Sturman A. and Tapper N. 2006: The weather and climate of Australia and New Zealand, Oxford University Press, Melbourne, Melbourne.

Suggate R. P. 1952. Franz Josef Glacier, March, 1951. New Zealand Journal of Science and Technology, 33B: 299-304.

Takeuchi Y., Naruse R., Satow K. and Ishikawa N. 1999. Comparison of heat balance characteristics at five glaciers in the Southern Hemisphere. Global and Planetary Change, 22: 201-208.

Taylor S., Feng X., Kirchner J., Osterhuber R., Klaue B. and Renshaw C. 2001. Isotopic evolution of a seasonal snowpack and its melt. Water Resources Research, 37: 759-769.

Tedesco M. and Monaghan A. 2009. An updated Antarctic melt record through 2009 and its linkages to high-latitude and tropical climate variability. Geophysical Research Letters, 36: L18502.

Thomas J. 2009. Volume change of the Tasman Glacier using remote sensing, unpublished MSc thesis, University of Canterbury.

Thompson L., Mosley-Thompson E. and Henderson K. 2000. Ice-core palaeoclimate records in tropical South America since the Last Glacial Maximum. Journal of Quaternary Science, 15: 377-394.

Thomson J. 2005: A radio echo sounding survey of the Tasman Glacier névé area, Mount Cook National Park, New Zealand, Institute of Geological \& Nuclear Sciences, report 2005/08, Lower Hutt.

Trenberth K. 1976. Fluctuations and trends in indices of the Southern Hemisphere circulation. Quarterly Journal of the Royal Meteorological Society, 102: $65-75$. 
Ummenhofer C. and England M. 2007. Interannual extremes in New Zealand precipitation linked to modes of Southern Hemisphere climate variability. Journal of Climate, 20: 5418-5440.

Ummenhofer C., Gupta A. and England M. 2009. Causes of late twentiethcentury trends in New Zealand precipitation. Journal of Climate, 22: 3-19.

van den Broeke M. and van Lipzig N. 2004. Changes in Antarctic temperature, wind and precipitation in response to the Antarctic Oscillation. Annals of Glaciology, 39: 119-126.

Verge R. W. and Willams G. P. 1981. Chapter 16: Drift Control, in Gray, D.M and Male, D.H, Handbook of Snow: Principles, Processes, Management and Use, The Blackburn Press, Caldwell,

Walters R. A. and Meier M. F. 1989. Variability of glacier mass balances in Western North America, in Peterson, D.H., Aspects of climate variability in the Pacific and Western Americas, American Geophysical Union Geophysical Monograph 55, 365374.

WCRP 2009: Evaluating and improving regional climate projections, WCRP Informal Report No. 5/2009, http://wcrp.ipsl.jussieu.fr/Workshops/Downscaling/Documents/CORDEX_Workshop09 .pdf,

Wever N., Lehning M., Clifton A., Ruedi J. D., Nishimura K., MNemoto M., Yamaguchi S. and Sato A. 2009. Verification of moisture budgets during drifting snow conditions in a cold wind tunnel. Water Resources Research, 45:

WGMS 2008. Fluctuations of Glaciers, 2000-2005, Volume IX, in Haeberli, W, Zemp, M, Kaab, A, Paul, F and Hoelzle, M (eds.), ICSU (FAGS)/ IUGA (IACS)/ UNEP/ UNESCO/ WMO, World Glacier Monitoring Service, Zurich, Switzerland,

Whillans I. M. and Grootes P. M. 1985. Isotopic diffusion in cold snow and firn. Journal of Geophysical Research, 90: 3910-3918.

Willis I., Arnold N. and Brock B. 2002. Efffect of snowpack removal on energy balance, melt and runoff in a small supraglacial catchment. Hydrological Processes, 16: 2721-2749.

Willsman A., Chinn T., Hendrikx J. and Lorrey A. 2009: Glacier snowline survey, National Institute of Water \& Atmospheric Research Ltd, Christchurch. 
Winkler S., Elehøy H. and Nesje A. 2009. Glacier fluctuation of Jostedalsbreen, western Norway, during the past 20 years: the sensitive response of maritime mountain glaciers. The Holocene, 19: 395-414.

Winstral A., Elder K. and Davis R. 2002. Spatial snow modelling of windredistributed snow using terrain-based parameters. Journal of Hydrometeorology, 3 : 524-538.

Woo M. and Fitzharris B. B. 1992. Reconstruction of mass balance for Franz Josef Glacier, New Zealand, 1913 to 1989. Arctic and Alpine Research, 24: 281-290.

Yoshimura Y., Kohshima S., Takeuchi N., Seko K. and Fujita K. 2000. Himalayan ice-core dating with snow algae. Journal of Glaciology, 46: 335-340.

Zangl G. 2005. The impact of lee-side stratification on the spatial distribution of orographic precipitation. Quarterly Journal of the Royal Meteorological Society, 131: 1075-1091.

Zangl G. 2008. The temperature dependence of small-scale orographic precipitation enhancement. Quarterly Journal of the Royal Meteorological Society, 134: 1167-1181.

Zhou S., Nakawo M., Hashimoto S. and Sakai A. 2008. The effect of refreezing on the isotopic composition of melting snowpack. Hydrological Processes, 22: 873-882. 


\section{Appendix}

\section{Appendix 1: End-of-winter snow accumulation measurement on Tasman Glacier}

2007

In December 2007 an attempt was made to quantify the amount of winter snowfall by locating the previous summer's snow surface in a core. Using a SIPRE ice auger, a core was retrieved to $8.5 \mathrm{~m}$ before the auger became jammed (170 $22^{\prime} 23^{\prime \prime} \mathrm{E}, 43^{\circ} 30^{\prime} 81^{\prime \prime} \mathrm{S}$, $2383 \mathrm{~m}$ a.s.1.). In order to retrieve the auger, a $5.75 \mathrm{~m}$ pit was dug. Excavation of the pit revealed two large ice layers at 5.05 and $4.65 \mathrm{~m}$ depth of 40 and $32 \mathrm{~mm}$ thickness respectively (Figure A1.1). These ice layers had not been identified in core sections and although distinctively thick, showed no discolouration or obvious debris particles. Once the auger was released, coring was resumed from the bottom of the snow pit. Snow density deceased below the bottom of the pit and coring ceased at depth of $8.8 \mathrm{~m}$.

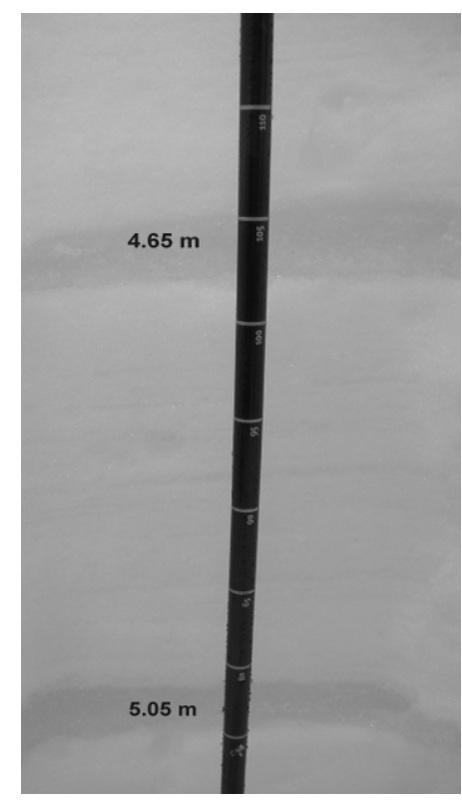

Figure A1.1: Prominent ice layers down a snowpit on Tasman Glacier at $2383 \mathrm{~m}$ a.s.1.

The average core density was $330 \mathrm{~kg} \mathrm{~m}^{-3}$, which is low, and a likely due to amount of snow that is scraped back into the hole each time the corer is removed or reinserted. In addition, partial core sections frequently fell out of the auger when being lifted out. This fallen core was then mixed with the next extracted segment, destroying stratigraphy and density profiles. The combined length of individual core sections equalled $15.9 \mathrm{~m}$ 
demonstrating how much additional snow was being scraped back into the core hole. Below $6 \mathrm{~m}$ depth, snow densities reduced to an average of only $250 \mathrm{~kg} \mathrm{~m}^{-3}$. Average snow density measured down the snow-pit (0-5.75 m depth) was $570 \mathrm{~kg} \mathrm{~m}^{-3}$, ranging from $330 \mathrm{~kg} \mathrm{~m}^{-3}$ at the surface to $670 \mathrm{~kg} \mathrm{~m}^{-3}$ at $4.85 \mathrm{~m}$ depth.

It was inconclusive as to whether the ice layers $\sim 5 \mathrm{~m}$ depth represented the summer snow surface, or whether these layers had formed during winter/spring in association with heavy precipitation and/or melting during fine weather. However, if they were representative of the previous summer surface then total winter snow accumulation at that point on Tasman Glacier for the 2007/08 mass balance year would be $\sim 2.9$ m w.e.

\section{8}

In December 2008 another attempt was made to determine the depth of the winter snowpack using the SPIRE ice auger. Initially a $3 \mathrm{~m}$ snow-pit was dug then coring began from the bottom of the snow-pit down to a total depth of $12.6 \mathrm{~m}\left(170^{\circ} 20^{\prime} 54 " \mathrm{E}\right.$, $43^{\circ} 30^{\prime} 70^{\prime \prime} \mathrm{S}, 2350 \mathrm{~m}$ a.s.1.). At $10.9 \mathrm{~m}$ depth an ice layer $5 \mathrm{~cm}$ thick was located; another notable ice layer ( $4 \mathrm{~cm}$ thickness) was located at $9.9 \mathrm{~m}$ depth. No further ice layers were detected down to $12.6 \mathrm{~m}$ depth. At this point, all corer extensions had been used and coring was abandoned.

It is inconclusive whether the $5 \mathrm{~cm}$ ice layer at $10.9 \mathrm{~m}$ depth $(6.5 \mathrm{~m}$ w.e. $)$ was indicative of the summer surface. However, average net accumulation for Tasman Glacier in March 2009 was $3.95 \mathrm{~m}$ w.e. A summer ablation total of $-1.2 \mathrm{~m}$ w.e. was measured at stakes in the accumulation area between December 2008 and March 2009, which if added to net accumulation would give a potential estimate of gross accumulation at that point of $\sim 5.3 \mathrm{~m}$ w.e. This figure is lower than the estimated $6.5 \mathrm{mw}$.e from the pit, but considering that the pit is a point measurement and the net accumulation is an average over a number of measurements from around the accumulation area, it would seem reasonable to suggest that the ice layer located in the core at $10.9 \mathrm{~m}$ depth was indeed the previous summers surface. Although minimal, results are in keeping with previous snow accumulation measurements made in the 1960s and 1970s (Chinn, 1994), which recorded maximum snowpack depths ranging from 2.3 to $7.3 \mathrm{~m}$ w.e. 


\section{Appendix 2: Mass balance measurements from Tasman Glacier 2007-}

2009.

In addition to annual net snow accumulation measurement by crevasse stratigraphy, mass balance measurements were made along the Tasman Glacier truck by installing six PVC monitoring stakes. The highest stake, stake 1, was situated at $1740 \mathrm{~m}$ a.s.l. (below the long-term equilibrium line), and stake 6 was the lowest at $935 \mathrm{~m}$ a.s.l. in debris covered ice (Figure A2.1 and Table A2.1). This altitudinal range was chosen as below $\sim 930 \mathrm{~m}$ a.s.1. very little snow accumulates, and what does fall tends to quickly melt, not contributing to mass gain. The upper limit was chosen as it was thought that snowfall would not be so great as to make maintaining the stakes above the surface impracticable with a 4-8 week field-work schedule throughout the year. Note that in the upper part of the glacier, accumulation was measured at the end of summer and at the end of winter.

Table A2.1: Initial position and elevation of mass balance stakes (grey circles in Figure A2.1) maintained on Tasman Glacier 2007-2009.

\begin{tabular}{|c|c|c|c|}
\hline Stake & $\begin{array}{c}\text { Easting } \\
\text { NZMG }\end{array}$ & $\begin{array}{c}\text { Northing } \\
\text { NZMG }\end{array}$ & $\begin{array}{c}\text { Elevation } \\
\text { m a.s.1. }\end{array}$ \\
\hline 1 & 2291572 & 5739487 & 1740 \\
2 & 2291349 & 5738977 & 1690 \\
3 & 2290172 & 5737289 & 1515 \\
4 & 2288271 & 5735883 & 1350 \\
5 & 2286445 & 5733021 & 1115 \\
6 & 2284361 & 5728218 & 935 \\
\hline
\end{tabular}

Spatial variability in the onset of the accumulation season (seasonality) was captured by the mass balance stakes during both years (Figures A2.2 and A2.3). The highest two stakes (Stakes 1 and 2) were accumulating snow by July, but it wasn't until September that snow was recorded at stakes 3 and 4 . Despite there being up to $20 \mathrm{~cm}$ of surface snow at times, the lowest stakes recorded net loss throughout the year. During both seasons all monitoring stakes recorded negative mass balance ranging from $-2.6 \mathrm{~m} \mathrm{w}$.e (1740 $\mathrm{m}$ a.s.1.) to $-13.7 \mathrm{~m}$ w.e. (1115 $\mathrm{m}$ a.s.1.). The mass balance gradient, from stake 5 at the end of the white ice, to the average net accumulation, measured in the accumulation area ( 2250 m a.s.1.), was 14.2 and $14.5 \mathrm{~mm} \mathrm{~m}^{-1}$ for the $2007 / 08$ and $2008 / 09$ mass balance years respectively. 


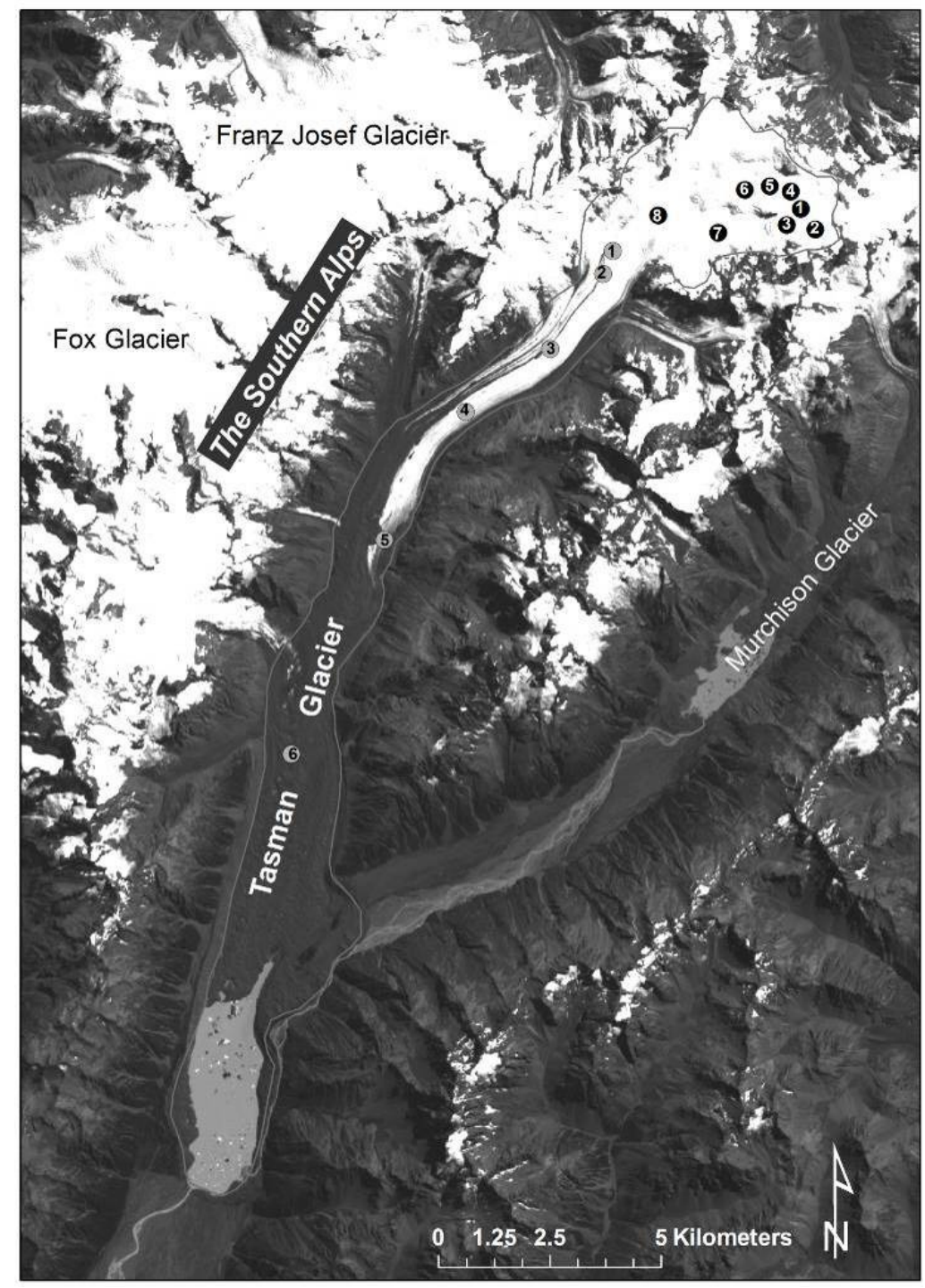

Figure A2.1: The location of the six mass balance stakes (grey circles) maintained on the Tasman Glacier trunk during 2007 to 2009, and ablation stakes (black circles) installed in the accumulation area during the summer of 2008/09. Base image is 2009 ASTER DEM.

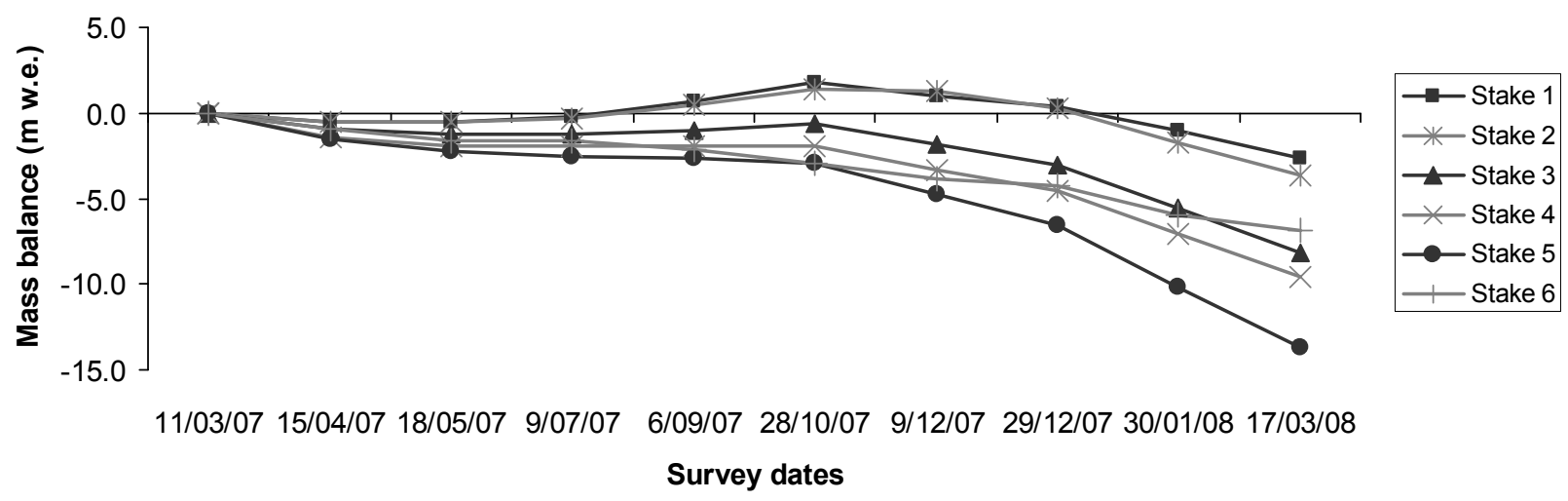

Figure A2.2: Mass balance results recorded at stakes on the Tasman Glacier trunk for the 2007/08 mass balance year. 


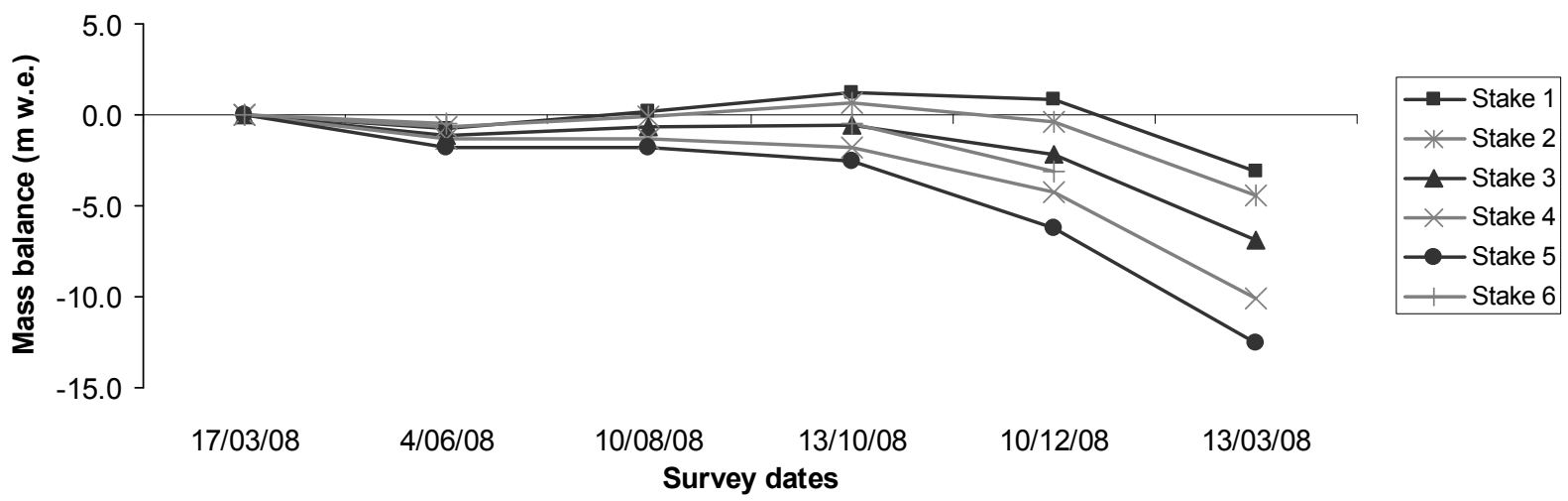

Figure A2.3: Mass balance results recorded at stakes on the Tasman Glacier trunk for the 2008/09 mass balance year.

In December 2008, eight stakes were installed in the accumulation area to record summer ablation. Of these, only six were relocated the following March for measurement (Table A2.2).

Table A2.2: Snow ablation in the upper accumulation area of Tasman Glacier 2008/09.

\begin{tabular}{|l|c|c|c|c|c|c|}
\hline Stake & 1 & 2 & 4 & 5 & 6 & 8 \\
\hline Elevation (m a.s.l.) & 2349 & 2376 & 2432 & 2373 & 2245 & 1868 \\
\hline Ablation (m w.e) & -0.76 & -1.20 & -1.20 & -0.62 & -0.58 & -2.40 \\
\hline
\end{tabular}




\section{Appendix 3: Spatial representivity of crevasse surveys}

To evaluate how well net accumulation data derived from the crevasse stratigraphy method represents the wider accumulation area ${ }^{1}$, the proportion of topography (elevation, slope and aspect) of the total accumulation area (above the estimated equilibrium line) was compared to the proportion represented by crevasse measurements (when $n>20$ ). On FJG it was found that, net accumulation measurements represent slope and aspect well, but under-represent terrain $<2100 \mathrm{~m}$ a.s.1. (13\% of accumulation area) (Figure A3.1). However, there is good spatial representation of net accumulation between $2100-2400 \mathrm{~m}$ a.s.1., which comprises $77 \%$ of the total accumulation area.

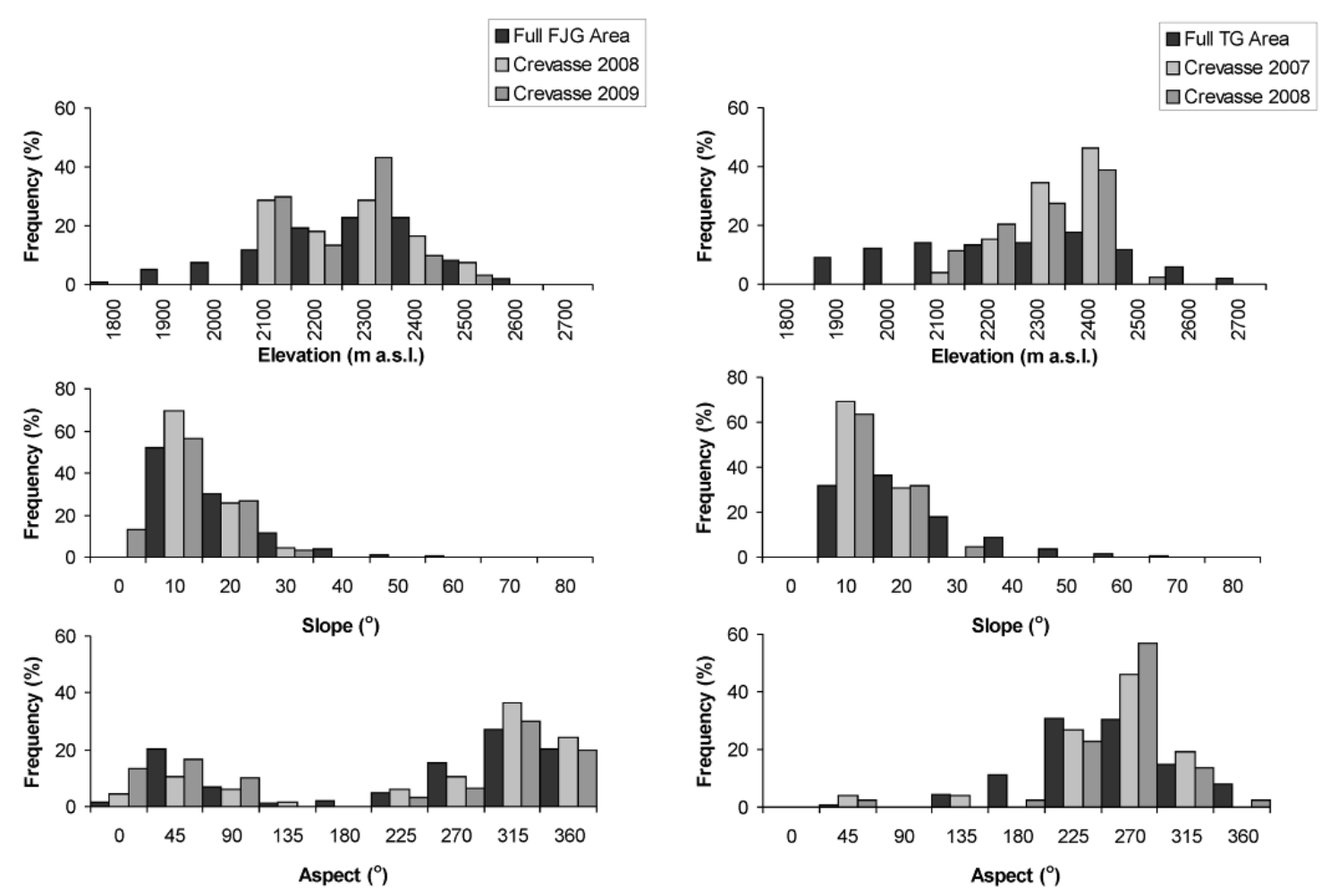

Figure A3.1: Frequency histograms showing proportional representation of elevation, slope and aspect of crevasse stratigraphy net accumulation measurements in comparison to the wider accumulation area of FJG and TG.

Net accumulation measurements on TG represent aspect and slope reasonably well, but there is a lack of measurement on slopes above $40^{\circ}$, which make up $15 \%$ of the total accumulation area. This lack of representivity is due to the hazard associated in working

\footnotetext{
${ }^{1}$ The question about spatial representivity of the crevasse stratigraphy data was raised during a presentation of this research after the paper (Chapter 2) had been accepted for publication. It was felt that it was an important issue that warranted investigation. Therefore this additional analysis was conducted and added as an appendix to Chapter 2. 
around crevasses in steep terrain. Net accumulation between $2100-2400 \mathrm{~m}$ a.s.1. is well represented, and this elevation band accounts for $60 \%$ of the accumulation area, but there is lack of measurement between $1800-2100$ ma.s.1 (20\% of the accumulation area), which may result in some bias, and explain the lack of correlation obtained between net accumulation data and elevation on TG. 